Structural Adjustment and Regulation of Nordic Fisheries until 2025

Nielsen, Max; Hoff, Ayoe; Nielsen, Rasmus; Andersen, Peder; Waldo, Staffan; Hammarlund, Cecilia; Kristófersson, Dað̃i Már ; Sævaldsson, Hordur ; Virtanen, Jarno ; Setälä, Jari; Roll, Kristin; Asche, Frank; á Rógvi, Heri ; Ellefsen, Hans

DOI:

10.6027/TN2018-547

Publication date:

2018

Document version

Publisher's PDF, also known as Version of record

Citation for published version (APA):

Nielsen, M., Hoff, A., Nielsen, R., Andersen, P., Waldo, S., Hammarlund, C., Kristófersson, D. M., Sævaldsson, H., Virtanen, J., Setälä, J., Roll, K., Asche, F., á Rógvi, H., \& Ellefsen, H. (2018). Structural Adjustment and Regulation of Nordic Fisheries until 2025. Nordic Council of Ministers. TemaNord Vol. 2018 No. 547 https://doi.org/10.6027/TN2018-547 
(11) Nordic Council of Ministers

\section{STRUCTURAL \\ ADJUSTMENT AND \\ REGULATION OF \\ NORDIC FISHERIES \\ UNTIL 2025} (1)

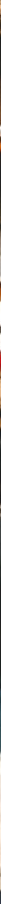





\section{Structural Adjustment and Regula- tion of Nordic Fisheries until 2025}

Max Nielsen, Ayoe Hoff, Rasmus Nielsen, Peder Andersen, Staffan Waldo, Cecilia Hammarlund, Daði Már Kristófersson, Hordur Sævaldsson, Jarno Virtanen, Jari Setälä, Kristin Roll, Frank Asche, Heri á Rógvi and Hans Ellefsen

TemaNord 2018:547 


\section{Structural Adjustment and Regulation of Nordic Fisheries until 2025}

Max Nielsen, Ayoe Hoff, Rasmus Nielsen, Peder Andersen, Staffan Waldo, Cecilia Hammarlund, Dađ̇i Már Kristófersson, Hordur Sæevaldsson, Jarno Virtanen, Jari Setälä, Kristin Roll, Frank Asche, Heri á Rógvi and Hans Ellefsen

ISBN 978-92-893-5802-6 (PRINT)

ISBN 978-92-893-5803-3 (PDF)

ISBN 978-92-893-5804-O (EPUB)

http://dx.doi.org/10.6027/TN2018-547

TemaNord 2018:547

ISSN 0908-6692

Standard: PDF/UA-1

ISO 14289-1

(c) Nordic Council of Ministers 2018

Cover photo: Unsplash.com

Print: Rosendahls

Printed in Denmark

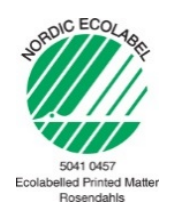

Disclaimer

This publication was funded by the Nordic Council of Ministers. However, the content does not necessarily reflect the Nordic Council of Ministers' views, opinions, attitudes or recommendations.

Rights and permissions

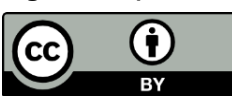

This work is made available under the Creative Commons Attribution 4.0 International license (CC BY 4.0 ) https://creativecommons.org/licenses/by/4.0

Translations: If you translate this work, please include the following disclaimer: This translation was not produced by the Nordic Council of Ministers and should not be construed as official. The Nordic Council of Ministers cannot be held responsible for the translation or any errors in it.

Adaptations: If you adapt this work, please include the following disclaimer along with the attribution: This is an adaptation of an original work by the Nordic Council of Ministers. Responsibility for the views and opinions expressed in the adaptation rests solely with its author(s). The views and opinions in this adaptation have not been approved by the Nordic Council of Ministers. 
Third-party content: The Nordic Council of Ministers does not necessarily own every single part of this work. The Nordic Council of Ministers cannot, therefore, guarantee that the reuse of third-party content does not infringe the copyright of the third party. If you wish to reuse any third-party content, you bear the risks associated with any such rights violations. You are responsible for determining whether there is a need to obtain permission for the use of third-party content, and if so, for obtaining the relevant permission from the copyright holder. Examples of third-party content may include, but are not limited to, tables, figures or images.

Photo rights (further permission required for reuse):

Any queries regarding rights and licences should be addressed to:

Nordic Council of Ministers/Publication Unit

Ved Stranden 18

DK-1061 Copenhagen K

Denmark

Phone +4533960200

pub@norden.org

\section{Nordic co-operation}

Nordic co-operation is one of the world's most extensive forms of regional collaboration, involving Denmark, Finland, Iceland, Norway, Sweden, and the Faroe Islands, Greenland and Åland.

Nordic co-operation has firm traditions in politics, economics and culture and plays an important role in European and international forums. The Nordic community strives for a strong Nordic Region in a strong Europe.

Nordic co-operation promotes regional interests and values in a global world. The values shared by the Nordic countries help make the region one of the most innovative and competitive in the world.

The Nordic Council of Ministers

Nordens Hus

Ved Stranden 18

DK-1061 Copenhagen K, Denmark

Tel.: +4533960200 www.norden.org

Download and order Nordic publications from www.norden.org/nordpub 



\section{Contents}

Preface

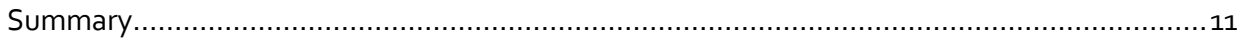

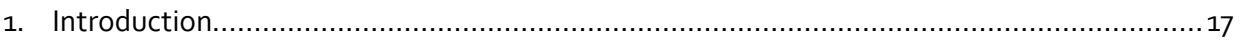

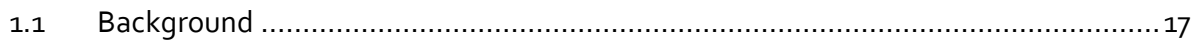

1.2 Purposes ........................................................................................ 18

1.3 Why knowledge on future structural adjustment and management is important .... 19

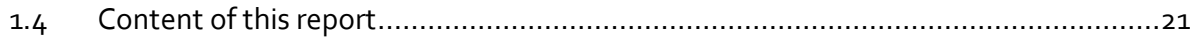

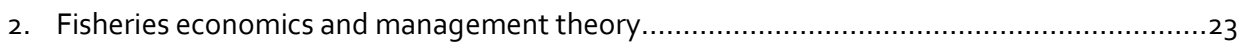

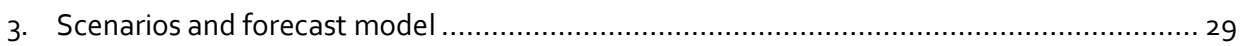

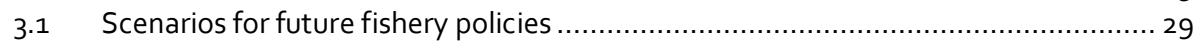

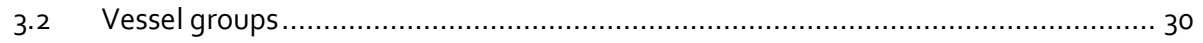

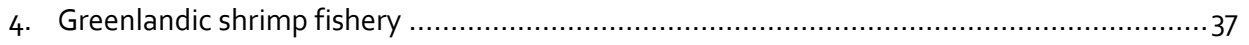

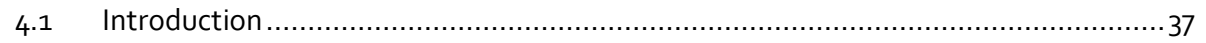

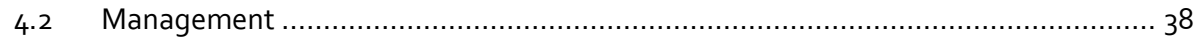

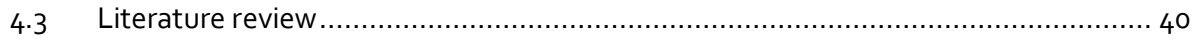

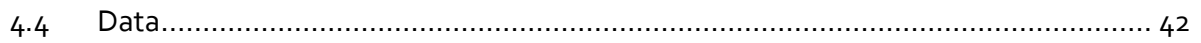

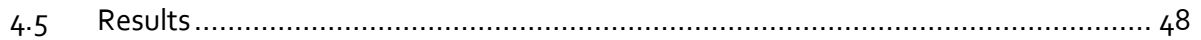

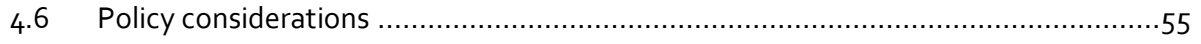

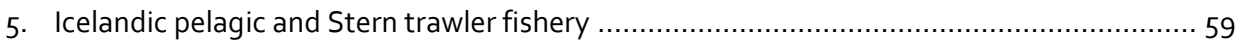

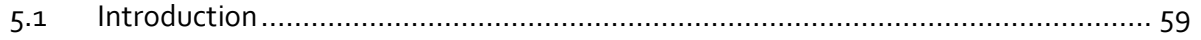

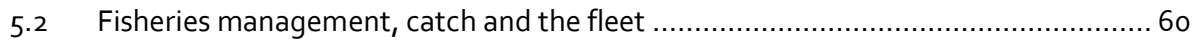

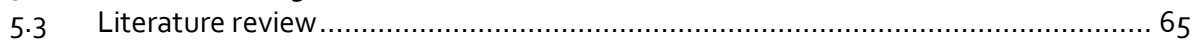

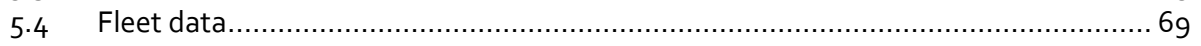

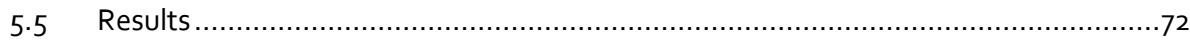

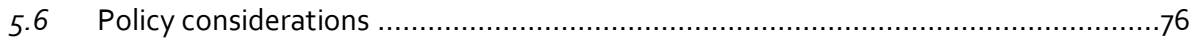

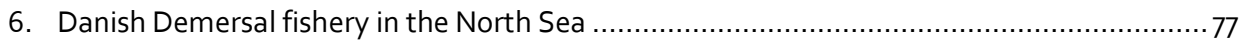

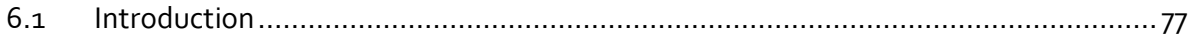

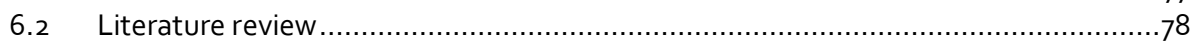

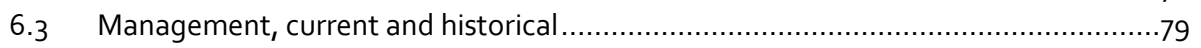

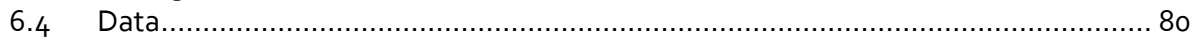

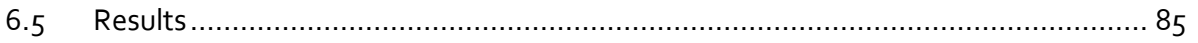

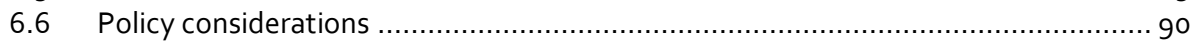

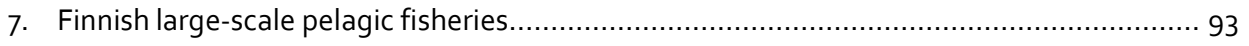

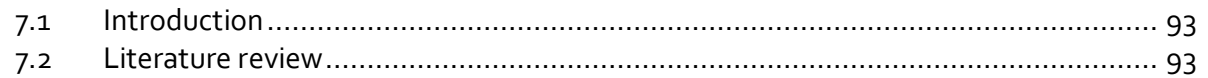

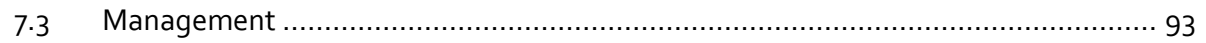

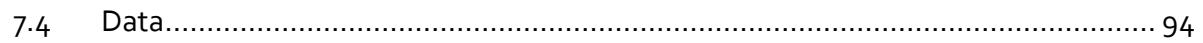

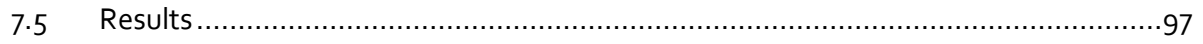

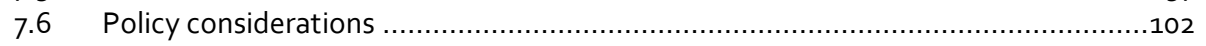

8. Swedish large-scale pelagic fisheries .............................................................. 103

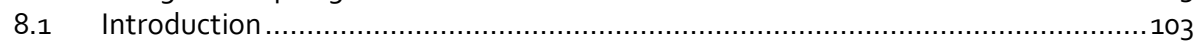

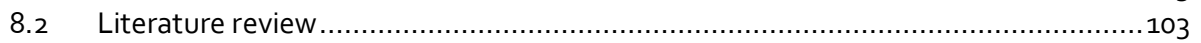

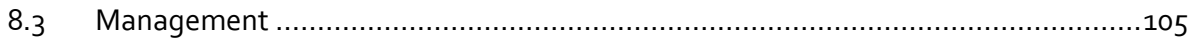

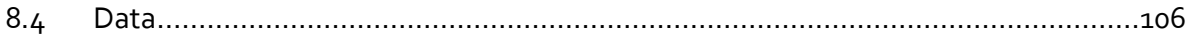

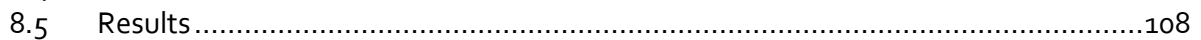

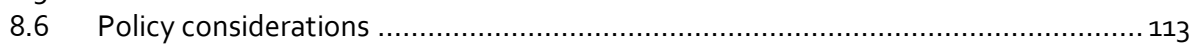




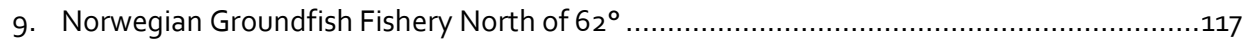

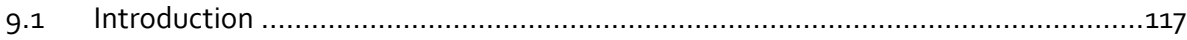

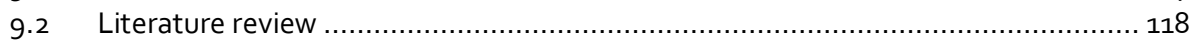

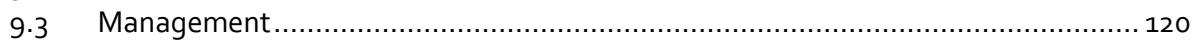

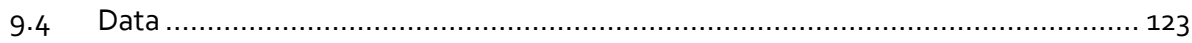

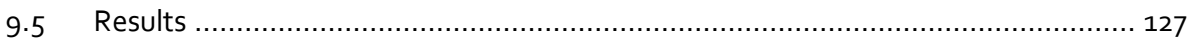

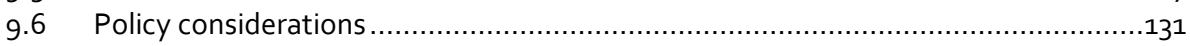

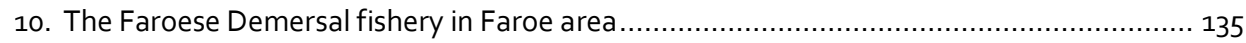

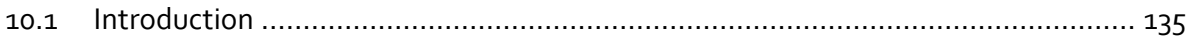

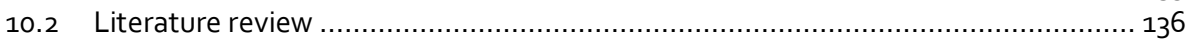

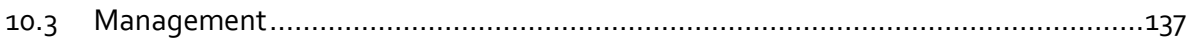

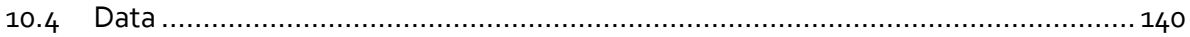

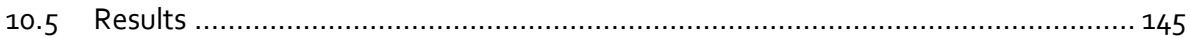

10.6 Policy considerations .......................................................................... 150

11. Nordic policy lessons on Market Based Fisheries Management .................................. 151

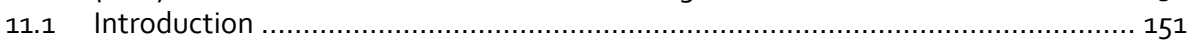

11.2 The use of Market Based Management in Nordic fisheries to 2015 ......................151

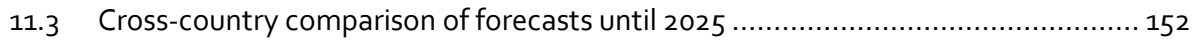

11.4 Nordic policy lessons on Market Based Fisheries Management .......................... 162

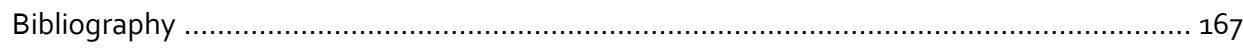

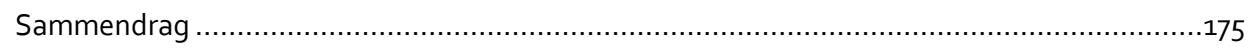

Appendix: The applied bio-economic model ............................................................. 181

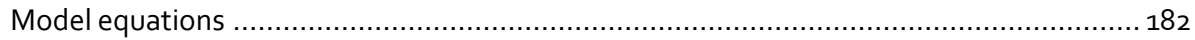

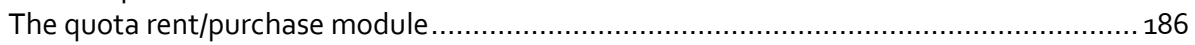

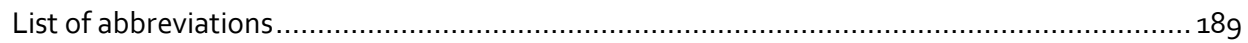




\section{Preface}

Fisheries policies are broadly debated in the Nordic countries with a focus on the balance between biological concern of fish stocks, economic return to society, profitability and interests of the coastal communities.

Fishery was in the first half of the twentieth century considered as subsistence trade for the poor. This has changed dramatically due to high investments giving improved efficiency of the fleets and today fishing is considered an industry in the Nordic countries. Many coastal communities remain, however, economically dependent on fisheries in terms of employment, income etc. While this transition was followed by the introduction of Total Allowable Catches to solve increasing pressure on fish stocks, more focus is today on how to regulate the fish resources in the most economically efficient way, in order to get high economic returns to society. This has led to the introduction of Market Based Fisheries Management in many countries and in other countries, where Market Based Fisheries Management is not implemented, debate whether introducing it.

The debates on Nordic fishery policies and in particular on Market Based Fisheries Management have been going on for many years, emphasizing that Market Based Fisheries Management is a powerful, but also a controversial tool. The supporters claim that Market Based Fisheries Management increase economic returns, while opposers states that employment falls, that a handful large companies end up overtaking the whole fishery, use cheap foreign labour and destroy the coherence of small local coastal communities. Therefore, a deeper understanding of the functioning of Market Based Fisheries Management is warranted. Indeed, a need for demystifying Market Based Fisheries Management prevails.

Some examples shed light on this point as follows:

- In Greenland, a Bill of a New Fishery Law, suggesting both the introduction of a notice period for termination of ITQs in the shrimp fishery and reallocation of quotas from large to small vessels, was the most mentioned Law in the Greenlandic national media in 2017;

- In Denmark, a report from the State Auditors from 2017 criticized the administration of the ITQ system for not delivering on the political intention on preventing concentration of quotas on a few owners and not administrating the rules on concentration properly. A public debate on quota concentration followed and lasted for months. Whether right or wrong, it became one of the reasons why the fishery policy administration organizationally was moved from the Ministry of Environment and Food to the Ministry of Foreign Affairs; 
- In Sweden, evaluations have shown that the ITQ system in pelagic fisheries has served its purpose and changed the fleet structure. However, the system has not been introduced to other fisheries even though the Swedish Parliament in 2014 delegated the decision on the possible introduction of ITOs in other fisheries to the Government;

- In Norway, a Parliamentary Committee in 2014 recommended introduction of a full ITQ system. Another Parliamentary Committee concluded in 2016 that it would be beneficial to rationalize and simplify the Norwegian quota system, pursuing the objectives of an industry exercised and owned by active fishermen and that also include a variation in the fleet with regard to vessel size and regional affiliates;

- In the Faroe Islands, the 2018 revision of the fisheries policy have been debated for many years and led to the introduction of a new Individual Quota regulation with quotas sold at auctions coming into force in the demersal fishery in 2019;

- Iceland was the first Nordic country to introduce ITQs. The system is well established and the debate appears less heated. However, some opposition against the system remains and in 2009 extra quota for fishermen using jigging reel was added to the coastal quotas of rural communities;

- In Finland, the poor economic performance was an important reason for introducing ITQ's in the large-scale pelagic fishery in 2017.

This report forecasts the development in seven Nordic fisheries until 2025 assuming unchanged fisheries policies. The forecast is compared to developments under hypothetical policy changes. The report contributes to the debate by clarifying the economic effects of different policy priorities ex ante. The results are presented as a basis for discussions at the Conference "Fisheries and Society - challenges to 2025". The target group is Nordic civil servants and policy makers, fishermen and their organisations, researchers, non-governmental organizations and other stakeholders with an interest in fisheries.

This report is part of the project Structural development and regulation of Nordic fisheries approaching 2025. The project is funded by the the Fisheries Cooperation of the Nordic Council of Ministers, from which funding is gratefully acknowledged. The results and views presented in the report, however, remain solely the responsibility of the authors.

The report consists of seven country case studies and a cross-country assessment. The Greenlandic and Danish cases are written by Ayoe Hoff, Max Nielsen and Rasmus Nielsen, University of Copenhagen. The Icelandic case is written by Daði Már Kristófersson, University of Iceland and Hordur Sævaldsson, University Akureyri. The Finnish case is written by Jarno Virtanen and Jari Setálá, Natural Resources Institute, Finland, the Swedish case by Staffan Waldo and Cecilia Hammarlund, Swedish University of Agricultural Sciences/Lund University and the Norwegian case by Kristin Roll, University of South-Eastern Norway, and Frank Asche, University of Florida, USA. Finally, the Faroese case is written by Heri á Rógvi and Hans Ellefsen, Ministry of 
Fisheries of the Faroe Islands. The forecasting for all country chapters are based on extensive bio-economic modelling, which was done by Ayoe Hoff in close collaboration with the person responsible for each country chapter. Hans Staby Frost, University of Copenhagen, has contributed with valuable discussions regarding the model setup. The chapter on the economics of fishery policy is written by Peder Andersen. Charlotte Bukdahl Jacobsen has edited the report. The project was coordinated by Max Nielsen, who has also written the remaining chapters.

We hope that this report will contribute to the ongoing debate on both the future fisheries policies in the Nordics countries and on the effects of Market Based Fisheries Management.

Carl-Cristian Schmidt

Chair Nordic Marin Think Tank and organizer of the Conference

Fisheries and society - challenges to 2025 11-12 October 2018

Copenhagen September 2018 



\section{Summary}

Fishery policies are broadly debated in the Nordic countries, focusing on balancing biological concern of fish stocks, economic return to society and coastal communities' interests. Market Based Fisheries Management is used in several Nordic countries today and is the core of these debates. While it by many is considered a powerful tool that works towards ensuring improved economy of fisheries, it is also considered a controversial tool.

In this report Structural Adjustment and Regulation of Nordic Fisheries until 2025 we: (i) document the effects of Marked Based Management in selected Nordic fisheries historically, (ii) analyse and forecast the structural development of the selected Nordic Market Based Managed fisheries until 2025 under the current fisheries regulation, (iii) analyse and forecast the structural development of these fisheries under alternative hypothetical regulations serving other political purposes, and (iv) provide Nordic lessons on Market Based Fisheries Management as a basis for the political debate on the future of Nordic Fisheries. The results will be presented at the Conference "Fisheries and society - challenges to 2025," to be held in Stockholm 11-12 October 2018.

In chapter 2, standard fisheries economics and management theory is presented. It is explained how open access in fisheries leads to a "race for fish" ending with overfishing, small fish stocks, too many fishing vessels and low earnings. It is further explained how different fisheries management instruments can solve this "tragedy of the commons", emphasizing the efficiency of instrument focusing at Market Based Fisheries Management. This scheme is founded on allocation of property rights that can be traded on a market. The choice will, off course, depend on the objectives of the fishery policies.

Chapter 3 introduces the dynamic bio-economic Fishrent model, which is applied to forecast socio-economic return and profit from the base period 2012-2014 until 2025. The following scenarios are analysed: (i) Current management with a $4 \%$ limit on yearly adjustment in number of vessels, (ii) Free quota trade between all vessels with a $4 \%$ limit on yearly adjustment in number of vessels, (iii) Current management with no limit on fleet adjustment, and (iv) Current management with a $4 \%$ limit on yearly adjustment in number of vessels and a $10 \%$ extra fishing tax on turnover. The socio-economic return measures "The net-surplus that, at a given time, remains for the remuneration of capital and labour above the rate that is achieved in other businesses including extraordinary taxes paid".

Seven country cases of Market Based Managed fisheries from each of the Nordic countries are studied and results presented separately in chapter $4^{-10}$.

Chapter 4 presents the case of the Greenlandic single species shrimp fishery. The fishery consists of large off-shore vessels processing on board and coastal vessels supplying factories. The off-shore fishery has been regulated with Individual 
Transferable Quotas (ITOs) since 1991 and the coastal fishery since 2000. Coastal vessels are not allowed to transfer quotas to off-shore vessels.

The annual socio-economic return provided from the 30 vessels is EUR 82 Million (average of 2012-2014), corresponding to $44 \%$ of the turnover. Fishery employment is 291 fulltime persons. The socio-economic return relative to turnover is the highest observed in this study and follows from a two-third fleet reduction since 2002. The high socio-economic return is due to the long presence of ITQs, high efficiency of off-shore vessels and $5-6$ years of price increases.

It is predicted that socio-economic return, compared with today, can increase with up to $60 \%$ in 2025 with the current regulation, following continued structural adjustment and forecasted shrimp stock increases. This is the highest predicted in this study. The fleet will be reduced to 20 vessels, accompanied by decreasing employment, met by increasing factory employment. Free quota trade can raise the socio-economic return even more. Shrimp taxes on top of income and corporation taxes are important to fund public spending, forming $9 \%$ of the landing value in 2012-2014. It is predicted that an extra $10 \%$ tax on turnover will not reduce profit in 2025 , since continued structural adjustment increase profit more.

Chapter 5 analyses the Icelandic pelagic and Stern trawler fishery. Demersal fresh fish trawlers, demersal freezer trawlers, pelagic fresh fish vessel and pelagic freezer vessels are studied. Focus is on the large vessels with most Stern trawlers being over 42 meter and most pelagic vessels being 60-80 meter. Iceland has the longest Nordic history of ITQs and one of the longest worldwide, starting in the mid-1980s.

The annual socio-economic return of the 79 vessels is EUR 255 Million, corresponding to $42 \%$ of turnover (2012-2014). Fulltime employment is 2,394 persons. As in the Greenlandic case, the socio-economic return is high, mainly due to the long presence of ITOs and the following continued structural adjustment, and due to the fact that the large vessels take advantage of economies of scale.

The socio-economic return with unchanged management is predicted decrease to EUR 203 Million in 2025, corresponding to $26 \%$ of turnover. The fleet is reduced to 57 vessels and employment to 1,764 fulltime persons. The reduction follows from the forecasted fish stock reductions and from a choke problem, which significantly reduces fishing on some species unrealistic much and induces underestimation of the socioeconomic return. Free quota trade raises the socio-economic return to $51 \%$ of turnover, while full adjustment allows for an increase to $54 \%$ of turnover. Under full adjustment the fleet is reduced to 33 vessels and employment to 1,066 fulltime persons. Hence, the structural adjustment seems to continue. Given that the fishery has already been regulated with ITQs for many years, the predicted reduction in the socio-economic return is surprising, but reasons include that reduction in fish stocks and choking effects induces underestimation of the socio-economic return. But the reason may also be that vessels have high capital costs with expected future earnings capitalized in the quota values, affecting profit negatively when stocks dwindle.

Fishing taxes on top of income and corporation taxes are important to fund public expenditures in Iceland, forming $6 \%$ of the turnover in 2012-2014. It is predicted that an extra $10 \%$ tax on turnover reduces profit in 2025 . The reason may well be that 
expected future earning has been capitalized in quota values, thereby taxing the current quota owners that have already paid a part of their expected profit to former quota owners.

In chapter 6, the case of the Danish demersal fishery in the North Sea is presented. Six groups of vessels of different length up to 40 meter using net, trawl and seine are included. These small and medium sized vessels have been managed with ITQs since 2007.

The annual socio-economic return of the 147 vessels is EUR 19 Million, corresponding to $19 \%$ of the turnover (2012-2014). Fulltime employment is 359 persons. The socio-economic return is of medium size in this study following a large fleet reduction since 2007 .

The socio-economic return is predicted to grow to EUR 28 Million in 2025, to $31 \%$ of the turnover, under the current management regime. The fleet size will decrease to 117 vessels and employment to 272 fulltime persons. Full adjustment will increase the socio-economic return to $39 \%$ of the turnover, further reducing the fleet to 90 vessels and employment to 192 fulltime persons. Hence, the strong structural adjustment that started after 2007 is predicted to continue. It is further predicted that an extra $10 \%$ fishing tax on turnover will not lead to reduced profit in 2025 compared to 2012-2014. Profit increases, induced by the continued structural adjustment, more than counterbalanced this effect.

In chapter 7, the case of Finnish pelagic fisheries with vessels above and below 24 meter is analysed. The fishery has been managed with ITQs since 2017.

The annual socio-economic return from the 63 vessels was zero in 2012-2014 with employment being 110 fulltime persons. The zero return follows from the absence of input regulation with only Total Allowable Catches being in force until 2017.

The annual socio-economic return in 2025 is predicted to EUR 2 Million with unchanged management, which is $10 \%$ of the turnover. This is expected to rise to $38 \%$ under full adjustment. The fleet reduction is correspondingly reduced to respectively 42 and 31 vessels, while employment falls to 73 and 37 fulltime persons. Hence, socio-economic return and profit is predicted to increase substantially, but it might take some years since the ITO system has just been initiated. A possible $10 \%$ tax on turnover added to the current management is not predicted to change profit compared to 2012-2014. The reason is that structural adjustment presses profits up and counterbalance the effect.

Chapter 8 provides the Swedish case of pelagic fisheries with vessels in the group of 18-24 meter and larger than 24 meter. The fishery has been regulated under an ITO scheme since 2009. Coastal herring fishery is not included in this study, since it is managed separately.

The annual socio-economic return of the 30 vessels is EUR 12 Million, corresponding to $23 \%$ of the turnover. Employment is 167 fulltime persons. The socio-economic return is medium sized in this study and follows from a fleet reduction of 55\% in 2009-2013.

The annual socio-economic return is with unchanged management predicted increase to EUR 22 Million in 2025 following fish stock increases. This corresponds to $35 \%$ of the turnover and increases to $40 \%$ with full adjustment. The fleet is reduced respectively to 25 and 22 vessels, while employment falls to 141 and 120 
fulltime persons. Hence, even though ITQs have already improved the socioeconomic return and profit, the structural adjustment seems to continue. A $10 \%$ tax on turnover added to the in other respects unchanged management is not predicted to reduce profit compared to 2012-2014, since met by increased profit resulting from structural adjustment

In chapter 9 , the Norwegian demersal fishery north of $62^{\circ}$ is analysed. Five vessel length groups on up to 28 meters using conventional gear and a trawler group are considered. Individual Quotas have prevailed since 1996. These are transferable within but not between vessel groups, with transferability further restricted regionally and with $20 \%$ of quotas sold kept back and reallocated to all vessels in the group. Overall quotas are allocated between vessel groups by holding smaller vessels using conventional gears less prone to quota fluctuations than trawlers.

The annual socio-economic return of the 1,192 vessels is EUR 233 Million, $26 \%$ of the turnover (2012-2014). Fulltime employment is 5,489 persons. The socio-economic return is of medium size in this study and is achieved after a fleet reduction to half since 1996. Hence, despite the fishery is performed with on average relative small vessels, the socio-economic return is on a medium level, indicating that the current management ensures some structural adjustment.

The socio-economic return is predicted to be reduced to EUR 198 Million in 2025, following forecasted fish stock reductions and choking problems. The choking problem reduces fishing on some species unrealistic much, leading to some degree of underestimation. The socio-economic return relative to turnover is, however, predicted to increase to $36 \%$ of the turnover. The fleet is reduced to 792 vessels and employment to 3,637. Free quota trade raises socio-economic return a little, while full adjustment allows for an increase to $49 \%$ of the turnover in 2025 . Thus, adjustment sluggishness shift gains further into the future.

The last country case of demersal fishery at the Faroe Islands is presented in chapter 10 focusing on large trawlers and longliners. The fishery has been regulated with transferable days at sea since 1996, but it has been decided to change regulation to Individual Quotas from 2019.

The annual socio-economic return provided from the 45 vessels is EUR -7 Million, a deficit on $9 \%$ of the turnover. The deficit indicates that the Faroe society is better off economically by stopping the demersal fishery and use the capital and labour in other sectors. The deficit indicates that the current effort regulation have not been able to limit fishing significantly.

With the 2019 management shift and otherwise unchanged regulation, the socioeconomic return is predicted to increase to EUR 16 Million in 2025, corresponding to $25 \%$ of the turnover. But the adjustment takes time and with full adjustment it can increase to $43 \%$. The fleet is reduced to 34 vessels, with full adjustment to 22 . Free quota trade is predicted to result in socio-economic return on $30 \%$ of the turnover. A tax on $10 \%$ of turnover, which can also be public revenue of selling quotas at auctions, can be introduced together with the new 2019 management, with the profit still predicted to increase from the 2012-2014 level. 
In chapter 11, the annual socio-economic return in 2012-2014 is compared across countries. It is largest in Greenland ( $44 \%$ of the turnover) and Iceland $(42 \%)$, following both from the long presence of ITOs and from the fact that these fisheries are performed with large vessels exploiting economics of scale.

The predicted socio-economic return in 2025 is also compared across countries. Again, with continued current management it is largest in Greenland $60 \%$ of the turnover) and Iceland (49\%), but it increases in all countries. The largest increase is predicted at the Faroe Islands (from $-14 \%$ to $+25 \%$ of turnover) and in Finland (from $-7 \%$ to $+10 \%)$. These predicted large increases follows from improved management, with Finland introducing ITQs in 2017 and with the Faroe Islands having decided to introduce Individual Quotas from 2019. In all the seven country cases, fleet reductions are predicted.

Founded on the country cases, several lessons are learned. These lessons are important in the debate on future fisheries policy in the Nordic countries. The debate centers on prioritizing the socio-economic return of fisheries to wealth creation, on employment in fishing communities that is often spread around the coast in sparsely populated areas, and on fishing taxes as a funding source for public spending. The different priorities also serve as a framework for the policy setting. The lessons learned from Market Based Fisheries Management in the Nordic countries by this study are:

1. ITQs is a powerful instrument to increase earnings and remove overcapacity, but simultaneously fleet size and employment in fisheries is reduced;

2. All prevailing Nordic Market Based Fisheries Management systems have special arrangements for some vessel groups;

3. The Market Based Management systems in the Nordic fisheries all have some variation of concentration rule in force;

4. It is not a universal rule that Market Based Fisheries Management always removes the small vessels;

5. Fishing taxes may play a core role for wealth creation in the fishery dependent Nordic countries;

6. Expensive quotas makes it difficult to remove or drastically change an ITO system;

7. Continued Market Based Fisheries Management is forecasted to increase socioeconomic return and profit towards 2025 substantially;

8. Free quota trade induces extra earning compared to current regulation in 2025;

9. An extra fishing tax on $10 \%$ of the landing value can in most of the country cases be collected without reducing profits in the long run. 



\section{Introduction}

\subsection{Background}

Fish stocks have by many been considered as inexhaustible for centuries. Half a century ago, however, the technological development gradually improved the efficiency of the fishing fleets, improving the economy of the fishermen that earlier had just been considered a subsistence activity. The improved income provided incentives for new fishermen to enter the fisheries sector. The result, in the Nordic countries and elsewhere, was an overexploitation of fish stock and in some instances stock collapses, because there were too many fishermen exploiting the resource. That changed the understanding of fish stocks from being inexhaustible to being a renewal and potential an exhaustible resource.

In the years around 1980, the 200 nautical mile Exclusive Economic Zone was introduced and provided the foundation for national fisheries management in the Nordic countries. Total Allowable Catches were implemented and licenses prevented the fleets from growing. While the focus was on biology and rebuilding of fish stocks, to many fishermen and vessels (overcapacity) typically remained within the fishing sector, often enhanced by subsidies for modernization and renewal of vessels with higher fishing capacity. On the other hand, considerable effort was put in force to reduce the overcapacity through decommissioning schemes (subsidies for stop fishing). To avoid the situation where too many fishermen were competing for too few fish, Market Based Fisheries Management (MBFM) has been introduced in several Nordic fisheries.

MBFM is founded on property rights to fish allocated to fishermen and often that the property right to fish can be traded on a market. MBFM includes ITQs, but also other regulation instruments that rely on a market, such as tradable effort regulation and quotas sold at auctions. MBFM reduces the fleet by letting the most efficient fishermen buy quotas from other fishermen. Through that, the aim to reduce the overcapacity problem and increase efficiency and earnings of the remaining vessels could be met. However, MBFM may also lead to fewer fishing vessels, and thereby to reduced employment in fisheries. While profits of the Nordic fleets were earlier very low and often negative, and the Governments had expenses for subsidies, several fisheries now generate profits and contribute to general wealth in the Nordic societies,.

The fishery policy agenda is thus turning. From the earlier directed focus on avoiding overexploitation and overcapacity, to a more positive focus today on how to allocate the economic wealth fisheries create. 


\subsection{Purposes}

The purposes of this report are: (i) to document the effects of Marked Based Management in selected Nordic fisheries historically, (ii) to analyse and forecast the structural development of the selected Nordic Market Based Managed fisheries until 2025 under the current fisheries regulation, (iii) to analyse and forecast the structural development of these fisheries under alternative hypothetical regulations serving other political purposes, and (iv) to provide Nordic lessons on MBFM as a basis for the political debate on the future of Nordic Fisheries.

One fishery subject to Marked Based Management is selected from each Nordic country and different types of fisheries are selected to represent the diversity of the Nordic fishing fleets. For Greenland, Iceland, Denmark, Finland and Sweden ITO regulated fisheries are selected. For Greenland, the shrimp fishery, for Iceland the pelagic and Stern trawler fishery, for Denmark the demersal fishery in the North Sea, and for Finland and Sweden the large scale pelagic fishery. For Norway, the groundfish fishery north of $62^{\circ}$ is selected. This fishery is regulated with Individual Quotas, where vessels with certain restrictions can trade quota with other vessels in the same vessel group, but not with vessels in other groups. For the Faroe Islands, the demersal fishery is selected, in which the current effort regulation will be replaced by an individual Quota system in 2019.It is a possibility of sale of demersal quotas at auction in the system, but it is not likely yet, since the quotas still are historically low.

The effects of MBFM are documented in the seven national case studies. The case studies identify the development in number of active vessels, fleet structure, profits, contribution to GDP, etc. over the period Marked Based Management has been in force. It is shown that Marked Based Management has a strong effect on the fisheries in terms of increasing the economic return to society and reducing the fleet size and employment. It is, however, further clear that the development is also driven by other factors. For example, a reduced fleet size can be due to new regulation, but also to technological development. Although it is often difficult to split the effects of the different drivers, this report provides important documentation on the functioning and effects of MBFM.

The structural development of the selected fisheries is forecasted until 2025, measured as number of vessels, employment, contribution to GDP and profits. The forecasts are made under a number of assumptions using a bio-economic model where fishermen maximize profit and where the society maximizes the contribution of economic return from fisheries to national wealth. Hence, the forecasts are based on the assumption that fishermen act in their own best economic interest and that fisheries regulators act in the economic interest of the society. A model named Fishrent is applied for the forecasts, see chapter 3 and the appendix.

Effect on the fish stocks are forecasted by estimating a function where recruitment of fish increases with biomass until the Maximum Sustainable Yield (MSY), after which it falls. This function is identified in a way such that the stock will not increase to above the maximum stock size observed over the last twenty years. Total Allowable Catch is determined through a policy aiming at MSY, while individual fisheries will set their 
catches at a level that is as close as possible to MSY, while at the same time ensuring maximum economic outcome from the fishery.

The economics of fisheries is analysed both from a fisherman perspective and from the perspective of society. The analyses depart from the financial accounts of companies. The private economic analysis of fishermen focuses on profits, while the socioeconomic analysis focuses on socio-economic return. Socio-economic return measures "The net-surplus that, at a given time, remains for the remuneration of capital and labour above the rate that is achieved in other businesses including extraordinary taxes pai". The definition appears from Nielsen et al. (2012) with taxes added. The socioeconomic return is calculated as turnover minus fuel costs minus variable costs minus fixed costs minus opportunity costs of labour minus opportunity cost of capital plus extraordinary taxes paid. In economic terms the socio-economic return is the sum of the resource rent and the producer surplus. Hence, while profit measures the net return a company have from their fishery, socio-economic return measures the net return a society have on the existence of a fishery, more than if labour and capital had been used in other sectors.

Economic forecasts are made for a representative vessel in each vessel group under several assumptions including fixed fish prices, fixed input prices, and that fishing technology remain unchanged in the future.

The purposes of the fishery policies differ substantially and includes, on top of maximization of profit and socio-economic return, also regional political priorities on settlement and local employment, as well as special arrangement e.g. for small vessels. This report doesn't prioritize these purposes. It rather forecasts what will happen until 2025 if these different policy priorities are implemented in practical policy.

The forecasts are subject to considerable uncertainty, implying that interpretation of the results must be made cautiously. However, the forecasts to 2025 also make it possible to discuss the direction of the fisheries policy early and at a time where it remains possible to change it. Furthermore, where the forecasts of each policy option are subject to uncertainty, comparing the forecasts of the different policy options provide less uncertain information, since the uncertainties are similar for all policy options.

\subsection{Why knowledge on future structural adjustment and management is important}

Regulation of the fishing sector is crucial to avoid the "tragedy of the commons", i.e. that everyone takes what he can get, because if he doesn't take it, then his neighbours will. Furthermore, regulation determines the structural and economic development of fishing fleets. Hence, MBFM and in particular ITQs have gradually become the foundation for the Nordic fishery policies, because MBFM has proven capable of balancing the fishing fleet to the available fish resources in a sustainable manner. That is the reason why this report focus on the importance of Marked Based Management for the Nordic fisheries until 2025. 
MBFM typically contributes to reducing a number of problems, mainly with overcapacity, induces increased efficiency and leads to increased earnings over time. With the improved economy, it becomes possible for the societies to prioritize new political initiatives in fisheries. For example, in the form of creating or maintaining special arrangements for certain vessels groups or regions, as is already the case in many Nordic countries and in particular in Norway, in the form of holding back a minor share of the quota for allocation to e.g. new establishment of young fishermen, in the form of funding public expenses by income from fishing taxes as is the case in the West Nordic countries, and in the form of the option of strengthening environmental regulation that affects fisheries, as it is done in the Baltic Sea area.

To get MBFM to be an effective tool, a long time horizon is needed to secure a willingness to invest the necessary means into the fishing sector. As such, MBFM reduces the degrees of freedom for politicians for many years ahead. When the system is introduced, it is to a large extent the "point of no return", unless the Governments buy back quotas at a market price that might be high (due to the fact that future earnings are capitalized in the quota values), unless bankruptcies in a large part of the fishing industry are acceptable or unless positive shocks such as price increases or unexpected quota increases saves the economy. Or that fishing quotas are only given for a fixed time period or other measures for return introduced. Such measures are off course affecting the value of the quota.

This report provides forecasts of the expected structural development in selected fisheries and draws the lessons learned from introducing MBFM. It forms the foundation for a political debate on where the current regulation brings Nordic fisheries until 2025. Thereby, political considerations on the direction and purposes of the fisheries policy become possible at an early stage, where it remains possible to act and mitigate possible negative and unwanted effects. Political priorities, such as increased wealth creation of fisheries, increased profit, increased employment, special arrangement for certain vessel groups and fishing taxes, are analysed.

The hypotheses in the report, based on standard fisheries economic theory, are: (i) that MBFM of Nordic fisheries have been, or will be, a powerful tool to eliminate earlier overcapacity which have led to increased profits and increased contributions to GDP, but also to reduced employment in fisheries and coastal communities, (ii) that this development continues in the future, but in countries that have had MBFM for many years at a reduced pace, and (iii) that focus in the future Nordic fishery policies with MBFM moves to take advantage of the improved wealth creation of fisheries to new political priorities, such as special arrangement for certain vessel groups, fishing taxes and to improve the marine environment. 


\subsection{Content of this report}

This report contains ten chapters after this introduction. In chapter 2, the economics of fisheries policy is focusing on the economic and regulatory framework conditions for fishermen from a theoretical angle. The point of departure is existent knowledge on natural resource and fisheries economics.

Chapter 3 presents the forecast scenarios, founded in alternative political priorities. Furthermore, the forecast model is described including the assumptions and limitations of the model.

Chapter 4-10 are case studies analysing a single fishery, one from each of the seven Nordic countries. Each of these chapters presents a separate country case study that can be read without reading the full report. The fisheries being regulated by ITOs are presented first. First the analysis of the Greenlandic single species shrimp fishery in chapter 4, then the Icelandic pelagic and Stern trawler fishery in chapter 5, the Danish demersal fishery in the North Sea in chapter 6 and the large scale pelagic fisheries in Finland and Sweden in chapter 7 and 8. Chapter 9 presents the Norwegian groundfish fishery north of $62^{\circ}$ regulated by Individual Quotas subject to restricted quota trade, while chapter 10 analyse the Faroese demersal fishery from 2019 managed with Individual Quotas.

Each of the chapters 4-10 goes through one case study and present earlier studies, fisheries regulation, data, forecast results and policy considerations. The historical effects of Market Based Management in each country case is analysed, forecast results are presented and compared across current regulation and hypothetical alternative regulation.

Chapter 11 presents the Nordic lessons on MBFM in the Nordic countries appearing from the cross-country comparison of the seven country cases provided. Finally, the report contains one appendix that present the formal basis for the applied bioeconomic forecast model. 



\section{Fisheries economics and management theory}

The use of the living marine resources plays an important role for the Nordic Countries, economically and socially, but in some countries significantly more than in others and often related to regional policy goals. The importance of marine resources is linked primarily to the fish resources, although the recreational use is of increasingly importance. At the same time, the governance of fish resources has changed quite dramatically over the last forty years going from an almost open access regime to well defined property right regimes. Since 1983, the European Fishery Policy has played an important role for the Nordic countries, members or non-members. The European Fishery Policy has also played an important role for understanding conflicts about fishing rights, market access and the priority between efficiency, employment in the fishery sector and more general in local regions.

Basic fisheries economics and management theory give a solid background for understanding major principles and dilemmas in various fisheries management systems and specific regulation initiatives. The role of and the importance of MBFM, founded on property rights, and the right economic incentives have become very clear, as the property right issue is important for understanding mankind's short-term and long-term management and mismanagement of the living resources in the oceans.

Historically, an important feature of mankind's exploration of renewable resources like fish stocks has been the lack of property rights to the fish stock. The implication has been the so-called "race for fish" and the "tragedy of the commons" phenomena. If nobody has the property right to the fish or everybody has the right to go fishing, "race for fish" will occur. The implication is economically overfishing and in many cases biologically overfished stocks as well, meaning small stocks and low long term catches. The tragedy is the fact that the economic surplus of the fishery, resource rent and producer surplus, will be low or completely disappear (the dissipation of rent), see Figure 1. The Figure is a simple presentation of classical fishery economics where open access is compared to economic optimal management (maximum long-term resource rent of a fishery). 


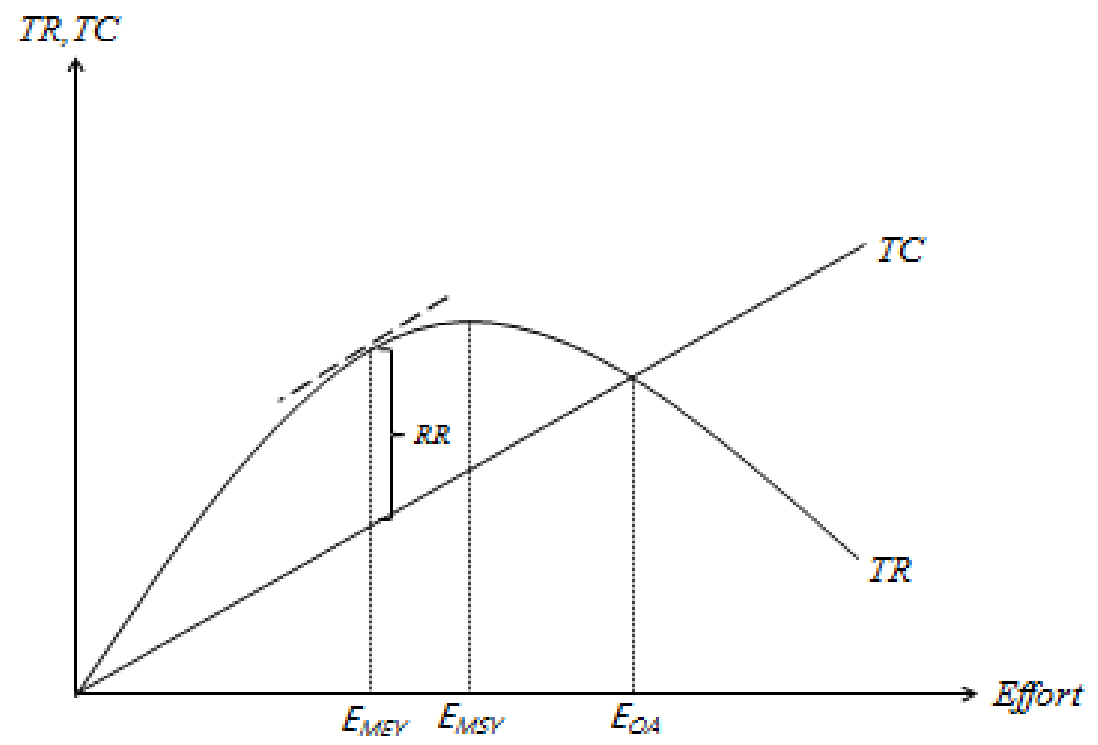

The $x$-axis represents the fishing effort, which could be the amount of days at sea, meanwhile the $y$-axis represent both the total revenue (TR) and the total costs with cost of capital and labour in their best alternative use (TC). The open access equilibrium is where the TR and TC curve intersect, which results in the effect, EOA, here the resource rent equals zero. $E_{M S Y}$ represents the effort at the MSY. The optimal fishing effort is where TC is moved up until it tangent TR. Here the fishing effort is $E_{M E Y}$, which equals the Maximum Economic Yield. At this level of effort the resource rent is maximized and equals $R R$.

Figure 1 show the long- term relationship between fishing effort (e.g. number of fishing days by the whole fleet) and total revenue (catch times the price of fish). The biological dynamics behind the model is the fact that you can catch the growth of the stock and keep the stock at a certain level. If you catch more, the stock will go down and vice versa. If the stock is very low, the growth is small due to a small spawning stock biomass. If the stock is very large, the growth is also small but this is due to lack of food relatively to the large spawning stock biomass. The shape of the curve is, of course, species specific and determined by the environmental conditions. The importance of this part is that fisheries policy will determine the long-term harvest in the specific fishery. The dynamics of a fish stock also implies that it take time to rebuilt a stock and the less to catch during the rebuilt phase the faster the stock is rebuilt to the target stock level. When replacing costs of capital and labour in alternative use with actual costs, the analysis in Figure 1 also holds for profit instead of resource rent.

The economic part of the story is linked to fishing cost. In Figure 1, the cost structure is simple. We assume that the cost per fishing day is constant. Therefore, the cost curve is a straight line. A more realistic assumption will not change the fundamentals in the model. However, if the cost curve is not a straight line if some 
vessels are more efficient than others are, infra marginal vessels will gain producers surplus. The sum of resource rent and producer surplus is the socio-economic return to society. Under open access fishing activities, fishing effort $E$, will increase if the marginal vessel have a profit, i.e. as long there is a net profit of fishing. Therefore, under open access, fishing activities will be equal to EOA. If fishing effort could be reduced and cost reduced at the same time, society would gain resource rent (pure economic surplus from the fish resource). In Figure 1, the maximum resource rent would occur if fishing effort were reduced to the optimal level of fishing effort EMEY. This is where the difference between total revenue and total cost is the largest possible.

The lesson learned by using the simple model is that fishery management is needed if the objective is to create resource rent. Furthermore, fishing activities, measured by e.g. fishing days, will be smaller in the optimal managed fishery than in the open access fishery, and long-term catches might be smaller (as shown in the Figure) under open access fishery compared to optimal fishery. This implies that number of fishermen is smaller under optimal management compared to an open access fishery. However, the employment in the processing industry may be higher as catches might increase. The net employment impact depends on the specific fishery. If fishing is relatively cheap (low cost or high efficiency), biological overexploited stocks are most likely and as a consequence catches will be low, employment in the processing industry is small and there will be no resource rent and no or low producer surplus for the society from the fishing sector. Consequently, if fishing effort is not restricted and fish resources are mismanaged private and public consumption will be influenced negatively. If there is no or a minor focus on resource rent and the objective is to have a fishing fleet with many vessels and a high number of crew members management should focus on inefficient vessels which need a high number of crew members to operate.

The model presented in Figure 1 compares the start and final situations following a management change. But it does not consider the adjustment path and speed. For that, a dynamic model is needed that identify the Maximum Economic Yield by maximizing the discounted net present value of all future earnings. Thereby, the economic optimal adjustment path is identified taking into account when it from an economic point of view is best to catch fish and when it is best to leave the fish in the sea to spawn thereby making larger future catches possible. While a dynamic model provides detailed knowledge on the adjustment path, the policy conclusions of the simple bio-economic model in Figure 1 still holds.

There are many ways to control fishing effort but it is important for rent creation that the management are cost effective. The most used and classical methods such as closed areas, days in harbour, Total Allowable Catches, mesh size, fleet and horse power restrictions, and alike will reduce the pressure on the stocks as fishing effort will be less efficient. At the same time, it also means that cost of fishing a certain amount of fish goes up. Therefore, the resource rent will dissipate. In complicated fisheries (multispecies fisheries, different fishing areas, different fishing methods, and various types of fleets the right economics incentives have to be combined with other regulations to balance different goals and avoid conflict. It is important to notice that the use of only biological oriented management will not take into account fishermen's 
behaviour. Therefore, only if biological measures are combined with the right economic incentives, waste of resource rent due to high fishing cost can be avoided. If the objective of fishery management include biodiversity and environmental goals various non-economic incentives are relevant to include combined with economic instruments.

In order to create resource rent and to avoid biologically and economic overfishing, focus on the right economic incentives is important. Taxes on catch or revenue are in theory resource rent creating but in practice not very often used. ITOs works in theory as well in practice very well if rent creating is an objective of fishery management. ITOs work like taxes as they reduce the incentives to expand fishing effort. In the tax case, the revenue goes directly to the state (owner of the resource). If ITQs are used, the state can sell the quotas and the system is like a tax system. If the state allocates the quota to existing fishermen (grandfathering methods), the owners of the quotas gain the resource rent.

An ITO system is a market based system and has proved to be an efficient management system to create resource rent. The reason for power of the ITQ systems' capacity to create resource rent is simple. An ITO system gives the right economic incentives to solve the tragedy of the commons problem by moving the regulatory framework from open access to a Market Based Fisheries Management system. The core in the MBFM system is property right. In the ITO system the property right is the right to fish a given amount of fish (or share of the total quota), to buy more fish or to sell part of the quota or the whole quota. Over time, the ITQ market will allocate fishing rights to those fishermen who have the highest efficiency.

There are many versions of a MBFM system. In Table 1, an overview of the different types of MBFM systems is adopted from Eliasen et al. (2009) that use the synonymous Right Based Fisheries Management for Market Based Fisheries Management. 
Table 1: OECD typology of Right Based fisheries management systems

\section{Right Based Management type Key features}

Territorial Use Rights

Community Based Catch Quotas

Vessel Catch Limits

Individual Non-Transferable

Quotas

Individual Transferable Quotas

Limited Non-Transferable

Licenses

Limited Transferable Licenses

Individual Non-Transferable Effort Quotas

Individual Transferable Effort Quotas
Allocation of a certain area of the ocean to a single user, usually a group, who then undertakes fishing by allocating rights to users within the group.

Catch quotas are attributed to a "fishing community" with decisions on allocation on rights within the community taken on a cooperative basis.

Restrict the amount of catch that each vessel can land for a given period of time (week, month, or year) or per trip.

Provide a right to catch a given quantity of fish from a particular stock, or more usually, a percentage of the Total Allowable Catch.

Provide a right to catch a given quantity of fish from a particular stock, or more usually, a percentage of a Total Allowable Catch which is then transferable (sale, leasing, loan).

These licenses can be attached to a vessel, to the owner, or to both ad have to be limited in number and applied to a specific stock or fishery to be considered as market-like.

By making limited licenses transferable, fishermen are provided with an increased incentive to adjust capacity and effort over the long to short term in response to natural and economic conditions.

Rights are attached to the quantity of effort unit that a fisher can employ for a given period of time.

Transferability makes a short and long term adjustment easier and allows for a better use of fishing capacities.

Source: Eliasen et al. (2009).

The efficiency of the various systems of Right Based Fisheries Management depends on the time horizon of the right, the trading flexibility, and the how easy it is to substitute between different fishing input. If the time horizon is short, the incentives to long term planning are not in place. If quota trading is not allowed or trading is very restricted, the quotas will not end up at the most efficient vessels and the result is loss of resource rent as well as of producer surplus. Finally, if fishing rights are not connected to catch quotas but only right to fish (a license) or the right to some input like fishing days, to use specific vessels size or alike, fishing effort can increase by substitution. An example would be if fishermen buy more efficient technical equipment and catch more per fishing day. As all inputs cannot be restricted or controlled, effort regulation will not be an economically efficient Right Based Fisheries Management system.

The right mix of regulatory measures and type of Right Based Fisheries Management system are closely related to the objectives of the fishery policy. What is the political tradeoff between resource rent now and in the future, the tradeoff between employment on the vessels and in the fishing industry more generally, and the tradeoff between small vessels and larger vessels? Furthermore, in some cases there might be a tradeoff between fishing activities and environmental goals. Finally, if a fishery has overcapacity the question is how fast the capacity should be reduced, as the transition towards a more rent creating fishery is costly as fleet capacity has to be removed and fish stocks need to be rebuilt. To find the optimal adjustment path that maximizes the discounted net present value of all future earnings of e.g. a small fish 
stock and a large fishing fleet to larger fish stock and a smaller fishing fleet is a true dilemma as such an adjustment always have losers and winners. Similar true dilemma exists if a fishery is a mixed fishery with different fleets, target species and conflicting interests among fleets exists and adjustment can take place without transaction costs. Only in very simple fisheries these trade-offs do not occur. And even in these cases we can face management challenges related to monitoring and enforcement cost. To quantify these tradeoffs, empirical models and analyses are needed and the choice of the optimal mix of regulatory measures strongly depends on the objectives of the fishery policy. The following chapters provide country cases of Nordic Market Based Managed Fisheries. 


\section{Scenarios and forecast model}

\subsection{Scenarios for future fishery policies}

The analysis is based on the four scenarios in Table 2 and compared to the initial situation in 2015. The initial 2015 situation is estimated, since fishery account statistics including fishing cost data were not known at the time of modelling. The reason is that it typically takes up to two years before account statistics becomes publicly available, since company accounts first have to be recorded and on the basis of these statistics must then be collected. The 2015 initial situation is therefore identified on the basis of the base period, which is the average of 2012-2014, corrected for known changes in the fishing patterns in 2015 .

\section{Table 2: Definition of scenarios for future fisheries policies}

\begin{tabular}{|c|c|}
\hline Scenarios & Definition \\
\hline 2015 initial situation & $\begin{array}{l}\text { For } 2015 \text {, fleet data, catches and prices are known at the time of modelling, while } \\
\text { costs are not known. Therefore, } 2015 \text { is calculated in the forecast model and adjusted } \\
\text { in relation to known adjustments. }\end{array}$ \\
\hline $\begin{array}{l}\text { 1. } 2025 \text { with current } \\
\text { management }\end{array}$ & $\begin{array}{l}\text { Current regulation continues unchanged and a } 4 \% \text { limit is imposed on yearly } \\
\text { adjustment in number of vessels in each segment. Current regulation of the selected } \\
\text { vessel groups is in Greenland, Iceland, Denmark, Finland and Sweden ITQs with } \\
\text { certain restrictions in most cases. In Norway it is Individual limited Transferable } \\
\text { Quotas and at the Faroe Islands it is Individual Quotas from 2019. }\end{array}$ \\
\hline $\begin{array}{l}\text { 2. } 2025 \text { with ITO management } \\
\text { and free quota trade }{ }^{1}\end{array}$ & $\begin{array}{l}\text { Free trade in permanent quotas between all vessel groups and a } 4 \% \text { limit on yearly } \\
\text { adjustment in number of vessels in each segment. This scenario corresponds to } \\
\text { scenario 1, except for free quota trade. }\end{array}$ \\
\hline $\begin{array}{l}\text { 3. } 2025 \text { with current } \\
\text { management and full } \\
\text { adjustment }\end{array}$ & $\begin{array}{l}\text { Current management with no limit on yearly fleet adjustment. This scenario } \\
\text { corresponds to scenario } 1 \text {, except for that there is no limits imposed on annual fleet } \\
\text { adjustment. }\end{array}$ \\
\hline $\begin{array}{l}\text { 4. } 2025 \text { with current } \\
\text { management and a } 10 \% \\
\text { landing tax }\end{array}$ & $\begin{array}{l}\text { Current management with a } 4 \% \text { limit and a } 10 \% \text { tax on the landing value. This } \\
\text { scenario corresponds to scenario } 1 \text {, except for the } 10 \% \text { tax on landings. For the } \\
\text { countries that already have fishing taxes, Greenland and Iceland, the } 10 \% \text { landing tax } \\
\text { is an extra tax on top of the ones that already are in force. }\end{array}$ \\
\hline
\end{tabular}

The first scenario is the continuation of the currents fisheries regulation in each of the seven country cases. Regulation of all selected vessel groups is founded on elements of MBFM. For the included vessel groups in Greenland, Iceland, Denmark, Finland and Sweden, the continuation of ITO systems, given certain restrictions in most countries, is analysed. For Norway it is Individual Quotas with limited transferability, while for the Faroe Islands, it is Individual Quotas, initiated in 2019. This scenario is founded on a limitation in the yearly adjustment in the fleet on $4 \%$, implying that only $4 \%$ of the fleet 
can either enter or exits the fishery each year. The reason for the limitation is that this speed of adjustment following fishery reforms is observed in most fisheries.

Scenario $2-4$ departs from scenario 1 by changing different factors one by one, keeping everything else the same as in scenario 1 . In scenario 2, free exchange of quotas between all vessel groups are allowed in each country case, corresponding to lifting all restrictions on quota trade between the vessel groups. In scenario 3, the limitation on yearly adjustment of the fleet on $4 \%$ is removed, while everything else is the same as in scenario 1. This scenario measures what happens if fishermen act purely in their own economic interest and maximize earning without any delay. In scenario 4, the current regulation is also kept unchanged, but combined with a $10 \%$ tax on the landing value. For the countries where fishing taxes are already in force (Greenland and Iceland), it is an extra tax on $10 \%$ of the landing value.

There are numerous alternative ways for defining the scenarios of possible future political priorities. Considerations on economic earnings, (profit and socio-economic return), employment in coastal communities, special arrangements for part of the fleets and funding of public spending by fishing taxes, appears today as the most relevant considering the ongoing discussion in the Nordic countries.

\subsection{Vessel groups}

The forecasts are made for a representative average vessel in selected vessel group. The vessel groups are selected both to represent the diversity of Nordic fisheries and to ensure that data are available. The forecasted structural development depends on restrictions on permanent quota trade. The vessel groups analysed in this report are shown in Table 3 together with the prevailing restrictions on quota trade. 


\begin{tabular}{|c|c|c|}
\hline Country & Vessel groups included & Restrictions on quota trade \\
\hline Greenland & $\begin{array}{l}\text { Shrimp fishery } \\
\text { 1. Off-shore production trawlers } \\
\text { 2. Coastal trawlers (<120 GT) }\end{array}$ & $\begin{array}{l}\text { Off-shore vessels are allowed to sell to coastal vessels, the } \\
\text { opposite quota trade is not allowed. }\end{array}$ \\
\hline Iceland & $\begin{array}{l}\text { Pelagic and Stern trawler fishery } \\
\text { 1. Demersal fresh fish trawlers } \\
\text { 2. Demersal freezer trawlers } \\
\text { 3. Pelagic fresh fish vessels } \\
\text { 4. Pelagic frozen fish vessels }\end{array}$ & $\begin{array}{l}\text { All vessels are allowed to trade quota with each other, } \\
\text { except for vessels }<15 \text { meter that are not allowed to sell } \\
\text { permanent quota to larger vessels. }\end{array}$ \\
\hline Denmark & $\begin{array}{l}\text { Demersal North Sea fishery } \\
\text { 1. Netters }<15 \text { meter } \\
\text { 2. Netters } 15-25 \text { meter } \\
\text { 3. Trawlers }<15 \text { meter } \\
\text { 4. Trawlers } 15-24 \text { meter } \\
\text { 5. Trawlers } 24-40 \text { meter } \\
\text { 6. Danish seines } 15-24 \text { meter }\end{array}$ & $\begin{array}{l}\text { All vessels are allowed to trade permanent quotas with } \\
\text { each other, except for small vessels that have voluntarily } \\
\text { enrolled in one of the two special coastal arrangements; } \\
\text { one for vessels }<17 \text { meter from which the vessels cannot } \\
\text { sell permanent quota for a period of three years and } \\
\text { another for vessels }<15 \text { meter from which vessels cannot } \\
\text { sell permanent quota at all. }\end{array}$ \\
\hline Finland & $\begin{array}{l}\text { Large-scale pelagic fishery } \\
\text { 1. Trawlers }<24 \text { meter } \\
\text { 2. Trawlers }>24 \text { meter }\end{array}$ & $\begin{array}{l}\text { Vessels within the two groups are allowed to trade } \\
\text { permanent quota with each other. }\end{array}$ \\
\hline Sweden & $\begin{array}{l}\text { Large-scale pelagic fishery } \\
\text { 1. Vessels } 18-24 \text { meter } \\
\text { 2. Vessels }>24 \text { meter }\end{array}$ & $\begin{array}{l}\text { Vessels within the two groups are allowed to trade } \\
\text { permanent quota with each other. }\end{array}$ \\
\hline Norway & $\begin{array}{l}\text { Demersal fishery north of } 62^{\circ} \\
\text { 1. Conventional vessels }<11 \text { meter } \\
\text { 2. Conventional vessels }<11-15 \text { meter } \\
\text { 3. Conventional vessels }<15-21 \text { meter } \\
\text { 4. Conventional vessels }>21 \text { meter } \\
\text { 5. Conventional ocean vessels }<28 \text { meter } \\
\text { 6. Trawlers }\end{array}$ & $\begin{array}{l}\text { Vessels are allowed to trade quota with some restrictions } \\
\text { within each vessel group, but quota trade between vessels } \\
\text { groups is not allowed. }\end{array}$ \\
\hline $\begin{array}{l}\text { Faroe } \\
\text { Islands }\end{array}$ & $\begin{array}{l}\text { Demersal fishery } \\
\text { 1. Large demersal trawlers }>400 \mathrm{HP} \\
\text { 2. Long-liners }>110 \mathrm{GRT}\end{array}$ & $\begin{array}{l}\text { In the Individual non-Transferable Quota system the two } \\
\text { vessel groups are not allowed to exchange quotas. }\end{array}$ \\
\hline
\end{tabular}

Demersal vessel groups are selected in Norway, Denmark and at the Faroe Islands, while pelagic vessels are included from Finland and Sweden. From Iceland, both demersal and pelagic vessels are analysed, while for Greenland focus is on the single species shrimp fishery.

Restrictions on permanent quota trade are absent in the case presented for Finland and Sweden, while quota restrictions follow the vessel groups in the Norwegian and Greenlandic case. For Iceland and Denmark, special arrangements giving some advantages to small coastal vessels are not attached to a single vessel group, but are possible to achieve for vessels that cross more groups. In Denmark one of the coastal fishery arrangements is for vessel below 17 meter, i.e. with some vessels being in the group up to 15 meter and others in the group on 15-25 meter. Given this and that the arrangement is voluntary, implying that only a part of the vessel in the modelled group can trade quotas between them, the forecast of the Danish fishery is obsessed with uncertainty. However, with the focus on large vessels over 40 meters in Iceland and with the majority of the Danish vessels in coastal arrangements being in vessel groups below 
15 meters, the problem is of minor importance. At the Faroe Islands, Individual Quotas are introduced in 2019.

The forecasts are made on a year by year basis for the period 2016-2025 with 2025 chosen as the year that is given emphasis in the analyses. The applied dynamic bioeconomic model of fisheries, the Fishrent model, is used for the forecasts. The model forecast the future structural development in the selected fisheries, all other things being equal, by maximizing the discounted net present value of economic earnings for the period 2016-2025, by changing the number of vessels and number of days at sea. First, socio-economic return is maximized to provide a picture of the optimal use of the fish resources from a society point of view. Afterwards, profit is maximized to identify the optimal economic behaviour of the private fishing companies. These forecasts are made for all four scenarios. For a detailed formal presentation of the model see the appendix and for a theoretical foundation of the model, see chapter 2.

The Fishrent model consists of a number of interconnected modules/boxes, which are the biological box, the price formation box, the investment box, the fishing effort box, the management box and the economic box. The model is structured on feedback between the economy and capacity of the fishery, and the biology of the exploited fish stocks. This means that year-to-year changes observed for total fish stock biomass are fed back into the model and hereby influence fishing opportunities, economy and fleet size, while on the other hand year-to-year changes in fleet size, given fleet economy, will feed back into the model and affect stock development. The structure of the model is sketched in Figure 2.

Figure 2: Structure of the FishRent model

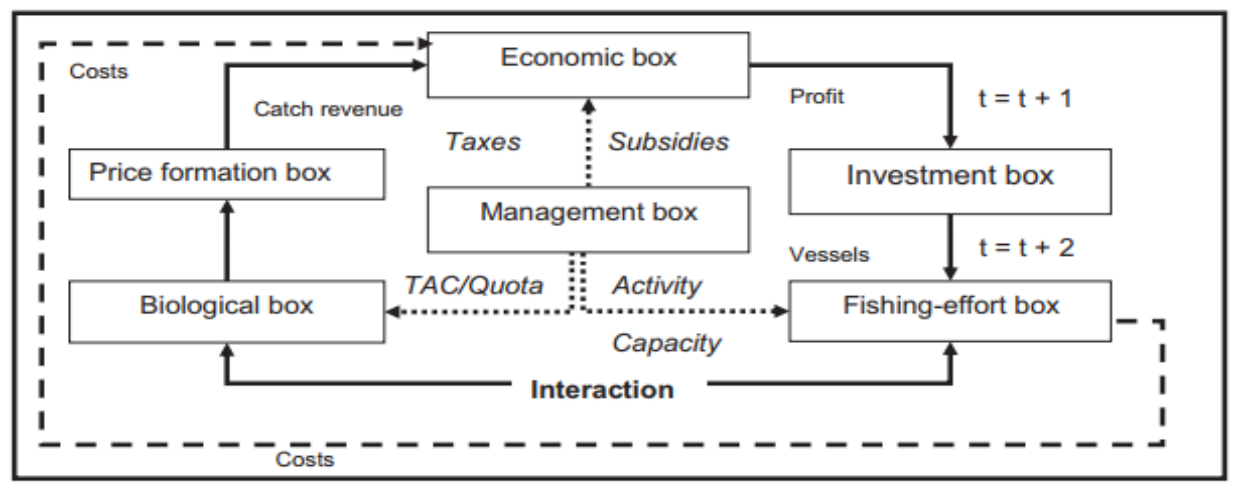

Source: Frost et al. (2013).

In the management box in Figure 2 it is assumed that the fishing activities are regulated with Total Allowable Catches and ITOs with different degrees of transferability in each country case, except for at the Faroe Islands. In the Faroese case, Individual Quotas sold at auction are applied from 2019. Catches for a given year are restricted by the Total Allowable Catches, assuming that the vessel groups included in the model together fishes a constant share of it. This implies that the catch from vessel groups, which are not included in this analysis, but fish the same stocks, develops the same catch patterns as the included vessel groups. The assumption is introduced to account for the total 
catch of the stocks. The assumption seems reliable for fish stocks regulated by Total Allowable Catches with a relative stable allocation, as the ones included in this analysis.

Catches are determined by the size of the fish stocks and fishing effort (fishing effort box) and are restricted by the quota limits, set in accordance with the Total Allowable Catches (from the management box). Fishing effort is defined as fleet size (capacity measured as number of vessels) times days at sea per vessel. In the multispecies fisheries, it is assumed that each vessel group's relative time spent on their target stocks is constant. This assumption is introduced since costs are only available on an annual basis, whilst the cost of targeting the individual stocks remains unknown. The implication is that it is not possible, for example, to switch effort away from a target stock that declines more than other stocks, as well as it is not possible to switch to completely new target stocks.

The fleet size is determined in the investment box and depends on previous year's profitability (economic box). Increasing profits lead to investments while decreasing profits leads to disinvestment. The catches in a given year will influence stock changes (the biological box) and as such future catch possibilities. Market prices are set in the price formation box and are assumed constant at the 2015 level. Socio-economic return and profit are determined in the economic box, and depend on landings, prices and costs/opportunity cost. These, again, are determined by fishing effort. Fuel use is determined by fishing effort, while fuel prices are assumed constant. Labour costs are determined by turnover, since shares are used as a basis for remuneration of the crew in the Nordic fisheries. Other variable costs are also determined by turnover. Fixed costs and capital costs are determined by number of vessels at constant cost per vessel.

Opportunity costs of labour are determined by fishing effort at a constant annual wage, as opposed to actual costs of labour that are determined by turnover. The reason is that wages in alternative jobs are determined on the labour market for alternative jobs and not within fisheries. Opportunity costs of capital are set to $6 \%$ of the physical assets, which is assumed a reasonable rate of return in fisheries. Opportunity cost of capital is taken of the physical assets. Since assets of owning fishing rights from a societal point of view is only a matter of allocation between seller and buyer of quotas, investment in purchase of quotas do not need to give return from a societal point of view.

Costs of purchase of permanent quotas are included in the operating costs of the vessels. Quota purchase costs are not known, but instead calculated approximatively as the average of the willingness to pay by the vessels that buy the quota and the willingness to accept by the vessels that sells the quotas. Both willingness to pay and willingness to accept are based on vessel profitability the previous year. Hence, the model is founded on, that vessels in the most efficient groups purchase quotas permanently from other vessel groups and, thereby, reduce the size of the other vessel groups.

Within the biological box, the forecast of catches is founded on the estimation of a function where recruitment of fish increases with the size of the fish stocks until the MSY, after which it falls. This function is identified in a way such that the stock will not come above the maximum observed over the last twenty years (1995-2014). Total Allowable Catch is determined through a policy aiming at MSY (the management box), while individual fisheries will set their catches at a level that is as close as possible to 
MSY (the effort box), while at the same time ensuring maximum economic outcome from the fishery.

The forecasts in this report are founded on data from the base period, which is the annual average of 2012-2014 where all data are available. From the base period, data for the initial year 2015 are calculated by taking into account that data on fleet, catches and prices are known. The calculation is made by scaling all other data after the development in the known data. From 2016 and onwards, forecasts are fully made in the model by maximizing socio-economic return and profit under the restrictions sketched above.

The causalities and relations in the model are summarized in Table 4.

Table 4: Summary of causalities and relations in the FishRent model

\begin{tabular}{|c|c|}
\hline Item & Description \\
\hline \multicolumn{2}{|l|}{ Biology/management: } \\
\hline $\begin{array}{l}\text { Biomasses (size of fish } \\
\text { stocks) }\end{array}$ & $\begin{array}{l}\text { Biomasses are determined by being the same as the year before with recruitment of fish added and } \\
\text { mortality of fish (fishing and natural mortality) removed. }\end{array}$ \\
\hline Recruitment of fish & $\begin{array}{l}\text { Recruitment of fish depends on the biomasses as given in a second degree polynomial with an optimum at } \\
\text { the MSY. }\end{array}$ \\
\hline $\begin{array}{l}\text { Total Allowable } \\
\text { Catches }\end{array}$ & The Total Allowable Catches are set given a MSY target. \\
\hline \multicolumn{2}{|l|}{ Economy: } \\
\hline Turnover & $\begin{array}{l}\text { Catches are determined by fishing effort and the size of the fish stocks (biomasses) in a Cobb-Douglas } \\
\text { production function. Fish prices are assumed constant at the average } 2012-2014 \text { level. }\end{array}$ \\
\hline Fuel costs & $\begin{array}{l}\text { Fuel consumption is determined by fishing effort and fuel prices are assumed constant at the average } \\
2012-2014 \text { level. }\end{array}$ \\
\hline Labour costs & Labour costs are determined as a fixed share of turnover and based on the average $2012-2014$ level. \\
\hline Other variable costs & $\begin{array}{l}\text { Other variable costs are determined as a fixed share of turnover and based on the average } 2012-2014 \\
\text { level. }\end{array}$ \\
\hline Capital costs & $\begin{array}{l}\text { Total capital costs are determined by number of vessels with capital costs per vessels being constant at } \\
\text { the average } 2012-2014 \text { level. }\end{array}$ \\
\hline Fixed costs & $\begin{array}{l}\text { Total fixed costs are determined by number of vessels with fixed costs per vessels being constant at the } \\
\text { average } 2012-2014 \text { level. }\end{array}$ \\
\hline $\begin{array}{l}\text { Opportunity cost of } \\
\text { labour }\end{array}$ & $\begin{array}{l}\text { The use of labour in alternative sectors is determined by fishing effort with annual wages in alternative } \\
\text { sectors being assumed constant in each country case at an assessed realistic annual level. }\end{array}$ \\
\hline $\begin{array}{l}\text { Opportunity cost of } \\
\text { capital }\end{array}$ & $6 \%$ of physical assets (i.e. assets excluding values of fishing rights) \\
\hline Investments & $\begin{array}{l}\text { Investments in vessels are determined by the profit last year with increased profit leading to investments } \\
\text { in more vessels and decreased profit inducing exit of vessels. }\end{array}$ \\
\hline \multicolumn{2}{|l|}{ Other: } \\
\hline Fishing effort & Fishing effort is determined by number of vessels and days at sea per vessel. \\
\hline Discount factor & $3 \cdot 5 \%$ \\
\hline Fishing technology & Unchanged at the $2012-2014$ level. \\
\hline $\begin{array}{l}\text { Maximum days at } \\
\text { sea/vessel/year }\end{array}$ & $\begin{array}{l}\text { Set in each case study to reflect the maximum days a vessel realistically, this has been set to at the } \\
\text { maximum observed days sea per vessel per year over } 2012-2014 \text { for each vessel group. The maximum } \\
\text { days at sea per year increase with size of the vessels with the largest vessels potentially being able to fish } \\
\text { almost year round. }\end{array}$ \\
\hline $\begin{array}{l}\text { Maximum } \\
\text { catch/vessels/year }\end{array}$ & $\begin{array}{l}\text { Set to reflect the maximum catch a vessel realistically is able to catch per year. The maximum catch per } \\
\text { vessel per year depends on size of the vessel and type of fishery (pelagic and demersal). }\end{array}$ \\
\hline $\begin{array}{l}\text { Trade in permanent } \\
\text { quotas }\end{array}$ & $\begin{array}{l}\text { The quantity of permanent quotas sold is determined by the relative expected future profits of vessel groups. } \\
\text { Vessel groups with high expected future profits buy permanent quotas from vessels with less expected future } \\
\text { profits. The annual price of quotas traded permanently is calculated as discounted future profits allocated over } \\
\text { the infinitive earning period. The price of the quotas is set as the average of the sellers' willingness to accept } \\
\text { and the buyers' willingness to pay, which again are determined by their profit. }\end{array}$ \\
\hline
\end{tabular}

Source: See Appendix. 
The causal structure of the model is that the activity of the fishing fleet (number of vessels and days at sea) in a year determines catches and costs and, through that, socioeconomic return and profit. The fishing activity also affects fish stocks and the larger the fishing effort, the less the fish stock. Hence, a large fishing effort leaves less fish in the sea for future fishing, corresponding to that savings on a Bank Account is used and the balance is reduced, while a small fishing effort leaves more fish in the sea to be caught in the future. Furthermore, many fish in the sea in the form of a large fish stock induce a high recruitment of fish, which lead to further growth of the stock in the long run. At sufficient high fishing efforts, fish stocks fall to a level where sustainable long run catches will fall. The activity of fishing, determined by the Total Allowable Catches, is set by the fishery regulator at the largest possible catch that can be sustained in the long run. That is, at the MSY.

Founded on this structure, the number of vessels and days at sea in each vessel group that gives the maximum net present value of all discounted future socioeconomic returns and profits are identified. The maximization made under a number of restrictions reflect that fishermen fish to earn money, and plan their fishery to earn as many money as possible, whilst the restrictions are included to reflect that in reality fishermen do not always fully do that. For example, the decision to stop fishing is often based not only on economic considerations, but also depend on age, family and future expectation of income. Hence, the forecasts are both founded on economic rational behaviour of fishermen reflected in the maximization and on corrections of realized behaviour deviating from this reflected in for example the annual $4 \%$ limit on fleet adjustment.

While forecasts can provide good input to the debate on future fishery policies, they also critically depend on the methodology applied and the assumptions on which the model forecast is built upon.

First, with forecasts made for representative vessels in each group, the results measure the effect of changing the activity and number of vessels in each vessel group, while it does not take into account that vessels within each vessel group can trade quotas with each other, implying that the most efficient vessels can buy quotas permanently from less efficient vessels. Socio-economic return and profit are underestimated due to that.

Second, the assumption of multi-species fisheries that each vessel group's relative time spent on the various stocks is constant makes switch of effort to other species impossible in the forecast model. When such switches are not possible, the "choke" species problem appear. The "choke" species problem indicates that if the Total Allowable Catch on one stock decrease, fishing on all stocks must be reduced correspondingly. The model does in such a situation forecast a substantially reduced activity of the vessel group, whilst in reality the vessels could have continued to fish on the remaining stocks. The implication is that socio-economic return and profit are underestimated.

Third, technology is assumed unchanged in the future, implying that to the extent technology improves over time, which is normally seen, socio-economic return and profit is underestimated. 
Finally, the use of a twenty years period as the basis for the biological forecasts implies that if the stock is larger in the base period 2012-2014 than over the last twenty years, catches will fall until 2025. On the other hand, if the stock is smaller in the base period 2012-2014 than over the last twenty years, catches will grow. That induces uncertainty in the forecasts in all scenarios. The relative forecasts between scenarios, however, are not uncertain, since the uncertainties are the same in all scenarios. 


\section{Greenlandic shrimp fishery}

\subsection{Introduction}

ITQs have been in force in shrimp fishery for offshore trawlers with onboard processing from 1990 and for coastal trawlers from 1997. The management have ensured reduction of earlier overcapacity and increased earnings without compromising sustainability. It has also reduced fleet size and employment. The system remains in play today.

The legal framework for taxing direct export of shell shrimp from offshore trawlers was introduced in 1990. While the tax revenue was high the first year, it was reduced to a low level over the following two decades. The tax rate, however, grow with the size of shrimp prices, in order for the Government to collect the surplus when they are high. And with price increases 2010-2015 and continue high prices afterwards, shrimp tax revenue has become a very important income source of the Government in 2017.

The policy consideration balance between a coastal fleet that supply factories and secures employment in both sectors and a highly efficient offshore trawler fleet contributing substantially to GDP and ensure funding of public spending through taxes. With one of the longest histories of ITO management and the highest resource rent tax in fisheries worldwide, the Greenlandic shrimp fishery present an interesting model of fisheries management relevant to consider in many countries.

The Parliamentary Bill on a New Fishery Law has been intensively debated in the media the last year. It suggests reallocation of quotas permanently from offshore to coastal shrimp trawlers and the introduction of a notice period of five years for termination of ITOs, instead of the current infinitively running system.

The proposers argue that recruitment of young people to shrimp fishing is ensured and that employment increase in coastal shrimp fishing and at factories. This is considered important with few alternative jobs.

Opponents find that the contribution of the efficient offshore shrimp trawlers to GDP and tax revenue is reduced, that termination of ITQs induces a compensation liability for the Government to the offshore trawlers and that employment consideration is expensive in fisheries and better provided by developing other industries. Furthermore, the New Fishery Law negatively affects the ability of the fisheries to contribute to fund independence of Greenland. The reason is that quotas are moved from efficient offshore trawlers exporting shell shrimp, to less efficient coastal trawlers supplying factories producing peeled shrimp at an aggregated substantial lower contribution to GDP.

The purpose of this chapter is to contribute to the debate on the future fishery policy by forecasting economy and employment quantitatively until 2025 under the current management, and compares with hypothetical policy changes of free quota 
trade and higher shrimp taxes. This case study analyses the economy of the whole domestic shrimp value chain, e.e. fishery and processing. The reason is that offshore vessels process on board implying that fleet segments can only be compared when including also land based processing. Experience on how ITOs and taxes play together is provided. The Bill of the New Fishery Law is not directly assessed, although the forecast provide indications on the size of the effects.

The case study is performed by Max Nielsen, Ayoe Hoff and Rasmus Nielsen, Institute of Food and Resource Economics, University of Copenhagen, Denmark. ${ }^{1}$

In the following, the current and historical management of Greenlandic fisheries is described, while section 3 provides a literature review of economic studies assessing fishery policy reforms in Greenland over the last decade. Section 4 present data and section 5 the results of the scenarios. Section 6 concludes the chapter with policy considerations.

\subsection{Management}

Fishing around Greenlandic dates back centuries, with fishermen from several European countries targeting mainly cod. European fishing continued up to modern time, with cod catches peaking over the 1980ies. Today, a few European vessels remain active at East Greenland. Commercial fishing by Greenlanders diversified from cod fishing to also include shrimp in particular over the 1980ies. Shrimp fishing began in the middle of the 1970 when the offshore fishing developed. Shrimp replaced cod almost fully in the 199oies and many Greenlandic shrimp trawlers were added to the fleet, including the publicly owned vessels operated by Royal Greenland Trading Department, today Royal Greenland Ltd.

Today, shrimp fishing and processing is by far the most important economic activity, although Greenland halibut fishing have also developed to a large business. With climate change, a larger diversity of species is now present and caught at East Greenland, including mackerel and herring.

With the 200 nautical mile Exclusive Economic Zone coming into force in 1982 with the Convention of Law of the Sea (United Nations 1982), Greenlandic ownership of fish stocks formed the foundation for stock management with Total Allowable Catches. It also made it possible to prioritize domestic vessels and exclude foreign vessels. Greenland remained, however, member of the European Union, implying that the Common Fisheries Policy made it possible for EU vessels to continue fishing until the EU exit in 1985. The EU exit was followed by an agreement that in return for free access for Greenlandic fish product to the EU market and financial compensation, allowed some European vessels to continue fishing, although the disappearance of cod over the 199oies limited their activity. Today, a limited number of European vessels prevail at East Greenland.

${ }^{1}$ Lector Emeritus Hans Frost has contributed with valuable comments and discussions. 
In the 1980s, total allowable catches were introduced. Subsidies were also given to new vessels and together with private overinvestment, overcapacity in the shrimp fishery were induced. The commercial disappearance of cod in the early 19goies made shrimp the most important species and led to vessels switching for the shrimp fishing, further worsening the overcapacity problem.

For offshore production trawlers, the solution in 1990 was ITOs. Since increased profit was anticipated, the legal basis for shrimp taxes was introduced at the same time for these vessels on the direct export in order for the Home Rule Government to achieve a share of the increased earning. For coastal shrimp trawlers, the solution at that time were a transferable license system (Directorate of Fisheries, Hunting and Agriculture 1995), where vessel capacity were graduated after catch capacity based on size of vessel, engine, historical catches, etc. A licensed vessel had free fishery and could sell its license to other vessels.

While the ITO management for offshore vessels reduced overcapacity and increased earning, the license system appeared not to have the intended effect, due to increased utilization of the single vessels and technological progress. The system was replaced by ITOs in 1997. ITOs have prevailed for shrimp since then and in 2012 the system was also introduced in the inshore Greenland halibut fishery for vessels over 6 meter.

Today, the Fishery Act (Greenland Parliament 1996) with revisions, together with Government Directives including for licenses, quotas and technical conservation measures, forms the legal framework. The Government fixes annually Total Allowable Catches following biological advice. Each vessel permanently owns a fixed share of the Total Allowable Catch that identifies the annual quota. Both permanent quota shares and annual quotas are freely tradable, except for that coastal vessels less than $120 \mathrm{GT}$ are not allowed to sell to offshore vessels. This limitation ensures the balance between the two vessel groups. The Fishery Act also specifies that offshore vessels are allowed to fish three nautical miles outside the baseline, where coastal vessels have to fish inside that area.

A landing obligation on $100 \%$ exists for coastal vessels and on $25 \%$ for offshore production trawlers, to ensure raw material for factories. Offshore production trawlers further have an on board production permit on the remaining $75 \%$. A few vessels had until 2015 a coastal license together with a $30 \%$ production permit.

Concentration rules prevail to avoid that few companies control the quota market. Ownership with decisive power ${ }^{2}$ of a company or individual is limited to $33.3 \%$ of the total allowable catches allocated to offshore vessels and to $15 \%$ of the Total Allowable Catch allocated to coastal vessels. In these shares, company ownership of another company with decisive power count.

The Act on Shrimp Taxes (Greenland Parliament 1990), which changed to the Act on Resource Taxes on Greenlandic Fishery (Greenland Parliament 2017), has been the legal foundation for the shrimp tax. Until 2017, the tax solely applied for shell shrimp

${ }^{2}$ Decisive power exist when one company own more than half of another company. 
processed on board offshore vessels and exported directly. The rationale is that since direct export doesn't contribute with jobs at factories, it must contribute to the society in another way, with tax revenue. The tax rate is progressive with the tax rate increasing when prices increase.

\subsection{Literature review}

The importance of the fishing industry for Greenland continuously induce political debate and recurring launches of analyses on the balance between the fishery policy purposes of contributing to the socio-economy and to national employment.

One literature direction of people emphasize the socio-economic contribution of the fishery sector to the national economy and GDP, given that fishery and fish processing is the most important sector economically. This direction favours the current ITQ management as an instrument to create societal welfare. Some finds that the current management with safe guards for coastal vessels to avoid that these are brought out by larger vessels, ensures a reasonable balance between the employment intensive coastal fleet, that also secure employment at factories, and the highly efficient offshore trawler contributing to GDP. Others find that the transfer of quotas from coastal vessels to more efficient offshore trawlers under increasing returns to scale induce substantial growth in the sectors socio-economic contribution. And some of these see that growth have a role to play in providing the economic foundation for Greenlandic independence.

Another literature direction focuses on fishery and fish processing as the largest sector nationally in terms of employment and considers maintenance of jobs as necessary for maintaining small fishing communities. Fishery reforms that at the expense of a larger GDP contribution reduce employment, induces a social risk when few alternative jobs are available. And such reform might aggravate the already prevailing social problems. This direction might be against ITQs since it reduce employment. But it might also favour it if quotas are reallocated from offshore to coastal vessels.

A third literature direction sees the extension of the efficient offshore trawler fleet as a way to achieve the maximum GDP contribution and thereby the largest possible welfare in the Greenlandic society. However, since profits goes to the private fishing companies, taxes are needed for the society to obtain a fair share. This direction is in favour of ITQs in combination with fishing taxes.

Over the last decade, more studies have been conducted for the shrimp fishery. The Greenland Home Rule (2009) initiated a Fishery Commission with industry members that were required to work within the policy purpose of maximizing earning of the sector for the Greenlandic society. The work was initiated at a time with the belief that new industries such as mining and hydropower would soon ensure full employment, implying that job maintenance in fishing was not of highest priority.

Their analysis showed that if offshore production shrimp trawlers replaced all coastal vessels and all factories, the sector contribution to GDP could increase EUR 10.3 Million (11\%), while employment would be reduced by 900 persons $(65 \%)$. On this basis 
the Commission recommended lifting the landing duty and the ban of quota sale from coastal vessels to offshore vessels. ITQs were further seen as the best instrument to ensure efficiency in Greenlandic fisheries and were recommended for more fisheries than shrimp, including halibut inshore. While ITQs were introduced for the inshore halibut fishery in 2012, the landing duty and the ban of quota trade for shrimp remains.

Schütt et al. (2014) show in their bio-economic analysis for the Nordic Council of Ministers that simultaneous lifting the landing duty and the ban of shrimp quota sale, with unchanged production permits for offshore vessels, would increase the socioeconomic return from EUR 34 Million to EUR go Million per year, corresponding to an increase of $37 \%$ of the landing value. Employment at vessels would be reduced from 572 to $332(58 \%)$, all coastal shrimp trawlers would disappear and employment at factories would be reduced to about half.

The larger socio-economic gain revealed in Schütt et al. (2014) compared to the Fishery Commission is due to price increases, biological gain from effort reduction and to the fact that socio-economic return include over-normal salary.

Nielsen et al. (2016) identify profit of one kilo of shrimp (live weight) in the whole value chain from catch in Greenland, over processing, export and consumption in Denmark for coastal caught and peeled shrimp and shell shrimp caught by an offshore vessels. In 2013, profit in the whole value was EUR 0.61 for peeled shrimp and EUR 1.08 for shell shrimp. It is concluded that profit per kilo shrimp can be increased substantially if offshore trawlers replace coastal trawlers. The amount is conservatively estimated to at least EUR 25.2 Million per year. Hence, the study confirms the gain found in earlier studies of lifting the landing duty and the ban of quota sale between vessel groups.

The study also finds that shrimp from Greenland compete at the world market with both Canadian shrimp and warm-water shrimp farmed in low wage countries such as Ecuador, Indonesia and Bangladesh (Ankemah-Yeboah et la 2017, Nielsen et al. 2018). Competition at the world shrimp market is assessed stronger for peeled shrimp than for shell shrimp, owing to peeled shrimp being labour intensive and to the prevailing higher tariffs. Higher profit and less competition are therefore assessed to make shell shrimp a safer choice for Greenland than peeled shrimp.

The studies demonstrate that a socio-economic contribution exists, which is the necessary for being able to collect any tax revenue. Against this background, the Ministry of Finance (2017) initiated a working group with members from the industry, banks and the ministry that identified the resource rent in Greenlandic fisheries and came up with models for resource rent taxation schemes. The group was required to work within the policy understanding that fish resources are the property of the society. The group found that all fishermen should contribute to society for access to fishing, but also found that the tax should be on level where fishing remains profitable. It was recommended that a possible taxation scheme consists of a general tax to cover public expenses to the fishery and a tax on extraordinary high earnings, with the tax rate increasing with at high prices.

The New Fishery Law was presented and discussed in the Greenlandic Parliament in 2017. It is suggested that the current shrimp quota allocation on $43-57 \%$ between coastal and offshore shrimp vessels is changed to fifty-fifty, that a 5 -years notice period 
for terminating the indefinitely running individual transferable shrimp quotas is introduced, and that minority ownership of companies have to count in the concentration rules (Government of Greenland 2017).

The Government of Greenland (2017) assesses that the Law increases fishery employment and with increased landings also employment in processing. It is further assessed that the socio-economic consequences are efficiency losses from less efficient coastal vessels taking over for offshore vessels and from reduced investments following uncertainty on future management. If the Government is liable to companies that loose quotas, a substantial one-time expense might also result. The loss in GDP contribution were in the long run identified to be up to EUR 24 Million annually, while the loss in public income is up to EUR 17.3 Million.

\subsection{Data}

Fishing and fish processing is the largest industry in Greenland. Fish products account for $87 \%$ of the goods export value (2015, Statistics Greenland 2018a), with shrimp, Greenland halibut and cod being most important. The sector is the largest industry in terms of contribution to GDP, with the direct contribution from fishery, processing and wholesale of fish products being 13\% (Copenhagen Economics 2013). With 3,548 registered employed, a fulltime employment on 1,867 persons and a large number of persons having some income from fishery, the sector is also the largest in employment terms (Nielsen et al. 2017). And employment in fishery further plays a central role in maintaining many small coastal communities.

Shrimp is the core economically. The shrimp sector account for $54 \%$ of the goods export value in 2015 (Nielsen et al. 2017), earn high profits, is the single product with the largest contribution to GDP (Nielsen et al. 2017) and deliver EUR 20.0 Million in shrimp tax revenue in $\mathbf{2 0 1 5}$, on top of income and company taxes. Shrimp is also important in providing jobs that are well-paid compared to in other parts of the fishery sector, with 573 fulltime employed totally in fishing and processing (in 2012-2014, see Table 5).

Shrimp are caught from the West Greenlandic stock in Davis Strait and Baffin Bay, while catches from the stock at East Greenland forms less than 1\% (2012-2014). Coastal vessels fish solely at West Greenland, while some off-shore vessels have a minor additional catch at East Greenland and earlier a small catch in a few years at Flemish Cap. All vessels use trawl. The products from the shrimp industry can be divided into mainly two categories of products; one is boiled frozen shrimp with shell produced onboard the off-shore production trawlers. These are exported directly from the trawlers without being landed to a land-based production facility in Greenland. The second category is produced from the shrimps landed in Greenland and produced as cooked and peeled shrimps at the land-based factories.

Physical data are known from the vessel and license register (Greenland Fishing License Control 2018) and the landing statistics (Statistics Greenland 2018a), while economic data and data for fulltime employment originates from the account statistics 
(Statistics Greenland 2018b). Physical and economic data for the shrimp industry is shown as annual averages over 2012-2014 in Table 5 for the coastal fleet, the off-shore production trawler fleet and for the land-based shrimp factories.

Table 5: Physical and economic data, annual average 2012-2014

\begin{tabular}{|c|c|c|c|c|}
\hline & $\begin{array}{l}\text { Coastal } \\
\text { trawlers }\end{array}$ & $\begin{array}{l}\text { Offshore } \\
\text { trawlers }\end{array}$ & $\begin{array}{r}\text { Land-based } \\
\text { factories }\end{array}$ & Total \\
\hline \multicolumn{5}{|l|}{ Physical data } \\
\hline Fulltime employment/segment & 203 & 88 & 282 & 573 \\
\hline Number of vessels & 21 & 9 & . & 30 \\
\hline Number of factories & & . & 4 & 4 \\
\hline DAS/vessel & 168 & 294 & . & . \\
\hline Posted quota rights assets/vessel (EUR 1000) & 156 & 312 & . & . \\
\hline 1st important species & Shrimp $(\sim 100 \%)$ & Shrimp $(\sim 100 \%)$ & . & . \\
\hline \multicolumn{5}{|l|}{ Total account data (EUR Million) ${ }^{1}$} \\
\hline Turnover & 34 & 153 & 121 & 309 \\
\hline Fuel Costs ${ }^{2}$ & 7 & 26 & 10 & 43 \\
\hline Crew costs & 12 & 39 & 16 & 67 \\
\hline Variable costs $^{2}$ & 5 & 25 & 80 & 110 \\
\hline Fixed costs ${ }^{2}$ & 5 & 18 & 10 & 33 \\
\hline Capital costs & 5 & 6 & 3 & 14 \\
\hline Opportunity labour cost ${ }^{3}$ & 8 & 11 & 11 & 31 \\
\hline Opportunity capital cost 4 & 5 & 9 & 3 & 16 \\
\hline Shrimp tax revenue & 0 & 14 & 0 & 14 \\
\hline Profit & 1 & 38 & 2 & 41 \\
\hline Socio-economic return 5 & 4 & 78 & 5 & 86 \\
\hline
\end{tabular}

Note: 1 . The account data for the coastal fleet is identified by upscaling from the available data from 16 vessels to the 21 active vessels. That data thus cover $86 \%$ of the vessels. For the production trawlers accounts are available from 5 of 9 vessels and cover $56 \%$. The reason for the lower coverage of offshore production trawlers is that separate account for the activity of these vessels within Royal Greenland and Polar Seafood Greenland has not been available. Account data for land-based factories are identified by upscaling from two factories on the basis of supply of raw materials to these. The analysis rest on the assumption that upscaling is representative. With fishing in each fleet segments and processing at each factories taking place in the same way, this is assessed to be the case.

2. The total costs of fuel costs, variable costs and fixed costs are known, but the allocation between the three components is an estimate.

3. Total opportunity cost of labour is identified on the basis of an annual average salary of a fishermen/factory worker in another sector on EUR 40,000 multiplied by the number of full time employed.

4. Total opportunity cost of capital is calculated as $6 \%$ of the physical assets of the companies. 5. The socio-economic return = turnover - fuel costs - variable costs - fixed costs - opportunity costs of labour - opportunity cost of capital - extraordinary taxes paid.

Source: Statistics Greenland (2018b), Account Data, Statistics Greenland (2018c), Landing Statistics and Greenland Fishing License Control (2018), The License Register.

1 coastal vessels and 9 off-shore production trawlers are active in 2012-2014 as an annual average. 2 vessels with a license for coastal fishing and with an onboard production permit on $30 \%$ of the catch are moved to the off-shore production fleet. In the period, 25 coastal vessels without onboard production were licensed, but only the 21 active vessels are included in this analysis. 4 factories prevail, two owned by Royal Greenland Ltd. and the two others by Polar Seafood Greenland Ltd. The factories are located in Nuuk, Sisimiut, Ilulissat and Aasiaat. Hence, the shrimp industry is 
concentrated in the largest cities in Greenland. Total fulltime employment was 573, half of these at factories. Coastal vessels employed 203 and off-shore production trawlers 88. The average asset of a coastal vessel was EUR 1.5 Million and 21.7 for an off-shore production trawler. That reveals a capital intensive off-shore trawler fleet producing shell shrimp founded on economies of scale and/or economies of scope in the production, and a coastal trawler fleet supplying factories, together being labour intensive in peeled shrimp. The annual days at sea per vessels is estimated, based on Schütt et al. (2014). The numbers indicate that the off-shore vessels are at sea a substantially larger number of days a year than the smaller coastal vessels.

The development in number of vessels in the two fleet segments is shown in Figure 3 together with total catches from the West Greenland shrimp stock.

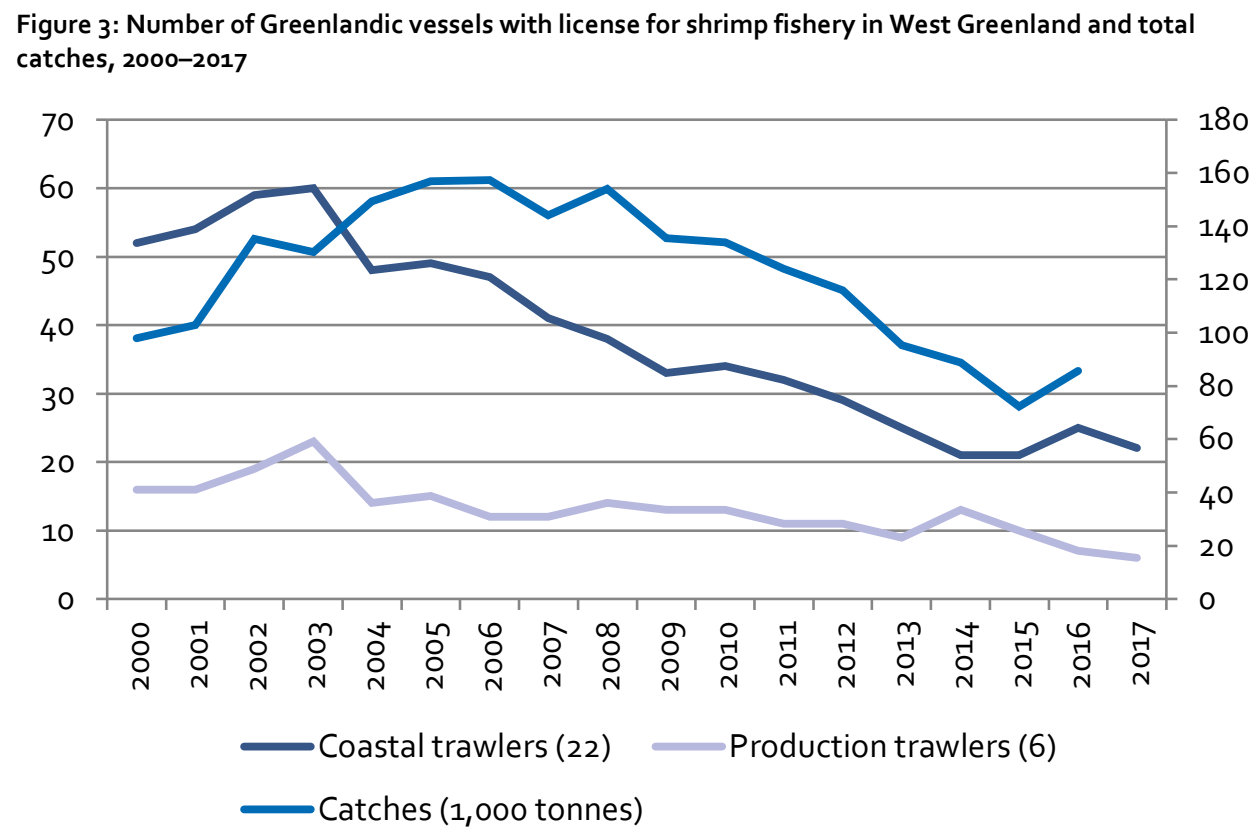

Note: Number of vessels includes all Greenlandic vessels with a license for shrimp fishing at West Greenland. Foreign vessels including Danish are not included. Vessels with a license at East Greenland are only included if it also hold a license at West Greenland. Research fishery licenses and licenses given to dinghies in 2008 are excluded. Production trawlers includes offshore trawlers with a license for offshore fishery and a production permit on $75 \%$ and trawlers with a license for coastal fishery with a production permit on $30 \%$ (where the last disappeared in 2015). Catches includes both Greenlandic and foreign fishing at the West Greenland stock.

Source: Greenland Fishing License Control (2018), License Register, Nuuk, Greenland, NAFO/ICES Pandalus Assessment Group (2017).

The number of licensed vessels dropped from 78 in 2002 to 28 in 2017, corresponding to a reduction on two-third. In 1993 the number of coastal vessels holding a license for shrimp fishery was 131, of which 119 were active (Directorate of Fisheries, Hunting and Agriculture 1994). That corresponds to a $82 \%$ decrease in number of active vessels from 1993-2017. The number of offshore vessels was also substantially higher at that time. Hence, a large reduction of the shrimp fleet is observed since the introduction of ITQs 
starting with offshore vessels in 1990 and continuing with coastal vessels in 1997. In 2002-2017, the fleet reduction in the two vessel groups is largely the same.

Total catches at the West Greenland shrimp stock are fully taken by Greenlandic vessels, except for a minor Canadian catch in the Baffin Bay in some years and a minor catch by one Danish vessel. The catch is increasing until 2000, at a stable high level in 2005-2008 and decreasing afterwards, although the catch increases again in 2016.

The continued fleet reduction over the period in both fleet segments might be explained by the diminishing resource base until 2015. However, the continued technological development and productivity growth are also gradually making the two fleets more efficient. The fleet adjustment is also made easy by the presence of ITQs, where it is possible for some vessels to buy other vessels out.

The account data in Table 5 are available for $86 \%$ of active coastal vessels, $56 \%$ of off-shore vessels and from half the factories. Based on this, total numbers for each fleet segment and for the shrimp factories are found by upscaling. Turnover is after payment of the EUR 14 Million by the off-shore vessels. Opportunity cost of labour is identified as the annual salary a fulltime fishermen/shrimp factory worker can achieve if they stop in the fishing industry and have a job in another sector. It is approximated to the annual salary of an unskilled industrial worker at land at EUR 40,000. Opportunity cost of capital is identified as $6 \%$ of the assets excluding the value if fishing rights.

Profits are with EUR 38 Million, corresponding to $25 \%$ of the landing value, high for the off-shore production trawlers. For both coastal vessels and factories profits are largely zero. Hence, the profit numbers confirms the finding of former studies that the profit of the shell shrimp value chain is substantially higher than for the peeled shrimp value chain.

Socio-economic return measures "The net-surplus that, at a given time, remains for the remuneration of capital and labour above the rate that is achieved in other businesses including extraordinary taxes paid." The definition appears from Nielsen et al. (2012) with taxes added. The socio-economic return is calculated as turnover minus fuel costs minus variable costs minus fixed costs minus opportunity costs of labour minus opportunity cost of capital minus extraordinary taxes paid. In economic terms the socio-economic return is the sum of the resource rent and the producer surplus. While profit measures the net return a company have from their fishery, socioeconomic return measures the net return a society have on the existence of a fishery, more than if labour and capital had been used in other sectors.

The socio-economic return is for the off-shore trawler with EUR 78 Million, $51 \%$ of the landing value, higher than profit. The reason is that actual cost of labour exceed the opportunity cost, i.e. that the crew on off-shore vessels have a higher salary than could have achieved in other sectors, and that off-shore vessels pay a shrimp tax of EUR 14 Million. For coastal vessels and factories, the socio-economic return is also higher than profit, but it remains close to zero. As for profit, the socio-economic return in the shell shrimp value chain is well above in the peeled shrimp value chain.

The shrimp tax was introduced in 1991 together with ITOs for off-shore vessels. The first year, EUR 17 Million was collected in tax revenue. However, pressure from the industry lead to a substantial reduction in the tax starting the following year and 
continuing (Ministry of Finance (2017). In Figure 4, the development in tax revenue in 2000-2015 is shown. Since the tax rate increase with shrimp prices, the development in prices is also presented.

Figure 4: Revenue collected by the Government of Greenland as taxes on shell shrimp and shell shrimp prices, 2000-2015

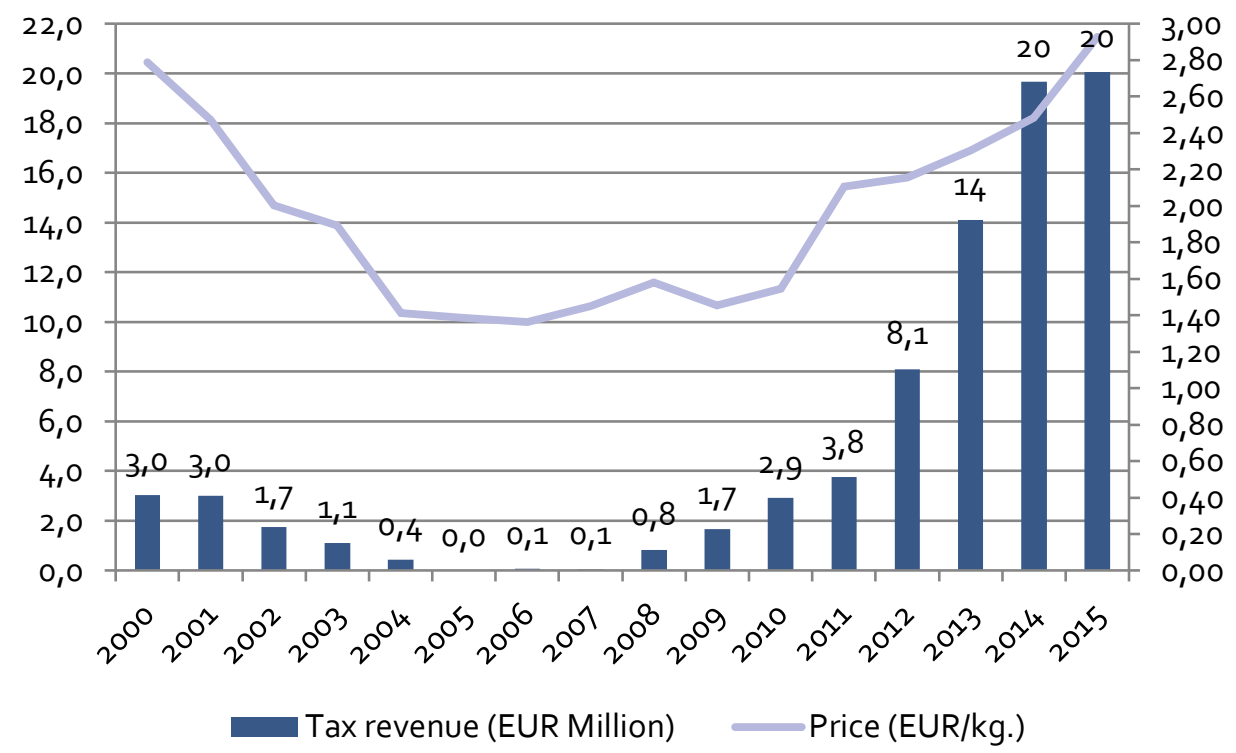

Source: Tax data are from Greenland Home Rule (2009) and Ministry of Finance (2017), while price data are from Statistics Greenland (2018a).

In 2012-2014, the shrimp tax revenue was on average EUR 14 Million, corresponding to $9.1 \%$ of the catch value for the offshore production trawlers. The shrimp tax also increase in 2015 and 2016. The shrimp tax revenue has become an important source of income for the Government of Greenland. The tax revenue follows the price development for shell shrimp. When prices are low, no taxes are collected, while tax revenue increase together with the price increases over the period 2010-2015. Prices on shrimp are formed on a world market in competition with cold-water shrimp from Canada and farmed warmwater shrimp from e.g. Ecuador and Asia. Both reduced catches from Greenland and Canada, and reduced growth of warm-water shrimp farming contribute to explain the price increase and, thereby, the increase in tax revenue.

The West Greenland shrimp stock is considered as one single population covering the whole West Greenland area (NAFO Subarea o/1), as shown at the map in Figure 5 . 
Figure 5: Map of fishing areas at West Greenland

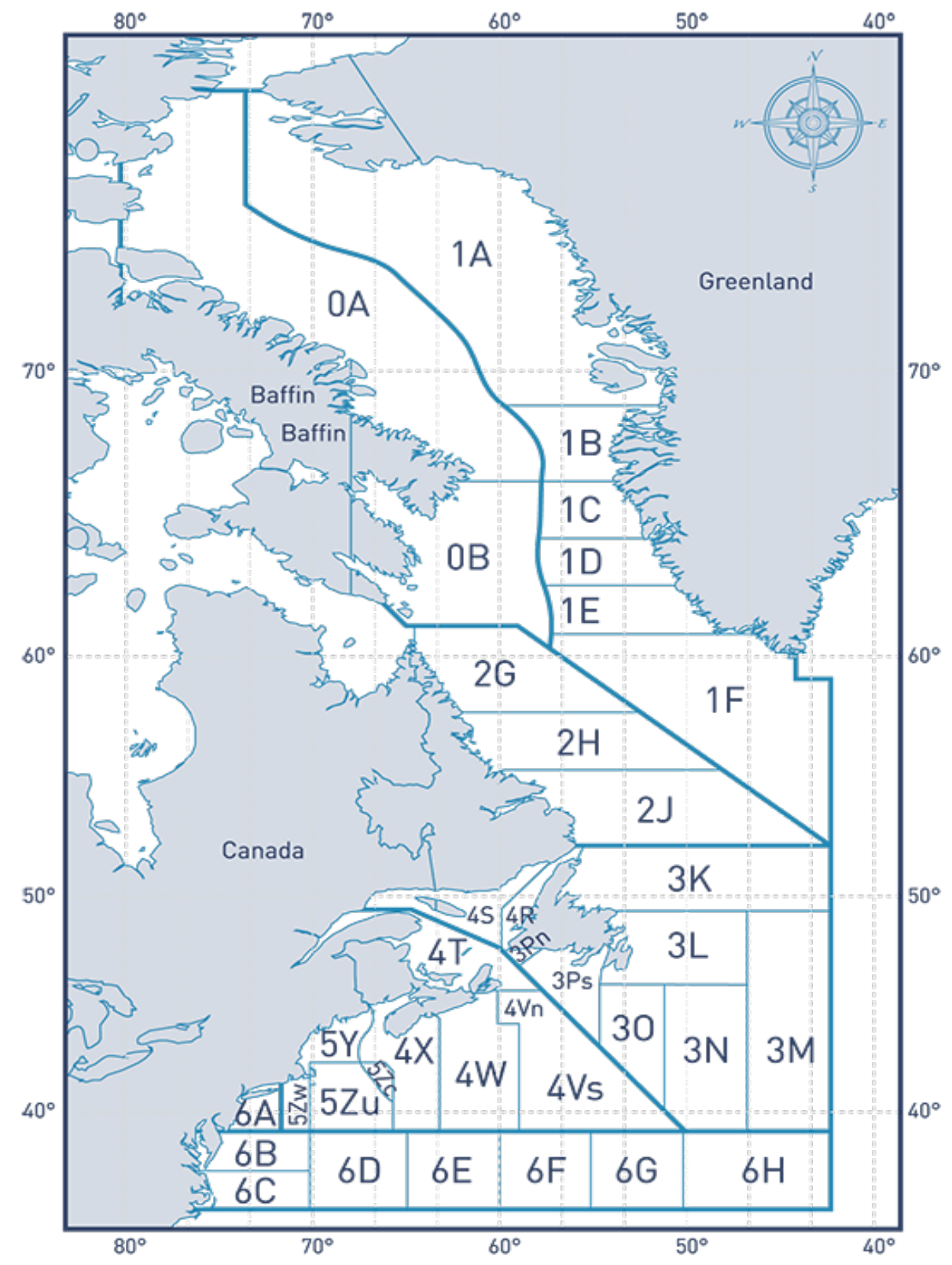

Source: NAFO (2018).

The Greenland fishery exploits the stock in Subarea 1 (Division $1 \mathrm{~A}-1 \mathrm{~F}$ ), where the Canadian fishery since 1981 has been limited to Division oA. The Total Allowable Catch is set by the Government of Greenland founded in biological advices from NAFO made by the NAFO/ICES Pandalus Assessment Group (2017). The Total Allowable Catch includes an amount unilaterally allocated for Canadian fishing. Key indicators for the status of the main West Greenlandic shrimp stock are presented in Table 6. 
Table 6: Status of stock, fishing and management of the West Greenland shrimp stock, 2015

\begin{tabular}{|c|c|c|c|c|}
\hline & \multicolumn{2}{|c|}{ Spawning stock biomass ${ }^{1}$} & \multirow[t]{2}{*}{ Total Allowable Catch ${ }^{2}$} & \multirow[t]{2}{*}{ Fishing mortality ${ }^{3}$} \\
\hline & Current & MSY & & \\
\hline Northern shrimp (tonnes) & 248,100 & 178,500 & 93,400 & $\begin{array}{r}\text { The probability that Z exceed ZMSY is } \\
15.5 \%\end{array}$ \\
\hline
\end{tabular}

Note: 1 . Spawning stock biomass is the fishable biomass (>17 $\mathrm{mm}$ ) for the whole West Greenlandic shrimp stock.

2. The Total Allowable Catch is for the whole West Greenlandic shrimp stock.

3. $Z$ measures the shrimp mortality caused both by fishing and cod predation. The risk of the total mortality exceeding the mortality corresponding to the MSY, ZMSY, is estimated to be $15.5 \%$.

Source: NAFO/ICES Pandalus Assessment Group (2017).

The current spawning stock biomass is about $40 \%$ above the spawning stock biomass corresponding to the MSY. The shrimp mortality from fishing and cod predation face a minor risk of exceeding the mortality corresponding to the MSY on $15.5 \%$. Thus, the current spawning stock biomass is at a sustainable size, while shrimp mortality faces a minor risk of not being sustainable. The West Greenlandic shrimp fishery certified for being sustainable by the Marine Stewardship Council.

Founded in the situation in 2012-2014, projections on the expected development in 2016-2025 are presented in the next section.

\subsection{Results}

The development in the shrimp fishery is forecasted until 2025 using the method described in chapter 3 in four scenarios and compared with the initial situation in 2015. The four scenarios for the Greenlandic shrimp fishery are:

1. Current management in Greenland: ITOs with coastal trawlers not allowed to sells to offshore trawlers and a $4 \%$ limit on yearly adjustment in number of vessels in each segment;

2. Free ITQ trade between all shrimp trawlers and a $4 \%$ limit on yearly adjustment in number of vessels in each segment;

3. Current Greenlandic management with no limit on yearly fleet adjustment;

4. Current Greenlandic management with a $4 \%$ limit and $10 \%$ extra taxes on the landing value. ${ }^{3}$ 
Two forecasts are made for each scenario, i.e. (i) the total socio-economic return is maximized over time with the results being presented in Table 7 and (ii) total profit of the fleet is maximized with the results in Table 8 . The net present value of all future earnings is maximized through variation in number of vessels and days at sea per vessel. The forecast results are shown in the Tables for 2025 comparted to the initial situation in 2015. While socio-economic return measures the extraordinary economic contribution of fisheries to the socio-economy, profit is the surplus for the private fishing companies. As opposed to the other country cases, the economic forecasts for the Greenlandic shrimp industry include both fishing and processing.

The biological foundation of the shrimp fishery in the initial situation is shown in Table 6. Future recruitment of shrimp is forecasted by estimating a function where recruitment of shrimp increases in spawning stock biomass until the MSY, after which it falls. This function is identified in a way such that the stock will not come above the maximum observed in the period 1995-2014. Catches are then determined at the MSY level by fleet size and total days at sea, thereby assuming a MSY quota setting policy. The forecasted catches are shown for maximizing socio-economic return (top chart) and for maximizing profit (bottom chart) in Figure 6. 
Figure 6: Predicted catches that induce the maximum socio-economic return and profit, 2012-2015, tonnes
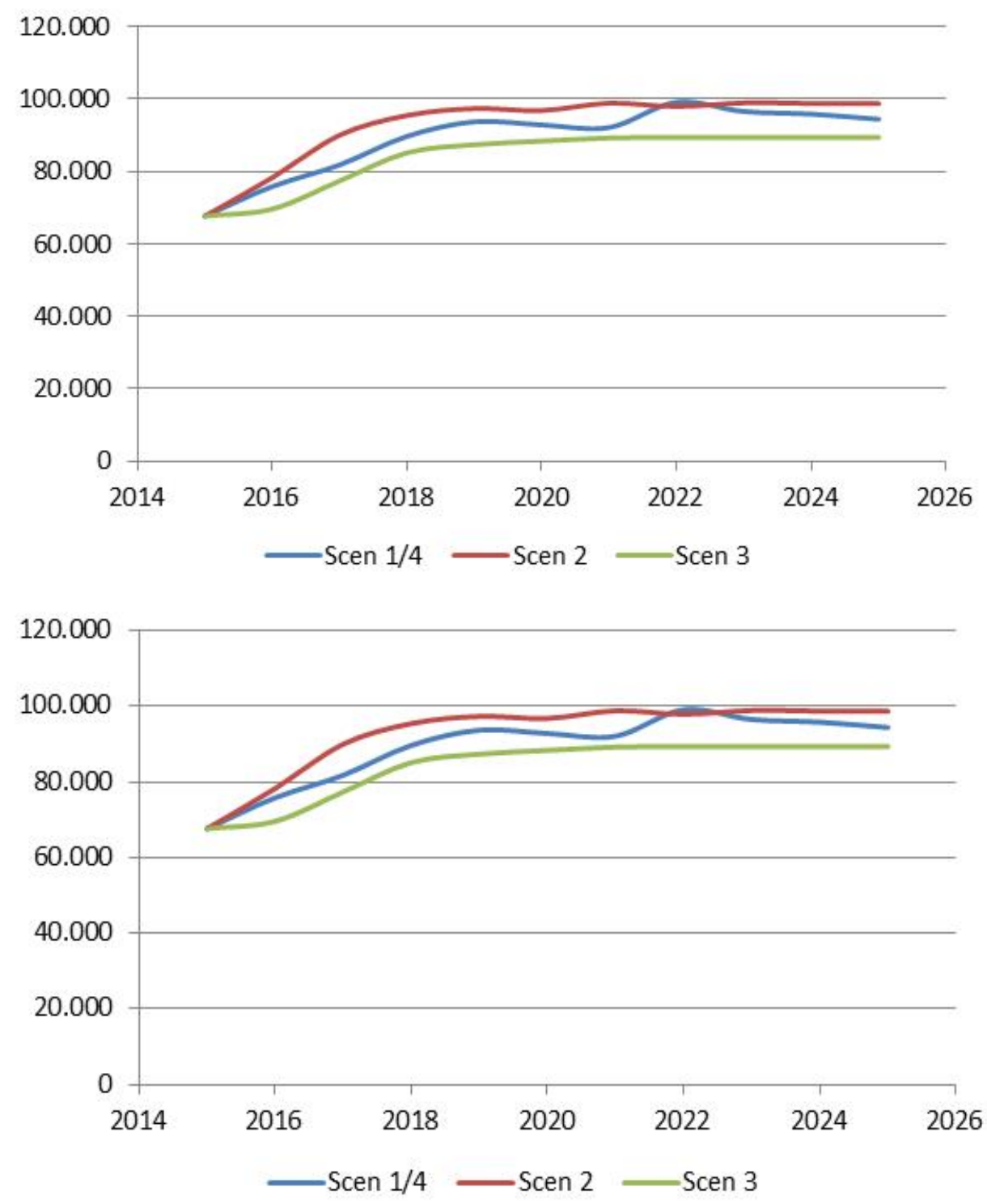

The reason for the increase in catches from the initial year is that the stocks were lower in the base period 2012-2014 than over the period 1995-2014 on which the biological forecast is founded. The predicted catches increase over time until 2025 both when maximizing socio-economic return and profit, as well as for all scenarios. The uncertainty of the future recruitment of shrimp also induce uncertainty on the economic forecasts. The relative forecasts between scenarios are, however, not affected by the uncertainty.

The forecasts are made under the following assumptions: i) Prices on shrimp and all inputs to production, such as fuel, salary and interest rate, are assumed constant, ii) 
Maximum days at sea per vessels is 270 for coastal vessels and 312 for offshore vessels, iii) Days at sea in the initial year 2015 scaled down to ensure that the known 2015 quota is not exceeded, iv) Maximum catch per vessel per year is restricted to be below a maximum of 2 times the catch per vessel in 2015 and $v$ ) the profit maximisation is performed with the expected value of future purchased permanent quota shares included as a cost, identified as the average of quota buyers and sellers willing to pay/accept.

Table 7 shows the forecasts where socio-economic return is maximized in the four scenarios. The Table displays the socio-economic return for the two fleet segments, land-based factories and total, together with the total number of vessels and the total fulltime employment. The total socio-economic return in the initial year 2015 on EUR 69 Million is smaller than in the base period 2012-2014. The same accounts for profit. The reason for the difference is the reduced West Greenlandic shrimp quota in 2015.

Table 7: Forecast of socio-economic return, fleet and employment adjustment in 2025 by maximizing socio-economic return

\begin{tabular}{|c|c|c|c|c|}
\hline & $\begin{array}{r}\text { Coastal } \\
\text { Trawlers }\end{array}$ & $\begin{array}{l}\text { Offshore } \\
\text { Trawlers }\end{array}$ & $\begin{array}{r}\text { Land-based } \\
\text { Factories }\end{array}$ & Total \\
\hline \multicolumn{5}{|l|}{ Socio-Economic return (mill EUR) } \\
\hline 2015 initial situation & 8 & 59 & 1 & 69 \\
\hline \multicolumn{5}{|l|}{2025 scenarios: } \\
\hline 1. Current management & 17 & 108 & 3 & 127 \\
\hline 2. ITO management free quota trade & 5 & 129 & 2 & 135 \\
\hline 3. Current management full adjustment & 15 & 112 & 3 & 129 \\
\hline 4. Current management $10 \%$ landing & 17 & 108 & 3 & 127 \\
\hline \multicolumn{5}{|l|}{ Number of vessels/processing (tons) } \\
\hline 2015 initial situation & 21 & 9 & 35,616 tons $^{1}$ & 30 \\
\hline \multicolumn{5}{|l|}{2025 scenarios: } \\
\hline 1. Current management & 14 & 7 & $36 \%^{1}$ & 20 \\
\hline 2. ITQ management free quota trade & 14 & 10 & $3 \%{ }^{1}$ & 24 \\
\hline 3. Current management full adjustment & 10 & 7 & $18 \%^{1}$ & 17 \\
\hline 4. Current management $10 \%$ landing & 14 & 7 & $36 \%{ }^{1}$ & 20 \\
\hline \multicolumn{5}{|l|}{ Employment (full-time) } \\
\hline 2015 initial situation & 203 & 88 & 282 & 573 \\
\hline \multicolumn{5}{|l|}{2025 scenarios: } \\
\hline 1. Current management & 135 & 66 & 384 & 585 \\
\hline 2. ITQ management free quota trade & 135 & 97 & 292 & 524 \\
\hline 3. Current management full adjustment & 98 & 69 & 333 & 500 \\
\hline 4. Current management $10 \%$ landing & 135 & 66 & 384 & 585 \\
\hline
\end{tabular}

Note: 1 . For processing, the total quantity of shrimp peeled at the land-based factories are shown for the 2015 initial situation, while increases in relation to this production in the initial 2015 situation is shown for scenarios 1-4.

The socio-economic return on EUR 69 Million in 2015, reveal a fishery that has been economically well-managed for many years. For off-shore vessels the initial socioeconomic return is with EUR 59 Million and $39 \%$ of the landing value remarkable. The socio-economic return in 2025 is projected to grow to EUR 127 Million with unchanged management that keeps the current separate management of coastal trawlers and offshore trawlers. This increase is both due the presumed shrimp stock increase and a continued fleet reduction with the coastal fleet being reduced from 21 to 14 vessels and the off-shore fleet from 9 to 7 vessels. Production on land-based factories increases with $36 \%$ in scenario 1 , due to the presumed growth in landings. But the socio-economic 
contribution of factories is in all scenarios close to zero. Employment will remain largely unchanged (rise from 573 to 585), following reductions in fishery and increased employment at factories on shore.

In scenario 2 with free trade of quotas, the socio-economic return is EUR 135 Million, 8 Million higher than in scenario 1 . The coastal fleet is reduced to the same degree as in the no-nothing scenario, while the off-shore fleet due to quota purchase from coastal vessels and the presumed increased catches, increase from 9 to 10, instead of fall to 7 vessels in scenario 1 . Factories remain almost unaffected, with reduced supply from coastal vessels counterbalanced by landings from off-shore vessels, despite these only land $25 \%$ of their catch. Fulltime employment is reduced to 524, $10 \%$, with employment in the coastal fleet falling from 203 to 135 , meet by a rise from 88 to 97 on off-shore vessels.

In scenario 3 with full adjustment the socio-economic return in 2025 comes to EUR 129 Million, almost the same as in scenario 1 . Hence, the adjustment largely happens before 2025 .

Profits from the fleets and factories in the initial year 2015 compared with the forecasted year 2025 is shown in Table 8. Profit is after subtraction of estimated costs of future purchase of quotas (permanent and leases). While socio-economic return measure the surplus for the society as a whole, profit measure the surplus for the companies, after taking costs of quota purchase into account. Profit determines production decisions of companies, implying that the profit scenarios are more realistic than the scenarios for socio-economic return. The reason is that companies take decisions in their own interest, not in the interest of the society.

Table 8: Forecast of profit, fleet and employment adjustment in 2025 by maximizing profit

\begin{tabular}{|c|c|c|c|c|}
\hline & $\begin{array}{l}\text { Coastal } \\
\text { Trawlers }\end{array}$ & $\begin{array}{l}\text { Offshore } \\
\text { Trawlers }\end{array}$ & $\begin{array}{r}\text { Land-based } \\
\text { factories }\end{array}$ & Total \\
\hline \multicolumn{5}{|l|}{ Profit (mill EUR) } \\
\hline 2015 initial situation & 2 & 29 & 0 & 31 \\
\hline \multicolumn{5}{|l|}{2025 scenarios: } \\
\hline 1. Current management & 7 & 61 & 1 & 70 \\
\hline 2. ITO management free quota trade & 4 & 67 & 1 & 72 \\
\hline 3. Current management full adjustment & 6 & 64 & 1 & 71 \\
\hline 4. Current management $10 \%$ landing tax & 6 & 51 & 1 & 58 \\
\hline \multicolumn{5}{|l|}{ Number of vessels } \\
\hline 2015 initial situation & 21 & 9 & 35,616 tons $^{1}$ & 30 \\
\hline \multicolumn{5}{|l|}{2025 scenarios: } \\
\hline 1. Current management & 14 & 7 & $31 \%{ }^{1}$ & 20 \\
\hline 2. ITQ management free quota trade & 14 & 9 & $17 \%^{1}$ & 22 \\
\hline 3. Current management full adjustment & 8 & 7 & $9 \%^{1}$ & 15 \\
\hline 4. Current management $10 \%$ landing tax & 14 & 7 & $31 \%^{1}$ & 20 \\
\hline \multicolumn{5}{|l|}{ Employment (full-time) } \\
\hline 2015 initial situation & 203 & 88 & 282 & 573 \\
\hline \multicolumn{5}{|l|}{2025 scenarios: } \\
\hline 1. Current management & 135 & 66 & 369 & 570 \\
\hline 2. ITQ management free quota trade & 135 & 85 & 332 & $55^{2}$ \\
\hline 3. Current management full adjustment & 82 & 70 & 308 & 460 \\
\hline 4. Current management $10 \%$ landing tax & 135 & 66 & 369 & 570 \\
\hline
\end{tabular}

Note: 1. For processing, the total quantity of shrimp peeled at the land-based factories are shown for the 2015 initial situation, while increases in relation to this production in the initial 2015 situation is shown for scenarios 1-4. 
Profits in 2025 are lower than socio-economic return, due to high salary in shrimp fishing and the shrimp tax. Just as for socio-economic return, profit in scenario 1 increase substantially, while fleet and employment is reduced. In scenario 2 with free trade of quotas, the same profit effects are seen as for socio-economic return, although profit change lees than socio-economic return. The offshore fleet includes 9 vessels for profit instead of 10 for socio-economic return, with the same effect on employment on these vessels. Factory activity and employment is reduced, as opposed to being unchanged for profit, since offshore vessels have to pay for quotas and, therefore, buy lesser quotas from coastal vessels.

Profit under full adjustment develops in the same direction as for socio-economic return, although the coastal fleet and employment at coastal vessels is reduced more and employment at factories is lower, which follow from higher costs of labour and quota purchase costs.

When introducing an extra tax on $10 \%$ in scenario 4 , profit is reduced from EUR 70 Million to EUR 58 Million, i.e. with EUR 12 Million. Both the fleets and employment remains unaffected in relation to scenario 1 . Since the forecasts of profit and socioeconomic return further leads to exactly the same fleet size, the extra tax can be imposed without any effect on societal wealth.

The results above are analysed for one year, 2025, but the effect comes gradually over time. Figure 7 displays the development over the forecasted decade, respectively for socio-economic return and profit. 
Figure 7: Forecast of socio-economic return (top) and profit (bottom) 2015-2025, EUR Million
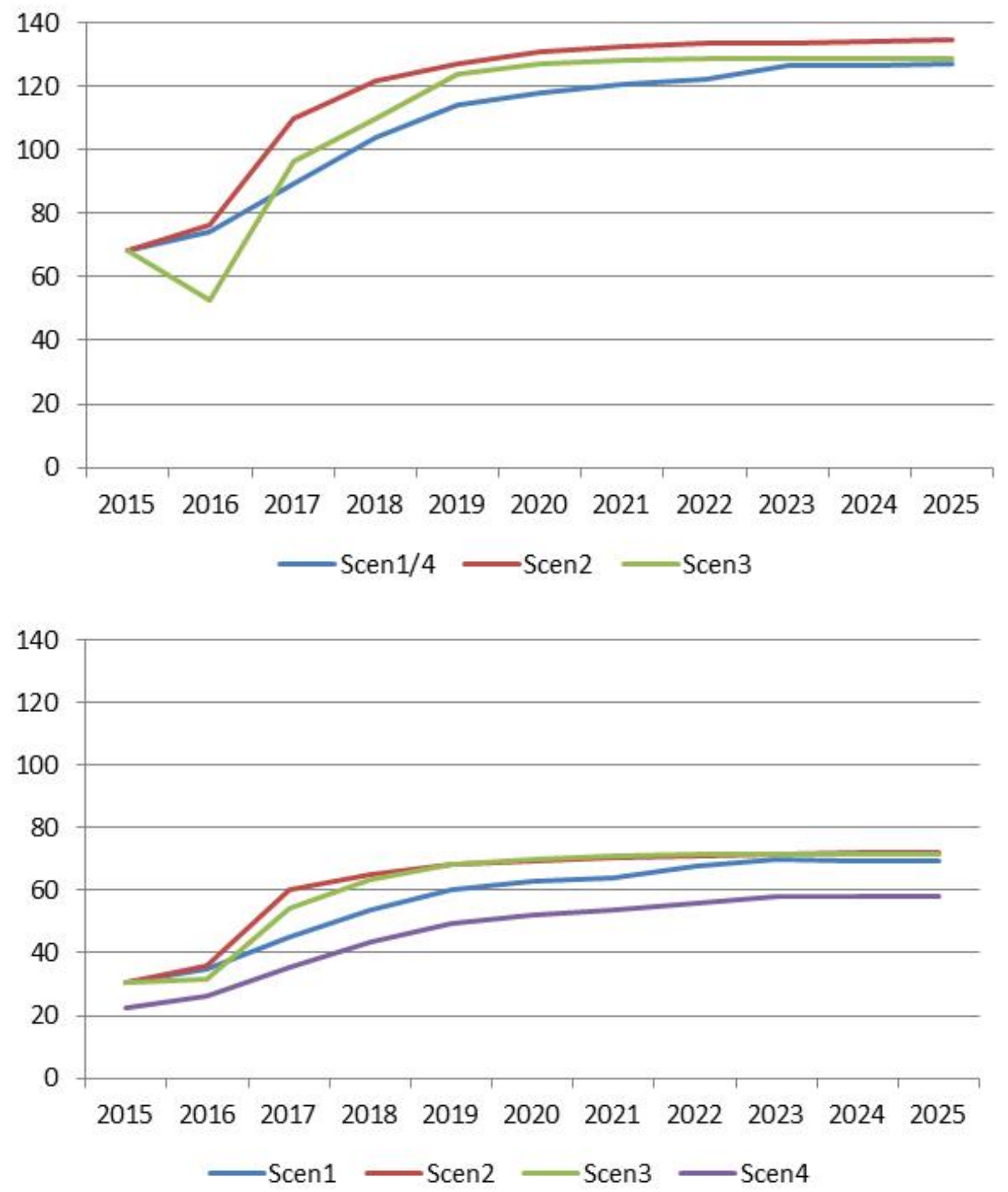

The trends shown are similar to the final 2025 results. Free quota trade gives the largest socio-economic return over the full period. The current management is lowest for socio-economic return from 2017 and onward, while the full adjustment scenario is lowest until 2017 and in between afterwards. Hence, the speed of adjustment is slowest in scenario 1. The same situation accounts for profit, except for that the tax scenario gives the smallest profit over the whole period, since the companies have to pay the tax. The adjustment appears similar for each scenario for socio-economic return and profit.

Where socio-economic return is a societal measure, profit is the company measure that determines the decisions by companies. Hence, with fleets developing very similar when forecasting socio-economic return and profit, the 
more realistic results appearing from profit maximization largely leads to the best possible situation for society in each scenario. Thus, the ITQs ensure that the contribution from the shrimp fishery to the Greenlandic economy is as large as possible under the circumstances.

\subsection{Policy considerations}

The Greenlandic shrimp fishery has been managed with ITOs since 1991. The fishery is well-managed ensuring biological sustainability and the management is mature in having allowed the industry to consolidate and increase efficiency. The number of vessels and employment has been substantially reduced over many years and fewer and larger companies remain. The forecasts support that this development is not over, even without changes in policy settings.

The fishery supply land-based factories. Coastal trawlers land all their catches to peeling factories, while offshore trawlers process $75 \%$ onboard and supply the remaining $25 \%$ to land-based factories. Coastal trawlers and factories are labour intensive, offshore trawlers are capital intensive.

The debate of the future policy for the Greenlandic shrimp fishery goes in three different lines of arguments, on top of keeping the management unchanged. Some argue that the Greenlandic society need more jobs, which can be achieved by letting labour-intensive coastal trawlers and factories takes over from offshore vessels. The new Fisheries Law that was intensively discussed in the Parliament and in the media in 2017 is a step in that direction. Others argue that the shrimp fishery have the ability to increase the contribution to GDP, thereby increasing, but far from providing the full the economic foundation for Greenlandic independence, needing replacement of the annual Danish Grant on at least EUR 500 Million. That argument claims that only the most efficient vessels, offshore vessels, stay active. That is, offshore trawlers must be allowed to buy quotas from coastal trawlers, which furthermore also reduce land-based processing. Finally, a group also argue that the shrimp tax in recent years have grown to a level where Government spending depends on them. That group sees the presence of an efficient fleet as a necessary precondition to be able to increase the shrimp tax, thereby making more public spending possible.

Employment in the shrimp industry can be prioritized politically by reallocating quotas to coastal trawlers from off-shore trawlers. The Bill on the New Fishery Law is a step in that direction, reallocating $7 \%$ of quotas. That gives 15 and 12 more employed at coastal trawlers and factories in 2025, while employment falls with 6 persons at offshore trawlers in the full adjustment scenario. The socio-economic return is reduced by EUR 5 Million.

The Law further provides the legal basis for a policy turn-around, by making it possible to terminate ITOs after a five years notice period. If the Law is adopted, it becomes possible to take the full step and increase employment in shrimp fishery substantially. With all quotas hypothetically given to coastal trawlers, total employment in the industry increase from 585 to 1,210 in scenario 1 . Socio-economic return, however, 
falls from EUR 127 Million to EUR 62 Million, corresponding to EUR 100,000 per extra person employed in the shrimp industry. That makes the Greenlandic society poorer. Moreover, the shrimp tax revenue fall and the Government might be liable to compensate losers of quota. The possible compensation liability remains uncertain and the question may be taken to Court. While the Law introduces a future policy option of notified termination of management, it doesn't suggest use of it for now.

Quota concentration also forms part of the debate. It is argued by some that the rules allow for too large quota ownership by individuals and companies, implying that ownership must be spread. Spreading is assessed to lead to more and smaller vessels, as well as larger employment, while the socio-economic return fall.

Enhancing employment in the shrimp industry does not lead to increased employment in the whole society in the long run, since labourers do not work in a sector where they contribute as much as possible to the national economy. By them working in other sectors where they are more beneficial would make the Greenlandic society wealthier, which also induce full employment in the long run. Hence, where employment in the shrimp sector may increase, employment in other sectors falls in the long run.

The GDP contribution of the shrimp industry can be letting only the most efficient vessels fish. Hence, the off-shore vessels must take quota over from the coastal vessels. In this situation, the ban of quota sale from coastal vessels to off-shore offshore vessels must be lifted and off-shore vessels must be allowed to fish within the 3 nautical mile zone. The free quota trade scenario identifies the socio-economic return to EUR 8 Million larger than in scenario 1 , with employment being reduced by 61 persons. That corresponds to EUR 130,000 per person annually.

In a hypothetical long run example where only off-shore vessels are fishing, the socio-economic return can be increased to EUR 156 Million, EUR 29 Million above the level in scenario 1 in 2025. Employment falls to 315 persons, 270 persons under the employment in scenario 1 in 2025. Hence, large gains in wealth can be achieved for the Greenlandic society by implementing a policy of letting the most efficient off-shore trawlers fish at the expense of coastal trawlers. Some further argue that such a policy can play an important role in funding Greenlandic independence.

In scenario 4, company profits are taxed and used to fund public welfare. It is found that increasing the shrimp tax with $10 \%$ of the landing value, doesn't affect fleet structure and employment. Profit fall, but Government income rise.

Taxes can be increased more, but only to the level where companies face deficits. Otherwise, they leave fishing and the socio-economic return fall. Under such circumstances, the maximum extra tax revenue that can be collected in 2025 is the full fleet profit of EUR 71 Million under the free quota trade scenario, corresponding to an extra tax rate on $35 \%$ of the landing value in 2025 . At higher taxes, fleet structure and employment will be affected in the long run, with less surplus prevailing for investments, over time making the fleet older and less efficient.

Since expected future earnings are capitalized in quota values, taxes must be set to avoid deficits of new quota owners. Otherwise, the socio-economic return fall. Taxing without societal losses therefore slowly becomes too late over time, making tax 
increases an option mainly when profits increase. For example following price and quota increases or policy changes.

With the shrimp stock sustainable exploited, the political tradeoffs is balancing (i) contribution to GDP, (ii) shrimp employment, and (iii) contribution to Government income. All three cannot be achieved at the same time and shifting circumstances and political priorities makes balancing ever-relevant. Revealed by the core role of (ii) and (iii) in the debate following the Fishery Commission in 2009 at a time where alternative jobs was expected in mining. And revealed by the core role of the (i) in the intensive debate on the Bill of the New Fishery Law in 2017 at a time where alternative jobs are difficult to see.

While forecasts can provide good input to the debate on future fishery policies, they are also founded on uncertain assumptions. First, it is assumed that the shrimp stock increase to the average level over 1994-2014 from the low level in the base period. If this doesn't happen, socio-economic return, profit and employment in the shrimp industry are overestimated. Second, the forecasts are made under constant prices. The predicted increase in Greenlandic catches, however, may all other things equal, induces a downward pressure on prices. While shrimp prices are formed on a world market, where Greenlandic and Canadian shrimp are perfect substitutes, and where these also substitute warm-water farmed shrimp (Nielsen et al. 2017), a downward price pressure exist. But it is limited. To the extend prices are overestimated, so are socio-economic return and profit. Third, the forecasts depart from that technology in the base period stays unchanged. With technological development happening continuously, for example currently by the introduction of robotics under deck on fishing vessels, socio-economic return and profit are underestimated, while employment in the shrimp industry is overestimated. Fourth, profit after cost of quota purchase is identified as an approximation for changes in quotas, not changes in permanent quota shares. If quotas increase due to biological improvements, the quota values are overestimated. On the other hand, with quota values identified only for quota changes, trade in quotas that appear as person shifts of non-economic reasons (e.g. pensioning), are not taken into consideration. That underestimates the cost of quota purchase. Underestimation of cost of quota purchase results in too low socioeconomic return and too low profit and it affects the speed of adjustment. Vise versa for overestimation. 



\section{Icelandic pelagic and Stern trawler fishery}

\subsection{Introduction}

The objective of this chapter is to forecast structural development of the Icelandic pelagic and stern trawler fleets until 2025. In total there are four segments as both fleets are split into fresh fish and frozen at sea vessels. Predictions and policy considerations are made with a model utilizing fleets current statistical and economic data and status of their target species.

The Icelandic fishing industry has been a paramount part of the nation's economy for a long time. The importance has though declined considerably in the past years, with growth in service and production sectors, but is still above $40 \%$ of nation's total value of goods export. Demersal products are thereof around $70 \%$ and pelagic products $30 \%$ (Statistics Iceland 2017). Icelandic authorities have been for a prolonged period at the forefront of fisheries management by extending the EEZ and to implement individual quotas and ITOs.

The Exclusive Economic Zone (EEZ) was extended in steps from 12 miles in 1952 to 200 miles in 1976. Management of pelagic species was initiated in 1969 with a Total Allowable Catch of Icelandic herring and in 1975 individual quotas (IO) were announced and in 1980 for capelin. Demersal ITO management system was established in the year 1984 and in 1990 a uniform system of ITQs covering almost all fisheries in Iceland was established, with almost full transferability of quotas.

Since 1990 the demersal catch almost halved in terms of quantity and the pelagic catch has also halved from year 2000. The adjustments were mostly left to the industry, with consolidation of quotas and scrapping of vessels and factories. Majority of the quotas are held by vertically integrated companies; managing quotas, fisheries and processing facilities. Specialization in fishing and processing is widespread, fleet segments target either demersal species, pelagic species or shellfish. Vessels size has increased and their number decreased. Majority of pelagic catch is landed by 25 vessels and the fleet of stern trawlers consist of 45 vessels which land $50-55 \%$ of all demersal catch.

Positive effects are felt in the industry: With less quotas the focus has turned from catch quantity to value maximization and full utilization of the whole fish. Output has risen with use of fully automated processing equipment with latest computer technology. Profitability and efficiency have increased with fleet and factories adjustments. Fishing fee is in force and its value has increased substantially with higher profitability. But, negative are as well felt: Consolidation of quotas, following sales or mergers, resulted in fewer vessels and factories, thus reducing employment 
opportunities. The transferability also resulted in quota displacements between geographical regions, negatively affecting some fishing communities.

The Icelandic case study is performed by Daði Már Kristófersson, Department of Economics, University of Iceland and Hörður Sævaldsson, Faculty of Natural Resource Sciences, University of Akureyri, Iceland.

This chapter contains five sections after this introduction. In section two the structure and history of the Icelandic ITO management system is discussed. Section three covers the literature review of research concerning Icelandic fisheries management. In section four underlying data and indicators for the analyses in the Icelandic case studies is addressed. Section five goes through model results on forecasted fleets structural development until 2025 . Section six concludes the Icelandic case with future policy considerations.

\subsection{Fisheries management, catch and the fleet}

Fishing around Iceland used to be open access with participation of foreign nations until the 1950s. The Exclusive Economic Zone (EEZ) was extended in three steps between 1952 and 1976. In 1952 it was extended from 3 to 4 miles and as well closing off bays and fjords. The year 1958 saw an extension to 12 miles, increased to 50 miles in 1972 . Finally, in May 1976 Icelanders won full jurisdiction over the 200-mile EEZ, thus fully controlling their fishing grounds (Hannesson 2004).

\subsubsection{Catch in Icelandic waters}

Catches on the pelagic fish herring increased rapidly late 1950 and reached a peak of 690 thousand tons in 1966, two years later the herring stocks collapsed. In the 1970 s production increased again with capelin fisheries. It made up roughly half of total catch in Icelandic waters some years, but the stock has been in low past years. Demersal catch increased during and shortly after WWII until 1960 with larger fleet of smaller boats and sidewinder trawlers. Following the collapse of herring stocks in late 1960 s the herring fleet turned toward demersal fisheries which increased the demersal catch substantially. The catch of Icelandic vessels augmented again in the 1970 s with introduction of stern trawlers and extension of the EEZ. Their number and share of total catch increased sharply the upcoming years, see area under the red line in Figure 8. Simultaneously, foreign trawlers lose their most important fishing grounds, following the 50 and 200-mile extension of the EEZ. Between 1970 and 1975 the annual average demersal fisheries in Icelandic waters were 765,000 tons; of which foreign catches were 300,000 tons. Demersal fisheries of Icelandic vessels peaked in the 1980 , but since the year 1990 the catch has almost halved in terms of quantity. 
Figure 8: Catches of the Icelandic fleet since $1945^{1}$

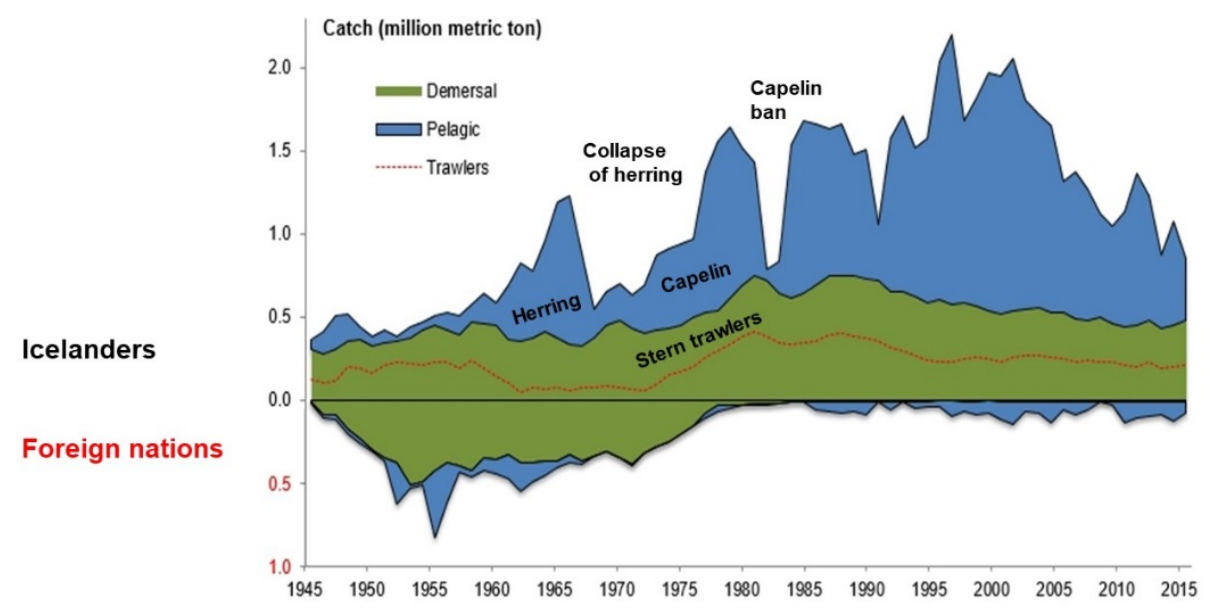

Note: 1 . The area under the red dotted line represents trawlers part of the demersal catch. Sidewinder trawlers until the introduction of stern trawlers in the 1970 .

Source: Statistics Iceland (2017b), Jónsson and Magnússon (1997).

\subsubsection{The fishing fleet}

Excess capacity and overcapitalization characterised the 1970 s and early 1980 . The fishing effort of the fleet increased constantly from late 1960s until the year 1977 concurrent with expanding vessel and engine sizes (Runolfsson and Arnason 2001). The previous herring fleet was in lack of projects outside the winter capelin season. This fleet of more than 200 vessels, build or renovated in the 1960s, turned to demersal fisheries with various fishing gears. As well, the stern trawlers replaced the old side winding trawlers build in the late 1940s, see Figure 9 . The first stern trawlers began operations in Icelandic waters in 1970, five years later there were 58 fishing in the EEZ. When the nation gained control over Iceland's 200 mile EEZ in 1976, serious concerns were raised that demersal stocks were being overfished, especially the valuable Atlantic cod (Gadus morhua) (Palsson and Helgason 1995). 


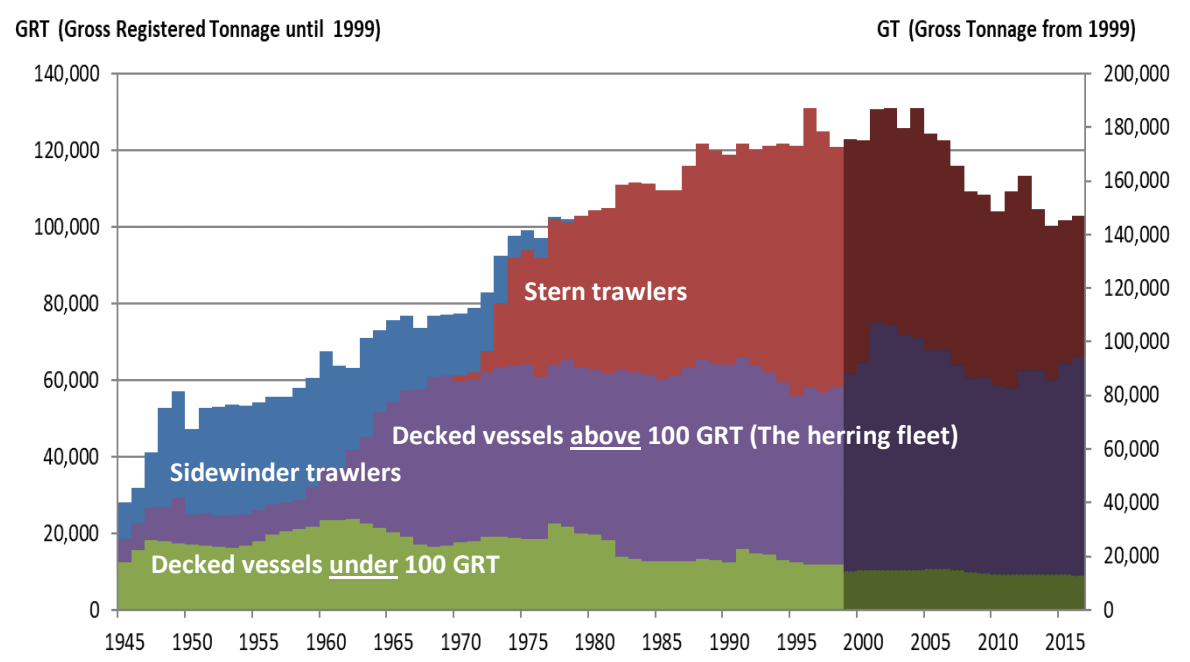

Source: Jónsson and Magnússon (1997), Statistics Iceland (2017c).

\subsubsection{Pelagic management}

The collapse of the Atlantic herring in 1968 acted as an alarm signal to the nation (Arnason 2005). Management of pelagic species was initiated in 1969 with a Total Allowable Catch of Icelandic herring and in 1975 individual quotas (IQ) were announced, in the wake of a three-year harvesting moratorium. In 1980 quotas for capelin were introduced, after warnings from fisheries biologists at the Icelandic Marine Research Institute which raised concerns of possible overfishing (Matthiasson 2003). In 1986 transferability of annual quotas was introduced and in 1988 consolidation of quotas was allowed among capelin going vessels. Initial allocations in Icelandic herring and capelin fisheries were divided between vessels participating in the fisheries the prior year and with an active fishing licence in those species; that is, not based on previous catch history. Today when fishing of new species commences (pelagic, demersal or crustacean) it often starts with some form of open access, with or without Total Allowable Catches, individual quota allocation then relies on each vessel catch performance the previous three fishing periods. (Ministry of Industries and Innovation 2014).

\subsubsection{Demersal management}

Various forms of fisheries restrictions have been applied in demersal fisheries. From 1977 to 1983 effort limitations were in force, principle of this system was to reduce fishing effort. In 1983, when the cod stock was in decline, the effort limitations were abolished as fishing effort and fleet capacity had been rising while number of days at sea contracted (Runolfsson and Arnason 2001). Then Iceland's Althing (national parliament) voted on and accepted a demersal management system with ITOs, 
according to which each vessel's allocation was based on catch performance between 1981 and 1983. The initial demersal quotas were allotted in 1984, with quotas being partly transferable by authority of the Ministry of Fisheries. Between 1985 and 1987 an effort option was active which offered vessel operators an opportunity to boost their share of the initial allocation. This system remained in force until 1990, although vessel allocations could not be increased after 1988. The effort system made it difficult to limit total available catches in some species (Runolfsson and Arnason 2001, Arnason 1993).

Vessel renewals or enlargements were integrated into the 1984 demersal ITO management. All vessels fishing in Icelandic waters in 1983 received fishing licences, indicating gross registered tonnage (GRT). New licences were not issued unless a vessel of similar size in GRT was decommissioned. However, vessels added to the fleet prior to 1 January 1986 could be enlarged, under certain conditions, until 1997. If a vessel was to be renovated, by import or newbuilding, the renovation GRT was restricted to vessel size registered 1 January 1985. All newbuilding/import of vessels, therefore, needed additional GRT from a vessel within the current fishing fleet; that is, GRT had to be bought. Restrictions controlling total fleet capacity were abolished in 1999; then renovation/newbuilding of vessels could be carried out without additional cost (Runolfsson and Arnason 2001, Lög um stjórn fiskveiða nr. 38/1990, Runolfsson 1999). Since then the fleet has been gradually modernized with the import of both newly built and used vessels.

\subsubsection{Uniform fisheries management}

The uniform system of ITOs established in 1990 covered almost all fisheries in Iceland. It combined fundamental laws and management regarding fisheries into a comprehensive Fisheries Management Act (No. 38/1990), which entered into force in 1991. Since then legislation relating to demersal, pelagic and crustacean species is combined into a single Act, allowing the majority of ITOs to be almost freely transferable; a move which has motivated the consolidation of fishing rights. Smaller boats below 10 GRT were outside the demersal ITO system between 1984 and 1990; during this period their number rose sharply (Runolfsson 1999). Boats below 10 GRT were outside the ITO system from 1984, but were included in 1990 (Ministry of Industries and Innovation 2014). Smaller boats less than 6 GRT were left out and only permitted to catch with hooks and lines. The majority of these boats were integrated into the ITO system in two steps; in 2001 and 2004.

\subsubsection{Current management system}

The structure of the Icelandic ITO system is still like the initial uniform system implemented in 1990. The fisheries act was reformed in 2006, resulting in the current Fisheries Management Act No. 116/2006. According to the Fisheries Management Act, the total allowable catch is issued annually by management of the Ministry of Fisheries, having obtained recommendations from the Marine Research Institute. The Total Allowable Catch is valid for one fishing year, a twelve-month period commencing 1st 
September annually. All species subject to the system are issued a Total Allowable Catch. Finally, the annual vessel catch quota (harvesting right) is issued by the Directorate of Fisheries, based on a vessel's share of the current Total Allowable Catch (permanent quota share). The annual and permanent quotas for each species are divisible and transferable among vessels with fishing licences (Ministry of Industries and Innovation 2014).

All entities participating in commercial fishing in Icelandic EEZ need fishing permit. The permits are split into two types; a general catch quota and a hook-and-line catch quota. Each vessel may only hold one type of fishing permit each fishing year. In general hook-and-line catch quotas may only be used for longline and hand-line fishing, two months of the year they can use gillnets for lumpfish fishing (Ministry of Industries and Innovation 2014). The catch from vessels with hook-and-line catch quotas is made up of demersal species. The recent fishing years, vessels with general catch quotas have been allocated about $90 \%$ of the quotas, calculated in cod-equivalent kilos. ${ }^{4}$ Vessels with hook-and-line catch quotas are allocated the remaining $10 \%$, but this fleet has more than $17 \%$ of the total issued quota of Atlantic cod (Directorate of Fisheries 2017a).

The vessels with current hook-and-line catch quota were outside of the 1984 demersal ITO management, this fleet mainly targets demersal species. In 1990 the size of these vessels where 6 GRT, in 2002 the size was increased to 15 GRT and in 2014 it was extended to $30 \mathrm{GRT}$ and maximum length 15 meters. The hook-and-line catch quotas were issued 1996, 2001 and 2004, since then all segments of the Icelandic fleet have been issued ITQs, later (2009) an open access costal jigging system was installed. Restrictions are valid in quota trade between vessel with general catch quotas and vessels with hook-and-line catch quotas. The hook-and-line vessel can freely transfer quotas within their system and from vessels with general catch quotas. However, to prevent consolidation of fishing rights the hook-and-line quotas cannot be transferred to vessels with general catch quotas.

In 1998 a maximum quota share was introduced which restricts a company's quota allowance, commonly named a "quota ceiling". The ceiling was introduced to reduce the ongoing quotas consolidation and to prevent a handful of firms controlling all fishing in the country. The current maximum quota share is $12 \%$ of the total issue quota in cod-equivalents kilos. For individual species the ceiling is normally $20 \%$, but in certain species it reaches $35 \%$.

\footnotetext{
4 A cod-equivalent kilo is a special conversion factor to assess all species at the same value as cod, which always equals one. All species are calculated by Directorate of Fisheries annually. Example: If the cod-equivalent kilo of haddock is 0.71 it means that 1.40 kilo of haddock equal one kilo of $\operatorname{cod}(1 / 0.71)$, or the value haddock is $71 \%$ of value of cod. (Ministry of Industries and Innovation 2014, Directorate of Fisheries 2014a).
} 


\subsection{Literature review}

The initial 1980 IQ IQ and later the 1990s ITQ system has been a controversial issue in Iceland. The system has been harshly criticised and different forms of fisheries management have been the subject of intensive political debate. Several matters of opinion have been brought to court and even to the UN Human Rights Committee (Hannesson 2004, Ministry of Industries and Innovation 2010). In 2009 a reconciliation committee was established on behalf of the Ministry of Fisheries to identify matters of dispute and bring forward a proposition regarding a future revision of the 2006 Fisheries Management Act. The committee's report was issued in 2010 (Einarsson 2011). Since then, a major policy review has not yet passed the Althing parliament. Revisions of the fisheries legislation were also carried out by committees in 1991-1993 and 1999-2001 (Ministry of Industries and Innovation 2001, Eythórsson 2000).

The fishing industry has been and still is an extremely important part of the rural economy of Iceland. Since 1984 structural changes have steadily emerged, following the fleet's efficiency optimization, aiming for reduced harvesting cost and increased profitability (Hannesson 2004, Arnason 2005, Arnason 1993, Runolfsson and Arnason 2001), (Eythórsson 2000, Gissurarson 2000, Arnason 2002, Yagi et al. 2012, Christensen, Hegland and Oddsson 2009). Restrictions on quota transferability within the uniform ITQ system were lifted in 1990, encouraging optimization of the industry. Consolidation of quotas, following sales or mergers, resulted in fewer vessels and factories, thus reducing investment and employment opportunities within the industry (Eythórsson 2000, Skaptadottir 2000).

The transferability also resulted in quota displacements between geographical regions, negatively affecting some fishing communities (Eythórsson 2000, Yagi et al. 2012, Skaptadottir 2000, Eythórsson 1996, Danielsson 1997). In 1998 a maximum quota share was introduced to restrict a company's quota allowance in terms of total catch share, as well as individual species (Ministry of Industries and Innovation 2014). A few large, vertically integrated companies have strengthened their quota holdings since 1990 (Arnason 2005, Palsson and Helgason 1995, Runolfsson and Arnason 2001), (Eythórsson 2000, Bjorndal, Child and Lem 2014, Directorate of Fisheries 2017a).

The issue of quota concentration into fewer hands has been on the agenda publicly in Icealnd and within the literature since early 1990. Criticism concerning quota consolidation has been along similar lines regarding the demersal and pelagic industry. Concerns were raised that demersal fishermen were becoming tenants leasing the quotas and reducing their income as the number of smaller ITQ holders fell and the larger companies increased their share (Palsson and Helgason 1995, Eythórsson 2000, Eythórsson 1996). Others maintained that although the number of companies and owners had decreased, the number of shareholders and, therefore, owners had risen parallel with the listing of fishing corporations on the Icelandic stock exchange (Runolfsson and Arnason 2001, Gissurarson 2000, Runolfsson 1997). Listing of fishing companies commenced in 1991 and increased sharply until 1997, peaking with 24 companies in 1999. Majority of these companies were deregistered between 2000 and 2008 , primarily owing to mergers and as former owners bought them back. Only one company is listed on the stock exchange in 2015 (Baldursson and Gunnlaugsson 2004, Gunnlaugsson 2014). 
Figure 10: Allocation of all quotas in cod-equivalent kilos on the largest companies, 1 September each year $^{1}$

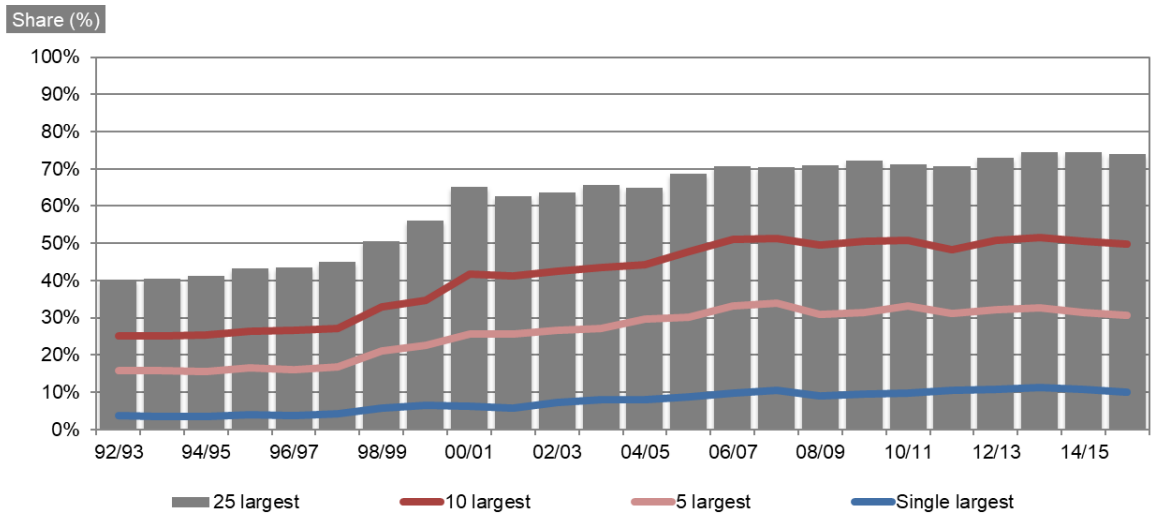

Note: $\quad$ 1. This series represents consolidation of demersal stocks quite well, as it contains all demersal quotas in the extended economic zone issued in the beginning of the fishing year.

Source: Directorate of Fisheries (2017a), Runolfsson (2000)

Less restrictions on quota transferability in the 1990 s enabled the industry to rationalize. Since year 1990 the demersal catch almost halved in terms of quantity. Icelandic authorities left it to the fishing industry to adjust to reduced quotas. The quota consolidation measured in cod-equivalent kilos* rose sharply between 1997 and 2000 following prolonged period of reduced quotas, see Figure 9 and 10. Small privatelyowned companies were bought or merged with other companies. The buyers often vertically integrated companies; managing quotas, fisheries and processing facilities. The larger companies, as well merged to operate their processing facilities year-round with enough raw material. Since 2007, 25 major companies controlled approximately $55 \%$ of the total demersal quotas issued each fishing year. During this three-decade period, the industry focus has as well turned from catch quantity to value maximization; aiming on product quality and full utilization of the whole fish.

The structure of the Icelandic pelagic industry has even changed further. Initial capelin quotas were issued to 42 companies in autumn 1980. Most of the companies were privately owned and only a quarter of them linked to enterprises within the pelagic processing industry. Since year 2000 the pelagic catch has almost halved, following less capelin quotas. Quotas concentrations increased continuously from 1997 to 2007, when the privately-owned companies were bought or merged with other companies, see Table 9. There are only 11 pelagic oriented companies left, as well they manage more than $1 / 3$ of all demersal fishing rights (Directorate of Fisheries 2017a). A maximum quota ceiling is valid for capelin and I-herring and currently three companies reach the maximum 20\% ceiling (Ministry of Industries and Innovation 2014). This ceiling will certainly affect future mergers and reductions of companies and quotas, thus restricting further consolidation. Moreover, in accordance with Act 98/1998 only Icelandic nationals and/or entities under the control of Icelandic parties can participate in Icelandic fisheries (Ministry of Industries and Innovation 2014). 
Table 9: Pelagic companies' consolidation, capelin as the fundamental species

\begin{tabular}{lrrrrrr} 
Year & Companies & Capelin & I-herring & A-herring & Blue Whiting & Mackerel \\
\hline 1982 & 41 & $100 \%$ & - & - & - & - \\
1992 & 33 & $100 \%$ & $18 \%$ & - & - & - \\
2002 & 26 & $100 \%$ & $88 \%$ & $97 \%$ & $99.7 \%$ & - \\
2012 & 11 & $99 \%$ & $99 \%$ & $100 \%$ & $96 \%$ & $82 \%$ \\
2012 & 8 Major & $94 \%$ & $93 \%$ & $92 \%$ & $62 \%$ & $58 \%$ \\
2012 & 5 Major & $74 \%$ & $71 \%$ & $53 \%$ & $51 \%$ & $34 \%$ \\
2012 & 3 Major & $55 \%$ & $53 \%$ & $13 \%$ & $5 \%$ & $13 \%$ \\
2012 & Largest & $20 \%$ & $20 \%$ & & & \\
\hline
\end{tabular}

Source: Directorate of Fisheries (2017), Saevaldsson (2014).

Other matters of dispute can be narrowed to three issues in random order:

1. Initial quota allocation and difficult entrance of newcomers: The demersal quotas were allotted in 1984 for free to a restricted number of individuals and companies that owned vessels with active fishing licence. Since then, entrance limitations have applied which has created dissatisfaction (Palsson and Helgason 1995, Eythórsson 2000, Gissurarson 2000). The scarce quotas are expensive (Arnason 2008, Saevaldsson 2007) thus making it very difficult for newcomers to enter the industry unless they are wealthy or have inherited vessels and quotas;

2. Property right and wealth creation by quota trading: In the wake of increased transferability of quotas in 1990 the system created wealth in the form of valuable fishing rights (Hannesson 2004, Eythórsson 1996, Arnason 2008). Holders of quotas gain wealth by selling out their share at a sizable profit. This has created dissatisfaction and given rise to complaints of inequality, uneven distribution of common rights and the privatization of these rights (Palsson and Helgason 1995, Yagi et al. 2012, Eythórsson 1996). The opponents of the system cite the first Article of the Fisheries Management Act No. 116/2006, amended in 1988, which states the following: "[T] he exploitable marine stocks of the Icelandic fishing banks are the common property of the Icelandic nation."(Ministry of Industries and Innovation 2014);

3. Fishing fee and property right: The fee was initially set in 2002 but did not become valid until 2004 (Lög um stjórn fiskveiða nr. 38/1990, Matthiasson 2008). It remained below EUR 0.03 per cod equivalent kilo until 2010 when it was increased to EUR/kg 0.04. The fee was raised significantly again in 2012 to EUR/kg 0.06. In 2012 a special fee, based on companies' profit, was levied on top of the normal fee amounting EUR 0.14-0.17 per cod equivalent kilo. In 2013 the special fee was EUR 0.04 for companies in demersal industry and EUR 0.24 for pelagic industry (Directorate of Fisheries 2017b). The size of fees has been a source of friction; the quota holders wanting a minimal fee while others maintain that fees should at least cover the cost of monitoring catches, enforcing management and conducting fisheries research plus a certain amount for the use of common property (Hannesson 2004, Gissurarson 2000, OECD 2011, Matthiasson 2008). The 
fishing fee was EUR 52.2 Million in 2014, around 5.9\% of fishing vessel ex. catch value and $3.3 \%$ of seafood export in goods value (Directorate of Fisheries 2017b). The fishing fee has been an important source of income for the Icelandic government since 2012 , constituting of $1.5-1.7 \%$ of the total revenue of the treasury, year 2013 and 2014 (Fjársýsla Ríkisins 2017a, Fjársýsla Ríkisins 2017b).

Figure 11: Annual fishing fee and share of catch and export value 1993-2014

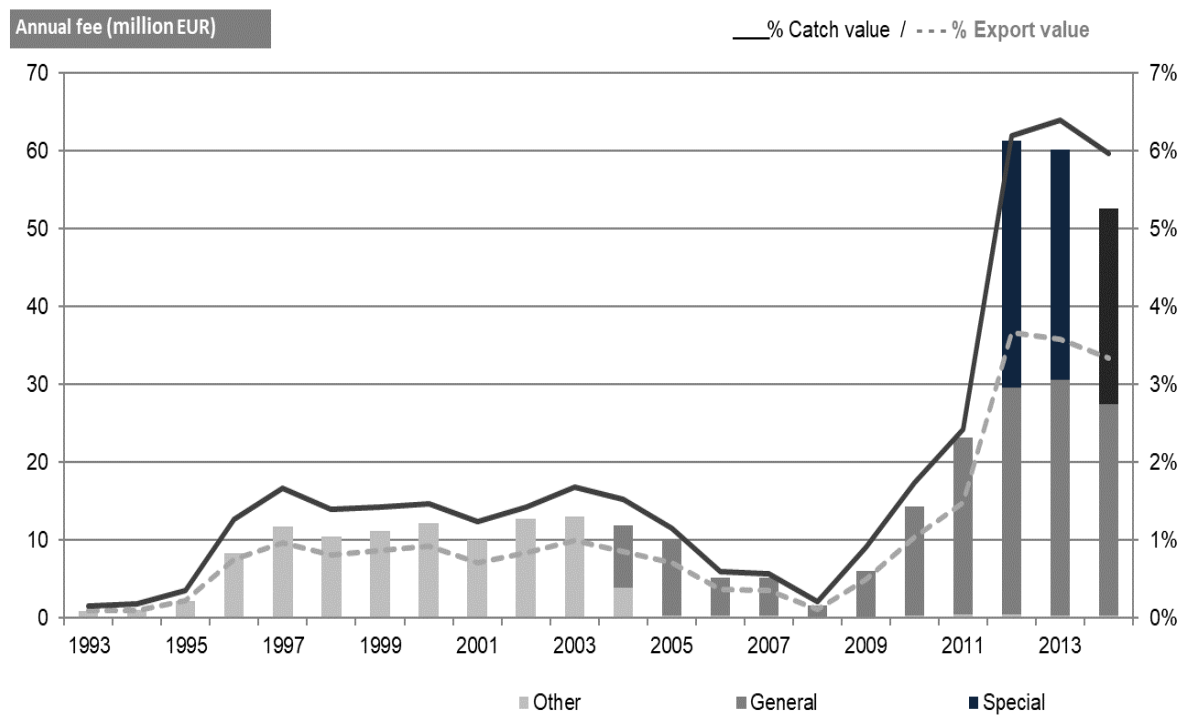

Source Runolfsson (2000), Arnason (2008).

To tackle the opposition to the ITO system various measures have beenw taken. The most important is that some quotas have been allocated to individual communities, following structural changes (Byggdakvoti) (Christensen, Hegland and Oddsson 2009, OECD 2011, Directorate of Fisheries 2017C). In 2003 approximately $0.4 \%$ of the total demersal quota was allocated to support rural communities adapting to structural changes. This has grown gradually, reaching around $2.0 \%$ in 2015 . In addition, the entry of newcomers to the fishing industry has been encouraged since 2009 allowing a certain category of vessels to participate in coastal fisheries using jigging reel only (Strandveidar) (Directorate of Fisheries 2014b). Initially 4,000 tons were allocated to this category, externally to the catch quotas. In 2015 a coastal fishery permit was issued for approximately 8,600 tons in cod equivalents of demersal fish, or around $2.0 \%$ of the Icelandic demersal quotas. Finally, quotas have been allocated to longline fisheries, baited onshore with fishing trips lasting no longer than 24 hours (Linuivilnun) (Directorate of Fisheries 2014C). In the past few years, longline fishery permits have been issued for around 5,500 tons in cod-equivalents of demersal fish, or around $1.5 \%$ of the Icelandic demersal quotas. The aim of these measures is to bolster employment in outlying coastal communities where much of Icelandic fisheries originated. The above measures were outside the pelagic fishing industry till 2012. Until then no quota had been allocated from pelagic species to outlying coastal communities. This is probably because catching and processing pelagic species is 
more capital intensive than demersal fisheries. Therefore, it is easier to recommence fishing and processing of demersal species to increase employment in outlying communities participating in structural changes.

\subsection{Fleet data}

This section describes historical and current statistical + economic data of all four fleet segments of the project, along with introduction of advances in the Icelandic fleet the past years. With less demersal catch in the 1990 and less pelagic quotas from 2000 the industry focus has turned from catch quantity to value maximization and full utilization of the whole fish. Improvements have been made in preservation of the raw material with increased chilling onboard the vessels and in the processing to sustain quality and extend shelf life of fresh and frozen products.

\subsubsection{Fleets specialization and increased profit}

Specialization in fishing is widespread in Icelandic fisheries, fleet segments target either demersal species, pelagic species or shellfish. Majority of the demersal catch is landed by stern trawlers both fresh and frozen at sea. Stern trawlers are large vessels, normally over 42 meters long, other important groups of vessels are fleet of large long line vessels and the smaller costal fleet. Pelagic fish is normally caught with vessels 60 to 80 meters long, capable of carrying up to 3,000 metric tons per trip in chilled storage rooms. Profitability and efficiency have risen substantially in the industry with fleet and factories adjustments and technology advances. The use of fully automated processing with latest computer technology is widespread. Improvements and innovations in transportation and logistics have as well increased efficiency; with use of temperature controlled containers, better storage boxes and readily available refrigerated warehouses. The availability of air cargo capacity has also greatly increased, supporting a huge rise in the export of chilled fresh fish products.

\subsubsection{Icelandic stern trawlers}

The first stern trawlers began operation in 1970 when they replaced former fleet of sidewinders trawlers. Five years later there were 58 of them fishing in the EEZ and their fishing effort increased sharply. With the stern trawlers, availability of raw material to demersal processing facilities equalised over the year. Formerly majority of the annual catch was landed by smaller bots during the winter fishing season. Stern trawlers proportion of demersal catch increased sharply to above $50 \%$ all total catch. The fleet size was restricted with the 1984 partly transferable quota system. Stern trawlers catch per vessel peaked in the 1980 s and reduced almost constantly until late 1990s, when fleets excess capacity was removed. Adjustments were not centralized by authorities, they were mostly left to the companies. The industry has in many ways adapted well. Part of the fleet was converted to freezer trawler in 1980 s and 1990s. The uniform ITO 
system allowed majority of ITO to be almost freely transferable, which led to consolidation. Since then number of trawlers and companies have decreased almost constantly. From 2010 the processing of fresh fish in land based facilities has increased at the cost of frozen at sea vessels. Catch per vessel has increased sharply the past years to 5,000 tons in year 2015 .

Table 10: Fleet of stern trawler, fresh and frozen at sea, and their precursor sidewinder trawlers

\section{$\begin{array}{llllllllll}1970 & 1975 & 1980 & 1985 & 1990 & 1995 & 2000 & 2005 & 2010 & 2015\end{array}$}

Stern trawlers

\begin{tabular}{lllllllllll} 
Fresh fish vessels & 3 & 58 & 87 & 102 & 109 & 65 & 51 & 36 & 29 & 26 \\
Frozen at sea vessels & & & & 7 & 29 & 47 & 33 & 29 & 28 & 19 \\
\hline Total stern trawlers & 3 & 58 & 87 & 109 & 138 & 112 & 84 & 65 & 57 & 45 \\
Annual catch & 600 & 172,000 & 377,000 & 342,000 & 371,000 & 278,000 & 26,600 & 275,000 & 23,600 & 225,000 \\
\% All demersal catch & $0.1 \%$ & $39 \%$ & $56 \%$ & $57 \%$ & $54 \%$ & $53 \%$ & $53 \%$ & $53 \%$ & $51 \%$ & $49 \%$ \\
Catch per vessel & 200 & 3,000 & 4,300 & 3,100 & 2,700 & 2,500 & 3,200 & 4,200 & 4,100 & 5,000 \\
\hline
\end{tabular}

Sidewinder trawlers

\begin{tabular}{lll} 
Fresh fish vessels & 22 & 6 \\
\hline Total side winder & 22 & 6
\end{tabular}

trawlers

Annual catch $\quad 80,000 \quad 11,000$

\begin{tabular}{lll}
$\%$ All demersal catch & $17 \%$ & $2 \%$ \\
\hline Catch per vessel & 3,700 & 1,700
\end{tabular}

Source: Statistics Iceland (2017).

\subsubsection{Pelagic going vessels}

Until mid-1990s the only pelagic species in Icelandic waters were capelin and Icelandic summer spawning herring. The capelin normally has more than $80 \%$ of the annual pelagic catch. Since 1995 three other pelagic species have entered the Icelandic EEZ; blue whiting, Atlanto-Scandian herring and Atlantic mackerel. Initial quotas in capelin were issued in 1980 and simultaneously, vessel size was restricted; i.e. vessels could not be added to the fleet without vessels of equivalent size being decommissioned. Restrictions controlling total fleet capacity were abolished in 1999. Transferability of permanent quotas was allowed among capelin going vessels in 1988. Then consolidation of quotas started and the number of vessels declined as companies merged vessels quotas. In 1990 the pelagic fleet merged to the uniform system of ITOs, with almost full transferability. The years between 1995 and 2005 were record years in terms of pelagic catch. The number of vessels increased until 2000, however, since then fleet size has declined sharply in numbers with less quotas. Pelagic companies have adjusted to these changes; number of vessels and fishmeal factories have been scrapped since 2005. At the same time, positive effects have followed by increased processing directly for human consumption, the industry aiming for value instead of quantity. 
Table 11: Fleet of pelagic going vessels, fresh and frozen at sea

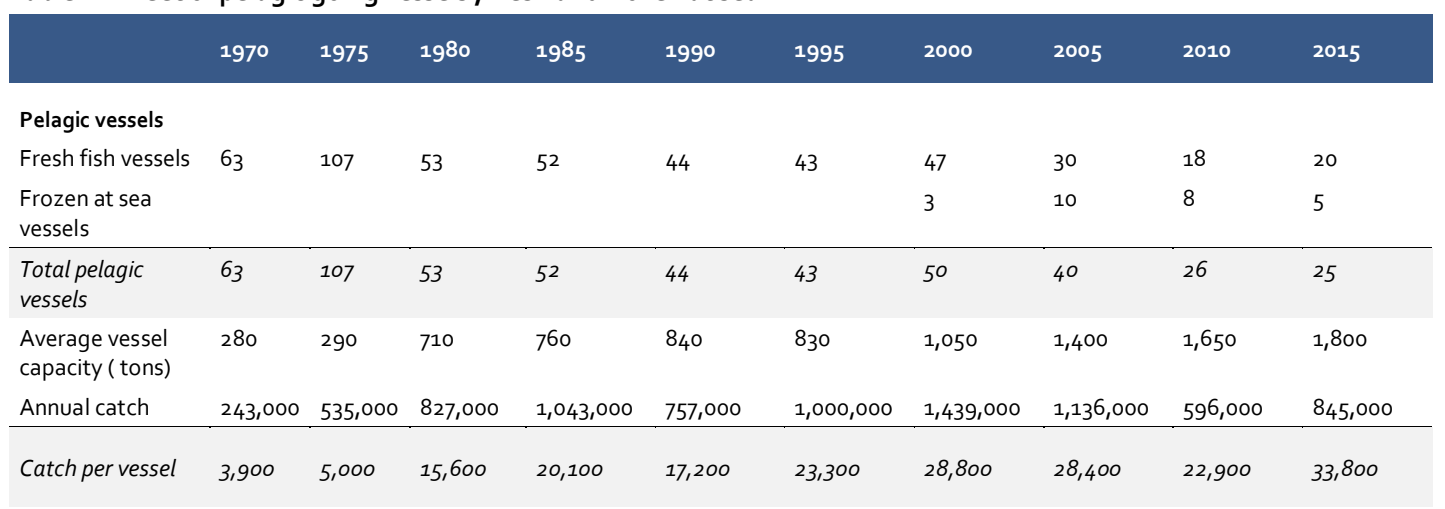

Source: Statistics Iceland.

Statistical and economic data of fleet segments utilized in the model are displayed in Table 12 as average of 2012-2014 numbers. The fleet consist of two groups; demersal and pelagic fleet which are then further divided into two sections; fresh and frozen at sea. Demersal fresh fish vessels focus on cod, while vessels with frozen at sea is more equally distributed among other species. It is similar for the pelagic fleet; frozen at sea focuses at Atlantic mackerel, while fresh fish vessels target capelin.

Table 12: Overview of fleets data per vessel, i.e. input to model

\begin{tabular}{r|rrrr} 
Average 2012-2014 & $\begin{array}{r}\text { Demersal trawlers } \\
\text { Fresh fish }\end{array}$ & $\begin{array}{r}\text { Demersal trawlers } \\
\text { Frozen onboard }\end{array}$ & $\begin{array}{r}\text { Pelagic vessels } \\
\text { Fresh fish }\end{array}$ & $\begin{array}{r}\text { Pelagic vessels } \\
\text { Frozen onboard }\end{array}$ \\
\end{tabular}

Physical data

Full Time Employment (per vessel)

Number of vessels

No. of Sea Days per vessel

Most important species NS (value)

Second important species NS (value)

Third important species NS (value)

23
27
195
$\operatorname{COD}(51 \%)$
$\operatorname{POK}(10 \%)$
$\operatorname{HAD}(8 \%)$

$\begin{array}{rr}48 & 15 \\ 25 & 21 \\ 232 & 71 \\ \operatorname{COD}(23 \%) & \operatorname{CAP}(39 \%) \\ \operatorname{POK}(12 \%) & \operatorname{MAC}(19 \%) \\ \operatorname{HAD}(6 \%) & \text { HER-vasu }(16 \%)\end{array}$

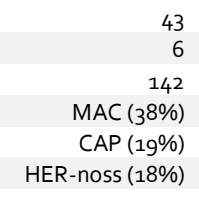

Account data (1000 EUR per vessel)

Turnover

Fuel Costs

Crew costs

Variable costs

Fixed costs

Capital costs

Opportunity labour cost/employee

Opportunity capital cost, $6 \%$

Estimated tax revenue

Profit

Socio-economic return2

4,671
575
1,728
1,073
331
226
48
241
271
737
1,937

\begin{tabular}{rrr}
9,842 & 6,132 & 16,980 \\
1,384 & 973 & 1,808 \\
3,838 & 2,085 & 6,622 \\
1,809 & 1,251 & 3,420 \\
579 & 532 & 1,757 \\
391 & 478 & 823 \\
48 & 51 & 55 \\
414 & 515 & 873 \\
571 & 356 & 985 \\
1,841 & 812 & 2,549 \\
4,339 & 2,353 & 7,503 \\
\hline
\end{tabular}

Note: 1 . Tax revenue is estimated as a fixed percentage of taxes paid by the whole Icelandic fishing fleet in 2013-2014, which formed $5.8 \%$ of the turnover.

2. The socio-economic return = turnover - fuel costs - variable costs - fixed costs - opportunity costs of labour - opportunity cost of capital - extraordinary taxes paid.

Table 13 shows the status of the fishing stocks included in the analysis. 
Table 13: Status of stock, fishing and management in Iceland, 2015

$\begin{array}{lrrr}2015 & \text { SSB (tonnes) } & \text { TAC (tonnes) } & \text { F-MSY* } \\ \text { Cod } & & & \\ \text { Haddock } & 533,000 & 216,000 & 0.20 \\ \text { Pollock } & 87,450 & 30,400 & 0.20 \\ \text { Capellin } & 135,000 & 58,000 & 0.20 \\ \text { Herring vasu } & 460,000 & 580,000 & 0,32 \\ \text { Herring noss } & 346,000 & 82,200 & 0.10 \\ \text { Blue Whiting } & 5,264,000 & 328,000 & 0.35 \\ \text { Mackerel } & 4,292,740 & 1,260,000 & 0.20 \\ & 4,886,564 & 1,229,000 & 0.15\end{array}$

Note: SSB is Spawning Stock Biomass, TAC is Total Allowable Catch and F-MSY measure fishing mortality at MSY of the stocks included in the analysis. All F-MSY are currently at sustainable level.

\subsection{Results}

As described in the introduction of this report 4 forecast scenarios are considered, the results of which in 2025 are compared with the initial situation in 2015. The specifics for the Icelandic case/management is:

1. Current Icelandic management: ITOs between but with no trade between stern trawlers and pelagic vessels (except mackerel that can be traded from stern trawlers to pelagic vessels). $4 \%$ limit on yearly adjustment in number of vessels in each segment;

2. Free ITQ trade of all species between all fleet segments. $4 \%$ limit on yearly adjustment in number of vessels in each segment; 5

3. Current Icelandic management with no limit on yearly fleet adjustment;

4. Current Icelandic management with a $4 \%$ limit (as in scenario 1 ) and extra taxes on $10 \%$ of the landing value. ${ }^{6}$

Two forecasts are made for each scenario. First the total socio-economic return is maximized over time with the results being presented in Table 14, while total profit of the fleet is maximized with the results in Table 15. The net present value of all future earnings is maximized through variation in number of vessels and days at sea per vessel. The forecast results are shown in the tables for 2025 compared to the initial situation. 2016 represent the initial year since haddock "choke" the results, meaning that if trade limits are maintained the vessels need to reduce their effort in the first year

\footnotetext{
5 Note that demersal fishing with pelagic vessels is technically infeasible. Hence, forecasts are made under the limitation that stern trawlers of fresh and frozen fish can only trade quota with each other, and trade mackerel quota with pelagic vessels. And pelagic vessels of fresh and frozen fish can only trade with each other and trade mackerel quota with pelagic vessels.

${ }^{6}$ While the shrimp tax revenue in $2013-2014$ period formed $5.8 \%$ of the landing value, scenario 4 impose an extra tax on $10 \%$ of the landing value.
} 
considerably to keep within the quota limits both for stern trawlers and pelagic vessels. Moreover, catch opportunities are predicted to be reduced in 2015 , as well as the Icelandic fleet has taken more than the haddock Total Allowable Catch in the years leading up to the modelling. Hence, comparison of 2016 with 2025 gives a more realistic development than comparing 2015 and 2025. Where socio-economic return measures the extraordinary economic contribution of fisheries to the socio-economy, profit is the surplus for the private fishing companies.

The biological foundation of the forecasts is for the main species haddock, capelin, herring, mackerel and whiting founded on the estimation of functions where recruitment of fish increases in spawning stock biomass until the MSY, after which it falls. This function is identified in a way such that the stock will not come above the maximum observed in the period 1995-2014. Catches are then determined at the MSY level by fleet size and total days at sea, thereby assuming a MSY quota setting policy. The Total Allowable Catch of capelin is held constant throughout the period, due to lack of information.

The forecasts founded on the estimated recruitment functions gives room for reduced catch opportunities in 2016-2015 compared to the base period 2012-2014. The reason is that catches were at a higher level in 2012-2014 than over the 1995-2014 period the biological forecasts are made. The predicted catches decrease until 2025 both when maximizing socio-economic return and profit, as well as for all scenarios. While future recruitment of fish is subject to uncertainty, the economic forecasts are also subject to uncertainty. The relative forecasts between scenarios are, however, not obsessed with the same uncertainty.

The forecasts are made under the following assumptions: i) Prices on fish and all inputs to production, such as fuel, salary and interest rate, are assumed constant, ii) Maximum catch per vessel per year restricted to 9,000 tons fresh fish (whole round weight) and 12,000 tons frozen fish for stern trawlers, and to 60,000 tons fresh fish and 25,000 tons frozen fish for the pelagic trawlers, iii) the profit maximisation is performed with the expected value of future purchased permanent quota shares included as a cost, identified as the average of quota buyers and sellers willing to pay/accept. 
Table 14: Forecast of socio-economic return, fleet and employment adjustment in 2025 by maximizing socio-economic return

\begin{tabular}{|c|c|c|c|c|c|}
\hline & $\begin{array}{r}\text { DEM } \\
\text { FF_TR }\end{array}$ & $\begin{array}{r}\text { DEM } \\
\text { FR_TR }\end{array}$ & $\begin{array}{c}\text { PEL } \\
\text { FF }\end{array}$ & $\begin{array}{r}\text { PEL } \\
\text { FR }\end{array}$ & Total \\
\hline \multicolumn{6}{|l|}{ Socio-economic return (mill EUR) ${ }^{1}$} \\
\hline 2016 initial situation ${ }^{2}$ & 44.65 & 65.50 & 20.53 & 32.72 & 163.40 \\
\hline \multicolumn{6}{|l|}{2025 results: } \\
\hline 1. Current management & 51.85 & 78.88 & 32.81 & 39.23 & 202.77 \\
\hline 2. ITQ management free quota trade & 34.92 & 104.76 & 48.15 & 23.56 & 211.39 \\
\hline 3. Current management full adjustment & 52.43 & 89.81 & 42.97 & 39.67 & 224.89 \\
\hline 4. Current management $10 \%$ landing tax & 51.85 & 78.88 & 32.81 & 39.23 & 202.77 \\
\hline \multicolumn{6}{|l|}{ Number of vessels } \\
\hline 2016 initial situation ${ }^{2}$ & 26 & 24 & 20 & 7 & 77 \\
\hline \multicolumn{6}{|l|}{2025 results: } \\
\hline 1. Current management & 18 & 17 & 14 & 8 & 57 \\
\hline 2. ITO management free quota trade & 18 & 17 & 14 & 4 & 53 \\
\hline 3. Current management full adjustment & 12 & 7 & 5 & 8 & 33 \\
\hline 4. Current management $10 \%$ landing tax & 18 & 17 & 14 & 8 & 57 \\
\hline \multicolumn{6}{|l|}{ Employment (full-time) } \\
\hline 2016 initial situation ${ }^{2}$ & 596 & 1,152 & 302 & 281 & 2,331 \\
\hline \multicolumn{6}{|l|}{2025 results: } \\
\hline 1. Current management & 413 & 798 & 209 & 344 & 1,764 \\
\hline 2. ITO management free quota trade & 413 & 798 & 209 & 175 & 1,595 \\
\hline 3. Current management full adjustment & 279 & 356 & 80 & 351 & 1,066 \\
\hline 4. Current management $10 \%$ landing tax & 413 & 798 & 209 & 344 & 1,764 \\
\hline
\end{tabular}

Note: 1. The socio-economic return includes fishing taxes, while the socio-economic return is maximized with respect to socio-economic return excluding taxes.

2. 2016 is used as the base year with 2015 being a model calibration year.

\subsubsection{Socio economic return and profit}

The Icelandic ITO system is matured. Trade within the fleet segments represented in this study has been unlimited since 1991. Large gains in profitability are not expected during the coming decade, since the ITO system has already resulted in consolidation of the fleet. However, Table 14 still shows that with current management (scenario 1) the total social-economic returns increases by about $24 \%$. Still further increases in socio-economic return from this base scenario seem possible if all limits on quota trade are removed and adjustment of the fleet is to its full level (scenarios 2 and 3 ). The increase for scenario 2 is $4 \%$ compared to scenario 1 , indicating the cost of the current management on e.g. fleet consolidation are restrictive on optimal fleet development. The model further predicts that full adjustment would result in an increase in socioeconomic returns of about $7 \%$ compared to scenario 2 . The model predicts that consolidation will continue along a similar pattern as already seen during the last decades (see e.g. Figure 9 and Tables $g$ and 10). The number of vessels and employees in the fishing sector is set to continue decreasing. The number of freezer trawlers is predicted to continue declining compared to fresh fish trawlers, regardless of scenario. Similarly, the model predicts that pelagic fresh fish vessels will maintain their strong 
position, with the exception of scenario 3 . The comparison of scenarios 1 and 2 is interesting from an Icelandic policy perspective.

Table 15: Forecast of profit, fleet and employment adjustment in 2025 by maximizing profit

\begin{tabular}{|c|c|c|c|c|c|}
\hline & $\begin{array}{r}\text { DEM } \\
\text { FF_TR }\end{array}$ & $\begin{array}{r}\text { DEM } \\
\text { FR_TR }\end{array}$ & $\begin{array}{r}\text { PEL } \\
\text { FF }\end{array}$ & $\begin{array}{r}\text { PEL } \\
\text { FR }\end{array}$ & Total \\
\hline \multicolumn{6}{|l|}{ Profit (mill EUR) ${ }^{1}$} \\
\hline 2016 initial situation ${ }^{2}$ & 20.29 & 24.61 & -1.16 & 7.77 & 51.51 \\
\hline \multicolumn{6}{|l|}{2025 results: } \\
\hline 1. Current management & 23.03 & 33.93 & 10.42 & 9.22 & 76.59 \\
\hline 2. ITQ management free quota trade & 10.52 & 51.97 & 15.27 & 6.06 & 83.83 \\
\hline 3. Current management full adjustment & 21.87 & -0.10 & $17 \cdot 47$ & 8.95 & 48.19 \\
\hline 4. Current management $10 \%$ landing tax & 18.09 & 28.87 & 7.61 & $5 \cdot 44$ & 60.01 \\
\hline \multicolumn{6}{|l|}{ Number of vessels } \\
\hline 2016 initial situation ${ }^{2}$ & 26 & 24 & 20 & 6 & 76 \\
\hline \multicolumn{6}{|l|}{2025 results: } \\
\hline 1. Current management & 18 & 17 & 14 & 7 & 56 \\
\hline 2. ITO management free quota trade & 18 & 17 & 14 & 4 & 53 \\
\hline 3. Current management full adjustment & 19 & 0 & 6 & 7 & 31 \\
\hline 4. Current management $10 \%$ landing tax & 18 & 17 & 14 & 6 & 54 \\
\hline \multicolumn{6}{|l|}{ Employment (full-time) } \\
\hline 2016 initial situation ${ }^{2}$ & 596 & 1,152 & 302 & 281 & 2,331 \\
\hline \multicolumn{6}{|l|}{2025 results: } \\
\hline 1. Current management & 413 & 798 & 209 & 305 & 1,725 \\
\hline 2. ITQ management free quota trade & 413 & 798 & 209 & 172 & 1,592 \\
\hline 3. Current management full adjustment & 427 & 5 & 85 & 297 & 814 \\
\hline 4. Current management $10 \%$ landing tax & 413 & 798 & 209 & 238 & 1,658 \\
\hline
\end{tabular}

Note: 1 . Note that profit of sold quota capitalizes in the model and comparison with current situation is difficult.

2. 2016 is used as the base year with 2015 being a model calibration year.

Table 15 shows the development of the fleet under pure profit maximization. The model indicates increases profits, especially for the freezer vessel groups. The overall profits are predicted to increase by $50 \%$ over the decade of the study. This is despite the fact that the model underestimates profit, since the model assumes that profits are capitalized in the model as quota is sold during consolidation and decreased vessel numbers. Many companies own more than one vessel and consolidation within company will not lead to capitalization. Therefore actual profits may increase even more. The results point to an important property of ITO systems - that although quota trade leads to increased productivity, industry profitability does not necessarily increase as capital is shifted to other investments. Socio-economic returns may therefore increase although industry profitability falls, as seen from results in Table 14. The starkest difference is for scenario 3 - full adjustment - where profits fall due to consolidation of quota, where trade leads to substantial capitalization. This case however leads to the largest increase in socio-economic returns and will free up large amounts of capital for investment in other profitable endeavours.

The results in Table 15 support the previous conclusion that current restrictions on quota trade have a negative impact on profitability. Comparing scenarios 2 and 3 indicates that these restrictions have a negative impact on profits of about $9 \%$. 
The predicted development is generally similar as for maximization of socioeconomic return. The model predicts continued reduction in fleet size and the maintained dominance of fresh fish vessels over frozen fish vessels, especially for pelagics. The extreme is scenario 3 , which predicts the disappearance of freezer trawlers.

\subsection{Policy considerations}

The Icelandic ITO has had free quota trade within fleet segments since 1991. The system is therefore mature. Most of the consolidation is already done. The data on recent development shows that the ITQ system has allowed the industry to consolidate and increase efficiency. The number of vessels has gone down, as well as the number of factories. It has led to fewer and larger companies, especially in the pelagic sector, and most of the quotas are in the hands of just a handful of enterprises. The model supports that this development is not over.

Quota trade leads to capitalization of profits. This is clearly visible from the results of the model. There are no predicted gains in profitability, but rather reductions. The model predict substantial gains in socio-economic returns from changing current policy. Current Icelandic management sets an upper limit on quota holding that aims to set a limit to concentration, keep ownership spread and maintain domestic competition in the fishing sector. Many companies have reached this limit and it sets a limit to their future growth and therefore overall increases in profitability. The results from the model support that this management comes at a cost. The results suggest that the loss in socio-economic returns is about $4-7 \%$ and about $9 \%$ in industry profits. Further, relaxing these restrictions will, according to the model free up capital, currently bound in the industry that can be used for other profitable investments.

Iceland has currently a fishing fee system, aimed at capturing some of the resource rent generated by Icelandic fisheries. The amount of the fee is currently $6 \%$ of landed value. Scenario 4 is therefore particularly interesting for the Icelandic case. According to the model the impact on fleet development is minimal. Difference between scenarios 1 and 2 and scenario 4 in terms of fleet development is minimal. The model therefore seems to suggest that the impact of the fee is not limiting to fleet development.

Simulations are good exercises to access how economic factors affect development. There are however other forces at play as well, both technical and political. Full relaxation of the limits on quota concentration in Iceland would probably speed up consolidation and create few powerful companies in Icelandic fisheries. The development under such a free system would, in all probability be in the direction predicted by the model. However, the most extreme predictions are probably not technically feasible, such as the complete disappearance of freezer trawlers from the Icelandic fleet. It is not feasible to fish certain fishing grounds and species using only fresh fish trawlers. Also, the political atmosphere in Iceland is unlikely to support this development. The fishing industry is the fundamental industry in many rural areas in Iceland and allowing full consolidation will meet with a strong political opposition in Iceland. It is, however, very useful to have an estimate of the cost of current restrictions so that the benefits to local communities can be compared to the costs such policies are likely to have. 


\section{Danish Demersal fishery in the North Sea}

\subsection{Introduction}

The purpose of this chapter is to forecast the development in the Danish demersal fishery in the North Sea until 2025 with the current management, and to assess the effects of possible future policy changes approaching 2025.

ITOs was introduced in the Danish fishery for herring in 2003, followed by other pelagic stocks in 2004. In 2007, ITQ management was implemented for the remaining fleet covering the demersal species. Hence, ITOs prevail today for all commercial active vessels. The reason for introducing ITOs was to adjust the Danish fishing capacity to the catch opportunities, making the fisheries more sustainable both from a biological and economic point of view. The ability of the system to improve vessel economy and remove earlier overcapacity seems broadly acknowledged and accepted today. However, the debate on how the fish resource should be distributed among fishermen to avoid concentration has recently received some attention. However, the question of using other regulatory systems than ITQs has not filled much in the public debate.

Since the introduction, a continuous debate about special arrangement for small scale coastal vessels has been the main focus of the debate. Thus, the coastal fishery arrangement has been revised several times. For the large vessels the issue of concentration of quotas has gained strong public attention after this issue was debated in a report from the Danish Parliamentary Auditors in 2017. Hereafter new rules have been implemented on concentration. Taxation of fishing rights has also been suggested as part of the solution in 2018 .

The demersal fleet in the North Sea is chosen, since it consists of small, medium and large sized vessels that use both trawl and nets. Therefore, it is well suited to reveal and debate main concerns of Danish fishery management today.

This case study is performed 7 by Ayoe Hoff, Rasmus Nielsen, and Max Nielsen, Institute of Food and Resource Economics, University of Copenhagen, Denmark.

In the following, a literature review of studies assessing fishery policy reforms in Denmark over the last decade is provided in section 2, while section 3 describes management of Danish fishery. Section 4 present data and section 5 the results of the scenarios. Section 6 concludes the Danish case with policy considerations.

${ }_{7}$ Associate professor emeritus Hans Frost has contributed with valuable comments and discussions. 


\subsection{Literature review}

Theoretically, the aim of introducing ITQs in the Danish fishery was firstly to encourage more sustainable exploitation of fish stocks, through adaptation of fishing capacity to existing fishing opportunities. Secondly, the aim was to give individual fishermen improved possibilities to operate and plan their fishery, given their fishing capital and activities. Finally, the aim was to increase and secure the total earnings of the Danish fishery. Andersen et al. (2010) used a linear programming model covering the total Danish fishery to investigate possible short and long run effects of ITQs management for the Danish fishery. They predicted that gross profit would increase with between 30 and $38 \%$ in the short run, depending on the degree of which quotas can be traded between vessels above and below 18 meters. This increase in gross profit is accompanied by an expected decrease in number of vessels of between 9 and $30 \%$.

Mearyo et al. (2018) uses a descriptive approach, analysing the development of the Danish fishery during the period 2002-2014, to investigate economic, social and environmental effects of introducing ITOs in the Danish fishery management. They base their analysis on observed key indicators for the Danish fishing fleet. In line with Andersen et al. (2010) a decline in the Danish fleet capacity has been observed, with a reduction of $62 \%$ in the number of commercially active vessels between 2002 and 2014, accompanied by a reduction of $68 \%$ in number of full-time workers (equivalent) on the commercially active fleet. Correspondingly a decrease is observed of $25 \%$ in the total profit of the fleet over the period, resulting from the reduced catch opportunities (reduction in the Total Allowable Catch). However, the profit per vessel increased by $96 \%$ over the same period.

Before the introduction of ITQs, Denmark has since 1988 applied decommissioning programs extensively. These programs were designed to alleviate the fishing pressure on stock for which the quotas were reduced and for fleets for which the profitability deteriorated. Hence the decommissioning programs caused a reduction in fleet capacity. Since 1987 until 2003 the number of vessels was reduced by $51 \%$ and the gross register tonnage (GRT) and the horsepower were reduced by $40 \%$ taking into account the changes in statistical recording and measurement of capacity, see Frost and Kjærsgaard (2002). When the ITO system was introduced the decommission system was abandoned.

Thus, these studies indicate that the introduction of ITQs led to a continuous reduction in overcapacity, which have been economically beneficial for the remaining fishermen. A question remaining is what happens to the workers that left the fishery. The general unemployment rate in Denmark decreased from 2002 to 2007 but then increased again towards 2014 (Mearyo et al. 2018), however with an overall decrease over the period. When examining the unemployment rate in the largest Danish fishing municipalities this has decreased more than the overall Danish average for all municipalities but one, indicating that the redundant fishers should have had possibilities to find alternative employment locally. This is supported by Nielsen et al. (2017) who investigate factors that influence why coastal fishermen leave the sector. It is shown that around 2007 (the introduction of ITQs in the demersal fishery) there is a 
strong incentive for coastal fishermen owning fishing vessels to sell quotas and leave the fishery, but that income from other sources also has a strong influence on this decision. I.e. a part of the fishermen left knowing they could earn a living in alternative ways. Moreover, the analyses showed that the possibility to obtain social benefits only to a lesser degree influenced the decision to leave over the period 2004-2009, and not significantly so after 2007, indicating that coastal fishermen have not left the fishery to base their future income only on social benefits. These results only applies for the coastal fishery, however given that this segment have been perceived to be under the greatest pressure economically and with regards to capacity reduction when ITOs was introduced, the study is believed to reflect the behaviour of the rest of the sector.

\subsection{Management, current and historical}

Management of the Danish fisheries is part of the Common Fisheries Policy of the European Union (Holden and Garrod 1996). The Common Fisheries Policy sets Total Allowable Catches for managed fish stocks in European waters. These Total Allowable Catches are allocated to each member state according to the relative stability principle. Moreover, technical conservation measures including mesh size and minimum fish size limits are set centrally by the Common Fisheries Policy.

Before 2003, management of Danish fisheries was performed through a license system combined with individual non-transferable weekly and monthly vessel quotas. Limits were also set on the days at sea and engine power for each vessel, cf. Andersen et al. 2005. Based on comprehensive investigations and discussions in the years before ITOs were introduced for herring in 2003, followed by mackerel and fish for reduction in 2004, cf. Frost and Løkkegaard (2001) and Løkkegaard et al. (2001), Subsequently, the ITQ system was extended to the entire Danish fleet in 2007 (Danish Ministry of Food, Agriculture and Fisheries, 2005). At the introduction of the ITQ programs, individual quota shares were allocated to individual vessels by the grandfathering principle (Danish Ministry of Food, Agriculture and Fisheries, 2008), i.e. based on landing shares in 2003-2005. Based on these shares, individual vessel quotas are set each year based on the Total Allowable Catches. The quota shares are fully tradeable between all vessels, regardless of size and gear used. However, there is a personal limit on the share that can be held, to avoid concentration (Danish Ministry of Food, Agriculture and Fisheries, 2008). On the other hand, vessels are allowed to construct quota communities, within which quotas can be transferred with a minimum of administration.

A special arrangement was set up in 2007 for the coastal fisheries (Danish Ministry of Food, Agriculture and Fisheries, 2005). Vessels below 17 meters, with at least $80 \%$ of their fishing trips being less than three days could enter this arrangement, in which they had to stay enrolled for at least 3 years. If entering, vessels were allocated extra quotas of cod and sole, but could then only trade quotas and quota shares with other vessels in the arrangement (Nielsen et al. 2013). This scheme has been revised in 2016 and an amended scheme introduced in 2017. Under the new scheme there will be additional 
quotas added for cod, sole and plaice, and moreover, for the first time, Norway lobster, turbot, sprat, herring and saithe. The new rules distinguish between two coastal segments; an open segment (vessels less than 17 meters, with $80 \%$ of the fishing trips shorter than 2 days) and a closed segment (vessels less than 15 meters, landing at least $70 \%$ of each quota covered by the scheme available through their initial transferable fishing concession allocation). Vessels in the closed segment can only trade quota (permanent quota shares and annual quotas) with other vessels in the same segment, but receive an extra premium compared to vessels participating in the open segment. As of 2017, vessels that once have joined the closed segment will not be able to return to the open segment.

Finally, the Danish fishery is subject to the landings obligation, which has been obligatory through the Common Fisheries Policy for all European fisheries since 2015 (EC, 2013). In Denmark, the landings obligation is being rolled out from 2016 to 2019.

\subsection{Data}

Table 16 displays key indicators for the historical development of the total Danish fleet over the period 2002-2014. Numbers are shown for the years 2002, 2007 and 2014, i.e. the year before introduction of ITQs in the herring fishery, the year of introduction of ITOs in the demersal fishery, and 7 years after this last change in management. Moreover, Figure 12 shows the development in the capacity (number of vessels) in the Danish fleet over the period 1995-2015. Table 16 firstly shows that the total number of vessels in the Danish fleet has been reduced by 36\% from 2002 to 2014. Looking at active vessels and at commercially active vessels (having an income from fisheries above EUR 33,500), the reduction is even higher, being $62 \%$ for the commercially active vessels. Figure 16 shows that this decrease is a continuation of a general trend in the Danish fishery during the last 20 years. The reduction in the fleet is explained by reduced fishing opportunities both before and after the introduction of ITOs. Decommission schemes and other initiatives were introduced to reduce capacity. However; the adaption of the fleet to the reduced fishing opportunities, was not happening fast enough before the introduction of ITOs because the technological development and increased productivity within the Danish fleet was occurring faster than the fleet were able to adjust under the former regulatory framework without transferability of quotas. Figure 12 shows that the decrease in number of vessels accelerated just after the introduction of ITQ management in 2007 in the Danish demersal fishery (with a fall of $23 \%$ in the total number of vessels), but then levelled out. This indicates an instant adjustment in the fleet just after introduction of ITQs in the demersal fishery. 
Table 16: Historical fleet development for the Danish fleet 2002-2014

\begin{tabular}{|c|c|c|c|c|}
\hline & 2002 & 2007 & 2014 & $\begin{array}{l}\% \text { change } \\
2002-2014\end{array}$ \\
\hline No. vessels ${ }^{1}$ & 3,816 & 2,957 & 2,442 & -36 \\
\hline No. active vessels & 2,699 & 2,087 & 1,578 & -42 \\
\hline No. commercially active vessels & 1,321 & 760 & 506 & -62 \\
\hline$\%$ landing value from commercially active vessels & 92 & 85 & 89 & \\
\hline \multicolumn{5}{|l|}{ Days at sea, commercially active fleet } \\
\hline Total & 214,160 & 100,305 & 71,582 & -67 \\
\hline Average per vessel & 162 & 132 & 141 & -13 \\
\hline Tonnage (GT), commercially active fleet & 90,465 & 61,118 & 59,844 & -34 \\
\hline \multicolumn{5}{|l|}{ Quota utilization\% } \\
\hline Total & 71 & 77 & 78 & +10 \\
\hline Industrial fishery & 67 & 74 & 74 & +10 \\
\hline Fishery for human consumption & 93 & 84 & 86 & -8 \\
\hline
\end{tabular}

Note: 1. "No. vessels" includes the entire fleet. All other numbers only include commercially active vessels except those in the mussels and horse/brown shrimps fishery sector.

Source: Statistics Denmark (2002, 2007, 2014); The Danish Agrifish Agency (2002, 2007, 2014). This Table has been adapted from Merayo et al. (2018).

Figure 12: Development (indexed) in number of vessels in the Danish fleet during the period 19952015. Number in parentheses display the absolute number of vessels in 2015

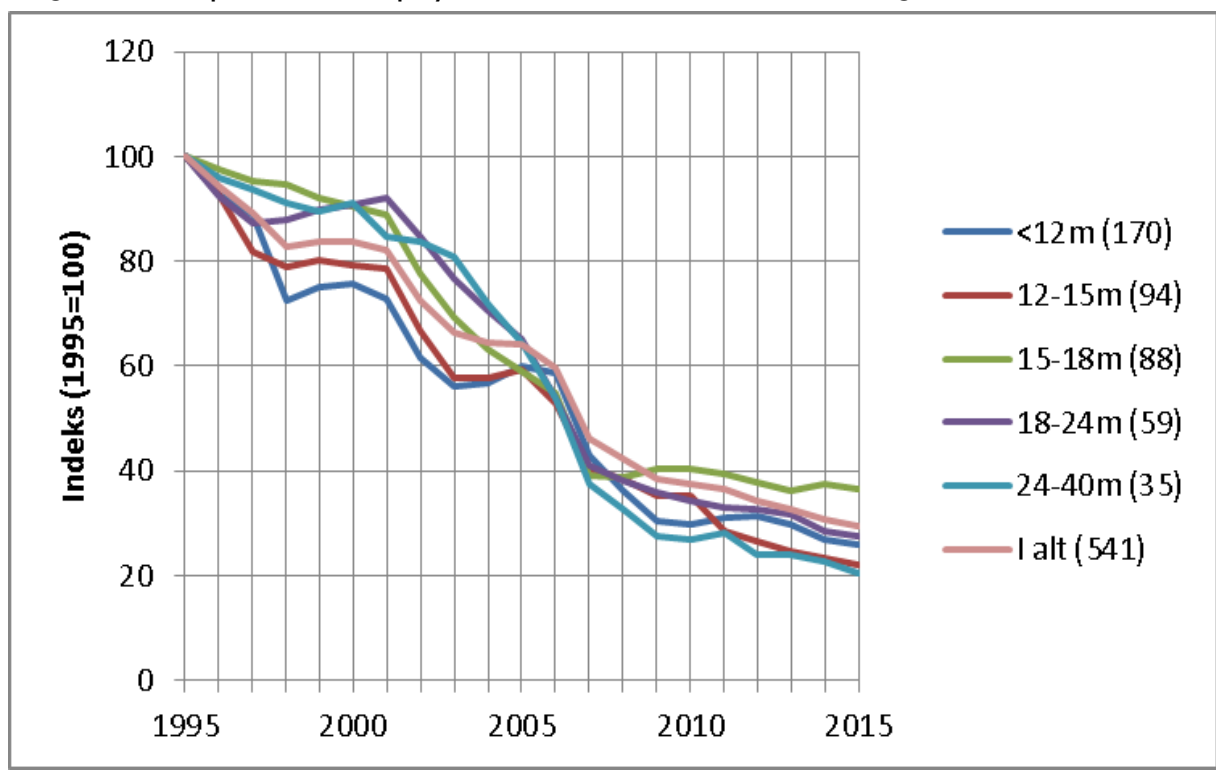

Following the decrease in number of commercially active vessels the total Days at Sea is also reduced by $67 \%$ from 2002 to 2014 , while the days at sea per vessel is only reduced by $13 \%$, thus indicating that the major fall in total effort is caused by a fall in number of vessels. The reduction in days at sea can also be seen as a consequence of a reduced "race for fish" and that fishermen now fish when the weather or season allows them the best opportunities to utilize the vessels capacity leading to higher catch efficiency among the remaining vessels. The tonnage (GT) has been reduced by $34 \%$ between 2002 and 2014, but this fall predominantly lie between 2002 and 2007, even though the dominant 
reduction in number of vessels lie between 2007 and 2014. Merayo et al. (2018) explains this seemingly paradox through two effects. Firstly, vessels over 24 meters have a slight increase in tonnage from 2007 to 2014. These segments mainly target pelagic and industrial species, for which both prices and stocks experienced a positive development after 2014. Secondly, the average tonnage per vessel has increased for all vessel groups, except vessels less than 12 meters, suggesting that it is the smallest vessels that have left the fishery in each vessel group. Finally, Table 16 show that the quota utilisation has increased in the industrial fishery while it has decreased in the fishery of species for human consumption. These effects may to a large degree be explained by uneven development of fish stocks over the period.

Table 17 displays the historical development in key economic and social indicators. The Table firstly shows that the total fleet profit decrease from 2002 to 2007 , but then increase again, ending $25 \%$ below the 2002 level. The average profit per vessel displays the same trend, but here the increase after 2007 is more pronounced, ending with an overall increase of $96 \%$ from 2002 to 2007 . The overall profit decrease is carried by vessels below 24 meters, while vessels above this length have an overall increase over the period (Merayo et al. 2018). For average profit vessels below 18 meters experience decrease while vessels above 18 meters have increasing profits per vessel. These trends may to some degree be based in the introduction of ITO management, but will also be influenced by other factors too, mainly by stock status (reflected in quotas) and by market dynamics (prices).

Table 17: Historical development in economic and social data for the Danish fleet 2002-2014

\begin{tabular}{|c|c|c|c|c|}
\hline & 2002 & 2007 & 2014 & $\begin{array}{r}\% \text { change } \\
2002-2014\end{array}$ \\
\hline \multicolumn{5}{|l|}{ Private economic indicators: } \\
\hline Profit ${ }^{3}$ & 74.0 & 33.9 & 55.6 & -25 \\
\hline Average profit per vessel & 0.1 & 0.0 & 0.1 & +96 \\
\hline Profitability $3 \%$ & 11.7 & 6.9 & 12.6 & +8 \\
\hline Capital intensity 3 & 0.2 & 0.4 & 0.5 & +116 \\
\hline Total value of fishery assets 3 & 634.2 & 840.2 & $1,219.0$ & +92 \\
\hline Value of quotas 3 & & 351.1 & 777.7 & $\begin{array}{r}+122 \\
(2007-2014)\end{array}$ \\
\hline Value of material fishery assets 3 & 634.2 & 489.2 & 441.3 & -30 \\
\hline \multicolumn{5}{|l|}{ Socioeconomic indicator: } \\
\hline Socio-economic return'2,3 & 74.6 & 49.2 & 73.0 & -2 \\
\hline \multicolumn{5}{|l|}{ Social indicators: } \\
\hline No. workers, total fleet & 4,258 & 2,573 & 1,988 & -53 \\
\hline No. full-time workers (equivalent), commercially active vessels & 2,949 & 1,260 & 954 & -68 \\
\hline Average annual wage, per full-time fisher, thousand DKK & 43.0 & 44.6 & $39.9^{\mathrm{a}}$ & -7 \\
\hline Unemployment rate\%, general, Denmark & 4.8 & 2.7 & 4 & -17 \\
\hline
\end{tabular}

Note: 1. Million EUR. Commercially active vessels, excluding shrimp beam-trawlers and mussel dredgers. Monetary values adjusted for inflation (base year 2002). Profitability $=\%$ of profit in relation to fishery assets (excluded fishing rights). Capital intensity=Fishery assets (excluding fishing rights)/no. workers.

2. Socio-economic return includes the producer surplus, as defined in the appendix.

3. Total for fleet. ${ }^{\text {a }}$ Data for 2012 instead of 2014. This Table has been adapted from Merayo et al. (2018).

Source: Statistics Denmark (2002, 2007, 2014). 
The profitability (percentage change in profit relative to physical fishery assets) follows the same trend as the profit, i.e. a decrease towards 2007 and a subsequent increase, leading to an overall increase of $8 \%$ from 2002 to 2014 . The increase is carried by the large vessels ( $>18$ meters) while the smaller vessels experience decreasing profitability (Merayo et al. 2018).

The capital intensity is defined as the material fishery assets relative to the number of full time workers. Table 17 shows that the capital intensity increases with $116 \%$ from 2002 to 2014 , corresponding with the observed decrease of $68 \%$ in number of full time workers.

Table 17 further shows that both the quota values and the total fishery assets value increases over the period, reflecting that under an ITO system the value of quotas will reflect the expected future earnings of the fishery, according to economic theory. This is confirmed by the decrease in physical fishery assets (excluding quotas), indicating that part of the quota values is embedded in total vessel assets. This also explains why profits, everything else being kept equal, have not increased more given the introduction of ITQs; profit has been capitalised in permanent quota shares.

The socio-economic return, representing the social welfare that the fishery comprises for society when compared with how the resources used in the fishery sector could be used in other sectors, is positive over the period, decreasing from 2002 to 2007, however; increases towards 2014 to almost the same level as in 2002. As the profit, the socio-economic return will be influenced by several factors, nevertheless; it is interesting to notice the recovery of this indicator after the introduction of ITQs in the demersal fishery.

Finally, Table 17 displays the development of labour and wages on the Danish fishing fleet. Following the decreasing number of vessels (cf. Table 16) the total number of workers and the equivalent number of full-time employed decrease by $53 \%$ and $68 \%$, respectively. However, given that the Danish unemployment has decreased over the period, a trend that is also observed for the large fishing communities (cf. Merayo et al. 2018), it must be assumed that the redundant fisheries labour have managed to find work on land. The annual wages decrease over the period, but given that wages are usually paid as part of the landed value, this indicator will vary with quota and market fluctuations. Thus, given the increased profit earned from 2007 to 2014, it seems that there has been a redistribution of welfare from labour to capital, which has been capitalized in the quota shares.

\subsubsection{The Danish North Sea demersal fishery}

The Danish North Sea fishery constitutes a major part of the total Danish fishery. In 2012-2014 this fishery harvested $68 \%$ of the total Danish landed value. The landings of demersal species constituted $25 \%$ of the landed value from the North Sea in the same period. The Danish demersal fleet consists mainly of netters and trawlers below 24 meters, with the exception of the larger trawlers (24-40meters) fishing for human consumptions. 
The Danish fleet targeting demersal species in the North $\mathrm{Sea}^{8}$ is parametrised using data from (i) the Danish Fisheries Analytical Database provided by the Danish Agrifish Agency, which comprises landings (weight and value), and effort data at trip level for the individual vessels in the fleet, and (ii) fleet cost data from Statistics Denmark's Account Statistics for Fisheries. Model parametrisation data are based on averages for the period 2012-2014, i.e. the three years leading up to the modelled period. Thus, it is assumed that the cost, price and catch patterns in the projection period (2016-2025) are identical to the structure in the years leading up to this period.

Vessels included from the Danish Fisheries Analytical Database to parametrize the model are vessels that have a turnover of more than EUR 37,000. This threshold excludes small vessels owned by part time fishermen, however; the total turnover of these vessels constitutes less than $2 \%$ of the total Danish turnover. Six fleet segments were identified for which the value of landed demersal species caught in the North Sea constituted more than $20 \%$ of their total landed value in $2012-2014$. Table 18 presents base physical and economic indicators, averaged over the calibration period 20122014, for these fleet segments. The average number of vessels and days at sea per vessel, together with the cost data given in Table 18 has been used to initialize the model in 2015 for each segment

Table 18: Average base indicators for the fleets included in the analysis over the calibration period 2012-2014

\begin{tabular}{|c|c|c|c|c|c|c|c|}
\hline Average 2012-2014 & $\begin{array}{r}\text { Net } \\
0-15 m\end{array}$ & $\begin{array}{r}\text { Net } \\
15^{-24 \mathrm{~m}}\end{array}$ & $\begin{array}{l}\text { Trawl } \\
0-15 m\end{array}$ & $\begin{array}{r}\text { Trawl } \\
15-24 \mathrm{~m}\end{array}$ & $\begin{array}{r}\text { Traw } \\
24-40 m\end{array}$ & $\begin{array}{l}\text { DK Sein } \\
15^{-24 m}\end{array}$ & $\begin{array}{r}\text { Average per } \\
\text { vessel } 5\end{array}$ \\
\hline \multicolumn{8}{|l|}{ Physical data } \\
\hline $\mathrm{FTE}^{1} /$ segment & 41.1 & 74.9 & $5 \cdot 5$ & 67.1 & 133.9 & 36.9 & 44.2 \\
\hline Number of vessels & 46 & 19 & 5 & 30 & 28 & 19 & 147 \\
\hline DAS/vessel in NS3 & 81 & 56 & 242 & 48 & 206 & 62 & 97 \\
\hline 1st important species ${ }^{2,4}$ NS & $\operatorname{COD}(44 \%)$ & PLE (46\%) & $\operatorname{HER}(56 \%)$ & PLE $(60 \%)$ & $\operatorname{COD}(27 \%)$ & PLE (44\%) & PLE (32\%) \\
\hline 2nd important species ${ }^{2,4}$ NS & PLE (33\%) & SOL $(25 \%)$ & PLE (31\%) & $\operatorname{COD}(13 \%)$ & SAI (17\%) & $\operatorname{COD}(34 \%)$ & $\operatorname{COD}(26 \%)$ \\
\hline 3rd important species 2,4 NS & SOL $(13 \%)$ & $\operatorname{COD}(21 \%)$ & $\operatorname{COD}(8 \%)$ & $\operatorname{NEP}(9 \%)$ & HKE (14\%) & SOL $(20 \%)$ & SAI $(11 \%)$ \\
\hline \multicolumn{8}{|l|}{ Account data (100oEUR/ vessel) } \\
\hline Turnover & 135 & 650 & 328 & 784 & 1,798 & 466 & 702 \\
\hline Fuel Costs & 9 & 58 & 38 & 111 & 379 & 34 & 111 \\
\hline Crew costs & 59 & 285 & 82 & 209 & 452 & 174 & 210 \\
\hline Variable costs & 23 & 108 & 27 & 92 & 218 & 117 & 98 \\
\hline Fixed costs & 33 & 118 & 49 & 112 & 237 & 75 & 105 \\
\hline Capital costs & 24 & 130 & 32 & 113 & 391 & 77 & 133 \\
\hline Opportunity labour cost & 46 & 187 & 63 & 116 & 258 & 103 & 97 \\
\hline Opportunity capital cost & 22 & 113 & 34 & 101 & 328 & 75 & 79 \\
\hline Profit & -12 & -49 & 101 & 147 & 121 & -10 & 45 \\
\hline Socio-economic return & 1 & 51 & 137 & 228 & 315 & 64 & 127 \\
\hline
\end{tabular}

Note: 1. "FTE"=Full Time Employment.

2. Relative importance of landed species is measured in value.

3. The vessels also operate in other waters than the NS.

4. "COD"=cod, "PLE"=Plaice, "HER"=Herring, "SOL"=Sole, "SAl"=Saithe, "NEP"=Nephrops, "HKE"=Hake.

5. For "Number of vessels" this column result represent the sum and not average.

${ }^{8}$ Comprising the Northern, Central and Southern North Sea. 
Table 18 shows that the most profitable segments in 2012-2014 were the trawlers, while the netters and seiners operated with losses. Likewise, the socioeconomic return, i.e. the social welfare that the fishery represents for society, was largest for the trawlers and smallest for the small netters. The largest turnovers were obtained by fleet segments larger than 24 meters, given that these segments have larger capacity and can thus catch larger amounts. However, these segments also carry the highest costs. Table 18 further shows that the most important species, in terms of value were plaice and cod in the period 2012-2014, followed by saithe, the latter because saithe constitutes $17 \%$ of the catch value of the large trawlers $24-40$ meters.

Table 19 displays the status of the major demersal stocks included in the model projections. Spawning stock biomass, Total Allowable Catches and fishing mortality corresponding to MSY are displayed, together with the status of the stocks in $2015 .{ }^{9} \cdot \mathrm{It}$ is seen that most stocks were sustainable in 2015 with the exception of Cod that was above Bpa but below MSY-Btrigger, and Nephrops in Functional Units 6 and 7. The spawning stock biomasses and Total Allowable Catches displayed in Table 19 are used as initiating values in 2015 for the model projections.

Table 19: Status, illustrated through Spawning Stock Biomass (SSB), Total Allowable Catch (TAC) and fishing mortality at MSY (F-MSY) of the main North Sea stocks included in the analysis in the start year 2015

$\begin{array}{lrrrl}2015 & \text { SSB (tonnes) } & \text { TAC (tonnes) } & \text { F-MSY } & \text { Status 2015 }{ }^{\mathbf{1}} \\ \text { Plaice (NS) } & 770,556 & 128,376 & 0.21 & \text { Above Bpa3, Above MSY-Btriggger }{ }^{4} \\ \text { Cod (NS) } & 134,323 & 29,189 & 0.31 & \text { Above Bpa, Below MSY-Trigger } \\ \text { Saithe (NS) } & 220,918 & 66,006 & 0.36 & \text { Above Bpa, Above MSY-Btriggger } \\ \text { Hake (NS) } & 272,795 & 90,849 & 0.28 & \text { Above Bpa, Above MSY-Btriggger } \\ \text { Sole (NS) } & 45,650 & 11,900 & 0.20 & \text { Above Bpa, Above MSY-Btriggger } \\ \text { Nephrops (NS) } & - & 17,843 & - & \text { Above MSY-Btrigger in FU2 8, 9, below MSY-Btrigger in FU 6, 7 } \\ \text { Haddock (NS) } & 142,921 & 40,711 & 0.194 & \text { Above Bpa, Above MSY-Btriggger }\end{array}$

Note: 1. According to ICES advice 2017.

2. "FU"=Functional Unit.

3. "Bpa"=The precautionary biomass level that triggers ICES to take action to raise the stock above this level.

4, "MSY-Btrigger"=The Biomass level that triggers ICES to recommend a fishing mortality below F-MSY.

\subsection{Results}

As described in the introduction of this report 4 forecast scenarios are considered. The results obtained in 2025 are compared with the initial situation in 2015. The specifics for the Danish case/management are: ${ }^{10:}$

1. Current Danish management: ITOs with quota trade restrictions between vessels above and below 15 meters, and $4 \%$ limit on yearly adjustment in number of vessels in each segment;

\footnotetext{
9 Source: ICES advice 2017, http://standardgraphs.ices.dk/stockList.aspx

${ }_{10}$ The constant recruitment scenario has been left out in the Danish case, given that it leads to unrealistic results, including extinction of the Haddock stock.
} 
2. Free ITOs with no trade limits. $4 \%$ limit on yearly adjustment in number of vessels in each segment;

3. Current Danish management: ITQs with quota trade restrictions between vessels above and below 15 meters. No limit on yearly fleet adjustment;

4. Scenario 1 with taxes on $10 \%$ of prices.

As discussed in the introduction two forecasts are made for each scenario: Maximization of the total socio-economic return and maximization the total profit, both over the period 2016-2025 (2015 being held constant), through variation in number of vessels and days at sea per vessel.

Table 20 display the model outcomes from the projection maximizing socioeconomic return. The Table displays total socio-economic return (summed over all included fleet segments), together with the total number of vessels and the total fulltime employment. Table 20 displays the corresponding indicators from the projection maximizing profit. Results are shown for the base year 2015 and for each scenario for the final projection year 2025 .

Table 20: Forecast of socio-economic return, fleet and employment adjustment in 2025 by maximizing socioeconomic return

\begin{tabular}{lrr|r|rrr|r|} 
Scenarios & Net & Net & Trawl & Trawl & Trawl & DK Sein \\
$0-15 \mathrm{~m}$ & $15-24 \mathrm{~m}$ & $0-15 \mathrm{~m}$ & $\mathbf{1 5 - 2 4 \mathrm { m }}$ & $\mathbf{2 4 - 4 0 \mathrm { m }}$ & $\mathbf{1 5 - 2 4 \mathrm { m }}$
\end{tabular}

\begin{tabular}{|c|c|c|c|c|c|c|c|}
\hline \multicolumn{8}{|l|}{ Socio-Economic return (mill EUR) } \\
\hline 2015 initial situation & -1.47 & 1.97 & 0.68 & $7 \cdot 35$ & 12.14 & 1.71 & 22.38 \\
\hline \multicolumn{8}{|l|}{2025 scenarios: } \\
\hline 1. Current management & -0.35 & 2.73 & 1.25 & 14.99 & 7.09 & 1.90 & 27.60 \\
\hline 2. ITQ management free quota trade & 0.67 & 2.28 & 1.28 & 14.97 & 7.09 & 1.80 & 28.09 \\
\hline 3. Current management full adjustment & 0.89 & 4.11 & 1.28 & 15.84 & 11.15 & 2.04 & $35 \cdot 31$ \\
\hline 4. Current management constant recruitment & - & - & - & - & - & - & - \\
\hline 5. Current management $10 \%$ landing tax & -0.35 & 2.73 & 1.25 & 14.99 & 7.09 & 1.90 & 27.60 \\
\hline \multicolumn{8}{|l|}{ Number of vessels } \\
\hline 2015 initial situation & 46 & 19 & 5 & 30 & 28 & 19 & 147 \\
\hline \multicolumn{8}{|l|}{2025 scenarios: } \\
\hline 1. Current management & 30 & 13 & 6 & 34 & 19 & 13 & 115 \\
\hline 2. ITQ management free quota trade & 30 & 13 & 7 & 34 & 19 & 13 & 116 \\
\hline 3. Current management full adjustment & 8 & 6 & 7 & 50 & 7 & 8 & 86 \\
\hline 4. Current management constant recruitment & - & - & - & - & - & - & - \\
\hline 5. Current management $10 \%$ landing tax & 30 & 13 & 6 & 34 & 19 & 13 & 115 \\
\hline \multicolumn{8}{|l|}{ Employment (full-time) } \\
\hline 2015 initial situation & 40 & 66 & 5 & 71 & 134 & 36 & 352 \\
\hline \multicolumn{8}{|l|}{2025 scenarios: } \\
\hline 1. Current management & 27 & 44 & 7 & 76 & 89 & 24 & 267 \\
\hline 2. ITQ management free quota trade & 27 & 44 & 8 & 76 & 89 & 24 & 268 \\
\hline 3. Current management full adjustment & 7 & 20 & 8 & 105 & 33 & 15 & 187 \\
\hline 4. Current management constant recruitment & - & - & - & - & - & - & . \\
\hline 5. Current management $10 \%$ landing tax & 27 & 44 & 7 & 76 & 89 & 24 & 267 \\
\hline
\end{tabular}


Table 21: Forecast of profit, fleet and employment adjustment in 2025 by maximizing profit

\begin{tabular}{|c|c|c|c|c|c|c|c|}
\hline Scenarios & $\begin{array}{r}\text { Net } \\
0-15 m\end{array}$ & $\begin{array}{r}\text { Net } \\
15-24 \mathrm{~m}\end{array}$ & $\begin{array}{r}\text { Trawl } \\
0-15 m\end{array}$ & $\begin{array}{r}\text { Trawl } \\
15-24 m\end{array}$ & $\begin{array}{r}\text { Trawl } \\
24-40 m\end{array}$ & $\begin{array}{l}\text { DK Sein } \\
15^{-24 m}\end{array}$ & Total \\
\hline \multicolumn{8}{|l|}{ Profit (mill EUR) } \\
\hline 2015 initial situation & -1.21 & -0.30 & 0.29 & 3.54 & 5.07 & 0.30 & 7.69 \\
\hline \multicolumn{8}{|l|}{2025 scenarios: } \\
\hline 1. Current management & -0.90 & 0.10 & 0.67 & 9.76 & 1.90 & 0.70 & 12.23 \\
\hline 2. ITQ management free quota trade & 0.52 & -0.66 & 0.70 & 9.73 & 2.05 & 0.63 & 12.96 \\
\hline 3. Current management full adjustment & 0.31 & 1.58 & 0.70 & 11.05 & 7.25 & 1.07 & 21.97 \\
\hline 4. Current management constant recruitment & - & - & - & - & - & - & \\
\hline 5. Current management $10 \%$ landing tax & -0.97 & -0.25 & 0.54 & 7.87 & 0.75 & 0.53 & 8.47 \\
\hline \multicolumn{8}{|l|}{ Number of vessels } \\
\hline 2015 initial situation & 46 & 19 & 5 & 30 & 28 & 19 & 147 \\
\hline \multicolumn{8}{|l|}{2025 scenarios: } \\
\hline 1. Current management & 30 & 13 & 5 & 34 & 19 & 13 & 114 \\
\hline 2. ITQ management free quota trade & 30 & 13 & 6 & 35 & 19 & 13 & 116 \\
\hline 3. Current management full adjustment & 6 & 5 & 6 & 62 & 7 & 11 & 97 \\
\hline 4. Current management constant recruitment & - & - & - & - & - & - & - \\
\hline 5. Current management $10 \%$ landing tax & 30 & 13 & 5 & 33 & 19 & 13 & 112 \\
\hline \multicolumn{8}{|l|}{ Employment (full-time) } \\
\hline 2015 initial situation & 40 & 66 & 5 & 71 & 134 & 36 & 352 \\
\hline \multicolumn{8}{|l|}{2025 scenarios: } \\
\hline 1. Current management & 27 & 44 & 6 & 77 & 89 & 25 & 267 \\
\hline 2. ITQ management free quota trade & 27 & 44 & 7 & 77 & 89 & 25 & 269 \\
\hline 3. Current management full adjustment & 6 & 17 & 7 & 124 & 34 & 20 & 208 \\
\hline 4. Current management constant recruitment & - & - & - & - & - & - & - \\
\hline 5. Current management $10 \%$ landing tax & 27 & 44 & 5 & 72 & 89 & 24 & 261 \\
\hline
\end{tabular}

\subsubsection{Socio economic return and profit}

The tables firstly show that given the current management (scenario 1) the total demersal fleet will be better off in 2025 than in 2015 . The total socio-economic return increases by $23 \%$ and the total profit by $59 \%$. Thus, both the social welfare that the fishery represents for society (through the socio-economic return) and the actual surplus obtained in the fishery after subtraction of all costs (including quota trade) is expected to increase considerably over the period given the current management system, and assuming a certain rigidity in investment/disinvestment speed. This effect is seen for most fleet segments, except the large trawlers 24-40 meters. The large trawlers take around $40 \%$ of the catches of the included segments and have a large catch of hake. This segment discarded a large amount of undersized hake before the introduction of the landings obligation and will have choke problems after 2019 where the landings obligation is enforced. It would therefore be optimal to buy hake quotas from other segments. However, given that this segment is the largest it is not possible to buy enough hake to avoid the choke problem and thus this segment has a decrease in the socio-economic return and profit over the period given the current management system.

The tables further show that removing the trade barrier between small and large vessels (scenario 2) will increase the economic outcome, but only marginally so, in 2025 both with respect to socio-economic return and profit (when comparing to scenario 1 ). 
Considering individual segments the picture is more mixed, as some segments have increasing socio-economic return and profit while others half have decreasing socioeconomic return and profit. It is interesting to notice that the small netters less than 15 meters is expected to make a profit if the trade barrier is removed between small and large vessels, i.e. it is predicted that only the most efficient vessels are left to fish the available resource.

Assuming instant capacity adjustment (scenario 3 ), as opposed to a $4 \%$ limit on yearly capacity change, will lead to a considerable profit increases compared to scenario 1: $28 \%$ increase in socio-economic return and $80 \%$ in profit, when compared to scenario 1 . This increase is carried by all fleet segments, and especially the large trawlers 24-40 meters and large netters above 15 meters benefit. This illustrates how reduction of overcapacity may generally make fleet segments (i.e. the remaining vessels) more efficient and thereby more profitable.

Introducing a landings tax of $10 \%$ (scenario 4 ) results in the socio-economic return being identical to what is obtained in the current situation (scenario 1) given that this tax is an income to society and as such will cancel out in the socio-economic return. However, the total profit decreases with $31 \%$ relative to the current situation (scenario 1). This decrease is carried by all fleet segments.

Figure 13 displays the development of profit and socio-economic return over the projection period of the total socio-economic return, respectively the total profit resulting from each projection. The trends shown in the figures are very similar to the final 2025 results, i.e. throughout the period the most profitable scenario, both with regards to socio-economic return and profit is scenario 3 (free capacity adjustment), followed by scenario 2 (no trade barriers between small and large vessels, i.e. free ITO trade) and scenario 1 (current management system), while scenario 4 (10\% tax) lies well below the other scenarios in the profit maximisation case. The decrease in the socioeconomic return and profit observed towards 2018 is caused by the landings obligation being phased in between 2016 and 2018. The large trawlers for human consumption is predicted to be severely affected by this, as discussed above, and the reduction in their profit and socio-economic return is reflected in the total profit and socio-economic return. 
Figure 13: Development in Socio-Economic Return (top) and Profit (bottom) in each of the two projections

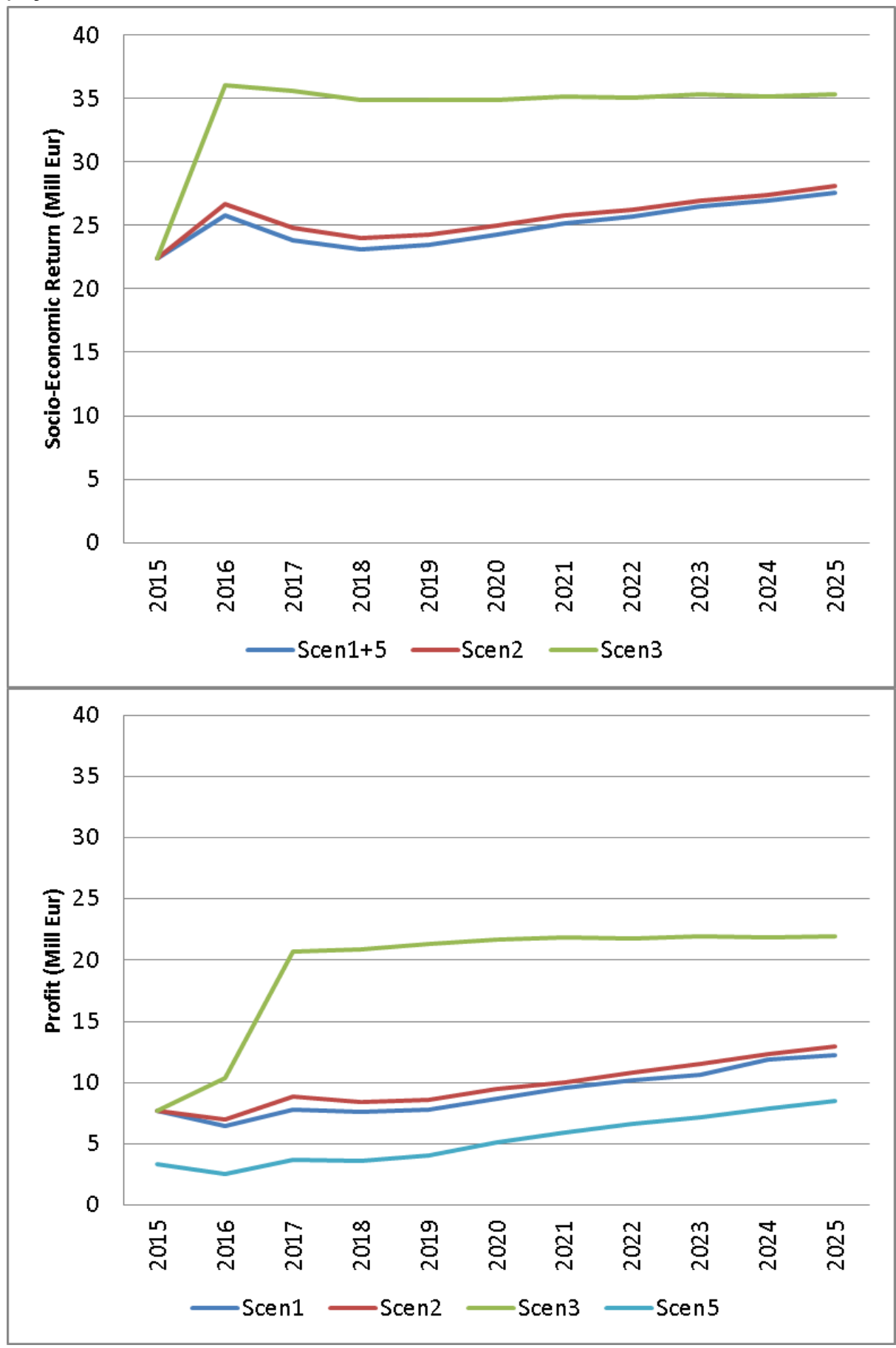




\subsubsection{Number of vessels and full time employment}

Tables 20 and 21 also display the total number of vessels respectively full time employed (FTE) resulting from maximizing socio-economic return and profit. The two tables firstly show that a reduction of $\sim 22 \%$ (equal for the socio-economic return and profit maximizations) is expected in number of vessels from 2015 to 2025 given the current management regime (scenario 1). Similar reductions are seen in scenarios 2 and 4 , given that the fleet is allowed to change a maximum of $+/-4 \%$ a year. Looking at individual fleet segments, similar reductions in number of vessels, relative to 2015 , is seen for most segments. However, trawlers 15-24 meters, experience an increase in number of vessels, illustrating that even though capacity reduction is optimal for most fleet segments, this segment profits to such a degree from quota transfers that it is optimal for new vessels to enter.

When assuming instantaneous capacity change (scenario 3 ), the total number of vessels is expected to decrease by $42 \%$ in the socio-economic return projection and by $34 \%$ in the profit projection relative to 2015 . Comparing the situation in 2025 with the current management scenario (scenario 1 ), the reduction of vessels are $25 \%$ for the socio-economic return projection and $15 \%$ within the profit projection (Table 20 ). These significant decreases are carried by most segments except the trawlers o-15 meters and 15-24 meters, that are both expected to increase the number of vessels, again illustrating how transfers of quotas may make some fleet segments more profitable and thus create incentives for new vessels to enter.

Given that full time employment is proportional to the number of vessels, the results for full time employment are identical to the results for number of vessels. I.e. it is generally expected that there will be a reduction in full time employment from 2015 to 2025 in all scenarios, with an approximately equal decrease in scenarios 1, 2 and 4 and with a more pronounced decrease in scenario 3.

\subsection{Policy considerations}

The above results firstly shows that given that the Danish management continues as today, i.e. with transferable vessel quota shares, and limits on trade between vessels in the coastal fishery arrangement, then both the outcome for society (socio-economic return) and for the fishermen (profit) will continue to improve towards 2025 compared to 2015 . The improvement is $23 \%$ in socio-economic return $59 \%$ in profit when it is assumed that the adjustment of the fleet is constrained (scenario 1 ). If it is on the other hand assumed that the adjustment of the fleet can happen instantaneously, given the profitability of the segments (scenario 3), a further increase, relative to scenario 1 , of $28 \%$ in socio-economic return and $80 \%$ in profit is observed. The actual outcome for the Danish fishery must be assumed to be in between these two extremes, however; it may be closest to the restricted capacity change outcome, acknowledging that (i) an average capacity decrease of $\sim 4 \%$ has been observed in the Danish fishery for the past decade and (ii) instantaneous capacity change given changes in fishing fleet profit 
seems unrealistic, given that there will be a natural lag between changing profits and ensuing investments/disinvestments in capital/capacity.

The Danish management can to a large degree be expected to continue in line with scenario 1 , i.e. quota trade and lease, , but with limits between vessels within and outside the coastal fishery agreement. A further development of the coastal fishery agreement is currently being implemented with restriction on transferability in exchange for higher quota shares of specific species as mentioned in the introduction.

It is also expected that restriction on how much a single quota holder can own will be more strictly enforced, given the recent discussion of quota concentrations raised by the Danish Public Accountant Committee. These limits have been in place from the introduction of the tradable quota system, however, the way they have been enforced was criticized in a report by the Danish Public Accountant Committee (Rigsrevisionen 2017).

Danish fishery is also subject to the Landings Obligation that is being rolled out from 2015 with full implantation in 2019 together with the rest of the EU fishing fleets. The current status of the Landings Obligation, and its expected implementation in Denmark, has been included in the projections presented in this chapter. Thus in scenario 1 , and to some degree 3 , must be expected to present the best possible prediction of the economic situation for the Danish fishery in 2025, however with the reservation that quote trade and lease may be more restricted in the future given possible new legislation aiming at preventing quota concentration.

However, it may be speculated how much could be gained, both for the society and for fishery in Denmark, if free quota trade is allowed (scenario 2) with no limits on trade with coastal fishery vessels or limits on quota concentration. Here the analyses indicate that the possible gain in 2025 is only marginally higher than what can be expected under the current management regime given rigid capacity adjustment (scenario 1), both with respect to the outcome to society and to the fishing fleet.

In scenario 4 a $10 \%$ tax on the landed value is examined. The result shows that this would leave the fishery worse off in 2025 than its current status in 2015. With regards to society, the outcome is the same as in scenario 1, i.e. as what can be predicted under current management with no taxes. The reason behind the emerging discussion of putting a tax on fish landings/fishing rights is that the fishermen (especially the large fishing enterprises) have had a substantial increase in earnings after the introduction of ITQs. The resource was given to the fishermen (for free) using grandfathering because the fisheries were in a very poor economic situation. However, this has changed and it now seems more and more reasonable that the exploitation of the common resource should also benefit the rest of the society (like exploitation of oil etc.) or at least be able to cover the cost that society have in regards to establishing, monitoring and enforcing rules and regulations.

In all the results in this chapter indicates that the Danish fishery, under its current management, is developing positively from an economic point of view, both with regards to the outcome to society and with regards to the outcome to the fishery. The fishery could be marginally better off if free quota trade (without protection of small scale fishermen) was allowed, and given that this may happen at the expense of 
increased quota concentration. However, given the recent debate in Denmark concerning quota concentration and "slipper skippers" (fishermen that rent out quotas without fishing them self) it seems realistic to assume that there will be a tightening of the rules rather than an opening for more free trade. For the moment, it is actually possible to take part in the quota trading no matter the size of the vessels, if you are not a part of the two existing coastal quota schemes set up to preserve/protect the small scale coastal fishermen.

The debate about preserving the coastal fisheries has been going on since before the introduction of the ITO schemes and focus mostly on the social dimension of the fisheries sector, keeping employment in fisheries depended communities and other social values related to having active fishermen in the local community/harbour (Nielsen et al. 2013 and 2017; Merayo et al. 2018). If the fishery sector is used as a political tool in regional development preserving employment in fisheries depended communities it is important that the cost of such interventions is known and compared to other alternative policies. Furthermore, the small scale fisheries are mostly targeting demersal species where the large vessels, where there have been issues of quota concentration, are targeting pelagic species (herring, mackerel and fish for reduction). Thus, some of the arguments presented againsts the ITO system (quota concentration) and for increasing the coastal fishery (employment, environmental sustainability etc.) in the debate seem to be based on myth rather than facts (Nielsen 2013 and 2017; Merayo et al. 2018).

The above results are good indicators of where the economic outcomes of the Danish fishery are heading towards 2025. However, some caution must be taken when interpreting the results. Firstly, the model applied runs at a yearly level. This omits seasonal changes in gear and catch patterns, and through this possibility for trading/swapping quotas not only between fleet segments but also between seasons. Thus the model underestimates the possible economic outcomes of the fishery. Secondly, the model is parametrized on data from 2012-2014. As such a constant price and cost structure is assumed over the total period, something that must be expected to change with market fluctuations and stock availability. Finally, quota prices are determined based on previous year's profitability of the buying/renting and selling/leasing fleet segments, as real quota prices are not known. Thus it must be expected that all these factors affect the absolute results. However, the relative difference between the results must be expected to be robust to these biases as all absolute numbers will change by the same amount if the biases are corrected. 


\section{Finnish large-scale pelagic fisheries}

\subsection{Introduction}

ITO system in the Finnish pelagic fisheries containing Baltic herring and sprat was introduced in the beginning of 2017. It covers the both large-scale trawler fleet and small-scale costal fishing. The pelagic trawler fleet is the most important fleet segment in Finland in terms of volume and value and accounts for 96 percent of all pelagic landings. The ITQ system was primarily designed for the pelagic trawler fleet but it also covers the small-scale coastal trap net fishing: ITO systems for these two fisheries are separated. In the Finnish case study we concentrate to analyse the development of pelagic trawler fleet.

\subsection{Literature review}

The only study on ITQs in the Finnish Baltic Sea herring fishery is by Lindroos et al. (2007). They carried out a bio-economic analysis of the in the Finnish trawling fisheries with two management options - an ITO system and non-tradable IO system - to examine possible economic, biological and social effects.

The results follow the realized development in other Nordic countries that ITOs leads to a marked decrease in capacity and number of vessels with improved economic performance leading to a balance between fishing opportunities and fleet that follows the ultimate objective of the Common Fishery Policy (Regulation (EU) No 1380/2013).

The poor economic performance of the Finnish pelagic trawler fleet has been recognized in the Economic Reports since late 1990s (Anon. 2001). The socioeconomic return of the fleet has showed continued zero profits: even with reasonable gross profits they have not been high enough to cover the opportunity costs of capital leading to decreasing number and aging fleet.

\subsection{Management}

The Finnish fisheries management was based on command and control quota-based regime until 2017. National Total Allowable Catch allocated to Finland was open for all licensed fishermen. This resulted into race to fish until the quota was fully utilised and the fishery was closed. The Ministry of Forestry and Agriculture was sometimes forced to regulate fishing with separate regulations in order to ensure balanced fishing 
opportunities throughout the year. Especially specific regulations were set to close sprat fishery if the quota uptake created risk of premature closure of herring fishing due to sprat bycatches in the main fishing grounds in the Bothnian Sea.

In the beginning of 2017 ITO system was implemented in the Finnish pelagic fisheries: Baltic herring and sprat. The initial quota share allocation was based on grandfathering system based on 2011-2015 track records: accounting for 3 highest annual catches during the 5 year period. Separate quota shares were allocated for coastal fishing to secure the continuance of the small scale coastal fishing.

The implemented ITO system is valid for ten years with an option of extension. Quota shares in the pelagic fleet are fully transferable with a limitation of concentration: no individual unit may exceed $20 \%$ of total quota.

The implemented ITO system is valid for ten years with an option of extension. Quota shares in the pelagic fleet are fully transferable with a limitation of concentration: no individual unit may exceed $20 \%$ of total quota.

\subsection{Data}

\subsubsection{The Finnish national fleet}

Table 22 presents the basic data on the development of Finnish national fleet in 20082014. The Finnish fishing fleet consisted of 3,144 registered vessels of which 1,460 were inactive in 2014 ; the active fleet consisted of 1,684 vessels, with a combined gross tonnage of 16 thousand GT. The number of active vessels shows an increase from 2008 to 2014 that is partly due to a change in statistical procedure that increased the number of active vessels in the small scale segment: since 2012 fishermen reported all vessels used during a year.

Total employment was estimated at 1,384 in 2014 jobs. The majority of the jobs are created by the small scale fleet that is a seasonal fishery. Therefore, the employment in that sector is usually only part-time and in terms of full time equivalent the total fleet added up to 355 FTEs. The number of fishermen has been dropping for long time.

The Finnish fishing fleet is dominated by small scale coastal fishing vessels: 1,621 out of $1,684(96 \%)$ active vessels were operating in small scale coastal fisheries. However the 63 trawlers accounted for two thirds in terms of gross tonnage of the total fleet tonnage. 
Table 22: Data on capacity, employment and Finnish national fleet

\begin{tabular}{|c|c|c|c|c|}
\hline VARIABLE & 2008 & 2011 & 2014 & $\% \Delta 2008$ \\
\hline \multicolumn{5}{|l|}{ Structure } \\
\hline Total No. Vessels & 3,240 & 3,365 & 3,144 & $-3 \%$ \\
\hline No. of Inactive vessels & 1,758 & 1,777 & 1,460 & $-17 \%$ \\
\hline No. of Active vessels & 1,482 & 1,588 & 1,684 & $14 \%$ \\
\hline Vessel tonnage (thousand GT) & 16 & 17 & 16 & $0 \%$ \\
\hline \multicolumn{5}{|l|}{ Employment } \\
\hline Total employed & 1,376 & 1,449 & 1,384 & $1 \%$ \\
\hline Full Time Equivalent (FTE) & 264 & 324 & 345 & $31 \%$ \\
\hline \multicolumn{5}{|l|}{ Effort } \\
\hline Days at sea (thousand days) & 130 & 148 & 123 & $-5 \%$ \\
\hline \multicolumn{5}{|l|}{ Output } \\
\hline Landings weight (thousand tons) & 112 & 120 & 148 & $33 \%$ \\
\hline Landings value (EUR Million) & 26.3 & 34.7 & 48.7 & $85 \%$ \\
\hline
\end{tabular}

The small scale coastal fishing fleet consists of diversified vessels targeting mainly freshwater fish species; European whitefish, pike-perch and perch. In 2014, the total value of landings of small-scale fishery was EUR 11.5 Million, generating EUR 6.6 Million in Gross Value Added and reasonable Gross profit margin of 25\%. However there are a large number of low activity vessels and accounting the value of opportunity cost of capital of all these vessels turned the segment net profit negative.

Pelagic trawlers are divided into two length group segments, with the $24-40$ meter segment being the most important economically. The fleet targets Baltic herring and sprat and these vessels accounted for over 70 percent of the total value landed by the Finnish fleet and employed 73 FTE. On average, these vessels generate a landings income of EUR 1.3 Million and employing 3.5 FTEs. The fleet segment generated EUR 7.8 Million in Gross Value Added or EUR 107 thousand per FTE. In 2012-2014 the Gross profit margin was $20 \%$ that was just high enough to cover the estimated opportunity cost of capital and the fleet was making zero profits (Table 23).

Figure 14: The development of number of vessels in the Finnish small scale coastal fishing fleet and large scale trawler fleet 2008-2014

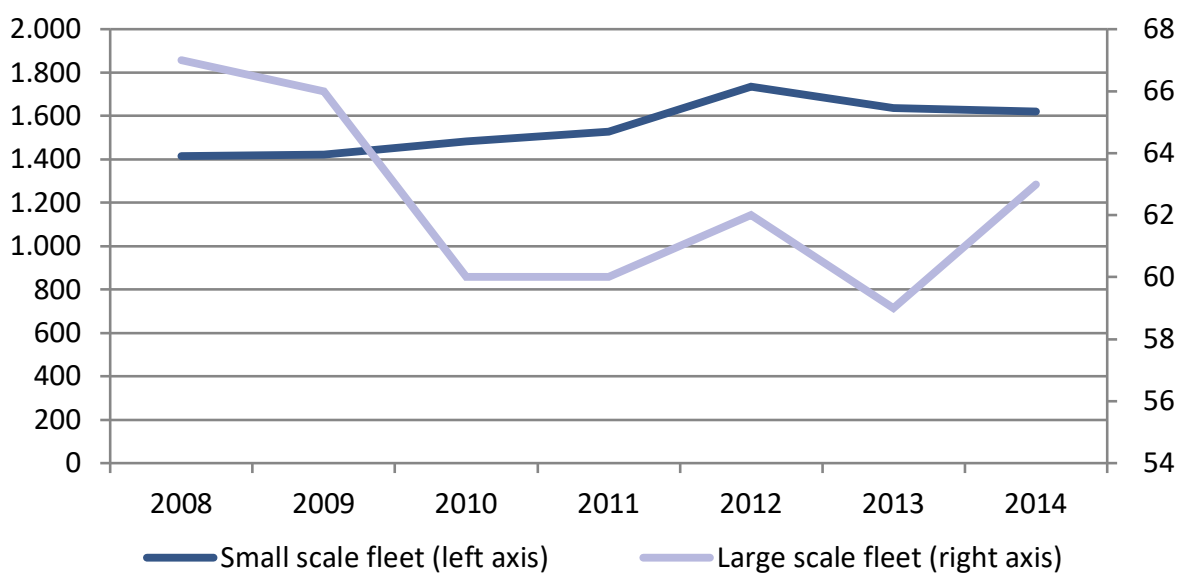


The number of vessels has remained rather stable during the last 10 years. Number of trawlers was decreasing but the anticipation of the planned ITO system turned the development (Figure 14).

\subsubsection{The Finnish pelagic trawler fleet}

Table 23 presents the basic data of the Finnish pelagic trawler fleet used in the initial setting of the modelling. In $2013-2014$ there were 63 vessels that are divided into two segments: under and over 24 meter. The number of Finnish pelagic trawlers has been fairly stable during the past years (Figure 14).

Table 23: Data of the Finnish trawler fleets included in the model, 2012-2014

\begin{tabular}{|c|c|c|}
\hline & $\begin{array}{r}\mathrm{TM} \\
<24 \mathrm{~m}\end{array}$ & $\begin{array}{r}\mathrm{TM} \\
>24 \mathrm{~m}\end{array}$ \\
\hline \multicolumn{3}{|l|}{ Physical data } \\
\hline Full Time Employment per segment & 33 & 77 \\
\hline Number of vessels & 41 & 22 \\
\hline No. of Sea Days per vessel & 60 & 150 \\
\hline Most important species (value) & HER $(92 \%)$ & HER ( $91 \%)$ \\
\hline Second important species (value) & SPR $(8 \%)$ & $\operatorname{SPR}(9 \%)$ \\
\hline \multicolumn{3}{|l|}{ Account data (1000 EUR per vessel) } \\
\hline Turnover & 175 & 981 \\
\hline Fuel Costs & 15 & 395 \\
\hline Labour costs & 54 & 147 \\
\hline Variable costs & 7 & 79 \\
\hline Fixed costs & 52 & 176 \\
\hline Capital costs & 10 & 164 \\
\hline Opportunity labour cost & 24 & 195 \\
\hline Opportunity capital cost & 57 & 267 \\
\hline Financial Net Profit & 37 & 21 \\
\hline Socio-economic return & 61 & -130 \\
\hline
\end{tabular}

Table 23 shows that Finnish pelagic trawlers are exclusively fishing for herring and sprat. The fishery is currently profitable, but only smaller trawlers are creating resource rent while larger trawlers show negative socio-economic return when considering the opportunity costs of production factors: labour and capital. This indicates that the larger trawler segment is not economically sustainable in the long term. However, one should notice that this data is from the race fishing period, when fishermen targeted highest possible catches in order to receive large individual quotas for future fishing

Currently the pelagic stocks in Baltic Sea harvested by Finnish fleet are at the MSY level. Especially the strong state of herring stock in the most important fishing ground for Finnish fleet, Bothnian Sea, have resulted record high catches year by year even the annual Total Allowable Catch was not fully utilized. 


\subsection{Results}

This section presents the FishRent model simulations after introducing ITO system in the Finnish pelagic fisheries until 2025 for the five scenarios presented earlier. However the scenario 2 is not relevant for the Finnish case due to the fact that the current ITO management does not have any restrictions on quota trade between segments; therefore the scenario 2 results are the same as those in scenario 1 and hence not presented here. Thus, the scenarios for the Finnish case are:

1. Current management in Finland: ITQs and $4 \%$ limit on yearly adjustment in number of vessels in each segment;

2. Free ITO trade between segments, not presented for the Finnish case;

3. Current management with full adjustment and no limit on yearly fleet adjustment;

4. Scenario 1 with taxes on $10 \%$ of prices.

For each scenario model simulated the fleet and economic development maximizing the socio-economic return accounting for opportunity costs for capital and labour and the financial profitability with actual capital and labour costs respectively.

\subsubsection{Socioeconomic return}

Here we present the model results where the socioeconomic return from the fishery is maximized. In here we consider the opportunity costs of labour and capital and hence the resource rent generated by the fleet. The development of the fleet capacity, employment, and socio-economic return between 2015 and 2025 are presented in Table 24 below. 
Table 24: Forecast of socio-economic return, fleet, and employment in 2025 by maximizing socioeconomic returns

\begin{tabular}{|c|c|c|c|}
\hline Scenarios & $\begin{array}{r}\text { TM } \\
12-24 \mathrm{~m}\end{array}$ & $\begin{array}{r}\text { TM } \\
>24 \mathrm{~m}\end{array}$ & Total \\
\hline \multicolumn{4}{|l|}{ Socio-Economic return (mill EUR) } \\
\hline 2015 initial situation & 0.85 & -2.86 & -2.02 \\
\hline \multicolumn{4}{|l|}{2025 scenarios: } \\
\hline 1. Current management & 3.46 & -0.96 & 2.49 \\
\hline 3. Current management full adjustment & 3.61 & 3.10 & 6.71 \\
\hline 4. Current management constant recruitment & $4 \cdot 51$ & 1.53 & 6.04 \\
\hline 5. Current management $10 \%$ landing tax & 3.46 & -0.96 & 2.49 \\
\hline \multicolumn{4}{|l|}{ Number of vessels } \\
\hline 2015 initial situation & 41 & 22 & 63 \\
\hline \multicolumn{4}{|l|}{2025 scenarios: } \\
\hline 1. Current management & 27 & 15 & 42 \\
\hline 3. Current management full adjustment & 27 & 5 & 31 \\
\hline 4. Current management constant recruitment & 32 & 15 & 47 \\
\hline 5. Current management $10 \%$ landing tax & 27 & 15 & 42 \\
\hline \multicolumn{4}{|l|}{ Employment (full-time) } \\
\hline 2015 initial situation & 33 & 77 & 110 \\
\hline \multicolumn{4}{|l|}{2025 scenarios: } \\
\hline 1. Current management & 22 & 51 & 73 \\
\hline 3. Current management full adjustment & 21 & 16 & 37 \\
\hline 4. Current management constant recruitment & 26 & 51 & 73 \\
\hline 5. Current management $10 \%$ landing tax & 22 & 51 & 73 \\
\hline
\end{tabular}

In the initial situation the Finnish pelagic trawler fleet is making overall negative profits i. e. the fleet as whole is not creating resource rent that indicates a long term unbalanced fleet with the fishing opportunities available i.e. economic overcapacity: gross profit generated by the fleet does not cover the opportunity cost capital and labour. However the smaller trawlers are generating positive resource rent and therefore evidently in balance.

Scenario 1 presents the outcome of introducing ITOs with a 4 percent annual limitation of fleet restructuring. The results show that in 10 years the number of vessels have decreased one third from the initial number. However in 2025 due to the adjustment limitation the larger trawler fleet is far from long term equilibrium size and will continue to decrease as seen in the scenario 3 below. At the same time the profitability has improved significantly and the total socioeconomic return has turned positive indicating that the fleet is generating resource rent. Once again the larger trawlers are not making positive result. The employment follows the trend of fleet size with a drop of one third.

Scenario 3 shows the results without restriction on the speed of adjustment that is relevant for the Finnish case where the ITQ system is just introduced. Therefore the ten year simulation allows a marked restructuring of the fleet and the number of vessels drop further down to half of the initial level. Now also the larger trawlers are settled to the long term equilibrium size same as the smaller vessels. The drop of fleet size down to half follows the experiences of introduction of ITQs in other Nordic countries: Sweden and Denmark. 
The profitability improved significantly with improved efficiency of the fleet. Now also the larger trawlers are generating a generous resource rent - almost 40 percentage of the revenue. The whole fleet is generating EUR 7 Million resource rent and contributing to the society total value of EUR 9 Million in net value added: that is benefit to society as income in terms of resource rent and wages.

In scenario 4 where 10 percent landing tax is introduced the socioeconomic return is by definition the same as in scenario 1 since this is the maximum possible economic return from the fishery for society as whole. This would mean that the society would in this case tax EUR 2 Million out from resource rent of EUR 2.5 Million in 2025. It would be heavy burden for the sector in the beginning but after full adjustment the improved profitability generating profits of EUR 7 Million (see in scenario 3 ) would counterbalance the burden of additional tax. In this scenario, it is assumed that fishermen do not change behaviour due to taxation and thus allocate resources in order to maximize the socioeconomic return. The private profit will however change, as discussed below. 
Figure 15: Development in Socio-Economic Return (top) and Profit (bottom) in each of the two projections

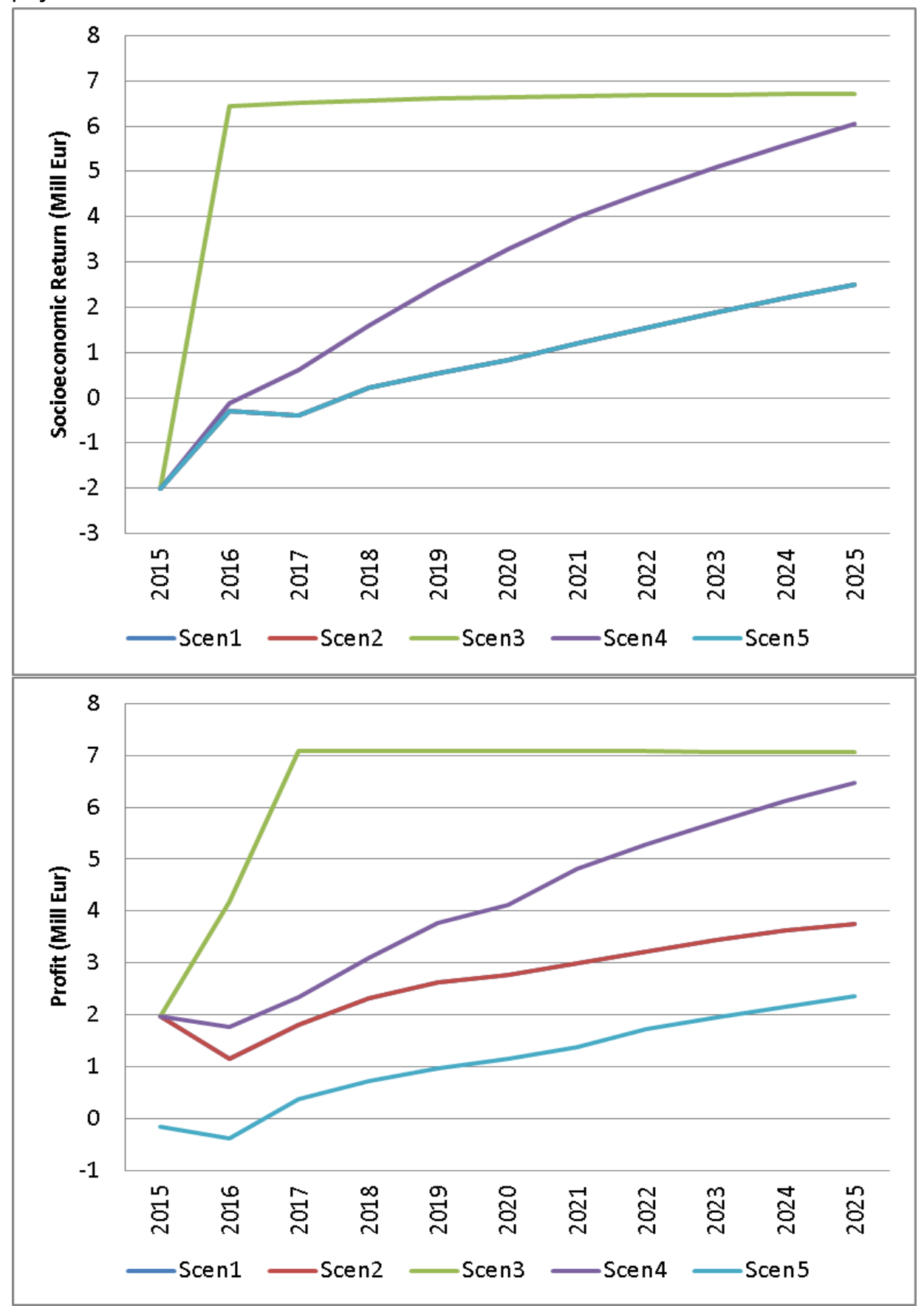




\subsubsection{Financial profitability}

In here we present the simulation results for financial profitability maximization that relates to actual costs paid by fishing enterprise from the initial reference year. The development of the fleet capacity, employment, and socio-economic return between 2015 and 2025 are presented in Table 25 below.

Table 25: Forecast of profit, fleet and employment in 2025 by maximizing financial profit

\begin{tabular}{|c|c|c|c|}
\hline Scenarios & $\begin{array}{r}T M \\
12-24 \mathrm{~m}\end{array}$ & $\begin{array}{r}\mathrm{TM} \\
>24 \mathrm{~m}\end{array}$ & Total \\
\hline \multicolumn{4}{|l|}{ Financial return (mill EUR) } \\
\hline 2015 initial situation & 1.52 & 0.46 & 1.98 \\
\hline \multicolumn{4}{|l|}{2025 scenarios: } \\
\hline 1. Current management & 3.63 & 0.11 & 3.74 \\
\hline 3. Current management full adjustment & 3.73 & 3.33 & 7.06 \\
\hline 4. Current management constant recruitment & 4.40 & 2.08 & 6.48 \\
\hline 5. Current management $10 \%$ landing tax & 2.87 & -0.50 & 2.37 \\
\hline \multicolumn{4}{|l|}{ Number of vessels } \\
\hline 2015 initial situation & 41 & 22 & 63 \\
\hline \multicolumn{4}{|l|}{2025 scenarios: } \\
\hline 1. Current management & 36 & 15 & 51 \\
\hline 3. Current management full adjustment & 42 & 5 & 47 \\
\hline 4. Current management constant recruitment & 33 & 15 & 48 \\
\hline 5. Current management $10 \%$ landing tax & 32 & 15 & 47 \\
\hline \multicolumn{4}{|l|}{ Employment (full-time) } \\
\hline 2015 initial situation & 33 & 77 & 110 \\
\hline \multicolumn{4}{|l|}{2025 scenarios: } \\
\hline 1. Current management & 29 & 51 & 80 \\
\hline 3. Current management full adjustment & 33 & 18 & 51 \\
\hline 4. Current management constant recruitment & 27 & 51 & 78 \\
\hline 5. Current management $10 \%$ landing tax & 26 & 51 & 77 \\
\hline
\end{tabular}

Introducing ITQs lead to a major restructuring of the fleet same as in the socioeconomic analysis. In scenario 1 the outcome for larger trawlers in number of vessels is the same as in previous analysis. However the decrease of small trawlers is slightly more lenient than in socioeconomic scenario due to a reasonable good profitability of the segment. Respectively the economic performance improve but not in the same extent as earlier. However the smaller trawlers gain a marked improvement in profitability while the larger ones are worse of in 2015 before the full adjustment to the long term equilibrium.

Scenario 3 shows the full adjusted situation where the number of small trawlers has increased by one vessel but larger ones are reduced to 5 . However due to the improved efficiency of the large trawlers the profitability increased to the same level as that in smaller trawlers. Total net profit realized of the fleet raised to EUR 7 Million. Again employment follows the number of vessels and is halved from the initial situation in 2015 .

Regardless of underutilized herring quota the increased fishing opportunities improve the economic performance significantly from the scenario 1 situation. Now the smaller fleet segment decreases in numbers slightly and the improved profitability resulted in net profits of EUR 4 Million, higher than in the full adjustment scenario 3. 
Larger trawlers fleet remains the same size as in scenario 1 but the profitability improved significantly to EUR 2 Million.

In scenario 4 with $10 \%$ landing tax together with ITOs (with $4 \%$ limit on yearly adjustment in number of vessels in each segment as scenario 1) improves the profitability compared to initial situation. However compared to scenario 1 profits are lower due to the taxes. By 2015 the smaller trawlers make net profits of EUR 3 Million that is lower than that in scenario 1 and the larger trawlers result turned negative. However in longer run after full adjustment the larger trawlers become very profitable. Total tax revenue to society is EUR 3 Million that will in the long run be well counterbalanced by the improved profitability that increase to EUR 4 Million after tax.

\subsection{Policy considerations}

The fundamental objective of the Common Fishery Policy is the balance between the fishing capacity and fishing opportunities. Evidently the Finnish fleet has operated for long time at zero profit level that was enabled by the fisheries management. This has leads to slowly decreasing and aging fleet. The ITO system was introduced in the pelagic fisheries in the beginning of 2017 and this created a framework for the fleet to restructure and achieve a long term sustainable fleet both in economic and biological sense.

The results suggest that the balance will be achieved. Evidently the results rely on the assumptions that the model is based. However in the bio-economic model used all scenarios in both socioeconomic and financial analysis showed improved profitability with decline in number of vessels. At the same time the spawning stock biomass was rebuilt to enable more efficient fishing. The results follow the economic theory that supports more conservative fishery management than that following the MSY stock level.

In general the outcome of different scenarios in two analyses follow each other quite closely, especially the full adjusted outcomes are similar. In the long run after full adjustment both segments are creating reasonably high resource rent. And even introducing landing tax that would be heavy burden in the beginning would in the end be outweighed by the improved profitability. The tax revenue would be around EUR 2 Million while the improved profitability would increase the resource rent to EUR 6.5 Million.

The forecast induce a choking situation, due to the full uptake of the sprat quota while herring quota was still available. This resulted from the model assumption of fixed catch composition. In practice fishermen can influence the catch composition: studies show that sprat by-catches are highly dependent on area and season. Furthermore, ITO systems by definition facilitate opportunity of efficient catch composition if the quota markets are efficient: those with highest marginal profitability had highest willingness to pay for adequate by-catch quota and with efficient ITO market would allocate the harvesting efficiently.

Summa summarum: the results here support that the ITO regime introduced in Finnish pelagic fisheries will enable the fisheries to achieve the objective of long term biologically and economically sustainable fishery with balance in fishing capacity and fishing opportunities. 


\section{Swedish large-scale pelagic fisheries}

\subsection{Introduction}

The Swedish case study contains an analysis of large-scale pelagic fisheries. This pelagic fleet is currently the only Swedish fleet managed with ITOs. The ITO system was introduced in 2009 in a situation where the fleet was characterized by overcapacity and low economic performance (SWaM, 2014). The purpose with the ITO system was to improve the structure of the fleet which should contribute to an economically, environmentally, and socially sustainable fishery. Less efficient fishermen should be provided with a way out of the fishery without public support. Also, the reform was intended to improve the timing of landings to match the demand from the processing industry. However, while the purpose of the ITO reform was to change the structure of the fleet there was still some features of the existing fleet that was considered important to maintain also after the reform. Thus, coastal fisheries were left out of the system and special rules were applied to parts of the Baltic Sea fleet in order for the fleet to keep landing in Baltic harbours.

The case study is performed by Staffan Waldo and Cecilia Hammarlund, AgriFood Economics Centre, Department of Economics, SLU, Sweden

\subsection{Literature review}

Several studies of the Swedish large-scale pelagic fisheries and the ITO system have been published. The poor economic performance of the pelagic fleet before the ITO system was studied by Nielsen et. al (2012) who found the resource rent in the fishery to be low ( $3 \%$ of catch value) despite a high potential. The result was compared to a set of other management systems in Nordic countries where higher performance was shown for the Icelandic ITO system (30\%), a Danish small-scale co-management system for mussels (51\%), and the Faroese system with tradable fishing days (28\%).

Two public evaluations of the pelagic ITO system have been made; one by the Swedish Agency for Marine and Water Management (SwAM, 2014) and one by the Swedish Parliament (2017). SwAM (2014) finds that the number of vessels in the pelagic fishery has been reduced with $55 \%$ between 2009 and 2013. In the same period, the overall decrease in the Swedish fleet was about 12\%. The decrease in the pelagic fleet was larger for vessels above 24 meters than for those below. The regional distribution of pelagic vessels has not changed significantly during the ITO system. Of special political interest is the potential concentration to the Gothenburg area, where the 
evaluation shows that the share of the fleet from Gothenburg has decreased somewhat from about $58 \%$ in 2008 to $54 \%$ in 2013 . Increasing the economic performance of the pelagic fleet was one of the objectives of the system, and the segment currently has the highest value added and the highest return on invested capital in the Swedish fleet (SWAM, 2014).

The evaluation by SwAM has been criticized by Stage et al. (2016) for not performing a counterfactual analysis, i.e. an analysis of the performance of the pelagic compared to a fleet where the ITO system had not been introduced. This would be necessary in order to separate the effects of the ITO system from other effects such as changes in other regulations, stock development and price levels. The authors also put forward a number of deviations from the "classic" ITO model that have affected the possibility of the Swedish ITO system to achieve the main objective of re-structuring the fleet. The deviations are the limitation of the system to ten years, the possibility for pelagic fishermen to enter other fisheries, ownership caps on quotas (maximum allowed shares of quotas), that ITOs are not possible to use as collaterals for bank loans, and the role of the coastal quotas.

The Swedish Parliament (2017) concludes in their evaluation that the pelagic fleet is currently economically viable. Further, the objectives that the ITO system should reduce fleet size and enable improved possibilities to match landings with the demand from the processing industry have been met. The evaluation stresses the importance of the continued existence of small-scale fisheries and local landings serving local markets. They do not find the system to solve problems with access to local landings of pelagic species, and stress the importance of the special quotas set aside for small-scale coastal fisheries ("coastal quotas"). Further, the authors conclude that new fishermen (not previously involved in pelagic fisheries) face increased barriers for entering the pelagic fishery due to necessary investments in quotas.

The coastal quotas set aside to small-scale fishermen have been analysed by Waldo et al. (2013) in a case study on the western Baltic Sea herring fishery with gill-nets. This fishery takes place in the Öresund between Sweden and Denmark and was originally allocated about $5 \%$ of the Swedish quota in 2007 . Coastal quotas are fished jointly by all coastal fishermen. The quota was attractive at the time and fishing increased, especially in the early season in the southern part of the sound. The traditional fishermen landing in the northern parts of the Öresund in late autumn receive about $30 \%$ higher prices since they sell on the market for Christmas herring, but faced quota restrictions due to competition for the joint quota. As a response the SwAM increased the coastal quota successively step by step until 2010 where it reached $20 \%$, after which the share has been fixed.

Björk (2017) study the efficiency of quota trade using network analysis. She shows that trade with permanent quotas was more frequent in the early years of the system, while leasing is more frequent in recent years. She also finds a concentration of quotas to the Swedish west coast. This shows the potential regional imbalance in quota trade that was the motivation for assigning regional non-transferable quotas (these are not part of the analysis). Björk further point out that there is a lack of a transparent market for quota trade that will cause inefficiency since prices paid are private information. This 
increases transactions costs and the results show that trade is more likely to occur between actors that are more likely to physically interact (geographically close and have the same distribution channels) which reduces transaction costs. A less transparent market with high transaction costs might cause inefficient trading patterns. Thus, despite a high degree of reduced capacity during the initial phase of the Swedish ITO system there might be a potential for further rationalizations within the pelagic fleet.

\subsection{Management}

Sweden is part of the European Union, and thus all Swedish fisheries management is within the framework of the Common Fisheries Policy. An important aspect of the Common Fisheries Policy is to find a balance between fleet capacity and fishing opportunities, and the Common Fisheries Policy states that the member states can choose its own measures to achieve this objective (EU, 2013; Article 22). The Swedish government has chosen ITQs for the pelagic fleet, and has opened for an expansion to other fisheries although the system has not been expanded yet. A system with leasable quotas has, however, been introduced in the demersal fishery in 2017 (SWAM, 2016) mainly as a response to the landing obligation adopted in the Common Fisheries Policy (Article 15).

\subsubsection{The pelagic ITQ system}

Before the ITO system the pelagic fishery was managed by vessel catch limits designed as short term quotas lasting for two weeks at the time. Unutilized fish was returned to a common quota and redistributed among all fishermen. When the total Swedish quota was filled, the fishery was stopped (Nielsen et al., 2012). As a transition to ITQs, a system with individual non-transferable quotas was introduced in 2007 , followed by the ITQ system in September 2009 (SFS 2009:866).

Transferable quotas have been introduced for herring, sprat, mackerel, Sand eel, and Blue Whiting. Since Swedish fisheries are geographically dispersed, this includes several quotas in both the Baltic Sea and the North Sea for herring and sprat. Quota trade is only possible among licensed fishermen, i.e. it is not possible for individuals or companies outside the fishing sector to own quota. To avoid ownership concentration, a cap of $10 \%$ of the total quota is applied.

An important feature of what is commonly called "the pelagic system" is that the Swedish pelagic quotas are divided into three parts. The first, and major, part is allocated to individuals and potentially traded within the system. The second part is a "coastal quota" that is set aside for coastal fisheries. This part of the quota is jointly utilized by small scale vessels primarily using gill-net, although small-scale trawling is allowed in some cases. These vessels are not allowed to simultaneously own tradable quotas. The share of total quota set aside for coastal fisheries vary with stocks, ranging from $0.5 \%$ to $20 \%$ of the total quota. The third part of the quota is a regional share for 
Baltic Sea vessels. This part is allocated to vessels that fish in the Baltic Sea and land in Baltic Sea harbours. These vessels are larger than the coastal vessels and are included in the ITO part of the pelagic system, although the additional regional quotas they get are not tradable. The regional quota is approximately $10 \%$ for Baltic sprat and $15 \%$ for Baltic herring.

\subsection{Data}

This section contains two parts. The first is a background describing the Swedish national fleet including a historical review of the development of the fleet. The second part focuses on the pelagic fleet (i.e. large-scale pelagic vessels included in the ITO system) and contains the data used in the economic modelling.

\subsubsection{The Swedish national fleet}

Swedish fisheries consist of both marine and fresh water fisheries. The fisheries in marine water landed about 172 thousand tons of fish and crustaceans in 2014, where a majority (61\%) was caught in the Baltic Sea (Statistics Sweden 2015a). The total catch value in 2012 was EUR 77 Million (SEK 700 Million, exchange rate 2014 is SEK/EUR 9.1), where herring, sprat, cod, Norwegian lobster, and North Sea shrimp are economically important species. The fresh water fishery is considerably smaller; total landings in 2014 were 1,598 tons at a total value of EUR 9 Million (SEK 82.7 Million; Statistics Sweden, 2015b).

The development of the Swedish national fishery from 2002 to 2014 is presented in Table 26.

Table 26: The Swedish national fleet, 2002, 2007 and 2014 and change between 2002 and 2014

\begin{tabular}{lllll} 
& 2002 & 2007 & 2014 & $\begin{array}{l}\text { \% change } \\
\text { 2002-2014 }\end{array}$ \\
\hline $\begin{array}{l}\text { Physical indicators } \\
\text { No. vessels }\end{array}$ & 1,818 & 1,527 & 1,266 & $-30 \%$ \\
Days at sea (DAS) & 122,300 & 152,700 & 77,700 & $-36 \%$ \\
DAS per vessel & 67 & 100 & 61 & $-9 \%$ \\
Tonnage (GT) & 44,900 & 43,300 & 29,000 & $-35 \%$ \\
Economic indicators & & & &
\end{tabular}

Source: Data for 2002 and 2007 are from The 2011 Annual Economic Report on the EU Fishing Fleet (STECF-1116). Data for 2014 is from The 2017 Annual Economic Report on the EU Fishing Fleet (STECF 17-12).

As is clear from the table, Swedish fisheries have a negative trend with fewer vessels, lower total tonnage, lower profitability, and less employment. 


\subsubsection{The Swedish pelagic fleet}

The number of vessels in the pelagic fleet dropped significantly after the introduction of the ITQ system in 2009 as is shown in Figure 16. After the initial drop in fleet size, the number of vessels has been stable around 35 .

Figure 16: Number of vessels in the pelagic fleet, 2008-2015

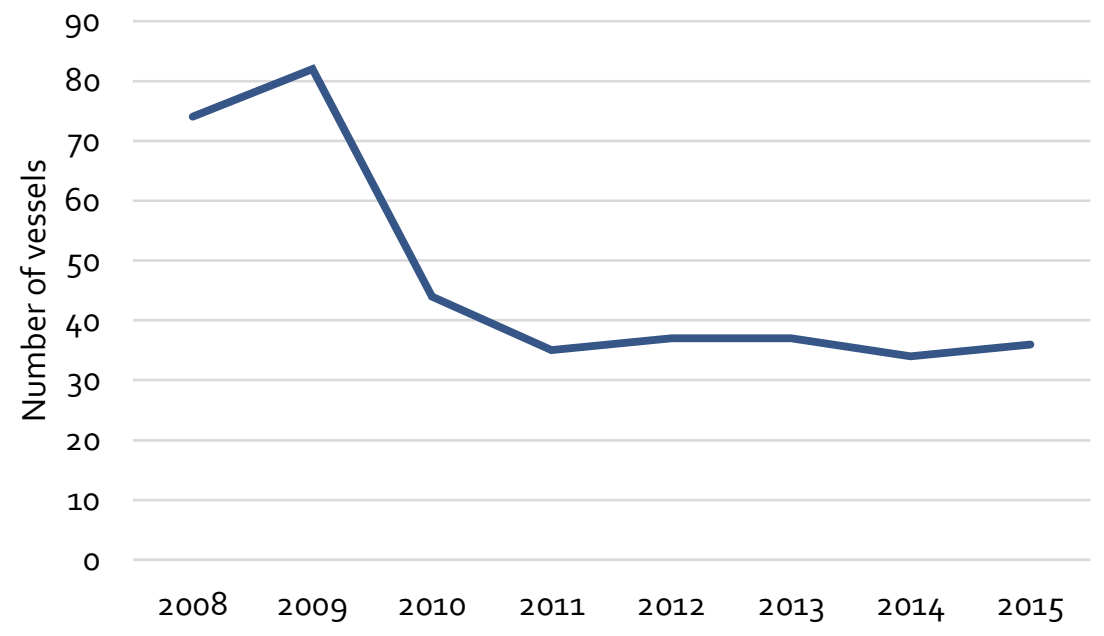

In the analysis of the segment only commercially active vessels are included. In 2013-2014 there were 30 such vessels as presented in Table 27. Data is split into vessels 18-24 meters and vessels that are larger than 24 meters.

Table 27: Data of the fleets included in the model, 2013-2014

\begin{tabular}{lrr} 
& PEL & PEL \\
& $18-24$ & \\
& & \\
Physical data & & \\
Full Time Employment per segment & 22 & 145 \\
Number of vessels & 9 & 20.5 \\
No. of Sea Days per vessel & 99 & 115 \\
Most important species (value) & HER (52\%) & HER (52\%) \\
Second important species (value) & SPR (21\%) & SPR (27\%) \\
Account data (10oo EUR per vessel) & & \\
Turnover & 412 & 2,355 \\
Fuel Costs & 73 & 484 \\
Labour costs & 119 & 338 \\
Variable costs & 116 & 410 \\
Fixed costs & 27 & 108 \\
Capital costs & 63 & 429 \\
Opportunity labour cost & 46 & 151 \\
Opportunity capital cost & 89 & 658 \\
Profit & 14 & 585 \\
Socio-economic return & 61 & 543 \\
\hline
\end{tabular}

The table shows that the most important species for both fleets are herring and sprat. Other important species, especially for the larger vessels, are mackerel and sand eel. The fishery is currently profitable, as opposed to the general trend for Swedish fisheries 
presented in Table 26 above. Notably, the opportunity cost for labour is lower than the accounting costs indicating that fishermen in the segments have higher income in fisheries than expected in alternative employment.

Total allowable catch and MSY fishing mortality is presented in Table 28 for each of the utilized stocks. Further, the stock size in relation to MSY b-trigger is presented. This is the biomass level that triggers ICES to recommend a fishing mortality below FMSY. The pelagic stocks utilized by the modelled fisheries are all above MSY b-trigger where this is defined.

Table 28: Biological data, 2015

\section{SSB (tonnes) TAC (tonnes) F-MSY Comment}

\begin{tabular}{lrrrl} 
Mackerel & $4,886,564$ & $1,229,000$ & 0.22 & Stock above MSY B-trigger. \\
Herring Autumn & $2,215,525$ & 445,000 & 0.27 & Kattegat, Skagerrack and North Sea. Stock size undefined for MSY B-trigger. \\
Herring Spring & 129,845 & 65,800 & 0.28 & Kattegat, Skagerrack and Western Baltic Sea. Stock size above MSY B-trigger. \\
Sprat North Sea & 370,460 & 350,000 & 1.20 & Stock size above MSY B-trigger. \\
Sprat Baltic Sea & 889,000 & 240,200 & 0.29 & Stock size above MSY B-trigger. \\
Herring Baltic Sea & $1,013,132$ & 186,351 & 0.26 & ICES areas 25-29 + 32. Stock size above MSY B-trigger. \\
Herring Bothnian Bay & 773,747 & 158,000 & 0.15 & ICES area 30. Stock size undefined for MSY B-trigger. \\
\hline
\end{tabular}

Source: All data is from the ICES advice.

\subsection{Results}

This section presents the results from the model runs using the FishRent model. As presented earlier in the report, four scenarios have been considered for the analysis. Of these, scenario 2 has not been run for the Swedish case. The reason is that the scenario is defined as a relaxation about quota trade restrictions between segments. There are no such restrictions in the Swedish case. However, coastal and regional quotas will be discussed in the discussion section, although it has not been possible to explicitly model these. Thus, the specific scenario characteristics for the Swedish case are:

1. Current Swedish management. Maximum annual change in fleet size is $4 \%$;

3. Current Swedish management with unlimited fleet adjustment. The change in fleet size is not limited;

4. Current Swedish management with a $10 \%$ landing tax. This scenario is the same as scenario 1 , but the fishery is taxed with $10 \%$ of the landing value.

Each of the scenarios are runs calculating the socio-economic return and the profitability respectively. 


\subsubsection{Socioeconomic return}

This section contains the model results where the socioeconomic return from the fishery is maximized. The result for 2015 and 2025 for the fleet size, employment, and socio-economic return is presented in Table 29 below.

Table 29: Forecast of socio-economic return, fleet, and employment in 2025 by maximizing socioeconomic returns

\begin{tabular}{|c|c|c|c|}
\hline Scenarios & $\begin{array}{r}\text { PEL } \\
18-24 \mathrm{~m}\end{array}$ & $\begin{array}{r}\text { PEL } \\
>24 \mathrm{~m}\end{array}$ & Total \\
\hline \multicolumn{4}{|l|}{ Socio-Economic return (mill EUR) } \\
\hline 2015 initial situation & 0.8 & 10.6 & 11.4 \\
\hline \multicolumn{4}{|l|}{2025 scenarios: } \\
\hline 1. Current management & 2.0 & 20.2 & 22.2 \\
\hline 3. Current management full adjustment & 2.1 & 23.9 & 26.0 \\
\hline 4. Current management $10 \%$ landing tax & 2.0 & 20.2 & 22.2 \\
\hline \multicolumn{4}{|l|}{ Number of vessels } \\
\hline 2015 initial situation & 9 & 21 & 30 \\
\hline \multicolumn{4}{|l|}{2025 scenarios: } \\
\hline 1. Current management & 8 & 17 & 25 \\
\hline 3. Current management full adjustment & 8 & 14 & 22 \\
\hline 4. Current management $10 \%$ landing tax & 8 & 17 & 25 \\
\hline \multicolumn{4}{|l|}{ Employment (full-time) } \\
\hline 2015 initial situation & 23 & 146 & 168 \\
\hline \multicolumn{4}{|l|}{2025 scenarios: } \\
\hline 1. Current management & 19 & 122 & 141 \\
\hline 3. Current management full adjustment & 21 & 99 & 120 \\
\hline 4. Current management $10 \%$ landing tax & 19 & 122 & 141 \\
\hline
\end{tabular}

Both segments show a positive socio-economic return in the initial situation. This implies that the fishery contributes to society with wages and return to capital that is larger than if the same resources were used in other parts of society. Notably, this was not the general case before the ITQ system, and many Swedish fleet segments outside the ITQ system still have negative socio-economic returns (Waldo and Wingård, 2010; Waldo and Paulrud, 2013). Further, the model predicts a substantial increase in the returns for the two fleet segments in 2025 . The reason for this is an expected improvement in stock development (i.e. stocks are closer to what is economically optimal) and an increased efficiency in the fleet, i.e. the fishery is in a situation closer to economic optimum. Increased efficiency could be due to improvements in the quota market (Björk, 2017) or due to better utilization of the vessels (more days at sea per vessel occurring when e.g. some fishermen choose to leave the fishery). The stock development implies that many stocks increase to (or even above) their historically observed maximum levels. This might not be biologically achievable simultaneously for all stocks, which is not considered in the model. Thus, the absolute values of the predicted socio-economic return should be viewed as an upper limit. In line with this, we do not further discuss the development compared to the current situation, but focus on comparisons between the different management scenarios discussed above.

Comparing the different scenarios, the first conclusion is that the fleet size is approximately the same in all cases ranging from 22 to 25 vessels. 22 is for scenario 3 where the model does not have any limitations on fleet development. This scenario also 
has the highest socio-economic return, EUR 26 Million. The result is due to the fleet rapidly adjusting to a long-run equilibrium fleet size that is economically more efficient than the current fleet. Such development has been observed historically in 2009-2011 when the ITO system was introduced. However, after that the fleet has adjusted only slowly and a rapid change in fleet structure is less likely to occur. Thus, scenario 3 can be viewed as the potential development in a fully efficient system. As modelled in scenario 1 , such changes might take time in practice, but could be expected to occur eventually.

Turning to scenario 4 , where $10 \%$ of revenues are taxed, the socioeconomic return is by definition the same as in scenario 1 since this is the maximum possible economic return from the fishery for society. However, in this scenario part of the rent is allocated to government through the landing tax. Total taxes would be approximately EUR 7 Million out of the EUR 22 Million in socioeconomic return. In this scenario, it is assumed that fishermen do not change behaviour due to taxation and thus allocate resources in order to maximize the socioeconomic return. The private profit will however change, as discussed below.

\subsubsection{Profitability}

This section contains the model results where the private profitability of the sector is maximized. The results showing the profitability of the sector in the different scenarios are presented in Table 30 below.

Table 30: Forecast of profit, fleet and employment in 2025 by maximizing profit

\begin{tabular}{|c|c|c|c|}
\hline Scenarios & $\begin{array}{r}\text { PEL } \\
18-24 \mathrm{~m}\end{array}$ & $\begin{array}{r}\text { PEL } \\
>24 \mathrm{~m}\end{array}$ & Total \\
\hline \multicolumn{4}{|l|}{ Profit (million EUR) } \\
\hline 2015 initial situation & 0.24 & 11.41 & 11.65 \\
\hline \multicolumn{4}{|l|}{2025 scenarios: } \\
\hline 1. Current management & 0.79 & $19 \cdot 33$ & 20.11 \\
\hline 3. Current management full adjustment & 0.44 & 22.67 & 23.11 \\
\hline 4. Current management $10 \%$ landing tax & 0.58 & $15 \cdot 42$ & 16.00 \\
\hline \multicolumn{4}{|l|}{ Number of vessels } \\
\hline 2015 initial situation & 9 & 21 & 30 \\
\hline \multicolumn{4}{|l|}{2025 scenarios: } \\
\hline 1. Current management & 6 & 17 & 23 \\
\hline 3. Current management full adjustment & 2 & 15 & 17 \\
\hline 5. Current management $10 \%$ landing tax & 6 & 17 & 23 \\
\hline \multicolumn{4}{|l|}{ Employment (full-time) } \\
\hline 2015 initial situation & 23 & 146 & 168 \\
\hline \multicolumn{4}{|l|}{2025 scenarios: } \\
\hline 1. Current management & 15 & 123 & 137 \\
\hline 3. Current management full adjustment & 5 & 105 & 110 \\
\hline 5. Current management $10 \%$ landing tax & 15 & 122 & 137 \\
\hline
\end{tabular}

Starting with the fleet development, the fleet is expected to decrease during the period. This is similar to the development in the model runs for socioeconomic returns. However, in scenario 3, where the fleet is allowed to develop without limitations, the reduction in the segment for vessels $18-24$ meters is more severe in the profit maximization case. In this case, the vessels are assumed to pay the crew a specific share 
of revenues as wages. This share is higher for the smaller vessels, and when the fleet is rationalized the wages per worker will increase more for the smaller vessels than for the larger. Thus, if labour contracts are not possible to re-negotiate, it might be more profitable to sell the quotas to fishermen with larger vessels.

Turning to profits, the profitability is lower than the socioeconomic returns in all cases. This might be due to several causes. One is that labour and capital has higher remuneration in the fishery than in alternative use, e.g. when workers are better paid than in other industries. This is a cost to the fishermen that will reduce profitability. Further, the fishermen will have to buy quotas if expanding their fishing which will reduce the private profits. The largest deviation from the socioeconomic return is for scenario 4 . In the case of private profits, the outcome is negatively affected by the taxes and the profits are thus considerably lower than for socioeconomic returns which include both private profits and tax revenues. In Figure 17, the socioeconomic return and profitability for each scenario are presented for the entire studied time period. 
Figure 17: Forecast of socio-economic return (top) and profit (bottom) 2015-2025, EUR Million
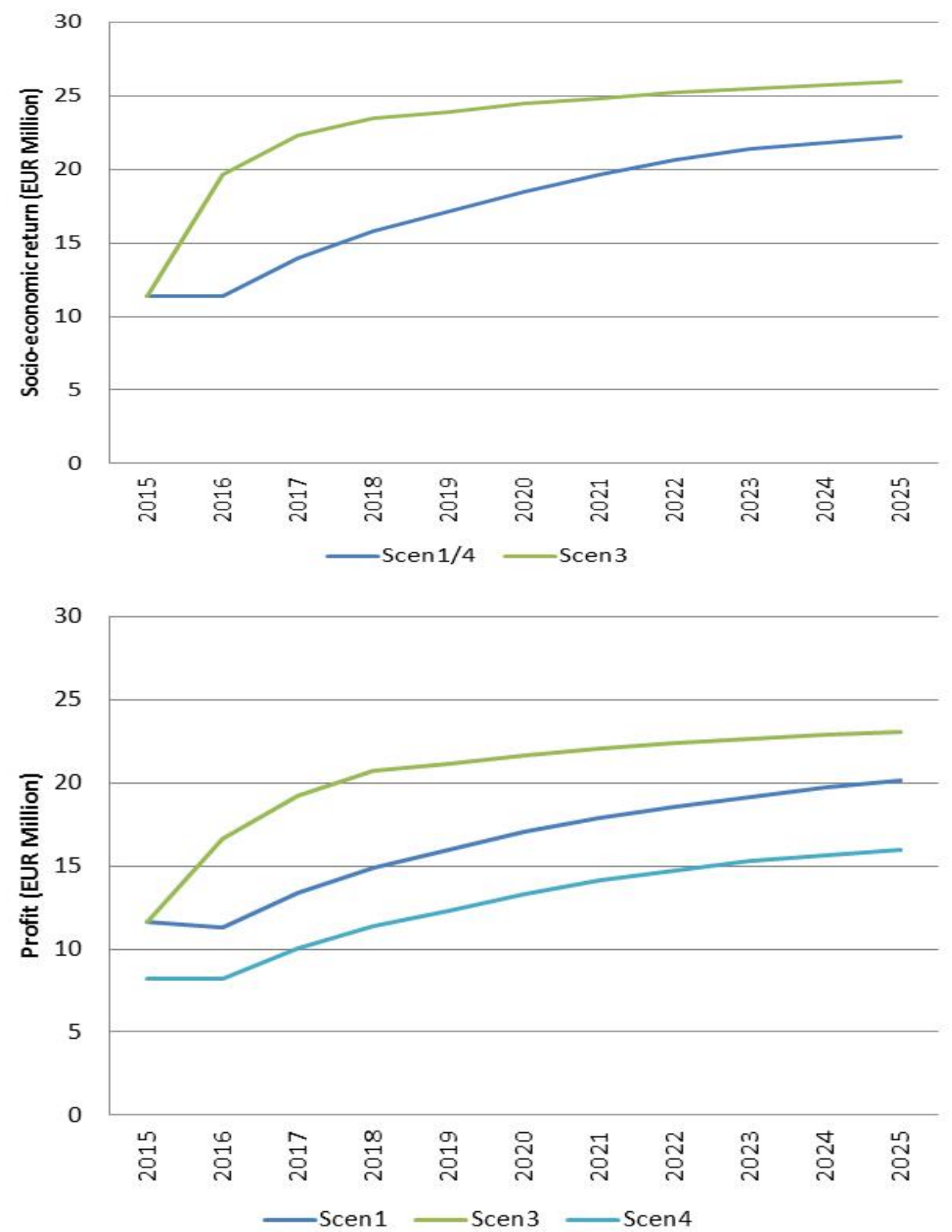

Both socioeconomic returns and profitability show very similar patterns, although the absolute values differ as discussed above. Scenario 3 has the highest values and deviates from the others by a much faster adjustment towards high profitability/socioeconomic returns. This is the scenario with no adjustment restrictions, and thus this could be viewed as an upper limit to possible adjustments. Scenario 4 is identical to scenario 1 for socioeconomic return, but for profit it is clear that the private profitability for a taxed fishery is below the other scenarios for all years. 


\subsection{Policy considerations}

A fundamental result from the analysis is that it supports the view of the Swedish ITO system generating an economically viable pelagic fleet. Before ITOs the fleet showed considerable over capacity and profitability was low. The purpose of the management system was to support a change in the fleet structure that would sustain fish resources and be economically and socially sustainable. The ITQ system has been evaluated twice since the introduction in 2009. SwAM (2014) concluded that "the effects observed in the pelagic system after the introduction of transferable fishing concessions do to a high degree coincide with the objectives of the system" (p31, author's translation). A few years later the Swedish Parliament (2017) concluded that "The purpose of the pelagic system with transferable fishing concessions has been fulfilled regarding changes in the fleet structure. The pelagic fishery has become more economically sustainable, but it is unclear if the fishery has become more environmentally and socially sustainable" ( $p$ 172, author's translation). Based on these evaluations, the pelagic system was made permanent in 2017 (Swedish government, 2017). The results from this study not only confirm that the fleet is economically sustainable, but also predicts that it will continue to be so over the studied period. The fleet is actually predicted to increase profitability over the studied period, but this depends on the possibilities of increasing stock sizes and further rationalizations of the fleet.

A profitable fleet contributes economically to society through the tax system. Tax revenues to society are thus expected to be higher today than before the ITO system when profitability was low. However, it is possible to further tax fishing companies motivated by the public ownership of the fish resource that is used for fishing. The result from scenario 4 shows that a $10 \%$ landing tax would reduce profitability in the sector, but that fishing patterns would stay approximately the same. The sector would still be profitable. Taxation has not been a major topic in the Swedish debate and it was not discussed in the process of making the system permanent in 2017. If introducing taxes in a mature ITO system (that is already decided to be permanent), it is important to take into account that additional taxation might be problematic for companies that have made major investments under the assumption of no taxation.

An important feature of the management system is the allocation of quotas to the Baltic Sea regional fleet, and the specific quotas for small-scale fisheries not modelled above. The purpose of the latter is to assure access to quota for the coastal fleet. The share depends on stock, but is most commonly only a few percentages of the total quota. An exception is the spring spawning herring in the western Baltic Sea where small-scale fisheries have been allocated a share of approximately $20 \%$. This system is strongly supported by the industry and the SwAM (2014) concluded that the small-scale fleet has been able to continue its fishing using this exception. The shares of the quotas allocated to small-scale fisheries have increased since the introduction of the ITO system. The size of the coastal quota is still discussed since this is an important aspect of the development of the small-scale fishing fleet. 
Recently, quota swapping between small- and large-scale fisheries has taken place in order to improve quota utilization. Regional quotas for the Baltic Sea pelagic fleet is allocated outside the ITO system, constituting $10 \%$ of sprat quota and $15 \%$ of the herring quota. Vessels with regional quotas may also own ITOs on top of the regional allocations, but the regionally allocated quotas are not possible to trade. The purpose of this is to maintain a pelagic fleet based in the Baltic Sea. According to SwAM (2014) the regional balance of the fleet has been maintained. From a theoretical perspective it could be argued that the regional quotas decrease economic efficiency in the fleet. Whether it is a preferred policy depends on the value of having a regional fleet, how important the regional quotas are for maintaining that fleet, and the economic loss of restricting trade.

In 2014 the Swedish parliament delegated to the government to decide whether ITQs should be introduced in other fleets than the pelagic (Prop. 2013/14:184). This opened for an extension of the ITQ system in the future. There is currently no decision to do this, but the SwAM has introduced a management system with individual leasable quotas for the demersal fishery. The background is the landing obligation decided in the 2013 reform of the Common Fisheries Policy (EU, 2013). In fisheries with multiple species caught at the same time, a landing obligation implies that all fishing must stop when the first quota is fully utilized. This is called a choke species. With common pool quotas, the incentive for the fishermen might be to fish as much as possible before this quota is full rather than investing in selective gear to avoid catching the choke species. Thus, individual quotas were allocated to all fishermen with the possibility of leasing quota on a yearly basis. Leasing was allowed for fishermen to be able to adjust their quotas to their catches in order to minimize the impact of choke species (SWAM, 2016). While it is clearly stated by the SwAM that this is not an ITO system and trading of permanent quotas is not allowed, it is still possible to own multiple vessels and it is possible to make long-term contracts on quota leasing. Thus, the system has some similarities with an ITO system. However, the new management system has not been in place long enough to see any long-term patterns with regard to this. If an ITO system is introduced in Swedish demersal fisheries it might increase profitability substantially, even if small-scale fisheries are protected by trade restrictions similar to those in the pelagic ITO system, as found in Waldo and Paulrud (2013).

Model results like the ones presented in this chapter should always be interpreted with caution since the development of the fleet and economic performance is highly dependent on assumptions. In the Swedish case the stock development for some of the stocks are very favourable and a combination of multiple stocks increasing might not be realistic from an ecosystem perspective. Thus, the development from today to the 2025 situation could be considered an upper limit. The strength of a model is the comparison between different scenarios. This shows how policy changes affect the sector under the same common development trends (e.g. stocks). In the scenario with instant adjustment, it is shown that there is a potential for further rationalization of the pelagic fleet that is less obvious in the other scenarios where the change in fleet adjustment is limited. Such efficiency gains might not be possible in the short run 
though, since current ownership structures, past fleet investments etc. set the baseline for the development until 2025. However, the model predicts that in the long run further rationalizations might take place. Also, potential changes in the system itself, such as the possibility to take bank loans based on quotas, might increase rationalizations.

The conclusion from the Swedish case study is that the pelagic fleet is economically viable and seems to continue being so during the studied period, although profitability in the sector will decrease if a landing tax is imposed. 



\section{Norwegian Groundfish Fishery North of $62^{\circ}$}

\subsection{Introduction}

The long Norwegian coastline is home to very rich fishing ground, making Norway one of the world's biggest fishing nation. The fishery sector has always played an important role both economically and socially, regionally and nationally, and has been important for settlement and employment along the Norwegian coast. In 2015 the total landings were $2,334,564$ tons, with a first-hand value of approximately NOK 16,928 Million (SSB 2016). In many coastal areas the fishing industry is very important, as a considerable number of people rely on the fishing industry for employment. There were in 2015 registered 5,884 fishing vessels in Norway, and 11,130 persons were register as fishermen, by these 9,259 fishing was the main occupation. Figure 18 shows the overall development in number of registered fishing vessels and persons occupied in fishing over time. As seen from the Figure the number of vessels and fishermen has decreased steady since the 1940 s. Despite the continued decline in number of vessels, overall engine power, and hence catching capacity is about unchanged. The reason is that the players invest in new vessels with larger catch capacity that replace the older and less efficient vessels

Figure 18: Development of vessels and fishermen 1945-2016

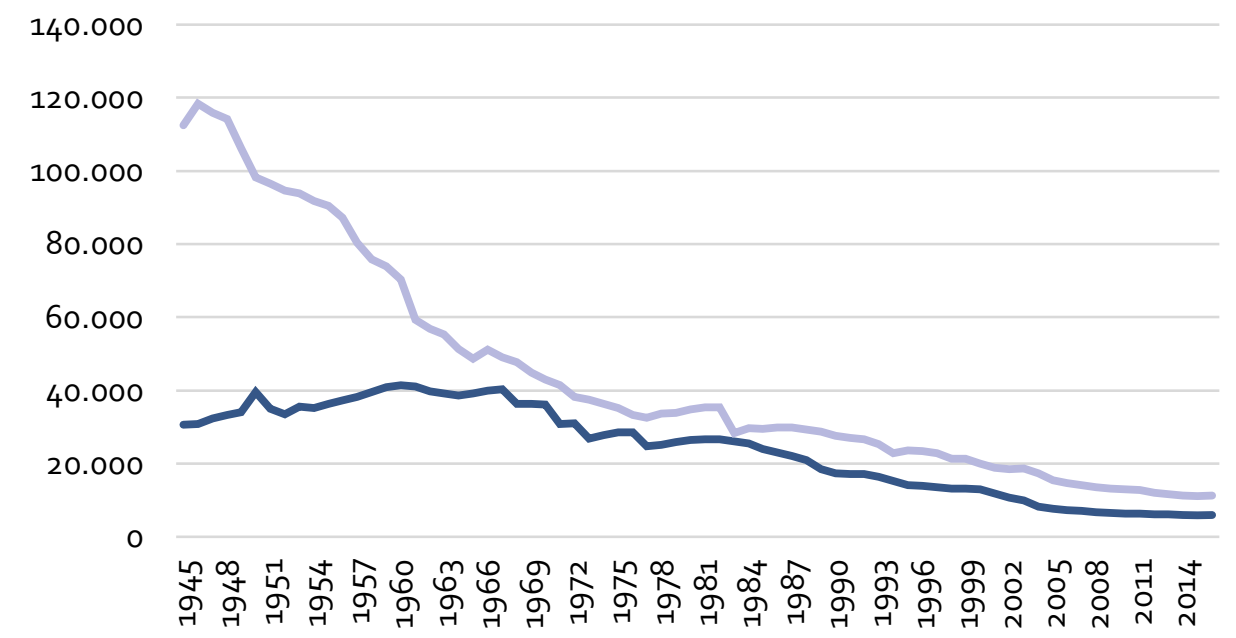

-Vessels Fishermen

Source: (SSB 2016). 
The main species in the Norwegian fishery include herring, cod, capelin, mackerel saithe, blue whiting and haddock. A number of additional species are caught in smaller quantities, but have high commercial values. The Norwegian fishing fleet is subdivided into two main fisheries; Demersal fisheries (i.e. cod haddock and saithe etc.) and pelagic fisheries (i.e. herring, mackerel, capelin, Norwegian pout and blue whiting etc.). While the pelagic fleet is largest in terms of landings, the demersal fishery is the most valuable. The Norwegian groundfish fisheries are by far the most valuable fisheries in Norway. They operate year-round, although with substantial seasonality in catches. Cod (Gadus morhua) is the main species, but large quantities of saithe, haddock, and Atlantic redfish are also harvested.

The fishing fleet working the ground fisheries is diverse, ranging from smaller coastal vessels fishing with gill nets, handlines, and Danish seines, to large, modern, oceangoing vessels. The ocean-going fleet is defined as vessels over go feet or 28 meters "hjemmelslengde", it is mainly trawlers and large conventional vessel using long-line. The conventional coastal vessels are the vessels under 28 meters, and load capacity below $500 \mathrm{~m}^{3}$ that uses mainly conventional gears to fish (such as nets, longlines, Danish seines, traps and hand lines) (NOU 16, 2006). While most of the coastal fleet operates in a relatively seasonal inshore fishery, the ocean-going vessels operate year-round in the North Atlantic. The ages of the vessels also differ substantially, leading to large variation in capital cost. Beside differences in size, gear type and age, individual vessel within this fishery are managed quite differently. Like most modern management systems, this fishery divides the fleet into groups. These groups are managed differently, to maintain fleet diversity and various social objectives, i.e. regional policy and planning.

The purpose of this chapter is to forecast the development in the Norwegian ground fishery North of $62^{\circ}$ until 2025 with the current management, and to assess the effect of possible future policy changes approaching 2025. We have chosen to focus on this fishery since it is the biggest fishery in Norway in terms of value, further it is highly diverse in terms of vessel size, management and gear utilized. In this study we are focusing on vessels from six different fleet segments; Trawlers, Conventional oceangoing vessels, and four length-groups of coastal vessels; and the four most important species: cod, haddock, saithe and herring.

The case study is performed by Kristin $\mathrm{H}$. Roll from the business school at University of South-Eastern Norway, Norway in collaboration with Ayoe Hoff from Institute of Food and Resource Economics, University of Copenhagen, Denmark.

\subsection{Literature review}

Several studies have been conducted to investigate different aspects of the Norwegian fishery management. Maurstad (2000) compare small-scale fishermen's practices before and after vessel quotas were introduced to Norway, and pose interesting questions concerning the models for resource management on which these regulations are based. Armstrong and Sumaila (2001) study the allocation rule (the trawl ladder) 
applied to split the Norwegian total allowable catch for cod between coastal and trawler vessels. Further, they explore the bioeconomic implications of an ITQ management system for this fishery. They find that an ITQ system for this fishery is likely to result in economic losses, as the biological advantages of harvesting with the two vessels types may be lost. Standal and Aarset (2008) analyse the Norwegian Individual Vessels Quota system and discuss whether the aggregate effects of the Individual Vessels Quota regime are congruent with the models' profound ideals of a diverse fleet structure and decentralized ownership of scarce cod resources. Guttormsen and Roll (2011) demonstrate how a heterogeneous fleet, both in terms of catch capacity and management regimes, can contribute to variations in vessel performance. The results indicate substantial variation in technical efficiency both between and within vessel groups and concludes that both managerial skills and an inefficient management regime contribute to heterogeneity in the Norwegian ground fish fleet. Gordon and Hannesson (2015) investigate the empirical impact of technological shocks on herring stocks in Norway. They illustrate that it was the unmanaged use of new technology (such as power block) in an unmanaged fishery that allow for the demination of the herring stock and argue that regulation of the new technology would have resulted in less stock depletion.

Hannesson (2013; 2014) argue that the fisheries management in Norway has some unmistakable characteristics of an ITO system. In the paper the development of this system in the purse seine fleet and the fleet fishing for cod and similar species is traced, and the concept of resource rent is discussed. The results show that the resource rent has become capitalized in quota values, which show up as a rise in value of long term assets of the fishing industry. This is further discussed in Hannesson (2016) where prices of fish quotas in Norway are estimated. It is found that quota prices in most cases exceed the resource rent and are more consistent with a willingness to pay for additional quotas bought to improve the utilization of existing equipment. Asche, Bjørndal, and Gordon (2009) also investigate rent generating proses for a fishery managed with individual vessel quotas - Norwegian trawlers with onboard processing. In a reason paper Pincinato et al. (2018) investigates the impact of transferable fishing quotas on cost, price and season length, for the smallest Norwegian coastal vessels.

Earlier studies have also compared the fishery management in the Nordic countries. Arnason, Hannesson, and Schrank (2000) investigate management costs in the fisheries of Iceland, Newfoundland and Norway and discusses the question of whether management costs should be paid by industry. Eggert and Tveterås (2013) analyses the Total Factor Productivity (TFP) performance of fisheries in Iceland, Norway and Sweden during the period 1973 to 2003. Their hypothesis is that rapid diffusion of fishing technology innovations contributing to productivity convergence, and that innovations in the public regulation and the industrial organization may also have influenced productivity growth during the period. The results reviled however, no evidence of productivity convergence among the three countries. 


\subsection{Management}

The aim of the Norwegian fishery management is two-sided; The goals of the regulations is not only to prevent overfishing and maintain a sustainable fishery, but also to ensure that fisheries play an important part in Norwegian regional policy and planning. (Guttormsen and Roll, 2010). Hence, the regulatory system has, to a certain degree, been developed to maintain coastal communities and traditional small-scale coastal fisheries, in addition to avoid the depletion of stocks.

Norwegian fisheries management system dates back to the 18-century. The regulations have however progressed gradually. Through interaction between industry and management, and trial and error teaching the Norwegian fishing industry has evolved into a highly regulated industry with both output- and input regulation. Input regulation means that the regulators restrict the access to fishermen, by restricting how many vessels that are allowed to participate, and also season length. It can also be technical regulations - such as gear restrictions. In Norway all vessels (except for a group of the smallest coastal vessels) require a license to participate in the fishery.

Output regulation means that regulators restrict how much fish that can be landed every year, by setting a Total Allowable Catch. In general, the quota system process starts with the Norwegian Government establishing the Total Allowable Catch for the main species for the domestic fleet based on ICES advice, which is supported by scientific stock assessments. The Total Allowable Catch is then allocated among the different fleet segments. For cod North of $62^{\circ}$ there are seven fleet segments. Figure 19 gives a simplified sketch of the quota allocation for Norwegian cod North of $62^{\circ}$ in 2016 (Nofima and Norwegian directorate of fishery). ${ }^{11}$ First the total Norwegian quota are divided between trawlers and conventional vessel. The Norwegian cod quota is allocated between trawlers and the conventional vessels using an instrument known as the "trawl ladder". The objective of this management tool is to give a high degree of predictability and stability to the smaller vessels, and hence contribute to Norwegian regional policy goals. The "trawl ladder" stabilizes the quota for coastal vessels by allocating coastal vessels a larger part of the total fishing quota in years with modest biomass than in years with higher biomass and higher total quota. If the total quota of cod is low, the trawlers get $27 \%$ of the quota, rising to $33 \%$ at high quota levels. This keeps coastal vessels yearly quota relatively stable compared to the larger vessels. Larger vessels are then granted a relatively smaller quota in years with a smaller total quota, and hence the size of their group quota fluctuates more than the total quota. The ladder is mainly based on historical rights between different gear and vessel groups. A similar system exists for Norwegian spring-spawning herring.

\footnotetext{
${ }^{11}$ For the distribution of the total quota, a smaller quantity is used for various purposes, such as recreational fishing, R\&D quota bonuses, etc. There is also a seventh regulatory group that is not included in the figure; an open group for conventional vessels with load capacity below $500 \mathrm{~m}^{3}$.
} 
Figure 19: Quota allocation for Norwegian cod North of $62^{\circ}$ in 2016

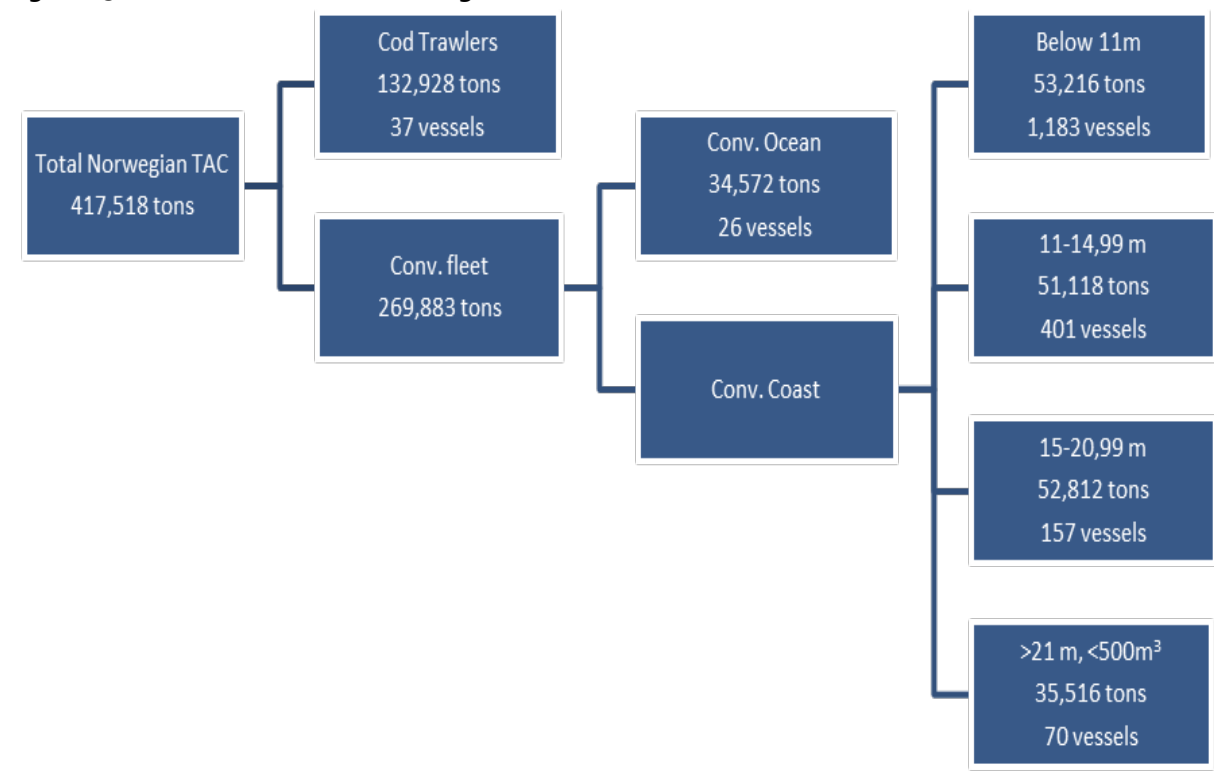

Source: Nofima and Norwegian Directorate of fishery.

The quota allocated to the conventional fleet are then subdivided between offshore and coastal vessels, before the coastal quota is subdivides into four different size groups. The background for the four-different size segment was to to shield the smallest coastal vessels and prevent the transfer of fishing opportunities from small to large vessels. Therefore, from 2003, the conventional gear vessels were grouped in four ranges size: 1) 8-9.9m, 2) 10-14.9m, 3) 15-20.9 and 4) 21-27.9m up to 2007, when a revision took place and rearranged the sizes to 1) $<10.9 \mathrm{~m}, 2) 11-14.9 \mathrm{~m}, 3) 15-20.9 \mathrm{~m}$, and 4) $21 \mathrm{~m}$ to a hull capacity of $500 \mathrm{~m}^{3}$. The classification of each vessel in these groups was based on their actual size in a specific date regardless later changes on the vessel. For the vessels smaller than 28 meter fishing for cod, the cutting date was on December 1998, while for the coastal vessels fishing for saithe and haddock that had access to participate in this group from 2003 the cutting date was on November 2002 (St. Meld 21).

The allocation of quota between different vessels within a group has varied over time. In the coastal fleet historical length is used as a criterion, while in the ocean going fleet weight and quota factors determine the distribution. As early as 1984 , a system with vessel-specific quotas was introduced for parts of the fleet. However, as the quota for a vessel group was smaller than the sum of the vessel quotas, the vessel quota primarily acted as the maximum catch for each vessel but without significantly reducing competition in the fishery. Further, the quotas have frequently been distributed in packages, which include several species (i.e. cod, saithe and haddock). This forces vessel to diversify instead of specializing on one species. The coastal fleet can, however, to some degree decide if they want to fish both whitefish and pelagic fish or if they want to specialize in one of the sectors, while ocean going vessels do not have the right to have quotas in both the whitefish and pelagic sectors. 
In order to reduce overcapacity and to increase the productivity in the sector two schemes were proposed by the Government: decommissioning and structural quotas. Structural quotas allow fishermen to transfer their vessel's quota to another vessel in the same group and region of the country. The premise is, however, that the vessel that sells its quota is actively removed from the fleet, and that the quota itself is returned to the resource base after a fixed period. In addition, an upper limit is set for how many quota factors each vessel could hold. By this system a vessel can acquire additional quotas and hence better utilize its capacity. As argued by Hannesson (2013) this system is similar to an ITQ system, but with more restrictions to it.

The trawlers were the first vessel group that implemented this system. From 1996, the vessel quotas added up to the total quota for the trawlers, and structural quotas were implemented. The aim of this system was to reduce overcapacity; however, according to Standal and Aarset (2008), as technological changes in the same period increased the capacity per vessel, capacity was not actually reduced. It was not until 2004, when quota tenure was increased, and smaller vessels were included in the same system, major capacity reduction took place. The first coastal vessel group to have a structural quota system were conventional coastal vessels over 14.9 meter in 2004. In 2006, the Government stopped processing new applications for the structural quota while evaluating this new measure. In 2007, after this review, also vessels over 10.9 meter were included under the structural quota system..$^{12}$ In 2007 there were also established a time limit for holding the structural quota. Structural quotas allocated before 2007 , can be hold for 25 years, while structural quotas awarded after 2007, can hold for 20 years.

To prevent geographical distribution and concentration of quotas among the largest and most capital strong players, the regulators has put some restrictions to this system. The quota exchange is limited to within the same vessel size group..$^{13}$ Therefore, if one vessel group develops a technology that makes it more efficient, it cannot obtain quotas from a less efficient vessel group to increase the efficiency of the total fishery. This restriction, which effectively prohibits changes in the composition of the fleet arising from vesselspecific innovations, has potentially led to a loss in efficiency for the industry as a whole. Further, the system also incorporates a regional preference as the quota exchange is limited to vessels within the same region. Southern vessels cannot buy quotas from northern vessels, but vessel owners in the northernmost part of Norway are allowed to buy vessels with quotas from the whole country. ${ }^{14}$ There is also an abbreviation of the quota transfer, as the regulator retains part of the quota from the removed vessel. When exchanged only $80 \%$ of the original quota is transferred to the buying vessel, while the remaining $20 \%$ is shared

\footnotetext{
${ }_{12}$ The smallest coastal group (vessels under 11 meter) are still not included in the structural quota scheme. This group is unattended because of their special importance for settlement, employment, geographical distribution and varied fleet structure. Instead of the structural quota scheme, this vessel group have instead an access to a "fish together" scheme. The "fish together" scheme indicate that two vessels in the closed group under 11 meters can share their quotas.

${ }_{13}$ This has one exception; quota transfer is possible between the two large trawler groups (factory trawlers and fresh/freeze trawlers).

${ }^{14}$ Southern located trawlers can buy quotas from Northern located trawlers, but the abbreviation is $60 \%$.
} 
among all the vessels in the same group for conventional ocean and coastal vessels. For trawlers there are no abbreviation for transferring of quota within a region.

Table 31: Structure status, 19 January 2016

Vessel group Quota roof (inkl. the vessels individual quota) Degree of structuring (\%)

$\begin{array}{ll}\text { Cod trawlers } & \text { Cod/haddock: } 61 \% \\ & \text { Saithe: } 62.5 \%\end{array}$

Conv. Ocean

Cod/haddock: 5 quota factors

Saithe: 2 quota factors

Cod: $68.9 \%$

Haddock: $70.6 \%$

Saithe: $41.8 \%$

Conv. Coast

For $15-27,99 m: 3+3$ or $4+2$

Cod: $33 \%^{1}$

Haddock: $33.6 \%^{1}$

For $11-14,99 \mathrm{~m}: 2+2$ or $3^{+1} \quad$ Saithe $: 33.6 \% \%^{1}$

Note: 1 . This includes all size groups within the conventional coast fishery, also vessel groups that are not part of the structure quota scheme.

Source: NOU2016: 26.

There are also limitations in how many structural quotas that can be allocated a single vessel. This "quota roof" is set separately by vessel group. Determining "quota roofs" is a dynamic process, where "quota roofs" change when efficiency and profitability advocates. The size of the quota factor also changes from year to year dependent of the total yearly quota. Table 31 gives the quota roof per 19 January 2016. The Table also reports the degree of structuring, which is the share of the total quota from structural quota. It is not possible to sell parts of the quota within a year, but there exist a number of schemes to remedy this lack of flexibility. NOU2016:16 summarize these structures in tidy manner.

\subsection{Data}

The data are provided by the Norwegian Directorate of Fisheries, which each year collects data for all vessels larger than eight meters. All whole-year operating vessels are legally obliged to complete and return the questionnaire together with their annual accounts and are hence include in our data. ${ }^{15}$

The fleet segments included in the analyses for the Norwegian case is:

- Conventional coastal fishing vessel below 11 meters "hjemmelslengde";

- Conventional coastal fishing vessels 11-14.9 meters "hjemmelslengde";

- Conventional coastal fishing vessels 15-20.9 meters "hjemmelslengde";

- Conventional coastal fishing vessel 21 meters long and above;

${ }_{15}$ Whole-year operating vessels are defined as vessels that landed fish in at least seven months in a year, and that have an income from fishing above a specific threshold. 
- Conventional ocean fishing vessels;

- Cod trawlers including trawlers in other bottom fisheries.

The first four are defined as coastal vessels, while the two last are defined as ocean going vessels. Summary statistics for the average vessels in each fleet segment are presented in Table 32. Model parametrization data is based on averages for the period 2012-20014, i.e. the three-year period leading up to the modelled period. ${ }^{16}$ The average number of vessel and days at sea per vessel, together with the cost data given in Table 32 has been used to initialize the model in 2015 for each segment.

Table 32: Average base indicators for the fleets included in the analysis over the period 2012-2014

\begin{tabular}{|c|c|c|c|c|c|c|c|}
\hline Average 2012-2014 & $\begin{array}{r}\text { Conv. } \\
\text { Coast } \\
<11\end{array}$ & $\begin{array}{r}\text { Conv. } \\
\text { Coast } \\
11-14,99\end{array}$ & $\begin{array}{r}\text { Conv. } \\
\text { Coast } \\
15-20,99\end{array}$ & $\begin{array}{r}\text { Conv. } \\
\text { Coast } \\
>21\end{array}$ & $\begin{array}{r}\text { Conv } \\
\text { Ocean } \\
<28\end{array}$ & Trawlers & $\begin{array}{r}\text { Average } \\
\text { per vessel }^{4}\end{array}$ \\
\hline \multicolumn{8}{|l|}{ Physical data } \\
\hline $\mathrm{FTE}^{1} /$ segment & 1.5 & 3.2 & 6.8 & 11.9 & 35.2 & 37.0 & 4.6 \\
\hline Number of vessels & 687 & 288 & 119 & 34 & 25 & 39 & 1,192 \\
\hline Days at sea/vessel & 149 & 159 & 168 & 201 & 315 & 294 & 163 \\
\hline 1st important species ${ }^{2,3}$ & $\operatorname{COD}(74 \%)$ & $\operatorname{COD}(69 \%)$ & $\operatorname{COD}(64 \%)$ & $\operatorname{COD}(51 \%)$ & $\operatorname{COD}(61 \%)$ & $\operatorname{COD}(57 \%)$ & $\operatorname{COD}(61 \%)$ \\
\hline 2nd important species ${ }^{2,3}$ & $\operatorname{HAD}(19 \%)$ & $\mathrm{HAD}(16 \%)$ & $\operatorname{HAD}(18 \%)$ & $\operatorname{HER}(20 \%)$ & $\operatorname{HAD}(30 \%)$ & POK $(23 \%)$ & HAD (20\%) \\
\hline 3rd important species ${ }^{2,3}$ & POK (7\%) & POK (12\%) & $\operatorname{HER}(11 \%)$ & $\operatorname{HAD}(17 \%)$ & POK (9\%) & $\operatorname{HAD}(20 \%)$ & POL (16\%) \\
\hline \multicolumn{8}{|c|}{ Account data (EUR 1000/vessel) } \\
\hline Turnover/Revenue & 149 & 365 & 828 & 1,931 & 5,475 & 9,876 & 750 \\
\hline Fuel Costs & 9 & 21 & 64 & 188 & 608 & 1,762 & 92 \\
\hline Labour costs & 70 & 168 & 349 & 705 & 2,168 & 3,043 & 281 \\
\hline Variable costs & 28 & 57 & 128 & 318 & 1,033 & 1,449 & 121 \\
\hline Fixed costs & 25 & 61 & 140 & 336 & 658 & 1,093 & 102 \\
\hline Capital costs & 7 & 13 & 29 & 54 & 43 & 412 & 26 \\
\hline Opportunity labour cost & 1 & 1 & 2 & 3 & 6 & 7 & 2 \\
\hline Opportunity capital cost & 77 & 164 & 354 & 616 & 1,818 & 1,914 & 238 \\
\hline Profit & 10 & 45 & 118 & 330 & 965 & 2,117 & 127 \\
\hline Socio-economic return & 9 & 61 & 140 & 470 & 1,352 & 3,651 & 195 \\
\hline
\end{tabular}

Note: 1. "FTE"=Full Time Employment.

2. Relative importance of landed species is measured in value.

3. "COD"=cod, "HAD"=Haddok "POK"=Saithe, "HER"=Herring.

4. For "Number of vessels" this column result represents the sum and not average.

Despite its smaller size, the coastal fleet is still important because its rich number of vessels. The large number of licenses and vessels make the fleet important and it takes about 50\% of the cod landings. The average profit is proportional to the size of the vessel. The profitability measured by the operational margin and returns of assets give a better picture of the average return within each vessel group. Figure 20 illustrates the development in operating margins and return of assets for the fleet segments over the last 10 years. Profitability varies over time and between vessels and vessel groups. As can be seen from the Figures, the trawlers are the most profitable for the most years, while the smallest coastal vessels are the least profitable. It should, however, be mentioned that this is average numbers and that there are large variations within each fleet segment.

${ }^{16}$ It is assumed that the cost, price and catch pattern in the projection period (2016-2025) are identical to the structure in the years leading up to the period. 
Figure 20: Development in operating margins (in percent) and return of assets (in percent) for the fleet included in the model projections

\section{Operating margins}

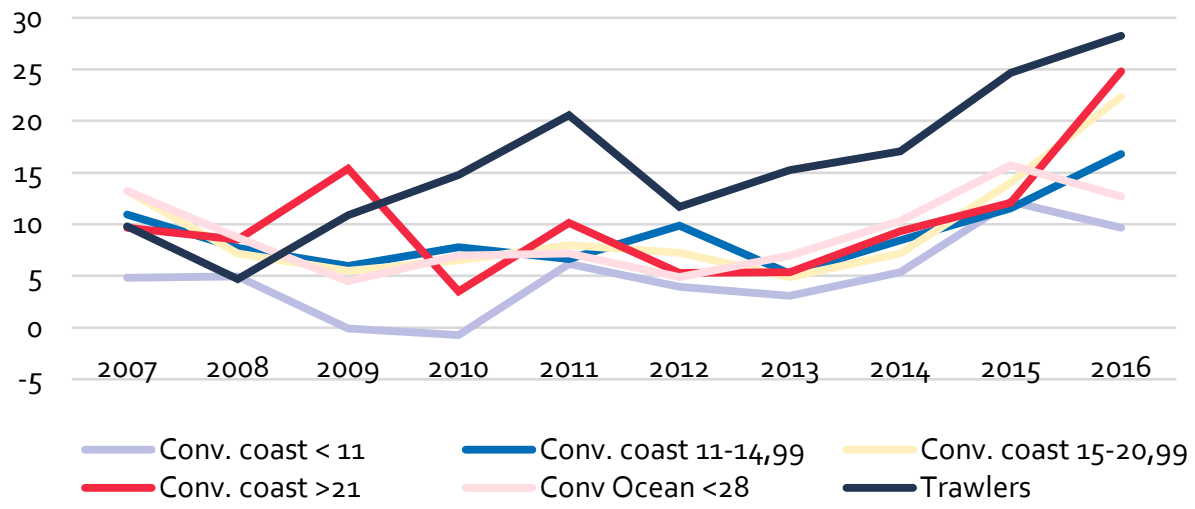

\section{Operating margins}

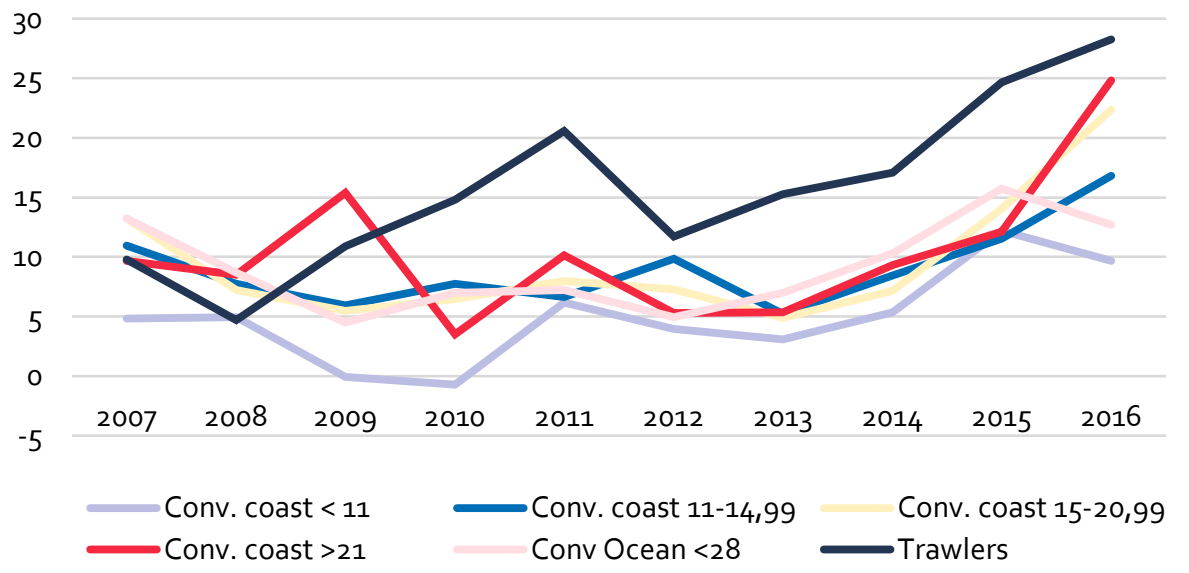

Table 32 further shows that the most important species in terms of value were cod $(61 \%)$, followed by haddock (20\%) and saithe (17\%). It is worth to mention that herring would be ranked higher is the chosen fleet segment included the pelagic fleet. Herring is mainly landed by the pelagic fleet which is not included in this study. However, for the two largest coastal vessel groups, herring is the second most important species.

The development in total landing quantities and value for each of the included species is presented in Figure $21 .{ }^{17}$ As seen from the Table herring has been the most important species in terms of volume from mid 1980 s to 2014. From 2009 the herring landings have, however, declined steadily and were surpassed by cod in 2013. Cod has been the most important species in terms of landing over the entire time period, and its importance relative to the other species increases over time.

\footnotetext{
${ }_{17}$ This is for the entire Norwegian fleet, not only the chosen fleet segments.
} 
Figure 21: Development in Norwegian landings quantity and value for the species included in the model projections
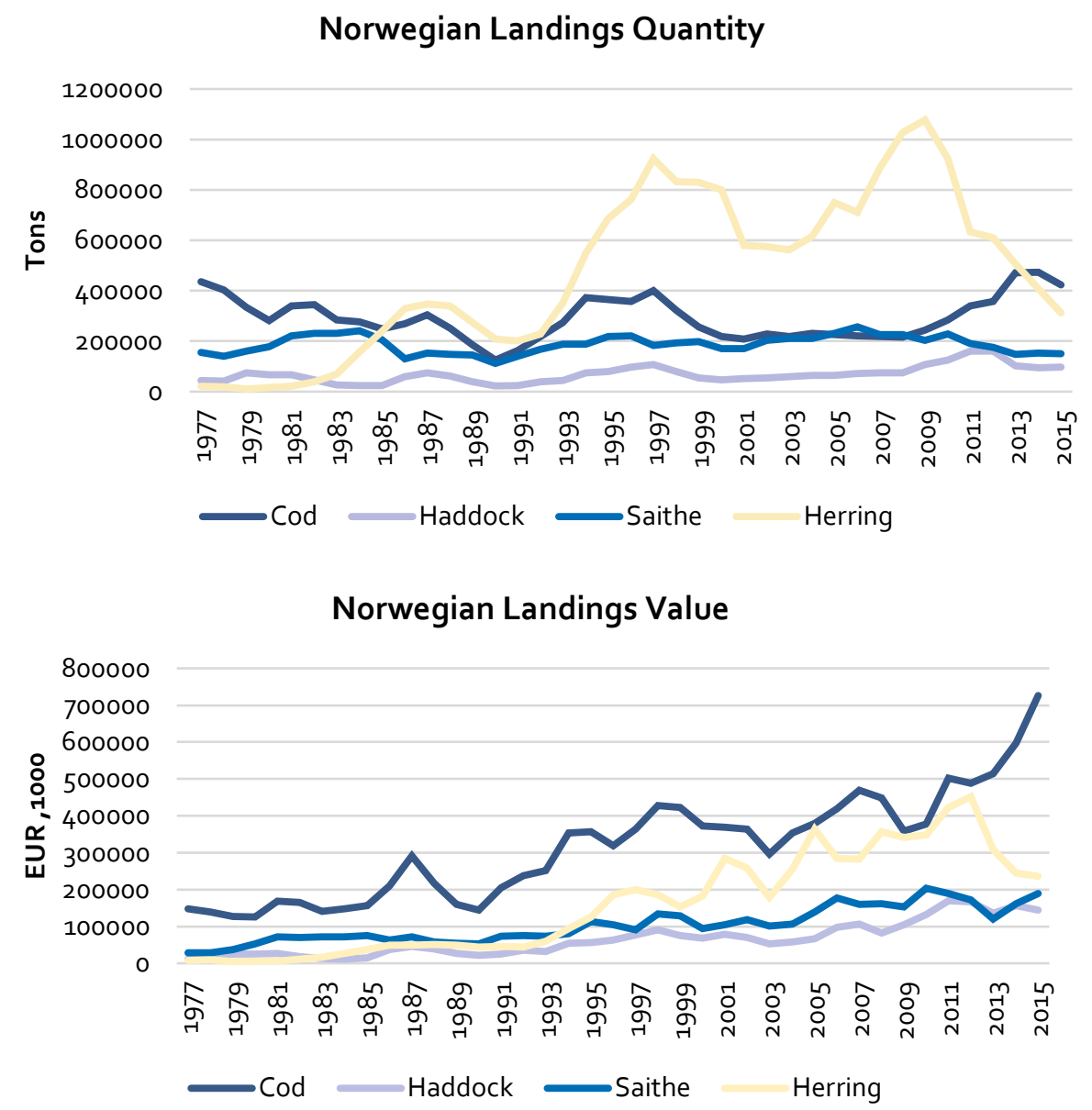

Table 33 display the status of the chosen stocks included in the model projections. Spawning stock biomass (SSB 2016), Total Allowable Catch and fishing mortality corresponding to the MSY are displayed, together with the status of the stocks in 2015. As seen from the Table herring has the largest spawning stock biomass, while cod has the largest TAC in 2015.

Table 33: Status of stock, fishing and management, 2015

\begin{tabular}{lrrr}
2015 & SSB (tons) $)^{1}$ & TAC (tons) $)^{2}$ & F $_{\text {MY }}{ }^{3}$ \\
Northeast Arctic cod & $1,383,000$ & 894,000 & 0.40 \\
Northeast Arctic haddock & 802,000 & 165,000 & 0.35 \\
Northeast Arctic saithe & 357,000 & 122,000 & n.d. \\
Norwegian spring-spawning herring & $5,264,000$ & 283,013 & \\
\hline
\end{tabular}

Note: 1 "SSB"=Spawning Stock Biomass and 2 "TAC"=Total Allowable Catch. 3 "FMSY"=Fishing mortality at the MSY. 


\subsection{Results}

As described in the introduction of this report, 4 forecast scenarios are considered, the results of which in 2025 are compared with the initial situation in 2015. The specifics for the Norwegian case/management is:

1. Current Norwegian management: ITQs within (except for coastal vessels below 11 meters) but not between fleet segments. $4 \%$ limit on yearly adjustment in number of vessels in each segment;

2. Free ITQ trade of all species within and between all fleet segments. $4 \%$ limit on yearly adjustment in number of vessels in each segment;

3. Current Norwegian management (see scenario 1). No limit on yearly fleet adjustment;

4. Scenario 1 with taxes on $10 \%$ of prices.

As discussed in the introduction two forecasts are made for each scenario: maximization of the total socio-economic return ${ }^{18}$ and maximization the total profit, both over the period 2016-2025 (2015 being held constant), through variation in number of vessels and days at sea per vessel.

A number of assumptions restrict the model. (i) Maximum catch per vessel per year is restricted below a maximum of 2 times the catch per vessel in 2015, (ii) for all species the stock recruitment functions are constructed such that the stock will not at any point increase above the maximum observed from 1995-2014. This to prevent unrealistic increase in these stocks, and (iii) profit maximisation is performed with values of quotas traded included in the maximisation.

In Table 34 the outcomes from the projection maximizing socio-economic return is displayed, while indicators from the corresponding projection maximizing profit is displayed in Table 35. Table 34 displays total socio-economic return (summed over all included fleet segments), and total profit. The Table report the predicted total number of vessels and the total fulltime employment for each scenario. Results are shown for the base year 2015 and for each scenario for the final projection year 2025 .

\footnotetext{
${ }^{18}$ The socio-economic return, representing the social welfare that the fishery comprises for society when compared with
} how capital and labour used in the fishery could have been used in other sectors. 
Table 34: Forecast of socio-economic return, fleet and employment adjustment in 2025 by maximizing socioeconomic return

\begin{tabular}{|c|c|c|c|c|c|c|}
\hline Scenarios & $\begin{array}{r}\text { C.coast } \\
<11\end{array}$ & $\begin{array}{r}\text { C. coast } \\
11-14,99\end{array}$ & $\begin{array}{r}\text { C. coast } \\
15^{-20,99}\end{array}$ & $\begin{array}{r}\text { C. coast } \\
>21\end{array}$ & $\begin{array}{r}\text { C. Ocean } \\
<28\end{array}$ & Trawlers \\
\hline
\end{tabular}

Socio-Economic return (mill EUR)

\begin{tabular}{|c|c|c|c|c|c|c|c|}
\hline 2015 initial situation & -9 & 24 & 23 & 18 & 44 & 133 & 234 \\
\hline \multicolumn{8}{|l|}{2025 scenarios: } \\
\hline 1. Current management & 5 & 24 & 23 & 6 & 34 & 106 & 198 \\
\hline 2. ITQ management free quota trade & 6 & 24 & 17 & -2 & 45 & 127 & 218 \\
\hline 3. Current management full adjustment & 5 & 35 & 34 & 18 & 42 & 134 & 267 \\
\hline 4. Current management $10 \%$ landing tax & 5 & 24 & 23 & 6 & 34 & 106 & 198 \\
\hline \multicolumn{8}{|l|}{ Number of vessels } \\
\hline 2015 initial situation & 687 & 288 & 119 & 34 & 25 & 39 & 1,192 \\
\hline \multicolumn{8}{|l|}{2025 scenarios: } \\
\hline 1. Current management & 457 & 191 & 79 & 23 & 17 & 26 & 792 \\
\hline 2. ITQ management free quota trade & 457 & 191 & 79 & 23 & 17 & 26 & 792 \\
\hline 3. Current management full adjustment & 324 & 94 & 43 & 9 & 12 & 17 & 498 \\
\hline 4. Current management $10 \%$ landing tax & 457 & 191 & 79 & 23 & 17 & 26 & 792 \\
\hline \multicolumn{8}{|l|}{ Employment (full-time) } \\
\hline 2015 initial situation & 1,019 & 911 & 814 & 405 & 879 & 1,444 & 5,471 \\
\hline \multicolumn{8}{|l|}{2025 scenarios: } \\
\hline 1. Current management & 677 & 606 & 541 & 269 & 584 & 960 & 3,637 \\
\hline 2. ITQ management free quota trade & 677 & 606 & 541 & 269 & 584 & 960 & 3,637 \\
\hline 3. Current management full adjustment & 480 & 296 & 292 & 102 & 437 & 625 & 2,232 \\
\hline 4. Current management $10 \%$ landing tax & 677 & 606 & 541 & 269 & 584 & 960 & 3,637 \\
\hline
\end{tabular}

Table 35: Forecast of profit, fleet and employment adjustment in 2025 by maximizing profit

\begin{tabular}{|c|c|c|c|c|c|c|c|}
\hline Scenarios & $\begin{array}{r}\text { C.coast } \\
<11\end{array}$ & $\begin{array}{r}\text { C. coast } \\
11-14,99\end{array}$ & $\begin{array}{r}\text { C. coast } \\
15^{-20,99}\end{array}$ & $\begin{array}{r}\text { C. coast } \\
>21\end{array}$ & $\begin{array}{r}\text { C. Ocean } \\
<28\end{array}$ & Trawlers & Total \\
\hline \multicolumn{8}{|l|}{ Profit (mill EUR) } \\
\hline 2015 initial situation & 5 & 11 & 10 & 11 & 21 & 80 & 138 \\
\hline \multicolumn{8}{|l|}{2025 scenarios: } \\
\hline 1. Current management & -2 & 8 & 9 & 4 & 16 & 64 & 100 \\
\hline 2. ITQ management free quota trade & 7 & 12 & 3 & 1 & 18 & 72 & 112 \\
\hline 3. Current management full adjustment & 0 & 16 & 16 & 10 & 20 & 82 & 144 \\
\hline 4. Current management $10 \%$ landing tax & -3 & 6 & 7 & 3 & 13 & 50 & 75 \\
\hline \multicolumn{8}{|l|}{ Number of vessels } \\
\hline 2015 initial situation & 687 & 288 & 119 & 34 & 25 & 39 & 1,192 \\
\hline \multicolumn{8}{|l|}{2025 scenarios: } \\
\hline 1. Current management & 457 & 191 & 79 & 23 & 17 & 26 & 792 \\
\hline 2. ITQ management free quota trade & 457 & 191 & 79 & 23 & 17 & 26 & 792 \\
\hline 3. Current management full adjustment & 0 & 94 & 43 & 9 & 12 & 17 & 175 \\
\hline 4. Current management $10 \%$ landing tax & 457 & 191 & 79 & 23 & 17 & 26 & 792 \\
\hline \multicolumn{8}{|l|}{ Employment (full-time) } \\
\hline 2015 initial situation & 1,019 & 911 & 814 & 405 & 879 & 1,444 & 5,471 \\
\hline \multicolumn{8}{|l|}{2025 scenarios: } \\
\hline 1. Current management & 677 & 606 & 541 & 269 & 584 & 960 & 3,637 \\
\hline 2. ITQ management free quota trade & 677 & 606 & 541 & 269 & 584 & 960 & 3,637 \\
\hline 3. Current management full adjustment & 0 & 297 & 293 & 103 & 439 & 628 & 1,760 \\
\hline 4. Current management $10 \%$ landing tax & 677 & 606 & 541 & 269 & 584 & 960 & 3,637 \\
\hline
\end{tabular}


The Tables firstly show that given the current management (scenario 1) the total Norwegian groundfish fishery North of $62^{\circ}$ would be worse of in 2025 than in $2015 .{ }^{19}$ The total social welfare that the fishery represents for society (socio-economic return) is estimated to decreases with EUR 37 Million (16\%). This effect is seen for all fleet segments except the coastal vessels below 11 meters, which goes from a negative contribution to a positive. Especially for the three largest vessels group, the decline in socio-economic return is severe; the conventional coastal vessel over 21 meters will have a decline of EUR 12 Million (66\%) and trawlers a decline of EUR 27 Million (20\%). The situation is similar for the actual surplus obtain in the fishery after the subtraction of cost. The total profit is estimated to decline by EUR 38 Million (27\%) in 2025 compared to 2015 with the current management system. All vessel groups reduce its profit, and the smallest coastal vessels go from a positive to a negative profit.

Table 34 and 35, further display the numbers of vessel and full time employed for the different scenarios. As seen from the Table the number of vessels will decline by 400 vessels (34\%) and 1,834 fulltime employed (34\%) in 2025 compared to 2015 . The decline in number of vessels and full time employed are quite evenly distributed among the fleet segment all segment has a decline of between $32 \%$ and $34 \%$. This decline is the outcome of a trend that has lasted for decades.

In scenario 2 the trade barriers between all fleet segments are removed, but the capacity change is limited to $4 \%$ a year. As seen from the Table, this will improve the situation from scenario 1 by an additional EUR 20 Million (10\%) increase in socioeconomic return and EUR 12 Million (12\%) increase in profit, but the total socioeconomic return and profit is still significantly lower than in 2015. The two largest fleet segments among the coastal vessels (vessel between 15-21 meter and over 21 meter) are doing significantly worse in this scenario with a profit and socio-economic return significantly lower than in scenario 1 . It is, however, interesting to notice that for the smaller coastal vessels, profit and socio-economic return will increase relative to the current management. The predicted number of vessels and numbers of full time employed are however equal to scenario 1.

In scenario 3, we assume instant capacity adjustment (no yearly limit to capacity change). While this scenario is interesting, from a theoretical perspective (to quickly find the optimal steady state solution), the realism in this is more questionable. In this scenario, the forecasted total socio-economic return and profit in 2025 are as expected even higher than for scenario 2, with an estimated total socio-economic return that is EUR 70 Million (35\%) higher than in scenario 1 and an estimated total profit that is EUR 44 Million (44\%) higher. The conventional vessels under 11 meters do worse in this scenario, profit decline to zero and socio-economic return to 5 , but still this scenario is better than the results under the current management.

The predicted number of vessels and numbers of full time employed are significantly lower for this scenario than for the rest. The predicted total number of vessels decrease by additionally $78 \%$ when maximizing profit and $37 \%$ when

${ }_{19}$ The 2015 initial situation results are overestimated in this report. This is due to the low herring quotas in 2015. Using this as a basis for comparison can therefore be slightly misleading. 
maximizing socio economic return compared to scenario 1 . The situation is most dramatic for the smallest vessel groups, and most for the conventional vessel under 11 meter, which disappear when maximizing profit in this scenario. When maximizing socio economic return, the situation is less dramatic for the conventional vessel under 11 meter, with a decrease of $29 \%$. The results for the numbers of full time employees are closely related to the results for the number of vessels, since the full time employees are proportional to the number of vessels.

The last scenario (scenario 4 ) is also based on today's management but assumes a landings tax of $10 \%$. This will give a socio-economic return equal to scenario 1 but decrease the total profit by EUR 25 Million (25\%), but the retribution of the wealth will change. All the vessel groups will suffer under this management but maybe most the smallest conventional coastal vessel that get a highly negative profit. The predicted number of vessels and number of full time employed are equal to scenario 1.

Figure 22: Forecast of socio-economic return (top) and profit (bottom) 2015-2025, EUR Million
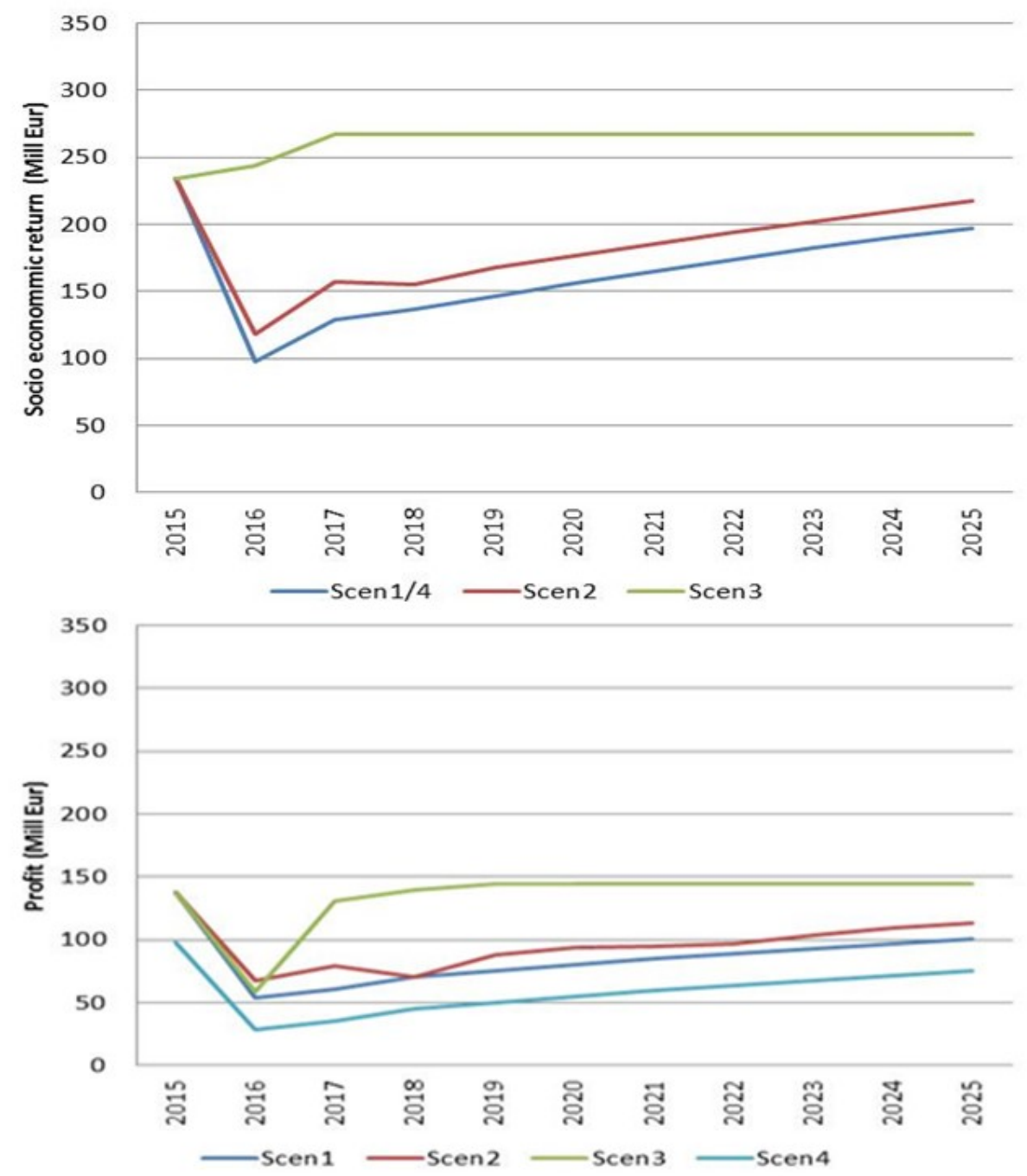
Figure 22 display the development over the projection period of the total socioeconomic return, and the total profit resulting from each projection. The Figure shows that for all scenarios the profit will decline sharply from 2015 to 2016 , since the main catches are predicted to drop over the coming decade. From 2016, the trend is more mixed; scenarios 3 shows a sharp increasing profit until 2017 and from then on stabilize, while the rest of the scenarios shows a more moderate increase profit towards 2025 . The development in socio-economic return is more mixed between the scenarios. For scenario 3, the socio-economic return increases from 2015 to 2017 and stabilize after this. For the other scenarios we see a sharp drop in socio-economic return from 2015 to 2016, and a after that a gradual improvement towards 2015 .

\subsection{Policy considerations}

What makes a quota system good depends both on its practical functionality and to what extent it reflects and maintains key societal values. However, it is also recognized that there are trade-offs between economic efficiency and the achievement of societal goals (Kroetz et al., 2015). The Norwegian authorities' responsibility to manage common fish resources has to be in accordance with the objectives of the fisheries legislation. "Havressursloven" (The marine resources act). $\$ 1$ states that the purpose of the act is to ensure a sustainable and socio-economically profitable management of wild marine resources, and to secure employment and settlement in coastal communities. The design of the regulations will be decisive for how this is done and what instruments are used.

The goals of sustainable resource management, maximum profit and to secure employment and settlement in coastal communities may be contradictory. Traditionally, the importance of sustainable management has been prioritized by Norwegian governance. So, when sustainability has come into conflict with profitability or employment, resource management has been prioritized. An example of this is the introduction of a total quota regime and closure of fishery to the public.

When the objective of profitability and employment and settlement in coastal communities has been contradictory, Norwegian management practices tended to prioritize societal objectives to the extent that many fishermen where heavily subsidized. However, since the early 1990s, economic efficiency and profitability in the industry has increasingly been prioritized (Standal and Asche, 2018). ${ }^{20}$ Still, the regulations are heavily influenced by the importance of maintaining coastal communities and a differentiated fleet. An example of this is how the structural quota schemes are designed, as the previously mentioned transfer can only occur within vessel groups and with limitations on trade between certain geographical regions.

\footnotetext{
${ }^{20}$ What is economically optimal depends on several other factors, such as competition from other industries and the need for labour. If capital and labour cannot be utilized better in other industries or that there are no alternative jobs, it will be economically profitable to prioritize high employment in fisheries.
} 
Figure 23: The development of vessels and profitability in the Norwegian fishery

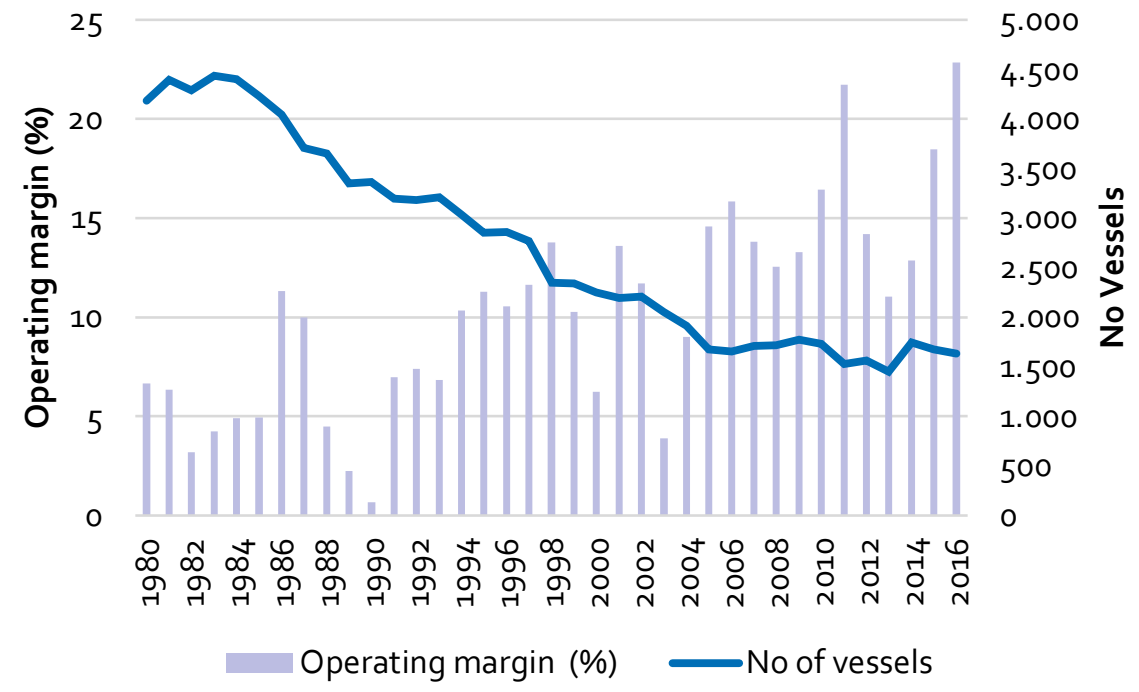

Increased productivity, competitiveness in the output market as well as paying competitive wages are not always easy to combine with small coastal vessels and maintaining coastal communities. In 2013 a committee where appointed by the Fisheries Minister in Norway at the time, Lisbeth Berg-Hansen, to give an account of how the seafood industry in Norway could become more efficient and profitable. The committee included a large number of recommendations that could contribute to improve profitability in the industry. A common thread in these recommendations was to give business players greater freedom to choose which economic and organizational models work best for the individual company in its market (NOU2014:16). Some of the suggestions, i.e. to reduce or remove the Participant Act (in Norwegian Deltagerloven) which limits who can own fishing vessels and to allow transfer of quota between vessel groups, might however lead to a change in today's structure, and many stakeholders are afraid that this would lead to an extinction of small coastal communities along the coast. As a consequence, few of the committee's proposals have been implemented.

Looking at the result from this study, profitability can be increased significantly by relaxing some of the restrictions the industry faces today. By lifting all trade barriers between fleet segments (scenario 2) but limiting how fast the fleet adjusts, the predicted socio-economic return will be $10 \%$ higher and profit $12 \%$ higher in 2025 , compared to continuing today's management scheme. Assuming instant capacity adjustment, leading us directly to the steady state solution, the benefit is predicted to be even larger with an average socio-economic return that is $35 \%$ higher and profit that is $44 \%$ higher in 2025 compared to continuing today's management scheme.

These results are largely as expected, since a segmented management where one cannot transfer quotas between vessel groups or different areas will lead to inefficiency. This is because existent efficiency differences between vessel groups or vessels in the different regions, will with today's management system be preserved, 
since the regulatory system protected the inefficient groups. The results also show that even though returns are increasing for fisheries as a whole by opening up for trade between vessels in different groups and areas, some groups are getting worse at least in the short run. Particularly the largest coastal vessels get their returns reduced. However, in the long run, it seems that all the vessel groups are doing better, except for the smallest coastal vessels that will not be viable, and accordingly disappear under the profit maximation scheme. ${ }^{21}$ Hence, the analysis gives those stakeholders that are concerned about the future of the smallest coastal fleet right in that they have no future if they are not protected. However, it is important to note that there will continue to be a coastal fleet even with free transfer of quotas between vessel groups, it will just not contain the smallest vessels.

As shown also in other countries (Kroetz et al., 2015), preserving a segmented fleet therefore has a cost in terms of lost revenue and profitability, and thereby also a loss of tax revenue for the society. A relevant question that the society must consider is therefore; are the price one must pay acceptable given the importance of preserving a heterogeneous fleet and maintaining the coastal communities?

In 2015 an expert committee appointed by the Fisheries Minister in Norway at the time was settled to discuss the development of Norwegian fishery management (NOU 2016:26). The committee concluded that it would be beneficial to rationalize and simplify Norwegian quota system and give the industry opportunities to do short- and long-term adjustment. At the same time, they point out that one should pursue the objectives of an industry exercised and owned by active fishermen, and a varied fleet with regard to vessel size and regional affiliates. A gradual and controlled adaptation to community development should be sought.

The reliability of this model is a matter that should be mentioned, and in particular how well it fits the Norwegian structure. The model is as all models a simplification, and a lot of strong assumptions are made. A major weakness of the model is that it assumes that the vessels within each vessel group are homogeneous. Previous research has shown that this is far from true. Guttormsen and Roll (2011) finds substantial variation in technical efficiency both between and within vessel groups in the Norwegian ground fish fleet. The results also indicate that none of the vessel groups dominate the others in terms of efficiency. Based on these results, there is therefore little indication that some of the vessel groups would disappear even if they were no longer protected by the quota distribution system with different vessel groups. The similarity of the results for many of the scenarios indicates that the adjustment restriction is binding in most cases. This is a consequence of how far the Norwegain fishing management system is from optimum in any dimension, and accordingly, how inefficient it remains when only moderate changes are carried out.

${ }^{21}$ We also see a sharp reduction in the number of vessels in all groups (especially tied to the smallest vessels), and for the individual fisherman this will be dramatic, especially if there is no alternative work. 



\section{The Faroese Demersal fishery in Faroe area}

\subsection{Introduction}

In this chapter, we forecast the development in the Faroese demersal fishery in the Faroe area until 2025, with the planned implementation of a quota system in 2019.

The Faroes have since 1996 had an effort regulation of the demersal fishery in the Faroe area, but this is planned to be changed in 2019 in a new law on fisheries management. The new fisheries management passed through the Faroese parliament in late 2017 , and came into force 1 January 2018. But in this law, the proposed quota system for large vessels in the Faroe area was postponed to 2019, while there are still plans to keep the effort regulation for the small-scale coastal vessels also after 2019. In this chapter, we look at the two groups of larger vessels with trawls and hooks that fish in the Faroe area for demersal species.

The new Faroese fisheries management law has been heavily debated in the Faroes over the last couple of years. Most of the debate has been about the allocation of fishing rights, but there are also still debates in the Faroes whether the quota system should be implemented at all for the demersal fleet in the Faroe area. The fishermen of the demersal fleet are not in favour of a quota system as well as many politicians. Their view is that a quota system will lead to a large discard of fish, which is practically non-existing in the current fishing days system.

Our choice of the demersal fleet in the Faroe area is partly based on that there still is debate on this part of the new law and partly because, in our view, this fleet as it is, does not function the way it should economically and biologically, as we will see in this chapter. This fleet in this study consists of medium sized vessels that use both trawl and hooks.

Hans Ellefsen of the Ministry of Fisheries ${ }^{22}$ and Heri á Rógvi independent advisor perform this case study.

In the following, a literature review of studies assessing fishery policy reforms in Faroes over the last decades is provided in section 2, while section 3 describes management of Faroese fishery. Section 4 present data and section 5 the results of the scenarios. Section 6 concludes the paper with policy considerations.

${ }^{22}$ The paper reflects solely the view of the author, not in any way of the employer institution. 


\subsection{Literature review}

The Faroe Islands have a high degree of dependency on fisheries. In economic terms the fisheries sector accounts for almost $20 \%$ of GDP and around $95 \%$ of goods exports of the Faroes are fish products (Hagstovan, 2018) (The Faroese statistical office). The fisheries sector of the Faroes is diverse and consists of fish farming, fish factories and fishing. The fishing part is divided into the pelagic fishery, distant water fishery, and the local demersal fishery. Historically local demersal fish stocks have been an important part of the total fishery, but in recent years the stocks of demersal stocks have declined and the other fisheries are much more important economically, when we look at the landing values. However, the demersal fishery is still a big part of the economy (GDP) and the basis for many fish factories around the islands.

The history of Faroese fishing of demersal species goes back more than 100 years. The main demersal stocks around the Faroes are cod (Gadus morhua), haddock (Melanogrammus aeglefinus), and saithe (Pollachius virens). With the 200 nautical mile Extended Economic Zone coming into force in 1977 the Faroese fishermen was forced to focus on the Faroese area and foreigners fishing in Faroese waters were not welcomed any more. However, until the beginning of the nineties, the fishing in the Faroe area was only managed by licenses. And in the eighties huge subsidies to the fishery were part of the Faroese fisheries. Following the crash in the main species in the early 1990ties (and de facto the Faroese economy) an ITO system was introduced by creditors, but that system was in place for only two years. After the main stocks miraculously returned in the mid 199oties the ITO system was abolished and the current fishing days system was introduced in 1996. This system regulates the effort instead of the catch and is coupled with a large system of closed areas on the Faroe shelf with gear restrictions. The fishing days are in principle transferable, but there has not been an effective market for fishing days since its introduction. From about 1996 to about 2002, this system was rather successful in an economic and a biological sense. However, this system has not been successful either economically or biologically since then, as we will see later.

Many studies have been made on the Faroese fishing days system over the years. However, not many of these are made of fisheries economists, and are many of a more descriptive nature. These articles have often been made as inspiration for other counties on how to make a fisheries management system that is different from the usual quota system.

In 2007 Løkkegaard et al. made a report describing and analysing the Faroese fishing days system until 2004 (Løkkegaard, Andersen, Boje, Frost, \& Hovgård, 2007). The report was a comparison between biological and economic results in the Faroese system and the results in Denmark from the EU regulatory system. Their conclusion was that the Faroese system was not outperforming the Danish. This analysis was made before the collapse of the cod and haddock stocks in 2004 and forward, so if this analysis was made today the conclusion probably had been that both the economic and biological results are much worse in the Faroese system than in the Danish.

In 2007 Jákupstovu et al. made a 10-year appraisal of the fishing days system (from 1996-2006) (Jákupsstovu, Cruz, Maguire, \& Reinert, 2007). Their perspective is biological 
and their conclusion is that the system of regulating effort does not have the desired effect on the biology of the fish since the fishing mortality had been well above biological safe limits. This was especially true for the two species cod and saithe. The idea from the beginning was that the system should induce the fleet to divert its fishing effort to more abundant species. However, this has not happened, according to Jákupstovu et al. (2007). Their "solution" to this problem of a too high fishing mortality is that the number of days were reduced significantly, which has however never happened.

In 2010, Baudron et al. also studied at the biology of the stocks cod, haddock and saithe in the Faroe area (Baudron, Ulrich, Nielsen, \& Boje, 2010). They conclude, "When stocks are considered in isolation, a total allowable effort system does not necessarily perform better than a Total Allowable Catch system. It depends on stock status and dynamics, the level of uncertainty, and the reactivity of the system to changes in scientific advice. When the stocks are considered together in mixed fisheries, effort management seems, however, to be appropriate, and inter-annual flexibility of the system appears to be the best compromise between short- and long-term objectives, as well as between biological sustainability and economic return". This paper therefore concludes that in some cases fishing effort regulation can be better than Total Allowable Catch management. But they also conclude that the number of days in the Faroese system should be reduced significantly in order for this to be the case.

FAO has made a report on effort regulation around the world (Squires, et al., 2012). Hans Ellefsen and Kjartan Hoydal, each have two chapters in this report about the Faroese system. Ellefsen studied the economic and biological data for the Faroese demersal fisheries. His conclusions were that the fishing days system does not perform well either economically or biologically, since the overall results for the companies in the fishery were negative and the stocks were below safe biological limits particularly in later years. Hoydal on the other hand concludes that there are many faults in a normal Total Allowable Catch system and the Faroese TAE system could solve some of these problems. But Hoydal further concludes that the Faroese system however has not been handled in the right way by the authorities in the Faroes, as the authorities have not monitored the development in effort. Hoydal also concludes that in the beginning the number of days were set too high and in the years after that, the fishing days have not been reduced nearly enough to compensate for the increased catchability in the fleets.

\subsection{Management}

Before the early 1990 s the fishing management system in the Faroe Islands was a combination of limited licenses, area closures and mesh size limits (Jákupsstovu et al., 2007). In the early 1990s, there was a collapse in the main demersal stocks around the Faroe Islands. To reduce the fishing mortality $(F)$ and rebuild the stocks, a quota system was introduced in 1994 as part of an agreement with the Danish government (Løkkegaard et al., 2007). However, the fishing industry and the politicians were not 
that happy with this arrangement. The quota system was criticized for leading to extensive discards when reaching the quota limits. Thus, in 1995, the industry and the government came up with a new system based on fishing effort. This system has been in place since 1996. The fishing days system was set up by a committee ("skipanarnevndin") consisting of managers, scientists, and key fishing industry representatives (Jákupsstovu et al., 2007). The main goal of the committee was to design a system such that the fishing mortality of the three key stocks were kept at 0.45 (corresponding to that approximately one-third of the stock was to be fished) as the recommendation from International Council for the Exploration of the Sea (ICES) then stipulated. A basic assumption of the system was that the effort applied to each of the three main stocks would change according to the relative abundance of the stocks. This does not seem to have happened though, as the more valuable specie cod was overutilized compared to saithe (Jákupstovu et al., 2007). 
Figure 24: The top figure (1a) shows the areas that are closed for spawning, and the bottom figure (1b) shows areas closed for trawling
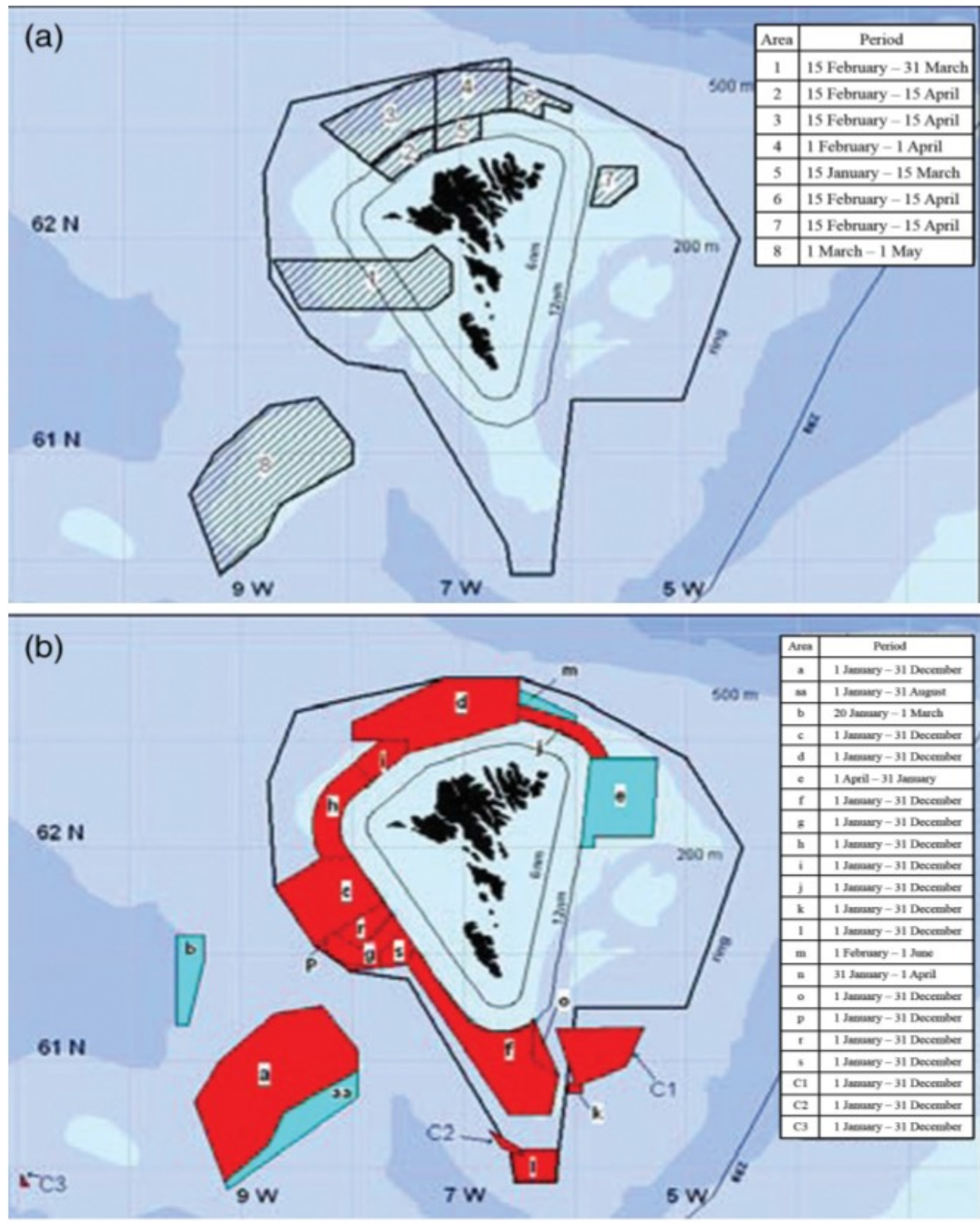

In addition to the management of effort more area closures and mesh size regulation were implemented in 1996. Firstly there is a ring around the Faroes where the sea level inside generally is shallower than 200 meter. Outside that area vessels are encouraged to fish through getting two additional days for each one fishing in this area. Within the 6 nautical mile of the baseline only smaller vessels are allowed to fish and no trawling is allowed inside the 12 nautical mile zone. Figure 24 a shows the areas that are closed during spawning for all fleet segments, and Figure $24 \mathrm{~b}$ shows areas that are closed for trawling some part of the year. Generally, $60 \%$ of the Faroe plateau shallower than 200 meter depth is closed for trawling (Jákupstovu et al., 2007). 
By 1st of January 2018 a new law on fisheries management in the Faroes comes into force, which reformed the Faroese fisheries management. One part of this reform was that the larger vessels in the demersal fleet around the Faroes were to convert to a quota system in 2019. The system is not an ITO system in the traditional sense, since fishermen do not own the quotas (the government owns them), and can only dispose of them on an open market, which means an auction. On the other hand, if you wanted to get out of the fishery owners of companies can sell their company i.e. shares to another Faroese company/person without restrictions. This quota system does not apply for the smaller vessels (<110 grt), which are still under the fishing days system also after 2019.

\subsection{Data}

Table 36: The groups of vessels in the Faroese fishing days system

\begin{tabular}{|c|c|c|c|}
\hline Group of fishing vessel & Licenses 2015 & $\begin{array}{l}\text { Landing value } 2015 \\
\text { EUR Million }\end{array}$ & $\%$ \\
\hline Group 2: Large trawlers > $400 \mathrm{hp}$ & 35 & 73.5 & $18.3 \%$ \\
\hline Group 3: Longliners > 110 grt & 18 & 29.8 & $7.4 \%$ \\
\hline \multicolumn{4}{|l|}{ Group 4: Large coastal vessels >15 grt } \\
\hline 4A: Longliners and jiggers $15-110$ grt & 9 & 1.2 & $0.3 \%$ \\
\hline - $\quad 4$ B: Small coastal trawlers $<500 \mathrm{grt}$ & 13 & 4.9 & $1.2 \%$ \\
\hline $4 \mathrm{~T}:$ Small trawlers $>55 \mathrm{grt}<500 \mathrm{hp}$ & 7 & 5.9 & $1.5 \%$ \\
\hline \multicolumn{4}{|c|}{ Group 5: Small coastal vessels < 15 grt (longlining and jigging) } \\
\hline $5 \mathrm{~A}:$ Full time fishermen & 20 & 3.4 & $0.8 \%$ \\
\hline $5 \mathrm{~B}:$ Part time fishermen & 280 & 3.1 & $0.8 \%$ \\
\hline Pelagic and distant water fishing & 17 & 276.6 & $69.0 \%$ \\
\hline Other (e.g. vessel for lobster and shellfish) & 13 & 3.2 & $0.8 \%$ \\
\hline Total & 412 & 401.6 & $100 \%$ \\
\hline
\end{tabular}

Source: (Fiskidaganevndin, 2017) and (Vørn, 2018) (Faroe Islands Fisheries Inspection).

The number of vessels in the studied groups 2 and 3 has been declining for a long time but not so much as could be expected. Figure 25 shows the decline in the number of licenses in these groups. 


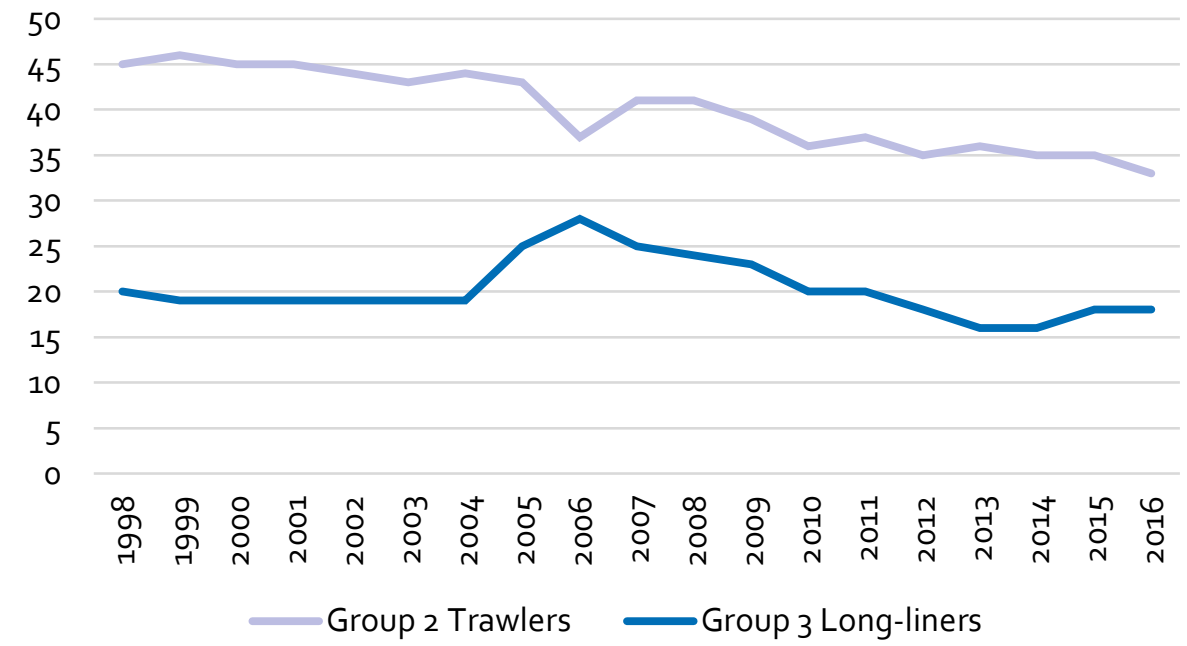

Source: $\quad$ (Fiskidaganevndin, 2017).

We see that the number of trawlers declined from 45 to 35 , while the number of longliners has declined from 20 to 18 . There were some years where the number of long liners was much higher and in 2006 there were 28 long-liners. Why there were so many vessels these years is not so clear, but maybe they were more optimistic on the state of the stocks back then with a series of good years, that ended around that time. Figure 26 shows the total amount of fishing days in the system compared to the days used. Each vessel in groups above are allocated a number of fishing days i.e. days that this vessel can be out on sea. This was set originally very high, and has been decreased since then, but not as much as the decline in used days. The total amount of used days is around $54 \%$ of the allocated days in 2014 . We can say that in some cases there is in fact open access fishing in the Faroe area and could this explain the bad economic results of the fleets as we will see. The excess of days are not so big in all groups. For the trawlers around $90 \%$ of the days were used until $2010 \mathrm{cf}$. the article on the Faroese effort system in (Squires, et al., 2012). The longliners do not use so many days as the trawlers, and they have other fishing grounds to fish on e.g. Iceland and Flemish cap, and have in later years only used one third of the total days in the Faroe area. 
Figure 26: Allocated and used days 1997-2014

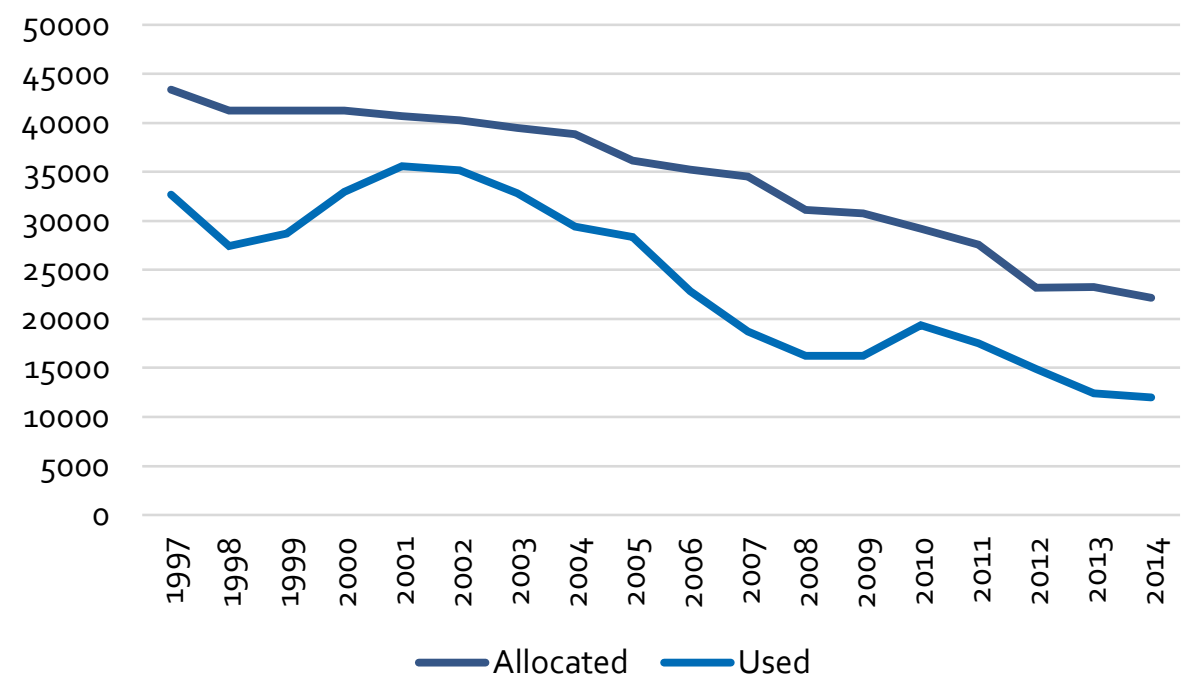

Source: $\quad$ (Vørn, 2018) (Faroe Islands Fisheries Inspection).

The stocks that we study in the chapter are the most important demersal stocks in the Faroese area. These are the cod, haddock and saithe. These three have all been on a low level for many years, especially cod and haddock while saithe seem to be increasing significantly in 2015. Figure 27 shows the spawning stock biomass for these tree stocks since 1961.

Figure 27: Spawning stock biomass 1961-2016 of main demersal species

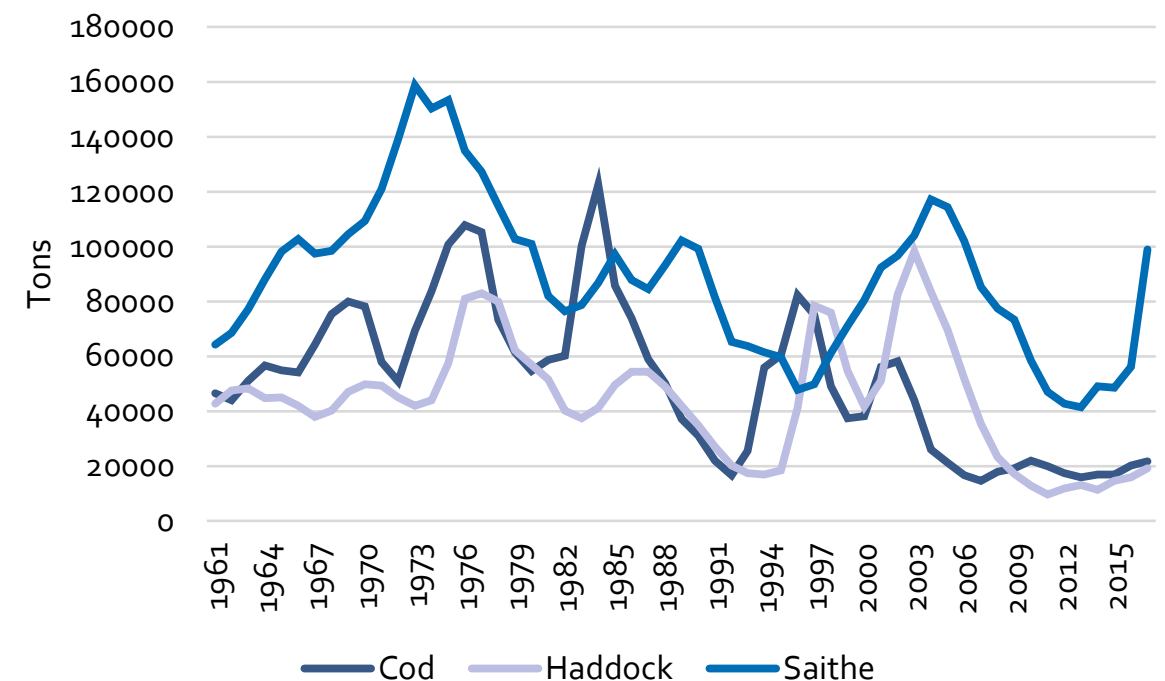

Source: $\quad$ (Havstovan, 2018) (Faroe Islands Marine institute). 
Figure 28: Catches 1961-2016 of main demersal species

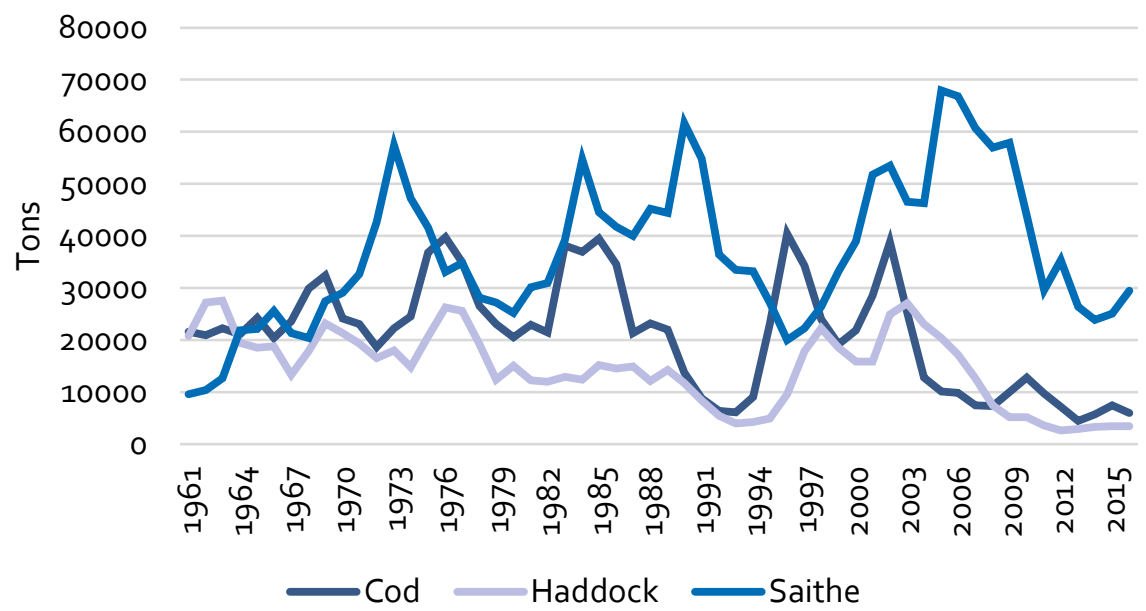

Source: $\quad$ (Havstovan, 2018) (Faroe Islands Marine institute).

Historically, the catch for cod in the Faroe area has been between 20,000 and 40,000 tons. However, for the last 10 years it has been below 10,000 tons. Also, haddock catches have been on a historically low level. The saithe has not been at such a low level the last couple of years, but compared to 10 years ago the catches of saithe are only half of what they were then.

The economic results of the vessels in the fishing days system has not been good since the introduction of the system. From 1996 to 2002 the outcome was encouraging, but this has not been the case the last 10-15 years. In Figure 29 we show the economic results for the fleets that we study in this chapter compared to the Faroese fleets that have an ITO system (i.e. pelagic and distant water fishing).

Figure 29: Profits for vessels in ITO system and vessels using fishing days system. Resource taxes are included in costs for the pelagic fleet

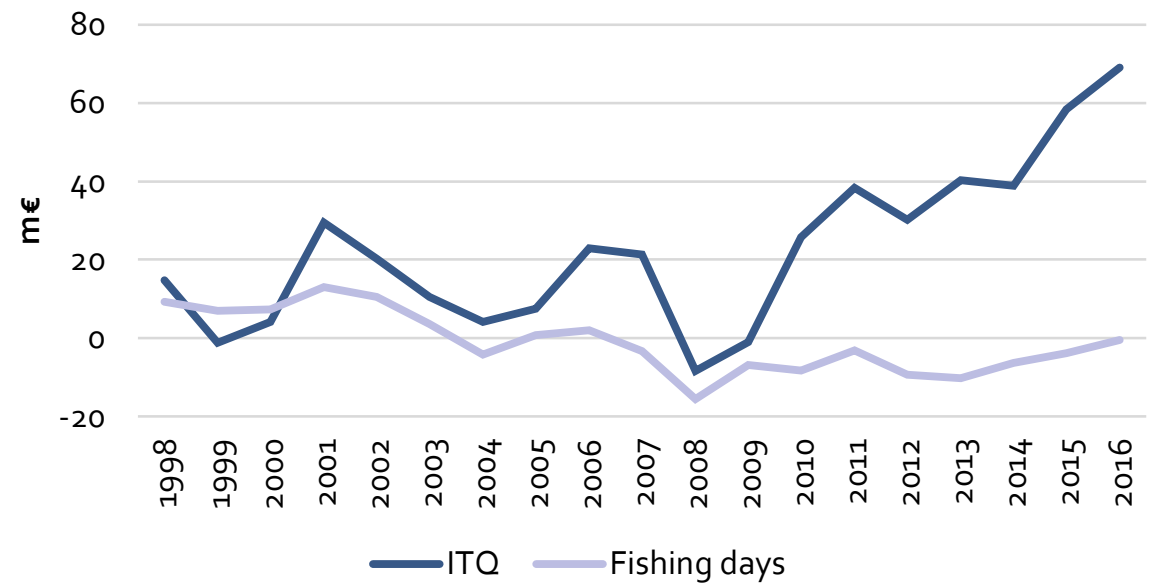

Source: (Januar, 2016) (Accounting firm). 
We see that the fleets that are using the fishing days system has had much worse economic results than those that have used ITO system. The Figure does not prove that the ITQ system implies good economic results; it can indicate such a theoretical result. The good economic results that we see in the ITO sector the last years can also be attributed to the good economic results that the pelagic sector has had the last couple of years. And these good results for the pelagic fleet can largely be attributed to the large abundance and fisheries of mackerel in Faroese area since 2010.

Table 37 shows the accounts for the fleets that we examine in this chapter.

Table 37: Physical and economic data, annual average 2012-2014

Group 2: Trawlers

Group 3: Longliners

Total

Physical data

Fulltime employment/segment

Number of vessels ${ }^{1}$

DAS/vessel

Important species

Total account data (EUR Million)

Turnover

Crew costs

Other costs ${ }^{2}$

Capital costs

Opportunity labour cost ${ }^{3}$

Opportunity capital cost ${ }^{4}$

Profit

Socio-economic return 5

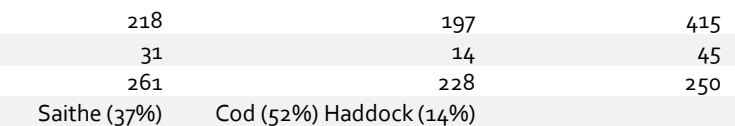

Saithe (37\%) Cod (52\%) Haddock (14\%)

$\begin{array}{rrr}58 & 22 & 80 \\ 22 & 10 & 32 \\ 35 & 11 & 46 \\ 9 & 2 & 16 \\ 14 & 12 & 26 \\ 12 & 3 & 15 \\ -1 & -8 & -9 \\ -3 & -4 & -7\end{array}$

Note: $\quad$ 1. The account data are retrieved from survey made by the Faroese accounting firm 'January'. Only vessels that are active are reported here. That is why the number of vessels from Table 36 does not match the numbers here.

2. The total fuel costs, variable costs and fixed costs are known, but the allocation between the three components is not estimated.

3. Total opportunity cost of labour is identified on the basis of an annual average salary of a fishermen in another sector on EUR 53,333 (400,000 DKK) multiplied by the number of full time employed.

4. Total opportunity cost of capital is calculated as $6 \%$ of the physical assets of the companies.

5. The socio-economic return = turnover - costs - opportunity costs of labour - opportunity cost of capital.

Source: (Januar, 2016) (accounting firm) and (Vørn, 2018) (Faroe Islands Fisheries Inspection).

Turnover of these two segments are EUR 80 Million, but after costs the profits are negative on average the years 2012-2014. Also, the socio-economic return is negative. Socio-economic return measures "The net-surplus that, at a given time, remains for the remuneration of capital and labor above the rate that is achieved in other businesses". The definition appears from Nielsen et al. (2012). The socio-economic return is calculated as turnover minus fuel costs minus variable costs minus fixed costs minus opportunity costs of labour minus opportunity cost of capital. In economic terms the socio-economic return is the sum of the resource rent and the producer surplus. While profit measures the net return a company have from their fishery, socio-economic return measures the net return a society have on the existence of a fishery, compared to if labour and capital had been used in other sectors than fishery. 
The socio-economic return of these two fleets are EUR -7 Million on average for the three years 2012-2014. The opportunity cost of labour is lower than the actual costs for trawlers while they are higher for longliners. The opportunity cost of capital is higher than actual capital costs for both groups.

Table 38 displays the status of the major demersal stocks included in the model projections. Spawning stock biomass, catches and fishing mortality corresponding to MSY are displayed, together with the status of the stocks in 2015. It is seen that cod and haddock were not sustainable in 2015 as they both were below Bpa and above MSYBtrigger. The saithe stock was sustainable, but fishing pressure was too high. The spawning stock biomasses and catches displayed in Table 38 are used as initiating values in 2015 for the model projections.

Table 38: Status, illustrated through Spawning Stock Biomass, Total Catch and fishing mortality at MSY (F-MSY) of the main Faroese demersal stocks included in the analysis in the start year 2015

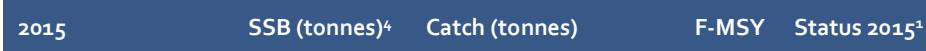

\begin{tabular}{|c|c|c|c|c|}
\hline $\operatorname{Cod}(\mathrm{FP})$ & 16,920 & 7,375 & 0.32 & Below $\mathrm{Bpa}^{2}$, Above MSY-Btrigger ${ }^{3}$ \\
\hline Saithe (FP) & 48,507 & 25,195 & 0.3 & Above Bpa, Above MSY-Btriggger \\
\hline Haddock (FP) & 14,625 & 3,395 & 0.25 & Below Bpa, Above MSY-Btriggger \\
\hline
\end{tabular}

Note: 1. According to ICES advice 2017 (ICES, 2017)

2 "Bpa"=The precautionary biomass level that triggers ICES to take action to raise the stock above this level.

3. "MSY-Btrigger"=The Biomass level that triggers ICES to recommend a fishing mortality below F-MSY. 4. SSB = Spawning Stock Biomass.

The advice from ICES for 2018 shows a very different picture than the advice from 2017 (ICES, 2018). ICES have become more optimistic of the cod and haddock stocks, while not so optimistic on the saithe stock. It has not been possible to include these results into the calculation below.

\subsection{Results}

The development in the demersal fishery is forecasted until 2025 using the method outlined in chapter 2 in four scenarios, of the Faroese demersal fishery around the Faroe Islands. ${ }^{23:}$

1. Current Faroese management: ITQs beginning in 2019, and constant effort 20152018. $4 \%$ limit on yearly adjustment in number of vessels in each segment after 2019;

2. ITQs from $2016.4 \%$ limit on yearly adjustment in number of vessels in each segment in all years;

${ }_{23}$ Maximum catch per vessel per year restricted below a maximum of 2 times the catch per vessel in 2015 . 
3. Current FO management: ITQs beginning in 2019, and constant effort 2015-2018. No limit on yearly fleet adjustment after 2019;

4. Scenario 1 with taxes on $10 \%$ of prices.

Two forecasts are made for each scenario. First, the total socio-economic return is maximized over time with the results being presented in Table 39, while total profit of the fleet is maximized with the results in Table 40 . The net present value of all future earnings is maximized through variation in number of vessels and days at sea per vessel. The forecast results are shown in the Tables for 2025 comparted to the initial situation in 2015. Where socio-economic return measures the extraordinary economic contribution of fisheries to the socio-economy, profit is the surplus for the private fishing companies. The biological foundation of the fishery in the initial situation is shown in Table 38.

Table 39 displays the model outcomes from the projection maximizing socioeconomic return. The Table shows the socio-economic return together with the total number of vessels and the total fulltime employment. Table 40 displays the corresponding indicators from the projection maximizing profit.

Table 39: Forecast of socio-economic return, fleet and employment adjustment in 2025 by maximizing socio-economic return

Socio-Economic return (mill EUR)

2015 initial situation

2025 scenarios:

1. Current management

2. ITO management free quota trade

3. Current management full adjustment

4. Current management $10 \%$ landing tax

$\begin{array}{ccc}2 & -11 & -10 \\ 12 & 4 & 16 \\ 15 & 4 & 19 \\ 24 & 4 & 28 \\ 12 & 4 & 16\end{array}$

Number of vessels

2015 initial situation

2025 scenarios:

1. Current management

2. ITO management free quota trade

3. Current management full adjustment

4. Current management $10 \%$ landing tax

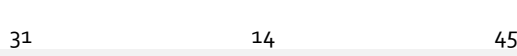

Employment (full-time)

2015 initial situation

2025 scenarios:

1. Current management

2. ITO management free quota trade

3. Current management full adjustment

4. Current management $10 \%$ landing tax

\begin{tabular}{rrr}
31 & 14 & 45 \\
23 & 11 & 34 \\
21 & 10 & 31 \\
12 & 10 & 22 \\
23 & 11 & 34 \\
& & \\
248 & 196 & 444 \\
186 & & \\
165 & 147 & 334 \\
94 & 144 & 309 \\
186 & 146 & 240 \\
& 147 & 334 \\
\hline
\end{tabular}


Profit (mill EUR)

2015 initial situation

2025 scenarios:

1. Current management

2. ITO management free quota trade

3. Current management full adjustment

4. Current management $10 \%$ landing tax

Number of vessels

2015 initial situation

2025 scenarios:

1. Current management

2. ITQ management free quota trade

3. Current management full adjustment

4. Current management $10 \%$ landing tax

Employment (full-time)

2015 initial situation

2025 scenarios:

1. Current management

2. ITO management free quota trade

3. Current management full adjustment

4. Current management $10 \%$ landing tax

\begin{tabular}{rrr}
-6 & -5 & -12 \\
3 & 2 & 5 \\
5 & 2 & 7 \\
12 & 2 & 14 \\
0 & 1 & 1 \\
& & \\
31 & 14 & 45 \\
& & \\
23 & 11 & 35 \\
21 & 11 & 32 \\
12 & 11 & 23 \\
23 & 11 & 34 \\
248 & & \\
& 196 & 444 \\
186 & & \\
165 & 159 & 345 \\
94 & 157 & 322 \\
186 & 152 & 246 \\
& 147 & 334 \\
\hline & &
\end{tabular}

Table 39 shows that the fleet will be much better off in all scenarios than in the initial situation. Scenario 1 shows the results in 2025 if the planned quota system is implemented in 2019. There is a $4 \%$ limit on how fast the adjustment can take place after 2019. We see that the socio-economic return goes from EUR -10 Million to EUR 16 Million. We also see that in scenario 2 where ITQs started in 2016 the socio-economic return is a bit higher at EUR 18 Million, this could be because the maximum adjustment of $4 \%$ has been taking place for three more years than in scenario 1 . In scenario 3 , when there is full adjustment, the total socio-economic return goes up to EUR 28 Million, in this case there is no restrictions on how fast the adjustment is taking place. In these three scenarios the longliners are not affected. This is probably due to the restriction that we made in the model that the maximum catch per vessel per year is 2 times the catch per vessel in 2015 . Finally, scenario 4 shows the results if a $10 \%$ landing tax was set, which gives the same socio-economic return as scenario 1 .

In Table 39 we also study the number of vessels that result from the model scenarios above. We see that the number of trawlers is reduced from 31 to 23 or $26 \%$ in scenario 1 , while the numbers of longliners drop from 14 to 11 or $21 \%^{24}$. For scenario 3 where there is full adjustment, the number of trawlers goes from 31 to 12 vessels or $61 \%$. In the other cases the number of vessel are reduced from 31 to 23 vessels (except scenario 2 where it is 21). The model only calculates based on the current situation, so these are vessels of the

\footnotetext{
24 It is worth mentioning that these results are not so drastic as the last time similar calculations were made in 2014 for the project 'Reducing Climate Impact from Fisheries' (Waldo, et al., 2014). In that report the long liners should be reduced to 5 while the trawlers were to be 11 . The reason for the lower reduction in this report is the restriction that in a given year the same vessel can at a maximum fish twice of what it is fishing in 2015 , and that that the adjustment can only be $4 \%$ each year (except in scenario 3).
} 
same size and capacity as today. The longliners were in 2014, 43 years old on average (Januar, 2016), so there could in the future come newer vessels that would fish more per vessel, so there would be fewer vessels than in the calculations above.

The number of full time employed is shown in the model scenarios above. In this case, it is assumed that there are 8 full time employed on a trawler while there are 14 on a longliner. The results here can be compared to the other results above. We see that the number of employed in the fleets are lowest in the full adjustment case, where the number of employed goes down from 444 to 249 . This is quite a low number, but maybe this case (scenario 3 ) is not so realistic.

In Table 40 we maximize the profit of the fishery. In the initial situation the total profit is EUR -12 Million, but in the case that the current planned management is implemented the profit is EUR 5 Million. We see that the other scenarios are all much better than the current situation. The highest profit comes with the full adjustment. The profits for the fleet in scenario 4 are very low; this could indicate that this fishery is not profitable in any case; if a landing tax of $10 \%$ does not produce a higher profit for the fleet.

Table 40 shows the total number of vessels in each group. The results are very similar to the ones in Table 39. Still the most drastic is the full adjustment scenario 3 , and the longliners do not show the same adjustment as the trawlers. Table 40 also shows the total number of full time employed. These are also similar to the results reported in Table 39.

Finally, while the results in previous Tables only show the numbers in 2025, Figure 30 shows the development of the results from 2015 to 2025 . The left Figure is socioeconomic return, while the right Figure shows the profit. We see that the results gradually move towards the results in 2025 reported in the Tables above. Scenario 1 and 4 are the same in the socio economic return maximization. In scenarios 1 and 3 the socio economic return and profit increases towards 2019 even though the effort is held constant in this period, because the stocks increase, thus increasing the catches. After 2019, when the ITQ system is implemented in scenarios 1, 3, and 4 it is seen that a shift occurs in the socio economic return and profit, given that the fishery now starts adjusting to the ITO system. In scenario 2 the steady increase over the total period is caused by a combination of stock increase and fleet adjustment given the ITO system. 
Figure 30: Forecast of socio-economic return (top) and profit (bottom) 2015-2025, EUR Million
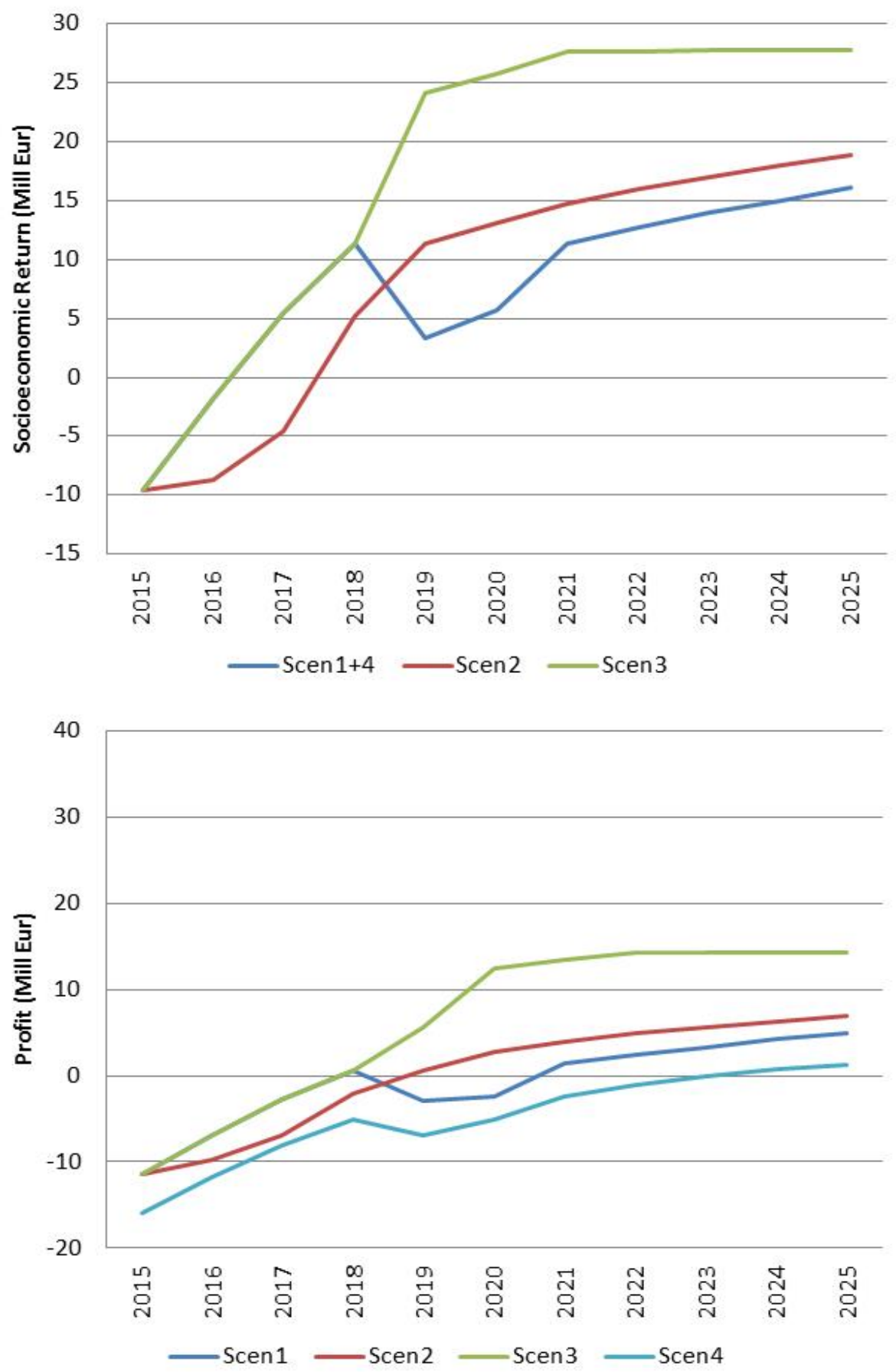


\subsection{Policy considerations}

As said in the introduction the Faroese demersal fleet has been regulated with a fishing days system since 1996. The economy of the fleet has not been a success and the biology of the stocks has not been favourable since 2002-2003. The results reported here are that the economy of the Faroese demersal fleet could be bettered significantly if the management system was changed from the current fishing days system to a quota system.

This is also been planned by the Faroese parliament to happen in 2019. The question whether this will actually happen is another question. The fishermen, and thereby some politicians, are not so keen for a quota system, and the official reason for their opposition has been that a quota system will induce considerable discards, even though these will be banned by law. The real reason might be that the fishing days system has so many excess days (cf. Figure 26 ) that the fishery is in reality almost open access, while the individual a quota system will restrict access to fish.

If we study the scenarios with the current management ( 1 and 4), and in this chapter this means that the quotas system is implemented in 2019. We see that in this case the socio-economic is much higher than in the current management i.e. with the fishing days system. The profit for the fishing industry is also much higher in the scenario 1 compared to the situation today.

There have been many discussions in the Faroes about the fisheries policy, especially the last three years, where the discussion concerned a new fisheries management system that was implemented in January 2018. One big part of this reform was a new allocation mechanism with auctions. There have been auctions in 2018 of around $15-25 \%$ of the rights for the pelagic fleet and the distant demersal fleet in the Barents Sea. In the case of the demersal fleet discussed in this chapter, the auctions of fishing rights are being initiated if the Total Allowable Catch is on a much higher level than they are today. For example, for the cod to be auctioned off, the Total Allowable Catch must be above 20 tons (cf. Figure 28). In the case that the Total Allowable Catch is increased to these levels, $25 \%$ of the stocks mentioned in this chapter are to be auctioned off. For the rest (i.e. the $75 \%$ ) there are plans that there shall be a resource tax, but only if the fleets are profitable. There have been resource taxes on the very profitable pelagic fleet since 2011 , and they still make a huge profit (cf. Figure 29). According to the model results presented in this chapter there is probably going to be a profit, if the planned implementation of the quota system goes ahead, in the demersal fleet, such that there is going to be a resource tax on the demersal around the Faroes. Scenario 4 presented above indicates what the outcomes of implementing such a tax will be.

There are of course uncertainties in the model, this chapter gives some indications what will happen if the current system was changed into an ITO system in 2019 as planned, and there is a restriction on a $4 \%$ adjustment per year. There are also other scenarios in the chapter, for example, were the adjustment was unrestricted. One thing that is not modelled is that if the fishery becomes profitable again, we could see that the vessels were modernized and become more efficient. So there are of course other limitations in a model like this and it does not show what will actually happen but can only give some indications. 


\section{Nordic policy lessons on Market Based Fisheries Management}

\subsection{Introduction}

Based on the country cases in the former chapters, the purpose of this chapter is to provide a cross-country comparison both of historical experiences with MBFM of Nordic fisheries and of forecasted future developments in the analysed fisheries under alternative hypothetical fishery policies. The cross-country comparison intends to serve as a basis for the political debate on the future of Nordic Fisheries.

In section 11.2, the prevailing MBFM systems are identified country-wise across the Nordic fisheries, while section 11.3 presents a cross-country comparison of the forecasted future developments in the selected cases under different fishery policies until 2025. Section 11.4 concludes with a list of Nordic policy lessons on MBFM.

\subsection{The use of Market Based Management in Nordic fisheries to 2015}

MBFM is founded on the direct use of the markets to allocate property rights of fishing. Transferability in the form of direct sale of fishing rights such as quotas is the core element. MBFM used in the Nordic countries today is shown in Table 41 including ITO systems, but also Individual Quota systems with restriction on transferability, and a transferable effort system. Common for these systems is the transferability of fishing rights, one way or the other. It might be argued that for example the ration regulation existing earlier in the Nordic EU countries are market based, since the value of fishing quotas are capitalized in the assets of the vessels and with vessels sold with fishing rights included, the price of a vessels was often much higher than the physical value of the vessel. Indirectly this management is also founded in the use of markets. However, ration regulation is not considered a MBFM instrument given (i) that the market foundation is only indirect and (ii) that in all the countries where ration regulation have been replaced by ITOs, a substantial structural adjustment has followed with improved economy and reduced fleet size and employment 
Table 41: Nordic fisheries subject to Based Management

\begin{tabular}{|c|c|c|c|}
\hline Country & Fishery & Market Based Management & Introduced \\
\hline \multirow[t]{2}{*}{ Greenland } & Offshore/coastal shrimp & Individual Transferable Quotas & $1991 / 2000$ \\
\hline & fisherylnshore halibut fishery & Individual Transferable Quotas & 2012 \\
\hline \multirow[t]{3}{*}{ Iceland } & Demersal fishery & Individual Transferable Quotas & $1984-1988$ \\
\hline & Pelagic fishery & Individual Transferable Quotas & 1986 \\
\hline & Vessels below 10 GRT. & Individual Transferable Quotas & 1990 \\
\hline \multirow[t]{2}{*}{ Denmark } & Pelagic fishery & Individual Transferable Quotas & $2004-2007$ \\
\hline & Demersal fishery & Individual Transferable Quotas & 2007 \\
\hline Finland & Pelagic fishery & Individual Transferable Quotas & 2017 \\
\hline \multirow[t]{2}{*}{ Sweden } & Pelagic fishery & Individual Transferable Quotas & 2009 \\
\hline & Demersal fishery & Individual Quotas with annual quota lease & 2017 \\
\hline Norway & Whole licensed fishery & $\begin{array}{l}\text { Individual Quotas with transferability within vessel groups with vessels } \\
\text { from the same region, but no transferability between vessel groups. Quota } \\
\text { transfer claims removal of selling vessel from the fleet. The regulator } \\
\text { keeps } 20 \% \text { of the quota sold and reallocates it to all vessels in the group. }\end{array}$ & 1996 \\
\hline \multirow[t]{3}{*}{ Faroe Islands } & Pelagic fishery & Individual Quotas partly transferable at auctions & 2018 \\
\hline & Demersal fishery & Transferable days at sea & Until 2018 \\
\hline & Demersal fishery & Individual Quotas & From 2019 \\
\hline
\end{tabular}

Individual Transferable Quotas is the type of management most used in Nordic countries, as appearing from Table 41, with Iceland and Greenland having the longest record with the management system. Individual Quotas is in force in Norway, with transferability of quotas being possible, but only to vessel within the same vessel group and from the same region, further claiming removal of the vessel that sells quota and with the regulator keeping $20 \%$ of the quota for reallocation to all vessels within the group. In the Swedish demersal fishery, Individual Quotas also exists with annual allocation of quotas only to active fishermen, but with the annual quota being transferable. Transferable days at sea prevail until 2018 in the Faroese Demersal fishery, after which it is replaced by an Individual Quotas system. It is a possibility of sale of demersal quotas at auction in the system, but it is not likely yet, since the quotas still are historically low.

\subsection{Cross-country comparison of forecasts until 2025}

For selected vessel groups from each of the Nordic countries, forecasts are presented in chapter $4^{-10}$ for representative average vessels in each group. The vessel groups selected all include elements of MBFM. The vessel groups are:

1. Greenlandic shrimp fishery managed by ITOs;

2. Icelandic pelagic and Stern trawler fishery managed by ITOs;

3. Danish demersal fishery in the North Sea managed by ITOs; 
4. Finnish large-scale pelagic fishery managed by ITOs;

5. Swedish large-scale pelagic fishery managed by ITQs;

6. Norwegian demersal fishery North of $62^{\circ}$ managed by Individual limited Transferable Quotas;

7. Faroese demersal fishery managed by Individual Quotas sold at auctions.

National aggregated totals of physical and economic data for the selected fisheries are shown for the base period 2012-2014 in Table 42.

Table 42: National aggregated physical and economic data, annual average 2012-2014 ${ }^{1}$

\begin{tabular}{|c|c|c|c|c|c|c|c|}
\hline & $\begin{array}{r}\text { Greenland } \\
\text { SHRIMP }\end{array}$ & $\begin{array}{r}\text { Iceland } \\
\text { DEM/PEL }\end{array}$ & $\begin{array}{r}\text { Denmark } \\
\text { DEM NS }\end{array}$ & $\begin{array}{r}\text { Finland } \\
\text { PEL }\end{array}$ & $\begin{array}{r}\text { Sweden } \\
\text { PEL }\end{array}$ & $\begin{array}{r}\text { Norway } \\
D E M>62^{\circ}\end{array}$ & $\begin{array}{r}\text { Faroe Islands } \\
\text { DEM }\end{array}$ \\
\hline \multicolumn{8}{|l|}{ Physical data } \\
\hline $\begin{array}{l}\text { Fulltime } \\
\text { employment/segment }{ }^{2}\end{array}$ & 291 & 2,394 & 359 & 110 & 167 & 5,489 & 415 \\
\hline Number of vessels & 30 & 79 & 147 & 63 & 30 & 1,192 & 45 \\
\hline Days at sea/vessel & 206 & 170 & 97 & 91 & 110 & 163 & 250 \\
\hline Main species & PRA ( 100\%) & $\begin{array}{r}\operatorname{MAC}(20 \%) \\
\operatorname{CAP}(15 \%) \\
\operatorname{COD}(12 \%)\end{array}$ & $\begin{array}{r}\operatorname{PLE}(32 \%) \\
\operatorname{COD}(26 \%) \\
\operatorname{SAl}(11 \%)\end{array}$ & $\begin{array}{r}\text { HER }(91 \%) \\
\text { SPR }(9 \%)\end{array}$ & $\begin{array}{l}\text { HER }(52 \%) \\
\operatorname{SPR}(25 \%)\end{array}$ & $\begin{array}{l}\operatorname{COD}(61 \%) \\
\operatorname{HAD}(20 \%) \\
\text { POL }(16 \%)\end{array}$ & $\begin{array}{r}\text { SAI }(30 \%) \\
\operatorname{COD}(22 \%)\end{array}$ \\
\hline Turnover/vessel (1,000 EUR) & 6,233 & 7,633 & 701 & 460 & 1,733 & 750 & 1,778 \\
\hline Fishing tax revenue (EUR Mill) & 14 & 35 & & . & . & . & \\
\hline $\begin{array}{l}\text { Profit (EUR Million) }{ }^{2} \\
\text { Profit (\% land. value) }\end{array}$ & $\begin{array}{r}39 \\
21 \%\end{array}$ & $\begin{array}{r}98 \\
16 \%\end{array}$ & $\begin{array}{r}7 \\
7 \%\end{array}$ & $\begin{array}{r}2 \\
7 \%\end{array}$ & $\begin{array}{r}12 \\
23 \%\end{array}$ & $\begin{array}{r}152 \\
17 \%\end{array}$ & $\begin{array}{r}-7 \\
-9 \%\end{array}$ \\
\hline $\begin{array}{l}\text { Socio-econ. return (EUR } \\
\text { Million) }^{2}\end{array}$ & 82 & 255 & 19 & o & 12 & 233 & -9 \\
\hline $\begin{array}{l}\text { Socio-econ. return (\% land. } \\
\text { value) }\end{array}$ & $44 \%$ & $42 \%$ & $18 \%$ & $-1 \%$ & $23 \%$ & $26 \%$ & $-11 \%$ \\
\hline
\end{tabular}

Note: 1. For details on each country cases and for sources, see country chapters. "DEM" = demersal, "PEL" = pelagic, "NS" = North Sea, "BIG" = large-scale vessels, "PRA" = shrimp, "MAC" = mackerel, "CAP" = capelin, "COD" = cod, "HER" = herring, "SPR" = sprat, "HAD" = haddock and "POL" = Pollack.

2. Data for Greenland includes only the fleets and not activities at the factories, see chapter 4 .

The considered Norwegian fishery is the largest both in terms of number of vessels $(1,192)$ and employment $(5,489$ fulltime employed). Iceland is also well covered with 2,394 fulltime employed. Number of vessels and employment included in the analysed fisheries are substantially smaller in the remaining countries. The vessel groups reflect the different types of fisheries that exist in the Nordic countries. Demersal fisheries are analysed in Norway, Denmark and at the Faroe Islands, pelagic fisheries in Finland and Sweden and both in Iceland. In Greenland, the shrimp fishery is included. Large vessels are selected for Iceland and Greenland measured in turnover per vessel, while vessels from the Faroe Islands are also relative large. Measured in turnover and average employed per vessel, the Finnish, Danish and Norwegian vessels are smallest. The Swedish and Faroese vessels are of medium size.

With the large fleet size in the selected vessel groups from Norway and with the large vessel size of the selected groups from Iceland, total annual profit is largest in these countries (respectively EUR 152 Million and EUR 98 Million). Measured in percentage of the landing values, however, profit is largest in Sweden $(23 \%$ of the 
landing value) and Greenland (21\%). Deficit only appears at the Faroe Islands, which is due to the lack of ability of the current effort regulation system to limit fishing activities.

Total socio-economic return, i.e. what societies gain from the existence of the fisheries annually, are also largest in Iceland and Norway with EUR 255 Million and EUR 233 Million. However, measured as percentage of the landing values, socioeconomic return is by far largest in Greenland (44\%) and Iceland (42\%).

The presence of ITOs in Greenland and Iceland for around thirty years is the main explanation for the economically well-performing fisheries in these two countries. Fishing taxes, on top of income taxes and corporation taxes, are in force in these two countries at a significant level, as opposed to the other countries where fishing taxes are not, or only to an insignificant degree, in force. For the Greenlandic shrimp fishery EUR 14 Million was collected, corresponding to $9 \%$ of the landing value, while for Iceland EUR 35 Million, $6 \%$ of the landing value, was collected. Such taxes are also in force in, for example Norway ( $0.2 \%$ of the landing value) and Denmark (per mille tax), but they are very small and serves other purposes.

It seems that management with ITQs for a long time period may aid fisheries in performing well economically. The increasing profits to the private fishing companies, which the remaining society automatically achieve a share of through income taxes and corporation taxes, seems to induce a pressure from the remaining society to receive their share. Arguments for introducing taxes are typically founded on, that the Nordic Fishery Laws indicate that fish stocks are the property of the societies. This pressure is behind the introduction of fishing taxes in Greenland and Iceland. The Faroe Islands also have experiences in collecting extra earning in the form of selling mackerel quotas on auctions. Hence, the three West Nordic countries where the socio-economy is severely dependent on the fisheries sector, all extraordinary collects profits from their fisheries, although the Faroe Islands in the analysed vessel group have not had much to collect with the deficits during 2012-2014.

The report has focused on the forecasted economic development for the fisheries summarised in Table 42, until 2025 using the method described in chapter 3. The following four scenarios have been analysed:

1. Current management and a $4 \%$ limit on yearly adjustment in number of vessels in each group;

2. Free ITO trade between all vessels and a $4 \%$ limit on yearly adjustment in number of vessels in each group;

3. Current management with no limit on yearly fleet adjustment;

4. Current management with a $4 \%$ limit on yearly fleet adjustment and $10 \%$ extra taxes on the landing value. 
The discounted net present value of future socio-economic return and profit are maximized through variation in number of vessels and days at sea per vessel for each included vessel group in the four scenarios. While socio-economic return measures the extraordinary economic contribution of fisheries to the socio-economy, profit is the surplus for the private fishing companies.

The forecasts depend critically on the biological development of fish stocks. Future recruitment of fish is forecasted by estimating a function where recruitment increases with the size of the fish stocks until the MSY, after which it falls. This function is identified not to let the fish stocks coming above the maximum observed in the period 1995-2014. Total Allowable Catch is determined through a policy aiming at MSY, while individual fisheries will set their catches at a level that is as close as possible to MSY, while at the same time ensuring maximum economic outcome from the fishery. An index of the development in the forecasted catches is shown for each country case in Figure 31.

Figure 31: Index of predicted catches for 2015-2025, $2015=100$

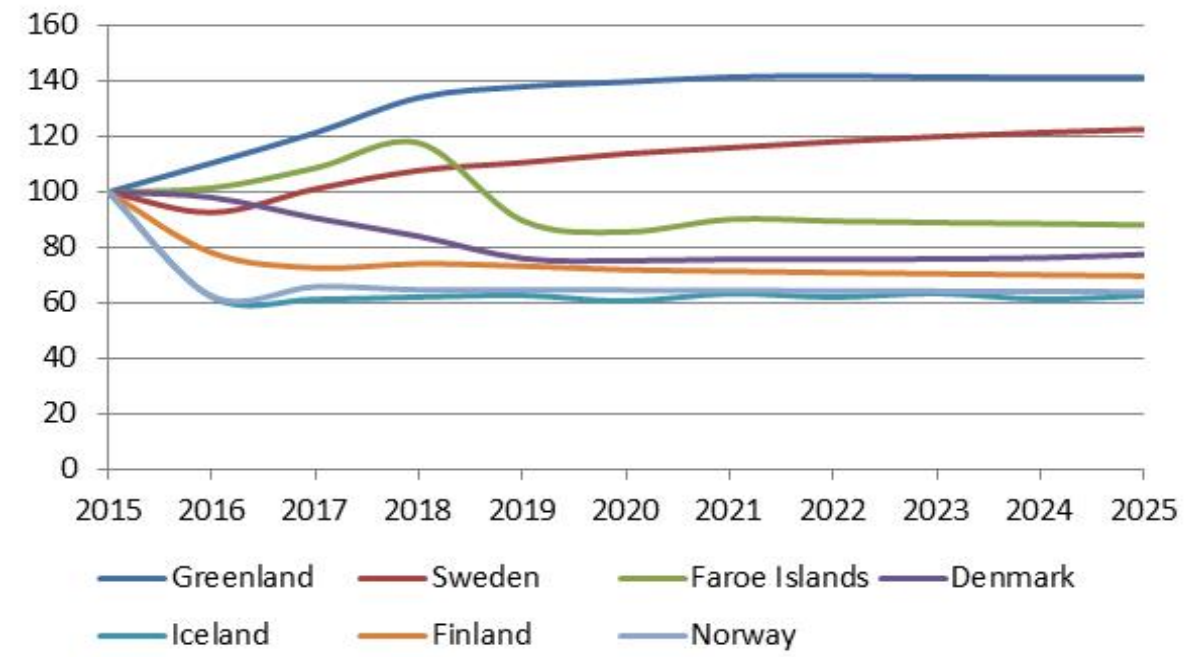

Note: 1. For each country, the index is calculated as average catches of the main species per year weighted with the share of the landing value of that species of the total turnover. The main species are those mentioned in Table 42. The countries are sorted after the size of the index in 2025. 2. The index is calculated on the basis of catches determined in the model that maximizes the net present value of future socio-economic returns. The corresponding index determined on the basis of profit does not deviation substantially from the above.

The index measures the average catch development for each country case until 2025 over the four scenarios. For each country case, the index is calculated as average catches of the main species per year weighted with the share of the landing value of that species of the total turnover. The larger index, the larger are the catches.

It appears that over the 2015-2025 forecast period catches increase most in the single species Greenlandic shrimp fishery, owing to that the shrimp stock were at a lower level in the base period 2012-2014 than over the period 1995-2014 on which the biological forecast is founded. Catches are also predicted to increase for the Swedish pelagic fleet. Catches in the remaining vessel groups are all predicted to fall. This is due to that stocks 
were at a higher level in 2012-2014 than over the entire 1995-2014 period and consequently due to that all these vessel groups perform multispecies fisheries giving rise to the "choke" species problem. The "choke" species problem indicates that if the quota on one stock is reduced, fishing effort on all stocks must be reduced correspondingly in the forecast model. The model does in such a situation forecast a substantially reduced activity in the vessel group, whilst in reality the vessels could have continued to fish on the remaining stocks, implying that the forecasted development is underestimated. Hence, since the biological forecasts might underestimate future catches in country cases where the index falls (Iceland, Norway, Finland, Denmark and the Faroe Islands) the economic forecasts are also underestimated. The relative difference of forecasts between scenarios, however, remains reliable, since all scenarios are subject to the same influence.

The forecast results are shown for 2025 in Table 43, displaying the results of the maximization of socio-economic return.

Table 43: Forecast of socio-economic return, fleet and employment adjustment in 2025 by maximizing socio-economic return

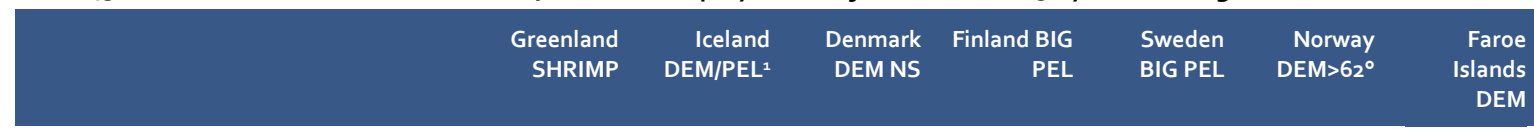

\begin{tabular}{|c|c|c|c|c|c|c|c|}
\hline \multicolumn{8}{|l|}{ Socio-economic return (EUR Million) } \\
\hline 2015 initial situation & 69 & 225 & 22 & -2 & 11 & 234 & -10 \\
\hline \multicolumn{8}{|l|}{2025 scenarios: } \\
\hline 1. Current management & 127 & 203 & 28 & 2 & 22 & 198 & 16 \\
\hline 2. ITQ management free quota trade ${ }^{2}$ & 135 & 211 & 29 & . & . & 218 & 19 \\
\hline 3. Current management full adjustment & 129 & 225 & 37 & 7 & 26 & 267 & 28 \\
\hline 4. Current management $10 \%$ landing tax & 127 & 203 & 28 & 2 & 22 & 198 & 16 \\
\hline \multicolumn{8}{|l|}{ Socio-economic return (\% land. value) } \\
\hline 2015 initial situation & 45 & 26 & 22 & -7 & 21 & 27 & -14 \\
\hline \multicolumn{8}{|l|}{2025 scenarios: } \\
\hline 1. Current management & 60 & 49 & 31 & 10 & 35 & 36 & 25 \\
\hline 2. ITO management free quota trade & 52 & 51 & 32 & . & . & 37 & 30 \\
\hline 3. Current management full adjustment & 61 & 54 & 39 & 38 & 40 & 49 & 43 \\
\hline 4. Current management $10 \%$ landing tax & 60 & 49 & 31 & 10 & 35 & 36 & 25 \\
\hline \multicolumn{8}{|l|}{ Number of vessels/processing (tons) } \\
\hline 2015 initial situation & 30 & 77 & 147 & 63 & 30 & 1,192 & 45 \\
\hline \multicolumn{8}{|l|}{2025 scenarios: } \\
\hline 1. Current management & 20 & 57 & 117 & 42 & 25 & 792 & 34 \\
\hline 2. ITQ management free quota trade & 24 & 53 & 118 & . & . & 792 & 31 \\
\hline 3. Current management full adjustment & 17 & 33 & 90 & 31 & 22 & 498 & 22 \\
\hline 4. Current management $10 \%$ landing tax & 20 & 57 & 117 & 42 & 25 & 792 & 34 \\
\hline \multicolumn{8}{|l|}{ Employment (full-time) } \\
\hline 2015 initial situation & 291 & 2,331 & 352 & 110 & 168 & 5,471 & 444 \\
\hline \multicolumn{8}{|l|}{2025 scenarios: } \\
\hline 1. Current management & 201 & 1,764 & 272 & 73 & 141 & 3,637 & 334 \\
\hline 2. ITQ management free quota trade & 232 & 1,595 & 273 & . & . & 3,637 & 309 \\
\hline 3. Current management full adjustment & 167 & 1,066 & 192 & 37 & 120 & 2,232 & 240 \\
\hline 4. Current management $10 \%$ landing tax & 201 & 1,764 & 272 & 73 & 141 & 3,637 & 334 \\
\hline
\end{tabular}

Note: $\quad$ 1. For Iceland, the initial year is 2016.

2. With the vessel groups included in the Finnish and Swedish cases, more quota trade than in scenario 1 is not possible in scenario 2. Therefore, scenario 1 and 2 are the same and only shown for scenario 1.

Source: Country cases in chapter 4-10. 
It appears from Table 43 that the socio-economic return increase in 2025 compared to 2015 in all countries except in the Norwegian and Icelandic case. The socio-economic return in these two countries falls due to the forecasted catch reduction and to the "choking" problem, except for in the full adjustment scenario in the Norwegian case. The catches in 2025 are forecasted to decrease in both countries (cf. the discussion of Figure 31). Given that the Icelandic and Norwegian fisheries have been managed with market based instruments in many years, the predicted reduction in socio-economic return is surprising. Reasons might include that reduction in fish stocks and choking effects induces underestimation of the socio-economic return. But the reason in particular in Iceland may also be that vessels have high capital costs with expected future earnings capitalized in the quota values, affecting profit negatively when stocks dwindle. For the remaining countries, socio-economic return increases in all scenarios. In scenario 1, the largest increase appears in Sweden, Greenland, and the Faroe Islands. These three countries are, however, also the countries that perform best on catch development over the period. Hence, the positive economic development is not only due to structural adjustment following from MBFM, but also due to a predicted positive biological development in the fish stocks.

To clean for exogenous development in the fish stocks, whether positive or negative, the socio-economic return in percentages of the landing value must be compared.

In 2015, the socio-economic return is largest in Greenland forming $45 \%$ of the landing value, on a medium level in Norway, Iceland, Denmark and Sweden (21-27\%), whilst negative at the Faroe Islands and in Finland. The high share of socio-economic return in the Greenlandic case is believed to reflect (i) that ITOs have been into force since 1991 for the large vessels and for all vessels since 2000 and (ii) that shrimp are caught by large vessels with increasing returns to scale. The low share in Finland reveals the earlier management with only Total Allowable Catches that are not followed by input regulation and, simultaneously, the negative socio-economic return at the Faroe Islands follows from the current days at sea management, with total days a sea not limiting the activity of the fleet. For the Danish and Norwegian cases the medium sized share might reflect that the demersal fleet consists of relative small vessels, while both the share and the vessels in the Swedish case are medium sized. Management is also important, with ITQs in Denmark since 2007 and only more recent in Sweden since 2009. The medium size of the share of the socio-economic return in the Norwegian case might reveal that the management with Individual Quotas have induced some medium level of structural adjustment in the fleet, despite the quotas only having limited transferability. The substantially reduced Icelandic share on $26 \%$ in 2015 compared to the $42 \%$ in base period (2012-2014) is surprising with the fleet consisting of large vessels, but might due to the forecasted catch reduction appearing in Figure 31 . The sharp reduction, however, also induce uncertainty on the Icelandic forecast results.

The socio-economic return in percentage of landing value is predicted to increase from 2015 to 2025 in all country cases in all scenarios from 2015, except in the Norwegian case in scenario 4 , with the introduction of a $10 \%$ landing tax.

Under the current management (scenario 1), the socio-economic return in percentage is predicted to increase most in relation to 2015 at the Faroe Islands from 
the current deficit on $14 \%$ to a surplus on $25 \%$ of the landing value. The percentage rises is also substantial in Iceland (23\%-points), Finland (17\%-points), Greenland (15\%points) and Sweden (14\%-points), while smallest in Norway and Denmark (9\%-points). Hence, in scenario 1 of unchanged management, the increases in socio-economic return in percentage of landing value at the Faroe Islands, Finland and Sweden are forecasted to follow the introduction of Individual Quotas (at the Faroe Islands in 2019) and ITQs (in Sweden in 2009 and in Finland in 2017). In the Icelandic case that has been managed with ITOs for many years, the sharp increase follows from catch fluctuations, while for Greenland a continued structural adjustment is forecasted leading to very high socio-economic return in percentage of the landing value. The increase for the Danish and Norwegian cases is relative small, which might be explained by this fishery being undertaken by relative small vessels.

The resulting situation in 2025 in scenario 1 reveals that the socio-economic return in percentage of landing values is highest in Greenland and Iceland (60\% and 49\%), which is believed to be due to the fisheries being performed with large vessels that have been managed with ITOs for many years, lowest in Finland (10\%) and at the Faroe Islands (25\%) due to earlier management where only a part of the expected structural adjustment comes before 2025 . The share in the remaining cases in between on 31$36 \%$ reflects both the size of the vessels, the type management and for how long the regulations have been in force.

The number of vessels is in scenario 1 forecasted to have decreased in in 2025 compared to 2015 with $17-34 \%$ in all country cases when maximizing socio-economic return, while employment is predicted to fall with $16-34 \%$ except in Greenland where the reduced employment at the vessels are counterbalanced by increased employment at the land-based factories included in this country case only. Maximizing profit (Table 44 below) induce largely the same structural adjustment. Hence, with a continuation of the current management and without any policy changes, the structural adjustment is predicted to continue and lead to both a lower number of vessels and a reduced employment. Furthermore, since these forecasts are made assuming unchanged technology and since the technology normally improves over time, this structural adjustment might well be larger.

In scenario 2, assuming free quota trade with a $4 \%$ limit on annual fleet adjustment, the socio-economic return in percentage of landing values are larger than under continuation of the current management (scenario 1) in all cases except the Greenlandic. The increase in the share is, however, small in all cases with the largest increase seen at the Faroe Islands. The development in number of vessels and employment doesn't differ more than $10 \%$ compared to continuation of the current management (scenario 1).

In the Greenlandic case, the socio-economic return in percentage of the landing value fall in scenario 2 compared to scenario 1 , although the absolute socio-economic return increases. The reason for the reduction is that catches increases with free quota trade, since all quotas can be used.

In scenario 3 of continuing the current management unchanged without limiting annual fleet adjustment, the socio-economic return share increases, compared to 
scenario 1 , in all cases. The increase in the share is largest in Finland with $28 \%$ (from $10 \%$ to $38 \%$ ) and at the Faroe Islands (18\%), where MBFM is first introduced in 2019. The increase in the Greenlandic and Icelandic case are very small, revealing that the structural adjustment has already lead to an approximately optimal fleet structure in these two countries, since they have had ITQs for many years. The Danish, Norwegian and Swedish cases are in between, revealing that some structural adjustment have already been seen, whilst some also remains.

The resulting situation in 2025 in scenario 3 is almost the same as in scenario 1 in Greenland and Iceland, while the share increase for the remaining countries $38-49 \%$ dependent on in particular management, size of vessels and returns to scale.

The number of vessels falls substantially with $12-42 \%$ and employment falls even more with $13-66 \%$ under scenario 3 compared to scenario 1 . Fleet size and employment are reduced least in Greenland and Sweden, owing to the forecasted growth in catches. In the Icelandic and Faroese case, the fleet size is forecasted to fall the most, for the Icelandic case due to the uncertain predicted catch reduction, while for the Faroese case catches are predicted more stable and the reduction is mainly due to the shift from the current effort regulation to Individual Quotas in 2019.

Scenario 2 and 3 consider the same situation as in scenario 1 except for respectively replacing current management with free quota trade and afterwards removing the $4 \%$ fleet adjustment limit to full adjustment. But the situation where the two changes, i.e. free quota trade and full adjustment, are made simultaneously is not analysed. In such a situation, the effects of scenario 2 and 3 are expected to be combined, inducing larger socio-economic return than in scenario 2 and 3 , as well as lower fleet size and lower employment.

In scenario 4 of continuing the current management with an added tax on $10 \%$ of the landing value the socio-economic return appears approximately the same as under the current management (scenario 1 ). The reason is that the tax transfer amounts from fishermen to the Government, but doesn't affect efficiency of fisheries substantially.

The forecast results where profit is maximized in the four scenarios are shown in Table 44. Profit differs from socio-economic return by being the economic surplus of fishermen where socio-economic return is the economics surplus of society. 
Table 44: Forecast of profit, fleet and employment adjustment in 2025 by maximizing profit

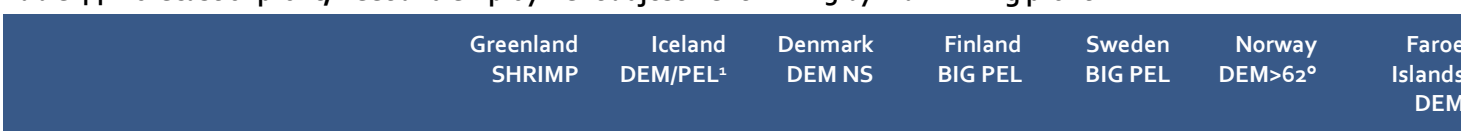

Profit (EUR Million)

2015 initial situation

2025 scenarios:

1. Current management

2. ITO management free quota trade 3

3. Current management full adjustment

4. Current management $10 \%$ landing tax

Profit (\% land. value)

2015 initial situation

2025 scenarios:

1. Current management

2. ITO management free quota trade

3. Current management full adjustment ${ }^{2}$

4. Current management 10\% landing tax

Number of vessels/processing (tons)

2015 initial situation

2025 scenarios:

1. Current management

2. ITO management free quota trade

3. Current management full adjustment

4. Current management $10 \%$ landing tax

Employment (full-time)

2015 initial situation

2025 scenarios:

1. Current management

2. ITQ management free quota trade

3. Current management full adjustment

4. Current management 10\% landing tax

$\begin{array}{ll}31 & 110 \\ 70 & 77 \\ 72 & 84 \\ 71 & 48 \\ 58 & 60\end{array}$

22
28
29
37
28

$2 \quad 12$

$\begin{array}{rrr}12 & 138 & -12 \\ 20 & 101 & 5 \\ . & 113 & 7 \\ 23 & 145 & 14 \\ 16 & 75 & 1\end{array}$

$20 \quad 8$

$33 \quad 18$

$28-31$

$28 \quad 20 \quad 32$

$34 \quad 12 \quad 39$

$\begin{array}{lll}27 & 16 & 34\end{array}$

$19 \quad 32$

2

38

$38 \quad 35$

$10-29$

$23 \quad 16 \quad-16$

$18 \quad 8$

$\begin{array}{lll}19 & 11 \\ 27 & 22\end{array}$

$14 \quad 2$

$30 \quad 76 \quad 147$

$\begin{array}{lllll}147 & 63 & 30 & 1,192 & 45\end{array}$

$\begin{array}{lllllll}20 & 56 & 117 & 51 & 23 & 792 & 35\end{array}$

$\begin{array}{lllllll}22 & 53 & 118 & 5 & . & 792 & 32\end{array}$

$\begin{array}{lllllll}15 & 31 & 90 & 47 & 17 & 175 & 23\end{array}$

$20 \quad 54$

117

47

$23 \quad 792 \quad 34$

Note: 1 . For Iceland, the initial year is 2016.

2. Profit in percentage of landing value before deduction of taxes is shown.

3. With the vessel groups included in the Finnish and Swedish cases, more quota trade than in scenario 1 is not possible in scenario 2. Therefore, scenario 1 and 2 are the same and only shown for scenario 1.

Source: Country cases in chapter 4-10.

The structural development when maximizing profits are to a large extent the same as maximizing socio-economic return. Some differences, however, remains. Profits are at a lower or the same level than socio-economic return in all countries in all scenarios due to (i) salary in fishing being higher than in other sectors, (ii) the rate of return on capital being higher in fishing than other sector, (iii) cost of quota purchase, and (iv) fishing taxes being paid by fishermen in some cases.

Profit in percentage of landing values are in 2015 all lower than or equal to the socio-economic share of landing values. The reasons are that remuneration of labour is larger in fisheries than in alternative sectors in which fishermen could work, that remuneration of capital is larger than in alternative industries assets could be invested and that profit over time is removed from the fishery through payment of permanent quotas to earlier fishermen. The profit share in 2015 confirms the result above that the Swedish, Danish and Greenlandic fisheries managed with ITOs are highest, while the Faroese and Finnish share are smallest. 
In scenario 1, profit in percentage of landing values confirms the relative sizes achieved for socio-economic return except for Iceland. For the Icelandic case the low profit share (8\%) indicates on top of reduced catches that ITOs have been in force for many years with expected future earnings therefore being capitalized in permanent quota values and removed from the fishery through quota trade. Forecasting profit also confirms the developments identified for socio-economic return in scenario 2 and 3 .

In scenario 4, the tax introduced under an otherwise unchanged management affects, as opposed to socio-economic return, profit. Profits in scenario 4 falls or stays unchanged in 2025 in all country cases compared to scenario 1. Compared to 2015, however, profit increases despite of the tax in all cases except in Iceland and Norway. In these two countries, profit is reduced due to the forecasted catch reduction. For the remaining country cases, this calculation tells that even with a 10\% tax on the landing value, profits will increase in 2015-2025 with unchanged continued management.

Hence, if taxes are introduced before structural adjustment is completed, the negative pressure on profits they induce, can often be more than meet by the positive pressure on profit from future structural adjustment. Thus, it may be free of charge for the fishing vessels that remain active to have taxes introduced in the long run, although taxes also affect fleet size and employment negatively.

The forecast results above are discussed only for the year 2025, while it should be kept in mind that the forecasts are made for the total period 2015-2025. In 2016, profits are forecasted either to decline or increase less than in the following years. After 2016 only increases are predicted. With company decisions on investment in quotas being based on profits, the speed of the structural adjustment is determined by profit.

In scenario 1 of current management, $75 \%$ of the development in profits in 20162025 is achieved after $3-8$ years, with the fastest speed in the Greenlandic case and the slowest in Denmark. In scenario 2 of free quota trade, the adjustment is slowest in Denmark, Iceland and Norway ( $75 \%$ of the adjustment is achieved after 7 years), whilst fastest in Greenland ( 2 years). In scenario 3, adjustment is substantially faster with $75 \%$ of the effect obtained after 1-4 years in all cases. In scenario 4 the adjustment is a bit slower than in scenario 1 with $75 \%$ of the adjustment achieved one year later than in scenario 1 in most of the country cases.

The speed forecasted reveals that structural adjustment following MBFM reforms doesn't happens overnight, but on the contrary can take some time. Further, taking into account improvements in fishing technology over time, biological fluctuations and price fluctuations, it must be concluded that fisheries are often prone to some degree of continued never ending structural adjustment.

While the forecasts presented in this report identify lessons on MBFM at an early time where it remains possible to revise the fishery policies, they are also based on an "all other things equal" assumption. This is in particular relevant for prices that are assumed constant over the whole 2015-2025 period at the level in 2012-2014. While constant fish prices over time might be realistic given the relative constancy over the last decade of the FAO fish price index (Food and Agricultural Organization of the United Nations 2018), price fluctuations may arise from supply and demand chocks. Prices for largely all species are, however, formed on international integrated markets 
at which supply from Nordic fisheries are in competition with many other countries. Hence, fish supply from one Nordic fishery is in most cases not able to have noticeable effect on prices at the world market. That accounts for whitefish (cod, haddock, saithe, pollack and plaice), fish for reduction (sprat and capelin) and presumable also for shrimp, where the species supply internationally integrated world markets, respectively for whitefish, fishmeal and oil and shrimp (Asche and Tveteraas 2004; Nielsen et al. 2009; Bronmann et al. 2016; Ankamah-Yeboah et al. 2017).

On the other hand, Nordic fisheries are affected by supply and demand developments at the world markets. Here the long run trend is an upward pressure on prices following increased demand due to population growth, income growth and growing preferences for healthy food such as fish. This trend is met by a downward pressure on prices following an expected continued growth in global aquaculture, with supply of capture fisheries globally expected to stagnate. Aquaculture growth in pangasius, tilapia and warm water shrimp may in particular be important for Nordic fisheries, since these species compete at the European markets, respectively for whitefish and shrimp. Hence, demand seems to press fish prices upwards and aquaculture supply to press prices downwards, making constant prices a reasonable albeit uncertain assumption.

\subsection{Nordic policy lessons on Market Based Fisheries Management}

Fishery policies are heavily debated across the Nordic counties. Earlier the main subject focused on avoiding overexploitation and overcapacity, where it today is agreed by most that fishing must be sustainable and quotas set according to MSY. Today, therefore, the debate has a more direct focus on how to distribute the economic wealth fisheries create, following the earlier introduction of MBFM.

The debates on MBFM in the Nordic countries generally go in three different lines of arguments that feed into political decisions. One line of arguments emphasizes the socio-economic contribution of fisheries to fund national wealth. This line of arguments favours MBFM as an instrument to create societal wealth by having a viable and efficient fleet. Some finds that the current management with special arrangements for certain vessel groups, in some instances also for certain regions, ensure a reasonable balance between large/small vessels and regionally. Other finds that such special arrangements are not needed and may reduce socio-economic return and profits in fisheries.

Another line of arguments focuses on fisheries as a job creating sector, often by providing employment in small fishing communities spread along the coast where alternative jobs are difficult to find, and where reduction of the local fleet may decimate the harbour community and labour opportunities. Fishery reforms that at the expense of a larger GDP contribute to reducing local employment, induces a social risk when few alternative jobs are available. This line of arguments might be against ITQs. But it might also favour it if quotas are reallocated from offshore to small and local vessels. 
A third line of arguments sees the extension of large vessels as a way to increase the maximum GDP contribution and societal welfare. However, since profits go to the private fishing companies, taxes or public sale of quotas are needed for society to obtain a fair share. This line of arguments is in favour of ITQs in combination with fishing taxes.

Nordic experiences and the forecasts provided in this report identify several lessons on the functioning of MBFM. These are relevant in debating the future Nordic fishery policies and enlighten the political trade-offs and dilemmas following from the three lines of arguments. The lessons are:

1. ITQs is a powerful instrument to increase earnings and remove overcapacity, but simultaneously fleet size and employment in fisheries is reduced;

2. All prevailing Nordic MBFM systems have special arrangements for some vessel groups;

3. The Market Based Management systems in the Nordic fisheries all have some variation of concentration rule in force;

4. It is not a universal rule that MBFM always removes the small vessels;

5. Fishing taxes may play a core role for wealth creation in the fishery dependent Nordic countries;

6. Expensive quotas makes it difficult to remove or drastically change an ITO system;

7. Continued MBFM is forecasted to increase socio-economic return and profit towards 2025 substantially;

8. Free quota trade induces extra earning compared to current regulation in 2025 ;

9. An extra fishing tax on $10 \%$ of the landing value can in most of the country cases be collected without reducing profits in the long run.

Each lesson is explained in the following below.

1. ITQs is a powerful instrument to increase earnings and remove overcapacity, but simultaneously fleet size and employment in fisheries is reduced

ITOs have in all the Nordic countries been used as a powerful management instrument to eliminate overcapacity, thereby increasing profit and socio-economic return substantially, but have also reduced fleet size and employment in fisheries substantially. Although fleet reductions are also caused by other factors, such as technological development, ITOs have contributed substantially to solve the overcapacity problem. And, thereby, solve the basic fishery management problem "to avoid that there are many fishermen to fish too few fish" that other types of regulation have struggled with for many years. ITOs have also made vessel modernization and decommissioning subsidies redundant and have led to their elimination. For example, the ITQ system in the Swedish pelagic fisheries have increased earnings substantially and reduced the fleet with $55 \%$ in four years (2009-2013), while the Greenlandic coastal 
shrimp fishery is reduced $82 \%$ in $1992-2017$ and today as opposed to earlier have surplus profit. While part of these effects may be due to other drivers than regulation, for example technological development, the Nordic experiences indicate that ITOs increase the speed of fleet adjustment. Other types of MBFM have had same effect as ITQs but to a lesser degree, except the Faroese effort regulation that is largely open access.

\section{All prevailing Nordic Market Based Fisheries Management systems have special arrangements for some vessel groups}

A fully liberal ITO system with fully free quota trade does not exist in the Nordic countries. Examples of special arrangements include coastal fishery arrangements for smaller vessels in Iceland and Denmark and for Greenlandic shrimp fishing. The smaller vessels are protected by a quota sales ban to larger vessels and in Denmark combined with extra allocation of quotas. In Sweden small-scale herring fishery in The Sound is not part of the ITO management, while in Norway quota transferability is limited to within each vessel group and further subject to geographical restrictions. The special arrangements reveal different purposes of the fishery policies that span from economic viability of the fleet and contribution to GDP, to regional priorities with the fleet spread in certain regions along the coast in many living fishing harbours. The broad use of special arrangement reveals that it is possible to control the structural adjustment in the Nordic Market Based Fisheries systems. Every time a special arrangement is introduced, however, profit and GDP contribution of fisheries is reduced.

\section{The Market Based Management systems in the Nordic fisheries all have some variation of concentration rule in force}

The Market Based Management of Nordic fisheries prevails only with concentration rules in force. MBFM has led to concentration of vessels and quotas on fewer hands, since such management is introduced when there are too many fishermen and too many vessels. The whole idea is to concentrate fishing on fewer fishermen and fewer vessels. However, to avoid concentration of ownership of vessels and quotas on very few hands and following the principle that "fishing must be performed by fishermen with boots on", Greenland, Iceland and Denmark, for example, all specify percentage of quotas that must be in the hand of a single company or person, while Norway uses quota roofs for each vessel for the same purpose. When concentration is restricted, profit and GDP contribution of fisheries are often reduced. 


\section{It is not a universal rule that Market Based Fisheries Management always removes the small vessels}

The fleet structure with large and small vessels is determined both by technology, regulation and type of fishery. While Market Based Management of Nordic fisheries have reduced the number of vessels totally, it is an empirical question whether the number of small vessels is reduced more than the number of large vessels. Since pelagic fish are in most cases caught by large vessels and demersal fish often caught by small and medium sized vessels, small and medium sized vessels are not expected to disappear. Small and large vessels do not fish the same species. In Denmark, for example, even with free trade in permanent quota shares, the reduction in different vessel length groups is largely the same from the year 2000 until today. What is observed, however, is that within each vessel group the average vessel size increases. In Greenland, the coastal and off shore production trawler fleet have also been reduced largely by the same percentage since 2000. In Sweden, following the introduction of ITQs for pelagic fisheries, the number of vessel above 24 meter is reduced more than vessel below 24 meter in the period 2009-2013.

\section{Fishing taxes play a core role for wealth creation in more of the fishery dependent Nordic countries}

Taxes are applied and very important to fund public wealth in Greenland and Iceland, and have lesser extent also played a role at the Faroe Islands. Fishing taxes can potentially also play a role in the remaining Nordic countries, but with fishing sectors being a small activity nationally the pressure from tax payers is small. In these countries, prioritizing socio-economic return from a national perspective may not necessarily induce positive effects on socio-economic return in local fishing communities. Transfer of revenue from fishing taxes to local communities may then have a role to play in mitigating negative effects of MBFM.

\section{Expensive quotas make it difficult to remove or drastically change an ITQ system}

Capitalization makes larger revisions of Market Based Managed fisheries in the form of special arrangements and taxes expensive over time. The reason is that expected future earnings are capitalized in quota prices when permanent quota shares are traded. The current generation of quota owners has paid a price for their quotas founded on what they can expect to earn in the future. Hence, the expected future earning is removed from the fishery and ends at the fishermen that sell quotas. New special arrangements and taxes may induce economic problems for the current vessels that, due to the earlier paid quota prices, may not earn over-normal profit. Capitalization also makes it economically difficult to replace MBFM. Finally, capitalization makes it economic difficult to introduce the management, see what happens, learn by mistakes and then revise the system until it fits the political priorities. MBFM makes great demands to clear political priorities and to design the system in a long-lasting way already at the introduction. Reforming Market Based managed fisheries is thus economical easiest at 
times where unexpected price increases and unexpected fish stock increases can counterbalance negative economic effects. The only Nordic example of a removal of an ITO system was at the Faroe Islands in 1996, where the management was abolished due to the unexpected return of demersal fish after being in force for only two years. At some point in time it may become so expensive to change the system that there is no point of return.

\section{Continued Market Based Fisheries Management is forecasted to increase socio- economic return and profit to 2025 substantially}

Socio-economic return and profit is forecasted to increase substantially over the period until 2025 in most of the country cases, while biological stock reductions are predicted to reduce socio-economic return and profit in other of the country cases. The fleet is forecasted to be reduced with $17-34 \%$ in $2015-2025$, where the socio-economic return cleaned for biological developments by being in percentage of landing values is forecasted to increase 9-39\%-points. Hence, despite MBFM has been in force for many years in some of the countries, structural adjustment is far from over. Further taking technological developments into account would lead to an even faster structural adjustment. Nordic fisheries faces over the coming decade continued growth in GDP contribution, continued fleet reduction and continued reduced employment in fisheries.

\section{Free quota trade induces extra earning compared to unchanged management in} 2025

MBFM and in particular ITQs is a powerful management instrument that increases the socio-economic return of the sector by letting the most efficient vessels buy quotas from other fishermen thereby from a society point of view taking advantage of fishermen skills, the best available fishing technologies, possible increasing returns to scale and clustering of the sector a few places instead of being spread. However, the effect of free quota trade on socio-economic return and fleet development is in this report predicted to be small, which might be due to that fishermen leaves fishing later than what is rational economically for them, for example following planned pension and time lags in their leave decisions.

9. An extra fishing tax on $10 \%$ of the landing value can in most of the country cases be collected without reducing profits in the long run

Introducing an extra tax on $10 \%$ of the landing value induce a downward pressure on profits, but otherwise unchanged management affect profits upwards over time. In most of the analysed cases, profits are forecasted to increase in 2025 compared to 2015, even with the $10 \%$ tax. Hence, the socio-economic return prevailing in fisheries with MBFM can still be collected to the Government to fund public wealth without inducing deficits in many of the Nordic fisheries. 


\section{Bibliography}

Andersen, J. L., Frost, H., \& Løkkegaard, J. (2005). Forvaltning af det danske konsumfiskeri. Fødevareøkonomisk Institut. Rapport / Fødevareøkonomisk Institut, Nr. 176.

Andersen P., Andersen J.L., Frost H. (2010). ITQs in Denmark and Resource Rent Gains. Marine Resource Economics, Vol 25., pp 11-22.

Ankamah-Yeboah, I., L. Staahl and M. Nielsen (2017), Market integration of cold- and warmwater shrimp in Europe, Marine Resource Economics 32(4):371-90.

Anon (2001) Economic performance of selected European fishing fleets: Annual Report 2001. Concerted Action FAIR CT-97-3541, Promotion of Common Methods for Economic Assessment of EU Fisheries.

Armstrong, C. W., \& Sumaila, U. R. (2001). Optimal allocation of TAC and the implications of implementing an ITQ management system for the North-East Arctic cod. Land Economics, 77(3), 350-359.

Arnason, R. (1993). The Icelandic individual transferable quota system: Adescriptive account. Marine Resource Economics, 8(3), 201-218.

Arnason, R. (2002). A review of international experiences with ITQs: Annex to future options for UK fish quota management. Portsmouth: University of Portsmouth.

Arnason, R. (2005). Property rights in fisheries: Iceland's experience with ITQs. Reviews in Fish Biology and Fisheries, 15(3), 243-264.

Arnason, R. (2008). Iceland's ITQ system creates new wealth. The Electronic Journal of Sustainable Development, 1(2), 35-41. Retrieved from http://www.ejsd.co/docs/ICELANDS_ITQ_SYSTEM_CREATES_NEW_WEALTH.pdf

Arnason, R., Hannesson, R., \& Schrank, W. E. (2000). Costs of fisheries management: the cases of Iceland, Norway and Newfoundland. Marine Policy, 24(3), 233-243.

Asche, F. and S. Tveteraas (2004), On the relationship between aquaculture and reduction fisheries, Journal of Agricultural Economics 55(2):245-265.

Asche, F., Bjørndal, T., \& Gordon, D. V. (2009). Resource rent in individual quota fisheries. Land Economics, 85(2), 279-291.

Baldursson, E., \& Gunnlaugsson, S. (2004). Sjávarútvegur í kauphöllinni: Saga og greining. Reykjavík: Kauphöll Íslands.

Baudron, A., Ulrich, C., Nielsen, R. J., \& Boje, J. (2010). Comparative evaluation of a mixedfisheries effort-management. ICES Journal of Marine Science(67), pp. 1036-1050. Retrieved from https://academic.oup.com/icesjms/article/67/5/1036/607659

Bjorndal, T., Child, A., \& Lem, A. (2014). Value chain dynamics and the small-scale sector: Policy recommendations for small-scale fisheries and aquaculture trade (FAO Fisheries and Aquaculture Technical Paper no. 581). Retrieved from http://www.fao.org/fileadmin/user_upload/fisheries/docs/Value_chain_dynamics_and_the_s mall-scale_sector.pdf

Björk, L. 2017. Who do you know? Transaction relations in the Swedish pelagic ITQ system. In Essays on Behavioral Economics and Fisheries: Coordination and Cooperation. Ph.D. thesis, Economic studies No. 229. Department of Economics, University of Gothenburg.

Bronmann, J., I. Ankamah-Yeboah and M. Nielsen (2016), Market integration of pangasius and tilapia in relation to wild-caught whitefish in Germany, Marine Resource Economics. 31(4):421-432.

Christensen, A. S., Hegland, T. J., \& Oddsson, G. (2009). The Icelandic ITQ system. In K. H. Hauge \& D. C. Wilson (Eds.), Comparative evaluations of innovative fisheries management: Global experiences and European prospects (pp. 97-118). New York: Springer. 
Chu, C., 2009. Thirty years later: the global growth of ITQs and their influence on stock status in marine fisheries. Fish Fish., 10 (2009), pp. 217-230.

Copenhagen Economics (2013), The Ecoonomic footprint of the fishery in Greenland, in Danish (Fiskeriets økonomiske fodaftryk i Grønland), report to the Greenland Business Association, October 2013, available at:

https://www.copenhageneconomics.com/dyn/resources/Publication/ publicationPDF/8/248/o/Fiskeriets\%20økonomiske\%2ofodaftryk\%20i\%20Grønland.pdf

Danielsson, A. (1997). Fisheries management in Iceland. Ocean \& Coastal Management, 35(2), 121-135.

Danish Agrifish Agency. Yearbook of fisheries statistics (2002, 2007, 2014).

Danish Ministry of Food, Agriculture and Fisheries, 2003. Regulation Directive no. 1028 of 11 December 2003.

Danish Ministry of Food, Agriculture and Fisheries, 2004. Directive on vessels used for commercial fishery in salt water, no. 124 of 27 February 2004.

Danish Ministry of Food, Agriculture and Fisheries, 2005. Parliamentary agreement on new regulation of Danish fisheries between the Government and Danish People's Party, 3rd November 2005 (In Danish).

Danish Ministry of Food, Agriculture and Fisheries, 2007. Strategy for the development of the Danish fishery and aquaculture sector 2007-2013 made for the European Fisheries Fund, 23 March 2007 (in Danish).

Danish Ministry of Food, Agriculture and Fisheries, 2008. Act on Fisheries and Aquaculture, Directive no. 978 of 26 September 2008.

Directorate of Fisheries, Hunting and Agriculture (1994), Modernization of the coastal and inshore fisheries, pp. 25-54, In Danish, review for the working group on structural adjustment under the Directorate of Fisheries, Hunting and Agriculture to the second spring meeting in the Greenland Parliament, Greenland Home Rule, Nuuk.

Directorate of Fisheries, Hunting and Agriculture (1995), Coastal shrimp fishery - capacity adjustment and regulation, in Danish, review made for the autumn meeting in the Greenland Parliament, Greenland Home Rule, Nuuk.

Directorate of Fisheries. (2014a). Fisheries management. Retrieved from http://www.fiskistofa.is/english/fisheries-management/

Directorate of Fisheries. (2014b). Strandveiðar (Quota to coastal fisheries). Retrieved from (Icelandic only) http://www.fiskistofa.is/fiskveidistjorn/umfiskveidistjornunarkerfid/strandveidar/

Directorate of Fisheries. (2014C). Línuívilnun (Quota to onshore bated longline). Retrieved from (Icelandic only) http://www.fiskistofa.is/fiskveidistjorn/linuivilnun/

Directorate of Fisheries. (2017a). Úthlutað aflamark fyrri ár (Annual catch quota previous years). Retrieved from (Icelandic only) http://www.fiskistofa.is/aflamarkheimildir/uthlutadaflamark/fyrriar/

Directorate of Fisheries. (2017b). Veiðigjöld (Fishing fees). Retrieved from (Icelandic only) http://www.fiskistofa.is/fiskveidistjorn/veidigjold/

Directorate of Fisheries. (2017c). Byggðakvóti (Quota to offset major disturbances within the system). Retrieved from (Icelandic only) http://www.fiskistofa.is/veidar/aflaheimildir/byggdakvoti/

Eggert, H., \& Tveterås, R. (2013). Productivity development in Icelandic, Norwegian and Swedish fisheries. Applied Economics, 45(6), 709-720.

Einarsson, N. (2011). Fisheries governance and social discourse in post-crisis Iceland: Responses to the UN Human Rights Committee's views in case 1306/2004. In G. Alfredsson \& T. Koivurova (Eds.), The Yearbook of Polar Law: Vol. 3 (pp. 479-515). Leiden: Martinus Nijhoff.

Eliasen, S., S. Sverdrup-Jensen, P. Holm and J. P. Johnsen. 2009. Nordic experience of fisheries management. Seen in relation to the reform of the EU Common Fisheries Policy. TemaNord 2009:579. Nordic Council of Ministers, Copenhagen.

EU 2013. Regulation No. 1380/2013 on the Common Fisheries Policy. 
Eythórsson, E. (1996). Theory and practice of ITQs in Iceland: Privatization of common fishing rights. Marine Policy, 20(3), 269-281.

Eythórsson, E. (2000). A decade of ITQ-management in Icelandic fisheries: Consolidation without consensus. Marine Policy, 24(6), 483-492.

Fiskidaganevndin. (2017). Tilmæli um fiskidagar 2017/2018.

Fjársýsla Ríkisins (2017a). Ríkisreikningur 2014. Retrieved from

http://www.fjs.is/media/rikisreikningur/Rikisreikningur-arid-2014-Heildaryfirlit-

Rafraenundirritun.pdf

Fjársýsla Ríkisins (2017b). Ríkisreikningur 2013. Retrieved from

http://www.fjs.is/media/rikisreikningur/Rikisreikningur-arid-2013,-Heildaryfirlit---Rafraenundirritun.pdf

Food and Agricultural Organization of the United Nations (2018), FAO Fish Price Index-March 2018 update, includes September 2017, available at: http://www.fao.org/inaction/globefish/fishery-information/resource-detail/en/c/338601/

Frost, H., \& Kjærsgaard, J. (2005). Overkapaciteten i den danske fiskerflåde. København: Fødevareøkonomisk Institut. Rapport / Fødevareøkonomisk Institut, Nr. 175

Frost, H. S., \& Løkkegaard, J. (2001). Individuelle omsættelige kvoter: kort belysning af vigtige spørgsmål for dansk fiskeri. København: Statens Jordbrugs- og Fiskeriøkonomiske Institut. Rapport / Statens Jordbrugs- og Fiskeriøkonomiske Institut, Nr. 119Frost H., Hoff A. (2017). The Landings Obligation in view of different management regimes. Fisheries Research, 195, pp 202-213.

Frost H., Andersen P., Hoff A. (2013). Management of Complex Fisheries: Lessons Learned from a Simulation Model. Canadian Journal of Agricultural Economics, 61(2), pp. 283-307.

Gissurarson, H. H. (2000). Overfishing: The Icelandic solution. Retrieved from http://billhutten.s3.amazonaws.com/fw/docs/301.pdf

Gordon, D. V., \& Hannesson, R. (2015). The Norwegian Winter Herring Fishery: A story of technological progress and stock collapse. Land Economics, 91(2), 362-385.

Guttormsen, A. G., \& Roll, K. H. (2011). Technical efficiency in a heterogeneous fishery: the case of Norwegian groundfish fisheries. Marine Resource Economics, 26(4), 293-307.

Government of Greenland (2017), Comment to the Bill of the New Fishery Law, in Danish, 14 August 2017.

Greenland Home Rule (2009), Report of the Fishery Commission, February 2009, In Danish, available at http://naalakkersuisut.gl/ /media/Nanoq/Files/Publications/

Greenland Parliament (1990), The Act on Shrimp Taxes no. 20 of 25 October 1990, In Danish, available at http://lovgivning.gl/?sc_lang=da-DK

Greenland Parliament (1996), The Fishery Act no. 18 of 31 October 1996, In Danish, available at http://lovgivning.gl/?sc_lang=da-DK

Greenland Parliament (2017), The Act on Resource Taxes on Greenlandic Fishery no. 46 of 23 November 2017, In Danish, available at http://lovgivning.gl/?sc_lang=da-DK

Gunnlaugsson, S. (2014). Fisheries companies within the Icelandic stock exchange 2004-2013. Unpublished data.

Hagstovan. (2018). www.hagstova.fo

Havstovan. (2018). www.hav.fo

Hannesson, R. (2004). The privatization of the oceans. Cambridge: MIT Press.

Hannesson, R. (2013). Norway's experience with ITQs. Marine Policy, 37, 264-269.

Hannesson, R. (2014). Norway's experience with ITOs: A rejoinder.

Hannesson, R. (2016). Fish Quota Prices in Norway. Marine Resource Economics, 32(1), 109-117.

Hoff A., Frost H. (2018). Adjustment of a fishery given the discard ban: The Danish North Sea Case. Under review in Marine Resource Economics.

Holden, M., Garrod, D., 1996. The Common Fisheries Policy: Origin, Evaluation and Future. Oxford: Fishing News Books, Blackwell Scientific Publications Ltd. 
http://px.hagstofa.is/pxen/pxweb/en/Atvinnuvegir/Atvinnuvegir_sjavarutvegur_aflatolur_lo ndunartegundir/SJAogo31.px

http://px.hagstofa.is/pxen/pxweb/en/Atvinnuvegir/Atvinnuvegir_sjavarutvegur_skip/SJA0500 2.px

ICES. The International Council for the Exploration of the Sea: Catch statistics. [Data set]. Retrieved from http://www.ices.dk/marine-data/dataset-collections/Pages/Fish-catch-andstock-assessment.aspx

ICES. (2017). Report on the North Western Working group.

ICES. (2018). Report on the North Western Working group.

Jákupsstovu, H., Cruz, L., Maguire, J., \& Reinert, J. (2007). Effort regulation of the demersal fisheries at the Faroe Islands:. ICES Journal of Marine Science(64), pp. 730-737. Retrieved from https://academic.oup.com/icesjms/article/64/4/730/642865

Januar. (2016). Report on accounts of Faroese fishing vessels.

Jónsson, G., \& Magnússon, M. S. (1997). Hagskinna: Icelandic historical statistics. Reykjavık, Iceland.

Kroetz, K., Sanchirico, J. N., \& Lew, D. K. (2015). Efficiency costs of social objectives in tradable permit programs. Journal of the Association of Environmental and Resource Economists, 2(3), $339-366$.

Løkkegaard, J., Andersen, J. L., Frost, H. S., Jørgensen, M., \& Lindebo, E. (2001). Udredning vedrørende anvendelse af individuelle kvoter (IOK) i det danske fiskeri. København: Statens Jordbrugs- og Fiskeriøkonomiske Institut. Rapport / Statens Jordbrugs- og Fiskeriøkonomiske Institut, Nr. 120.

Løkkegaard, J., Andersen, J. L., Boje, J., Frost, H. S., \& Hovgård. (2007). Report on the Faroese fisheries regulation: the Faroe model. Department of Economics, University of Copenhagen. Retrieved from https://curis.ku.dk/ws/files/103804471/FOI_Report_193.pdf

Lög um stjórn fiskveiða nr. 38/199o. Retrieved from (Icelandic only) http://www.althingi.is/lagas/132a/1990038.html

Marko Lindroos, Sakari Kuikka ja Soile Kulmala (2007) Individual transferable quotas in the Baltic Sea herring fishery: A socio-bioeconomic analysis, Fisheries Research.

Matthiasson, T. (2003). Closing the open sea: Development of fishery management in four Icelandic fisheries. Natural Resources Forum, 27(1), 1-18.

Matthiasson, T. (2008). Rent collection, rent distribution, and cost recovery: An analysis of Iceland's ITQ catch fee experiment. Marine Resource Economics, 23(1), 105.

Maurstad, A. (2000). To fish or not to fish: small-scale fishing and changing regulations of the cod fishery in northern Norway. Human organization, 59(1), 37-47.

Merayo E., Nielsen M., Nielsen R., Hoff A. (2018). Are Individual Transferable Quotas an adequate solution to overfishing and overcapacity? Evidence from Danish Fisheries. Marine Policy 89, pp 167-176.

Ministry of Finance (2017), Report on the resource rent in the Greenlandic fishery and proposals for new models for resource rent taxation, In Danish, March 2017, available at: http://naalakkersuisut.gl/ /media/Nanoq/Files/Publications/Finanser/.

Ministry of Industries and Innovation. (2001). Niðurstöður nefndar um endurskoðun laga um stjórn fiskveiða ásamt fylgiskjölum. Retrieved from (Icelandic only) http://www.atvinnuvegaraduneyti.is/media/Skyrslur/Nidurst-nfd-um-endursk-I-um-stjornfiskveida-asamt-fylgiskjolum.pdf

Ministry of Industries and Innovation. (2010). Skýrsla starfshóps um endurskoðun á lögum um stjórn fiskveiða: Álitamál, greiningar, skýrslur og valkostir við breytingar á stjórn fiskveiða. Retrieved from (Icelandic only). http://www.atvinnuvegaraduneyti.is/media/Skyrslur/meginskyrsla_uppsett_lokaeintak.pdf

Ministry of Industries and Innovation. (2014). Act on fisheries management as subsequently amended: Act no. 116, 10 August 2006. Retrieved from http://eng.atvinnuvegaraduneyti.is/media/acts/Act-no-116-2006-on-FisheirsManagement.pdf 
Ministry of Industries and Innovation. (2014). Act no. 98, 8 April 1998. Retrieved from http://eng.atvinnuvegaraduneyti.is/media/acts/Act-no-22-1998-Fishing-and-Processing-byForeign-Vessels-in-Iceland.pdf

NAFO (2018), Map of fishing areas, available at https://www.nafo.int/, accessed July 2018.

NAFO/ICES Pandalus Assessment Group (2017), Report from the meeting, 27 September to 3 October 2017 at the Swedish University of Agricultural Sciences, Lysekil, Sweden, available at http://www.ices.dk/sites/pub/

Nielsen, M., J. Smit and J. Guillen (2009), Market Integration of Fish in Europe, Journal of Agricultural Economics, 6o(2), 367-385.

Nielsen M., Flaaten O., and Waldo S. 2012. Management of and Economic Returns from Selected Fisheries in the Nordic Countries. Marine Resource Economics 27(1):65-88.

Nielsen, M., Larsen, E., Egekvist, J., Abate, T.G., Nielsen, R., Frost, H., Kjaersgaard, J., 2013. Danish coastal fisheries: Structure and economy (in Danish) (IFRO Commissioned report No. 2013-01). University of Copenhagen.

Nielsen, M., L. Ståhl, R. Nielsen, I. Ankemah-Yeboah and D. Schütt (2017), Economic analysis of value chains for Greenlandic fish products, in Danish with English summary, report made for Statistics Greenland.

Nielsen, M., I. Ankamah-Yeboah, L. Staahl and R. Nielsen (2018), Price Transmission in the Trans-Atlantic Northern Shrimp Value Chain, Marine Policy 93:71-79.

Nielsen M., Hoff A., Nielsen R., Waldo S., Blomquist J., Asche F., Bergesen O., Viðarsson J., Sigurðardóttur S., Sveinpórsdóttir R. (2017). Employment and salary of Nordic coastal fishermen. TemaNord 2017:558.

Norwegian Directorate of Fisheries Website https://www.fiskeridir.no/English

NOU2014:16 Sjømatindustrien — Utredning av sjømatindustriens rammevilkår, Tromsø.

NOU2016:16 Strukturvirkemidler i fiskeflåten, Tromsø.

NOU2016:26 Et fremtidsrettet kvotesystem, Oslo.

OECD. (2011). Fisheries policy reform: National experiences. doi:10.1787/9789264096813-en.

Palsson, G., \& Helgason, A. (1995). Figuring fish and measuring men: The individual transferable quota system in the Icelandic cod fishery. Ocean \& Coastal Management, 28(1), 117-146.

Pincinato, R.B., Asche, F., Cojocaru, A.L. \& Roll, K.H. (2018) The impact of transferable fishing quotas on cost, price and season length presented at The 4 oth Annual Meeting of the Norwegian Association of Economists 3-4 January 2018 at NHH, Bergen, Norway.

Proposition 2013/14:184 Ändringar i fiskelagen.

Regulation (EU) No 1380/2013 of the European Parliament and of the Council of 11 December 2013 on the Common Fisheries Policy.

Rigsrevisionen (2017). Rigsrevisionens beretning om kvotekoncentrationen i dansk fiskeri afgivet til Folketinget med Statsrevisorernes bemærkninger.

Runolfsson, B. (1997). Regional impact of the individual transferable quotas in Iceland. In L. Jones \& M. Walker (Eds.), Fish or cut bait! The case for individual transferable quotas in the salmon fishery of British Columbia (pp. 65-89). Vancouver: Fraser Institute.

Runolfsson, B. (1999). On the management measures to reduce overcapacity in Icelandic fisheries. A short report for the Ministry of Fisheries. Retrieved from http://www.hi.is/ bthru/Capacity.pdf

Runolfsson, B. (2000). Aflahlutdeildir og eignarhald útgerða (Catch quotas shares and companies' ownership. Retrieved from (Icelandic only)

https://notendur.hi.is/bthru/Audlindanefnd1.pdf

Runolfsson, B., \& Arnason, R. (2001). Initial allocation of ITQs in the Icelandic fisheries (FAO Fisheries Technical Paper no. 411). Retrieved from http://www.fao.org/docrep/005/y2684e/y2684e05.htm

Runolfsson, B., \& Arnason, R. (2001). The effects of introducing transferable property rights on fleet capacity and ownership of harvesting rights in Iceland's fisheries (FAO Fisheries Technical Paper nr. 412). Retrieved from http://www.fao.org/docrep/005/y2498e/y2498eo4.htm 
Saevaldsson, H. (2007). Áhrifapættir á verð porskaflaheimlda (B.Sc dissertation). Retrieved from (Icelandic only) http://skemman.is/handle/1946/815

Saevaldsson, H. (2014). Icelandic pelagic vessels carrying capacity \& age \& fishmeal factories total output 1991-2013. Unpublished data.

Salz P, Buisman E, Frost H, Accadia P, Prellezo R, Soma K. (2010). Study on the remuneration of spawning stock biomass. Final Report, Framian.

Schütt, D., F. Jensen and M. Nielsen (2014), Appendix C5 Greenland, pp 126-150 in Waldo, S., H. Ellefsen, O. Flaaten, J. Hallgrimsson, C. Hammarlund, $\varnothing$. Hermansen, J. R. Isaksen, F. Jensen, N. N. Duy, M. Nielsen, A. Paulrud, F. Salenius and D. Schütt (2014), Reducing Climate Impact from Fisheries: A Study of Fisheries Management and Fuel Tax Concessions in the Nordic Countries, pp. 126-150, Theme North report 2014:533.

Skaptadóttir, U. D. (2000). Women coping with change in an Icelandic fishing community: A case study. Women's Studies International Forum, 23(3), 311-321.

Squires, D., Maunder, M., Vestergaard, N., Restrepo, V., Metzner, R., \& Herrick, S. (2012). Effort rights in fisheries: General principles and case studies. FAO. Retrieved from http://www.fao.org/3/a-i5744e.pdf

Stage, J., Christiernsson, A., and Söderholm, P. 2016. The economics of the Swedish individual transferable quota system: Experiences and policy implications. Marine Policy (66):15-20.

SSB (2016) Statistics Norway Website https://www.ssb.no/en

Standal, D., \& Aarset, B. (2008). The IVQ regime in Norway: A stable alternative to an ITQ regime?. Marine Policy, 32(4), 663-668.

Standal, D., \& Asche, F. (2018). Hesitant reforms: The Norwegian approach towards ITQ's. Marine Policy, 88, 58-63.

St. Meld 21 (2006-2007) Strukturpolitikk for fiskeflåten.

Statistics Denmark. Fishery account statistics (2002, 2007, 2014), http://www.statistikbanken.dk

Statistics Greenland (2018a), Foreign Trade Statistics, available at: http://bank.stat.gl/pxweb/en/Greenland/

Statistics Greenland (2018b), Account Data, available at: http://bank.stat.gl/pxweb/en/Greenland/

Statistics Greenland (2018c), Landing Statistics, available at: http://bank.stat.gl/pxweb/en/Greenland/, accessed June 2018.

Statistics Iceland. (2017). Decked vessels and trawlers 1999 [Data set]. Retrieved from https://www.statice.is/

Statistics Sweden. 2015a. Swedish sea-fisheries during 2014. Definitive data. Sveriges officiella statistic. Statistiska meddelanden: JO 55 SM 1501.

Statistics Sweden. 2015b. Fishing in inland waters by commercial fishermen in 2014. Preliminary data. Sveriges officiella statistic. Statistiska meddelanden: JO 56 SM 1501.

Swedish Agency for Marine and Water Management. 2014. Effekterna av systemet med överlåtbara fiskerättigheter inom pelagiskt fiske, [The effects of the individual transferable rights system in the pelagic fishery], Swedish Agency for Marine and Water Management, Gothenburg, 2014.

Swedish Agency for Marine and Water Management. 2016. Remiss om fördelningen av fiskemöjligheter för att underlätta genomförandet av landningsskyldigheten. Dnr 613-16, Havs- och vattenmyndigheten, Gothenburg.

Swedish government. 2017. Förslag till statens budget för 2018. Areella näringar, landsbygd och livsmedel. Proposition 2017/18:1, utgiftsområde 23. Stockholm, Sweden.

Swedish Parliament. 2017. Uppföljning av systemet med överlåtbara fiskerättigheter i det pelagiska fisket. Report 2016/17:RFR7. Riksdagstryckeriet, Stockholm.

United Nations (1982), United Nations Convention of Law of the Sea, available at: http://www.un.org/depts/los/ 
Yagi, N., Clark, M. L., Anderson, L. G., Arnason, R., \& Metzner, R. (2012). Applicability of Individual Transferable Quotas (ITQs) in Japanese fisheries: A comparison of rights-based fisheries management in Iceland, Japan, and United States. Marine Policy, 36(1), 241-245.

Vørn. (2018). www.vorn.fo

Waldo, S., and Paulrud, A. 2013. ITQs in Swedish demersal fisheries. ICES Journal of Marine Science 70(1): 68-77.

Waldo, S., Berndt, K., Hammarlund, C., Lindegren, M., Nilsson, A., and Persson, A. 2013. Swedish coastal herring fisheries in the wake of and ITQ system. Marine Policy (38):321-324. Waldo, S., and Wingård, C. 2010. Resursräntan i svenskt fiske. AgriFood Policy Brief 2010:3. Waldo, S., Ellefsen, H., Flaaten, O., Hallgrimsson, J., Hammarlund, C., Hermansen, Ø.,

Salenius, F. (2014). Reducing Climate Impact from Fisheries (Tema Nord 533 ed.). Nordisk råd. 



\section{Sammendrag}

Fiskeripolitik debatteres bredt i de nordiske lande med fokus på at afbalancere biologiske hensyn, bidrag til samfundsøkonomien og kystsamfundenes interesser. Markedsbaseret fiskeriforvaltning anvendes i dag i flere nordiske lande i dag og er central i debatten. Men hvor mange betragter markedsbaseret fiskeriforvaltning som et virkningsfuldt redskab som sikrer bedre økonomi i fiskeriet, betragtes det af andre som et kontroversielt reguleringsredskab.

I nærværende rapport Strukturtilpasning og regulering af nordiske fiskerier frem mod 2025: (i) dokumenteres effekterne af markedsbaseret forvaltning i udvalgte nordiske fiskerier historisk, (ii) analyseres og forudsiges strukturudviklingen af de udvalgte fiskeri indtil 2025 med uændret fiskeriforvaltning, iii) analyseres og forudsiges strukturudviklingen i disse fiskerier under alternativ forvaltning med andre politiske målsætninger, og (iv) oplistes erfaringer opnået med markedsbaseret forvaltning af nordiske fiskerier, som grundlag for politisk debat om fremtiden for nordisk fiskeri. Resultaterne præsenteres på konferencen Fiskeri og samfund-udfordringer til 2025, der afholdes i Stockholm 11-12. oktober 2018.

I kapitel 2 præsenteres standard teori om fiskeriøkonomi og forvaltning. Det forklares, hvordan åben adgang til fiskeri fører til et "race for fish", som i sidste ende giver overfiskeri, små fiskebestande, for mange fiskerfartøjer og lav indtjening. Det forklares endvidere hvordan forskellige forvaltningsredskaber kan løse "fællesskabets tragedie", med fokus på hvordan markedsbaseret fiskeriforvaltning skaber effektivitet. Markedsbaseret fiskeriforvaltning kræver tildeling af ejendomsrettigheder, som kan handles på et marked. Valg af forvaltningsinstrument afhænger af målsætningerne i fiskeripolitikken.

Kapitel 3 introducerer den dynamiske bioøkonomiske Fishrent-model, der anvendes til forudsigelse af samfundsøkonomisk afkast og overskud fra basisperioden 2012-2014 frem til 2025. Følgende scenarier analyseres: (i) den nuværende forvaltning med en maksimumgrænse på 4 \% for årlig ændring i antal fartøjer, ii) fri kvotehandel mellem alle fartøjer med samme maksimumsgrænse, iii) den nuværende forvaltning uden grænser for flådetilpasning og iv) den nuværende forvaltning med en maksimumsgrænse på 4 \% for årlig ændring i antal fartøjer, samt en ekstra fiskeriafgift på 10\% af omsætningen. Det samfundsøkonomiske afkast forstås som: Det nettooverskud der er tilbage til aflønning af kapital og arbejdskraft ud over hvad der opnås i andre erhverv inkl. provenu af fiskeriafgifter.

Syv landecases med markedsbaseret fiskeriforvaltning, en fra hvert af de nordiske lande, analyseres og resultaterne præsenteres separat for hver landecase i kapitel 410.

Kapitel 4 gennemgår grønlandsk rejefiskeri. Fiskeriet foregår med store fartøjer med forarbejdning ombord, samt med kystfartøjer der forsyner fabrikkerne på 
land. De store fartøjer har været reguleret med individuelt omsættelige kvoter siden 1991 og kystfiskeriet siden 2000. Det er ikke tilladt at sælge kvoter fra kystfiskeriet til de store fartøjer.

Det årlige samfundsøkonomiske afkast fra de 30 fartøjer er 82 mio. EUR (gennemsnit for 2012-2014), svarende til $44 \%$ af omsætningen. Beskæftigelse i fiskeri udgør 291 fuldtidsansatte. Det samfundsøkonomiske afkast i forhold til omsætning er det højest observerede i denne undersøgelse og følger af 2/3-dels flådereduktion siden 2002. Det høje samfundsøkonomiske afkast skyldes den lange tilstedeværelse af individuelt omsættelige kvoter, de store fartøjers høje effektivitet, samt 5-6 år med prisstigninger.

Det forudsiges, at det samfundsøkonomiske afkast stiger til $60 \%$ af omsætningen i 2025 med den nuværende forvaltning, som følge af fortsat strukturtilpasning og en antaget forbedring i rejebestanden. Dette er det højeste samfundsøkonomiske afkast forudsagt i denne undersøgelse. Fiskeflåden vil blive reduceret til 20 fartøjer og fulgt af faldende beskæftigelse i primært fiskeri, dog opvejet af stigende beskæftigelse på fabrikkerne på land. Fri kvotehandel kan forøge det samfundsøkonomiske afkast endnu mere.

Rejeafgifter, oven i indkomstskat og selskabsskat, er vigtige til at finansiere offentlige udgifter. Disse udgjorde $9 \%$ af landingsværdien i 2012-2014. Det forudsiges, at en stigning i rejeafgiften på $10 \%$ af omsætning ikke vil reducere overskuddet i 2025. Fortsat strukturtilpasning forøger overskuddet mere end afgiften reducerer.

Kapitel 5 analyserer islandsk pelagisk fiskeri og Stern-trawlerfiskeri. Demersale frisk fisk trawlere, demersale frysetrawlere, pelagiske frisk fisk fartøjer og pelagiske frysefartøjer undersøges. Der fokuseres på de store fartøjer, hvor de fleste Sterntrawlere er over 42 meter og de fleste pelagiske fartøjer er 6o-8o meter. Island har den længste historie med individuelt omsættelige kvoter i Norden og en af de længste på verdensplan. Den begyndte i midten af 1980'erne.

Det årlige samfundsøkonomiske afkast for de 79 fartøjer er 255 mio. EUR, svarende til $42 \%$ af omsætningen (2012-2014). Fuldtidsbeskæftigelsen er 2.394 personer. Som i den grønlandske case er det samfundsøkonomiske afkast stort. Dels som følge af den lange tilstedeværelse af individuelt omsættelige kvoter og den efterfølgende vedvarende strukturtilpasning. Dels som følge af tilstedeværelsen af store fartøjer som udnytter stordriftsfordele.

Det samfundsøkonomiske afkast med uændret forvaltning forudsiges at falde til 203 mio. EUR i 2025, svarende til $26 \%$ af omsætningen. Flåden reduceres i dette scenarie til 57 fartøjer og beskæftigelsen til 1.764 fuldtidsansatte. Reduktionen følger af de forudsatte bestandsreduktioner og af "choking" problemet, som reducerer fiskeri på nogle arter urealistisk meget, og herigennem forårsager en undervurdering af det samfundsøkonomiske afkast. Fri kvotehandel forøger det samfundsøkonomiske afkast til $51 \%$ af omsætningen, mens fuld tilpasning giver mulighed for en stigning til $54 \%$ af omsætningen. Under fuld tilpasning reduceres flåden til 33 skibe og beskæftigelse til 1.066 fuldtidsansatte. Strukturtilpasningen synes således at fortsætte.

Da fiskeriet har været reguleret med individuelt omsættelige kvoter i en lang årrække, er den forudsagte reduktion i det samfundsøkonomiske afkast overraskende, men kan skyldes, at reduktion af fiskebestande og choking 
problemet fører til undervurdering af det samfundsøkonomiske afkast. Årsagen kan dog også være, at fartøjer har høje kapitalomkostninger, fordi forventet fremtidig indtjening kapitaliseres i kvoteværdierne, hvilket påvirker overskuddet negativt, når fiskebestandene reduceres.

Fiskeriafgifter, ud over indkomstskat og selskabsskat, er vigtige for at finansiere de offentlige udgifter i Island. Disse udgjorde $6 \%$ af landingsværdien i 2012-2014. Det forudsiges, at en fiskeriafgift på ekstra $10 \%$ af omsætningen reducerer overskuddet $i$ 2025. Årsagen er, at den forventede fremtidige indtjening er blevet kapitaliseret $i$ kvoteværdierne. Hermed beskattes de nuværende kvoteejere, der allerede har betalt en del af deres forventede fortjeneste til tidligere kvoteejere.

I kapitel 6 præsenteres den danske landecase for demersalt fiskeri i Nordsøen. Seks grupper af fartøjer af forskellig længde op til 40 meter som fisker med net, trawl og not er inkluderet. Disse små og mellemstore fartøjer er blevet forvaltet med individuelt omsættelige kvoter siden 2007.

De 147 fartøjers årlige samfundsøkonomiske afkast er 19 mio. EUR, svarende til 19 $\%$ af omsætningen (2012-2014). Heltidsbeskæftigelsen er 359 personer. Det samfundsøkonomiske afkast er af mellemstørrelse i dette studie og følger en kraftig flådereduktion siden 2007.

Det samfundsøkonomiske afkast forudsiges at vokse til 28 mio. EUR i 2025, svarende til $31 \%$ af omsætningen, under den nuværende forvaltning. Fiskeflådens størrelse falder til 117 fartøjer og beskæftigelse til 272 fuldtidsansatte. Fuld tilpasning vil forøge det samfundsøkonomiske afkast til $39 \%$ af omsætningen, yderligere reduceres flåden til go fartøjer og beskæftigelse til 192 fuldtidsansatte. Den kraftige strukturtilpasning, som startede i 2007, forudsiges således at fortsætte. Det forudsiges endvidere, at en fiskeriafgift på $10 \%$ af omsætningen ikke vil reducere overskuddet i 2025 i forhold til 2012-2014, i det den fortsatte strukturtilpasning formodes at opveje denne effekt.

I kapitel 7 analyseres den finske landecase for pelagisk fiskeri med fartøjer over og under 24 meter. Fiskeriet hqr4 været forvaltet med individuelt omsættelige kvoter siden 2017.

Det årlige samfundsøkonomiske afkast fra 63 fartøjer var nul i 2012-2014 med 110 fuldtidsbeskæftigede. Nulresultatet følger af fraværet af inputregulering, hvor alene totalkvoter var gældende indtil 2017

Det årlige samfundsøkonomiske afkast i 2025 forudsiges til 2 mio. EUR med uændret forvaltning, svarende til $10 \%$ af omsætningen. Dette forudsiges at stige til $38 \%$ under fuld tilpasning. Reduktionen af flåden reduceres til henholdsvis 42 og 31 fartøjer, mens beskæftigelsen falder til 73 og 37 fuldtidsansatte. Det samfundsøkonomiske afkast og overskuddet forudsiges således at stige betydeligt. Det kan dog tage nogle år, da individuelt omsættelige kvoter først blev indført i 2017. En evt. fiskeriafgift på $10 \%$ af omsætning med i øvrigt uændret forvaltning forudsiges ikke at ændre overskud i $2025 \mathrm{i}$ forhold til 2012-2014. Dette skyldes at struktureltilpasningen modvirker effekten.

Kapitel 8 indeholder den svenske case for pelagisk fiskeri med fartøjer på 18-24 meter og større end 24 meter. Fiskeriet har været reguleret med individuelt omsættelige kvoter siden 2009. Kystfiskeri efter sild indgår ikke i denne undersøgelse, da det forvaltes separat. 
Det årlige samfundsøkonomiske afkast for de 30 fartøjer udgør 12 mio. EUR, svarende til $23 \%$ af omsætningen. Beskæftigelsen er 167 fuldtidspersoner. Det samfundsøkonomiske afkast er af mellemstørrelse i denne undersøgelse og følger af en flådeduktion på $55 \%$ i 2009-2013.

Det årlige samfundsøkonomiske afkast er med uændret forvaltning forudsagt at stige til 22 mio. EUR i 2025 efter stigning i fiskebestandene. Dette svarer til $35 \%$ af omsætningen, stigende til $40 \%$ med fuld tilpasning. Flåden er reduceret til henholdsvis 25 og 22 fartøjer, mens beskæftigelsen falder til 141 og 120 fuldtidsansatte. Selvom individuelt omsættelige kvoter allerede har forbedret det samfundsøkonomiske afkast og overskuddet i fiskeriet, synes strukturtilpasningen at fortsætte. En fiskeriafgift på 10 $\%$ af omsætningen, under i øvrigt uændret forvaltning, forudsiges ikke at reducere overskuddet i forhold til 2012-2014, idet en vedvarende strukturtilpasning påvirker overskuddet i opadgående retning.

I kapitel 9 analyseres det norske demersale fiskeri nord for $62^{\circ}$. Der indgår fem fartøjslængdegrupper på op til 28 meter som anvender konventionelle redskaber, samt en trawlergruppe. Individuelle kvoter har været gældende siden 1996. Disse kan overdrages inden for men ikke mellem fartøjsgrupper, med omsætteligheden yderligere begrænset regionalt og med $20 \%$ af de solgte kvoter tilbageholdt og omfordelt til alle fartøjer i gruppen. Totalkvoter fordeles mellem fartøjsgrupper ved at holde de konventionelle fartøjers kvoter mere konstante end trawlernes kvotes kvoter.

Det årlige samfundsøkonomiske afkast for de 1.192 fartøjer er 233 mio. EUR og 26 $\%$ af omsætningen (2012-2014). Heltidsbeskæftigelsen er 5.489 personer. Det samfundsøkonomiske afkast er af mellemstørrelse i denne undersøgelse og opnås efter en halvering af flåden siden 1996. På trods af at fiskeriet udføres med gennemsnitligt set relativt små fartøjer, er det samfundsøkonomiske afkast af mellemstørrelse, hvilket indikerer at den nuværende forvaltning sikrer en vis strukturtilpasning.

Det samfundsøkonomiske afkast forudsiges reduceret til 198 mio. EUR i 2025 med uændret forvaltning, efter forudsatte reduktioner af bestanden, samt choking problemer. Choking problemet reducerer fiskeri på nogle arter urealistisk meget, hvilket fører til en vis undervurdering af det samfundsøkonomiske afkast. Det samfundsøkonomiske afkast i forhold til omsætning forudsiges dog at stige til $36 \%$. Flåden forudsiges reduceret til 792 fartøjer og beskæftigelsen til 3.637. Fri kvotehandel forøger det samfundsøkonomiske afkast, mens fuld tilpasning giver mulighed for en stigning til 49\% af omsætningen i 2025.

Den sidste landecase med færøsk demersalt fiskeri præsenteres i kapitel $10 \mathrm{og}$ inkluderer store trawlere og langlinefartøjer. Fiskeriet er blevet reguleret med omsættelige havdage siden 1996, men det er blevet besluttet at ændre reguleringen til individuelle kvoter fra 2019.

Det årlige samfundsøkonomiske afkast fra de 45 fartøjer er -7 mio. EUR, et underskud på $9 \%$ af omsætningen. Underskuddet tyder på, at det færøske samfund er bedre stillet økonomisk ved at stoppe demersalt fiskeri og bruge kapital og arbejdskraft i andre sektorer. Underskuddet viser at den nuværende indsatsregulering ikke har været i stand til at begrænse fiskeriet tilstrækkeligt.

Med forvaltningsskiftet i 2019 forudsiges det samfundsøkonomiske afkast at stige til 16 mio. EUR i 2025 svarende til $25 \%$ af omsætningen. Men tilpasningen tager tid, og 
med fuld tilpasning kan den stige til $43 \%$. Flåden er reduceret til 34 fartøjer med fuld tilpasning til 22. Fri kvotehandel forudses at resultere i et samfundsøkonomisk afkast på $30 \%$ af omsætningen. En fiskeriafgift på $10 \%$ af omsætningen, som også kan bestå i offentligt provenu fra salg af kvoter på auktion, kan indføres sammen med den nye 2019 forvaltning, hvor overskuddet stadig forudsiges at stige fra niveauet i 2012-2014.

I kapitel 11 sammenlignes det årlige samfundsøkonomiske afkast i 2012-2014 på tværs af lande. Det er størst i Grønland (44\% af omsætningen) og Island (42 \%), både som følge af den langvarige tilstedeværelse af individuelt omsættelige kvoter og som følge af at disse fiskerier gennemføres med store fartøjer som udnytter stordriftsfordele.

Det forudsagte samfundsøkonomiske afkast i 2025 sammenlignes også på tværs af lande. Igen er det med uændret forvaltning størst i Grønland (6o \% af omsætningen) og Island (49\%), idet det dog stiger i alle landene. Den største stigning forudsiges på Færøerne (fra $-14 \%$ til $+25 \%$ af omsætningen) og i Finland (fra $-7 \%$ til $+10 \%$ ). Disse forudsagte stigninger følger af forbedret forvaltning, i det Finland indførte individuelt omsættelige kvoter i 2017, og som følge af at Færøerne har besluttet at indføre individuelle kvoter fra 2019. I samtlige cases reduceres flåderne.

Baseret på landecases kan der læres flere forhold. Disse lærdomme er vigtige i debatten om den fremtidige fiskeripolitik i de nordiske lande. Debatten handler om at prioritere mellem fiskeriets bidrag til samfundsøkonomi og velstand, beskæftigelse i fiskerisamfund som ofte ligger spredt langs kysterne i tyndtbefolkede områder, samt at anvende fiskeriafgifter som en kilde til at finansiere offentlige udgifter. De forskellige prioriteringer udgør en ramme for de politiske beslutninger. Læringen fra Markedsbaseret fiskeriforvaltning i Norden ved denne undersøgelse er:

1. Individuelt omsættelige kvoter er et virkningsfuldt redskab til at forøge indtjening og fjerne overkapacitet, men samtidig reduceres flådestørrelse og beskæftigelse.

2. Alle eksisterende markedsbaserede fiskeriforvaltningssystemer i de nordiske lande har særordninger for visse fartøjsgrupper.

3. Alle eksisterende markedsbaserede fiskeriforvaltningssystemer i de Nordiske lande regulerer koncentrationen på den ene eller anden måde.

4. Det er ikke en universel regel, at markedsbaseret fiskeriforvaltning altid fjerner små fartøjer.

5. Fiskeafgifter kan spille en central rolle for fordelingen af velstand i de nordiske lande hvor fiskeriet fylder meget i samfundsøkonomien.

6. Dyre kvoter gør det vanskeligt at fjerne eller drastisk ændre individuelt omsættelige kvotesystemer.

7. Fortsat markedsbaseret fiskeriforvaltning forudsiges at forøge det samfundsøkonomiske afkast og overskud i 2025 betydeligt.

8. Frihandel med kvoter skaber ekstra indtjening i forhold til den nuværende regulering i 2025.

9. En ekstra fiskeriafgift på $10 \%$ af landingsværdien kan i de fleste landecases opkræves uden på lang sigt at reducere overskuddet. 



\section{Appendix: The applied bio-economic model}

FISHRENT is a dynamic bio-economic model with a long history of development (Salz et al. 2010, Frost et al. 2013). The structure of Fishrent is displayed in Figure 32. The model is implemented over time, meaning that the economic and biological conditions in year $t$ depend on what happened in year $t-1$. As such the model applies dynamic feedback between fisheries and exploited fish stocks in the sense that year-on-year changes observed for total fish stock biomass are fed back into the model and hereby influence fishing opportunities and capacity, while on the other hand year-to-year changes in fishing capacity will feed back into the model and affect stock development.

The model assumes that all fishing activities are regulated within a given management system, represented by the management box in Figure 32. In the present context it is assumed that the fisheries manager restricts catches for a given year by imposing quotas. Catches are determined by stocks size and fishing effort (fishing effort box) and are restricted by the quota limits. Fishing effort is defined as fleet size (capacity measured as number of vessels) times days at sea per vessel. The fleet capacity is determined in the investment box and depends on previous year's profitability (Economic box). Increasing profits lead to investments while decreasing profits leads to disinvestment. The catches in a given year will influence stock changes (the biological box) and as such future catch possibilities. Market prices are set in the price formation box, and depend on the landings in the given year. The total economic outcome, i.e. the profit, is determined in the economic box, and depend on landings, prices and costs.

Figure 32: Structure of the FishRent model

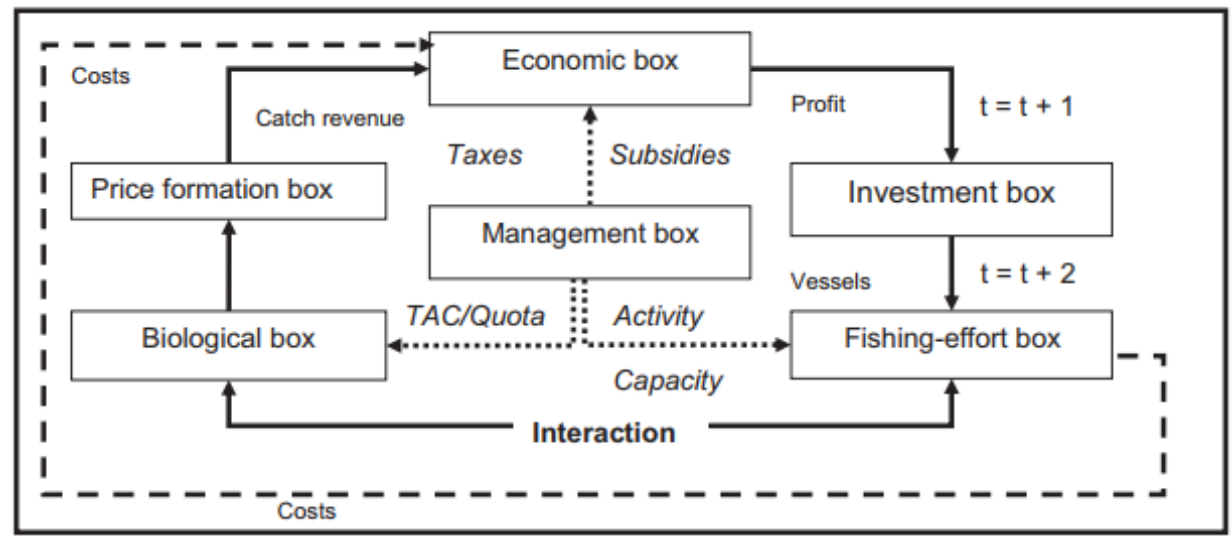

Source: Frost et al. (2013). 
The biological module is based on ICES published biomasses and catches (www.ices.dk) for the key stocks. Stock surplus production parameters are estimated externally, based on ICES data. The Economic module is based on national statistical databases, covering landings in weight and value, running and fixed costs, for the included fishing fleets.

\section{Model equations}

Individual Fishrent models have been constructed for each of the 7 country cases included in this study. Two economic maximisations have been performed for each case study:

1. Maximisation of the total profit, discounted to 2016 values, over the evaluation period (2016-2025);

2. Maximisation of the total socio-economic return over the evaluation period (2016-2025) discounted to 2016 values.

Thus, Fishrent maximizes the following two objective function for each country case:

$\max _{N V_{y, f}, D A S_{y, f}} \Pi=\max _{N V_{y, f}, D A S_{y, f}}\left[\sum_{y, f} \pi_{y, f} \cdot(1+\rho)^{-y}\right](\mathrm{a} 1)$

Where

$\pi_{y, f}=\left\{\begin{array}{c}\tilde{P}_{y, f} ; \text { Profit maximisation } \\ S E R_{y, f} ; \text { Socio-economic return maximisation }\end{array}(\right.$ a2 $)$

$\tilde{P}_{y, f}$ is the profit obtained by fleet $f$ and $S E R_{y, f}$ the socio-economic return produced by fleet $f$ in year $y . \rho$ is the discount rate, which is in the present context set to $3.5 \%$. The independent variables in the maximization are the number of vessels $N V_{y, f}$ in vessel group $f$ in year $y$ and the number of days at sea per vessel $D A S_{y, f}$ exerted by vessel group $f$ in year $y$. Thus, the actors in Fishrent are the fishers, or more specifically vessel groups, choosing to use their DAS per vessel, and invest/disinvest in number of vessels, in an economically optimal way over the simulation period. In scenarios 1, 2, and 4 it the yearly change in number of vessels in a given vessel group is constrained to be at the most $\pm 4 \%$. Thus, it is assumed in these scenarios that a fleet cannot "sell out" all vessels from one year to the next. In scenario 3 the yearly change in number of vessels is not constrained.

In the model maximisations, total country catches of each target species are restricted under the country quotas:

$\frac{\sum_{f} L_{y, f, s}}{\sum_{f} Q s h_{f, s}} \leq Q_{y, s}\left(\mathrm{a}_{4}\right)$ 
Where $L_{y, f, s}$ is the landings of target species s taken by vessel group $f$ in year, and $Q_{y, s}$ is the Country quota of species $s$ in year $y$ (cf. Table 45 ). $Q s h_{f, s}$ is the quota share of species $s$ historically taken by vessel group $f$. The sum in the nominator on the left side of the equation is the landings of species $s$ taken by the vessel groups included in the model, while the sum in the denominator is the historical fraction these segments takes of the national quota of species $s$, which is used to scale the catches determined by the model up to the full national catches of species s in year $y$.

When (a4) is the only landings constraint, landings are distributed between vessel groups in an economically optimal way, i.e. such that the overall profit/socio-economic return is maximised. This corresponds to free quota trade (ITOs). However, most of the national case studies have additional constraints on quota trade in their current management schemes, and thus additional constraints are included in the national models in scenarios 1,3 , and 4 (where scenario 2 represents free ITOs for case studies). Table 45 outlines the additional constraints included in the national models.

Table 45: Individual maximisation constraints for each Country case study

Case Management restrictions

Denmark ITQ, but with quota trade restrictions between vessels above and below 15 meters:

$$
\begin{gathered}
\sum_{\begin{array}{c}
f \\
\text { (vessel length<15m) }
\end{array}} L_{y, f, s} \leq Q_{y, s} \cdot \sum_{\begin{array}{c}
f \\
\text { (vessel length<15m) }
\end{array}} Q s h_{f, s} \\
\sum_{\substack{f \\
\text { (vessel length }>15 m)}} L_{y, f, s} \leq Q_{y, s} \cdot \sum_{\substack{f \\
(\text { vessel length }>15 m)}} Q s h_{f, s}
\end{gathered}
$$

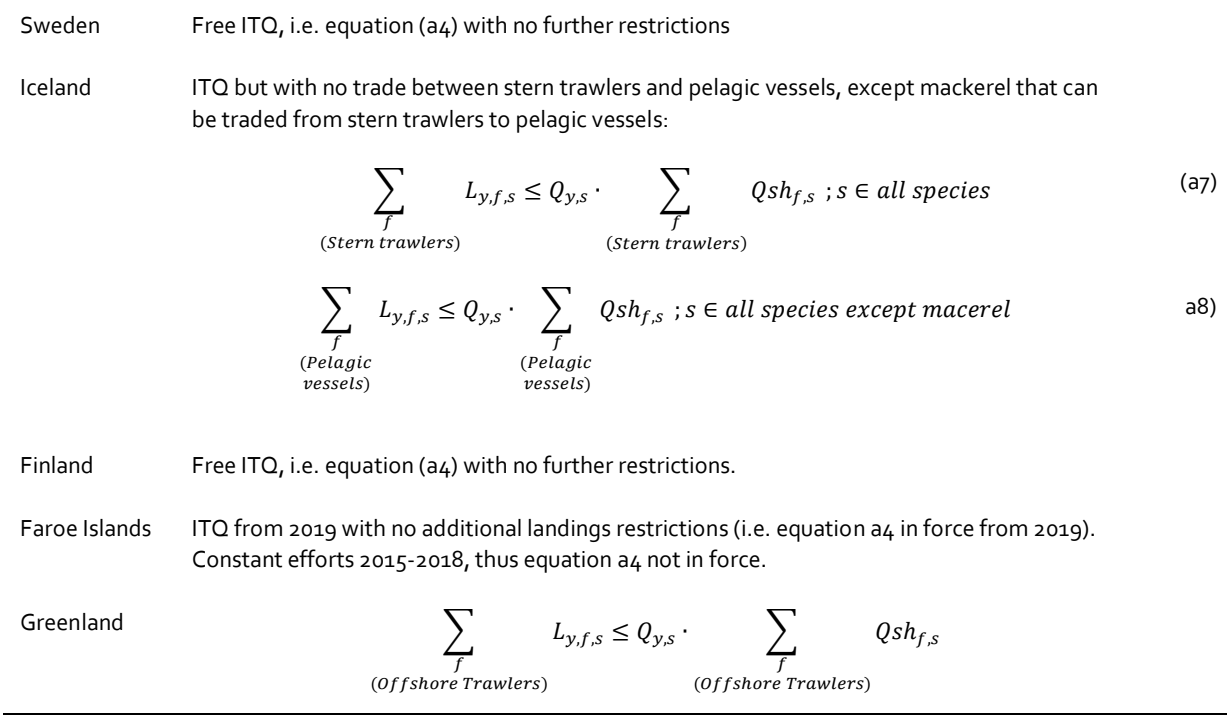

Regarding the maximisation of total socio-economic return (SER), the individual SER of fleet $f$ in year $y$ is given by:

$S E R_{y, f}=R_{y, f}-F u C_{y, f}-O C r C_{y, f}-V a C_{y, f}-F x C_{y, f}-O C a C_{y, f}$ (ag) 
Where $R_{y, f}$ is the revenue, $F u C_{y, f}$ the fuel costs, $\operatorname{OCr} C_{y, f}$ the opportunity crew costs, $V a C_{y, f}$ the other variable costs, $F x C_{y, f}$ the fixed costs and $O C a C_{y, f}$ the opportunity capital costs of fleet $f$ in year $y$.

The revenue is given by:

$R_{y, f}=\left(\sum_{s} L_{y, f, s} \cdot p_{f, s}\right) \cdot\left(1+O s F f_{f}\right)(\mathrm{a} 10)$

Where $p_{y, f, s}$ is the price obtained by fleet $f$ for species $s$ in all years (prices are in the present context assumed constant over the simulation period). $O s F f_{f}$ is a factor, based on historical revenue fractions, scaling the revenue of species included in the model up to the revenue of all species caught by vessel group $f$.

The fuel costs are given by:

$F u C_{y, f}=E_{y, f} \cdot f c_{f}(\mathrm{a} 11)$

Where $f c_{f}$ are the fuel costs per sea day, and $E_{y, f}=N V_{y, f} \cdot D A S_{y, f}$ is the total effort (number of sea days) exerted by vessel group $f$ in year $y$.

The oppertunity crew costs are given by:

$\operatorname{OCr} C_{y, f}=E_{y, f} \cdot o c C_{f}(\mathrm{a} 12)$

Where $o c c_{f}$ is opportunity crew costs per sea day for vessel group $f$.

The variable costs are given by:

$\operatorname{VaC} C_{y, f}=R_{y, f} \cdot v c_{f}(\mathrm{a} 13)$

Where $v c_{y, f}$ is the fraction that the variable costs will constitute of the revenue.

The fixed costs are given by:

$F x C_{y, f}=N V_{f, y} \cdot f c_{f}($ a14)

Where $f c_{f}$ is the fixed cost per vessel in fleet $f$.

The opportunity capital costs are given by:

$O C a C_{y, f}=N V_{y, f} \cdot o c a_{f}(\mathrm{a} 15)$

Where $o c a_{f}$ is the opportunity capital costs per vessel in vessel group $f$.

Regarding the maximisation of total profit, the individual profit of fleet $f$ in year $y$ is given by:

$\tilde{P}_{y, f}=R_{y, f}-F u C_{y, f}-C r C_{y, f}-V a C_{y, f}-F x C_{y, f}-C a C_{y, f}-Q C_{y, f}(\mathrm{a} 16)$ 
Where $R_{y, f}$ is the revenue (equation a10), Fu $C_{y, f}$ the fuel costs (equation a11), $\operatorname{Cr} C_{y, f}$ the crew costs, $\operatorname{Va} C_{y, f}$ the other variable costs (equation a13), $F x C_{y, f}$ the fixed costs (equation a14), $C a C_{y, f}$ the capital costs of fleet $f$ in year $y$ and $Q C_{y, f}$ the cost for quota trade and lease for vessel group $f$ in year $y$.

The crew costs are given by:

$\operatorname{Cr} C_{y, f}=R_{y, f} \cdot C c_{f}(\mathrm{a} 17)$

Where $c c_{f}$ is fraction the crew costs constitute of the revenue for vessel group $f$.

The capital costs are given by:

$\mathrm{CaC}_{y, f}=N V_{y, f} \cdot c a_{f}(\mathrm{a} 18)$

Where $c a_{f}$ is the capital costs per vessel in vessel group $f$.

Cost of quota trade $Q C_{y, f}$ is treated below in a separate section.

The landings, less highgrading, of species $s$ taken by fleet $f$ in year $y$ is given by the Cobb-Douglas form:

$L_{y, f, s}=a 0_{f, s} \cdot\left(E_{y, f}\right)^{a 1_{f, s}} \cdot\left(B_{y, s}\right)^{a 2_{f, s}(\mathrm{a} 19)}$

where $a 0_{f, s} a 1_{f, s}$ and $a 2_{f, s}$ are the parameters of the Cobb-Douglas function. $B_{y, s}$ is the total stock biomass of species $s$ in year $y$, which is given by the mass balance equation:

$B_{y, s}=B_{y-1, s}+R_{y-1, s}-\frac{\sum_{f} L_{y, f} \cdot\left(1+D i s c_{y, f}\right)}{\sum_{f} T A C s h_{f, s}}(\mathrm{a} 20)$

Where $T A C s h_{f, s}$ is the share that vessel group $f$ has historically taken of the overall TAC of species $s$.

The recruitment $R_{y, s}$ is given by a second degree polynomium as a function of the stock:

$R_{y, s}=\alpha_{1} \cdot B_{y, s}-\alpha_{2} \cdot B_{y, s}^{2}$ (a21)

I.e. a Schaefer like stock production function.

Given the stock in year y (assumed to be the stock in the beginning of year $y$ ) the total Total Allovable Catch for species s, $T A C_{y, s}$, is set according to the target fishing mortality $F_{S}^{0}$ (set according to MSY targets), which is constant over the simulation period: 


$$
T A C_{y, s}=\left\{\begin{array}{l}
\left(1-\lim _{T A C}\right) \cdot T A C_{y-1, s} ; B_{y, s} \cdot\left(1-e^{-F_{i}^{s}-M_{s}}\right) \cdot \frac{F_{s}^{0}}{F_{s}^{0}+M_{s}}<\left(1-\lim _{T A C}\right) \cdot T A C_{y-1, s} \\
\left(1+\lim _{T A C}\right) \cdot T A C_{y-1, s} ; B_{y, s} \cdot\left(1-e^{-F_{s}^{s}-M_{s}}\right) \cdot \frac{F_{s}^{0}}{F_{s}^{0}+M_{s}}>\left(1+\lim _{T A C}\right) \cdot T A C_{y-1, s} \\
B_{y, s} \cdot\left(1-e^{-F_{s}^{s}-M_{s}}\right) \cdot \frac{F_{s}^{0}}{F_{s}^{0}+M_{s}} ;\left(1-\lim _{T A C}\right) \cdot T A C_{y-1, s}<B_{y, s} \cdot\left(1-e^{-F_{d}^{s}-M_{s}}\right) \cdot \frac{F_{s}^{0}}{F_{s}^{0}+M_{s}}< \\
\left(1+\lim _{T A C}\right) \cdot T A C_{y-1, s} \quad \text { (a22) }
\end{array}\right.
$$

\section{The quota rent/purchase module}

In the profit maximization (equations a1 and a2) the sum of discounted annual profits is maximized:

$\max _{E_{y, f}} \sum_{y, f} \tilde{P}_{y, f} \cdot(1+\rho)^{-y}(\mathrm{a} 23)$

Where $\tilde{P}_{y, f}$ is the profit after possible money transfers $Q C_{y, f}$ has been subtracted (equation a16).

The long run socio-economic profit $P_{y, f}$ by fleet $f$ in year $y$ before subtraction of possible transfers for quotas is given by:

$P_{y, f}=R_{y, f}-F u C_{y, f}-\operatorname{Cr} C_{y, f}-V a C_{y, f}-F x C_{y, f}-C a C_{y, f}(\mathrm{a} 24)$

Where $R_{y, f}$ is the revenue (equation a10), $F u C_{y, f}$ the fuel costs (equation a11), $\operatorname{Cr} C_{y, f}$ the crew costs (equation a17), $V a C_{y, f}$ the variable costs (equation a13), $F x C_{y, f}$ the fixed costs (equation a14) and $\mathrm{CaC}_{y, f}$ the capital costs (equation a18) of fleet $\mathrm{f}$ in year $\mathrm{y}$. It is assumed that if $P_{y, f} \leq 0$ then no money transfer is taking place for the average vessel in fleet $f$ in year $y$.

If $P_{y, f}>0$ there is a possibility for money transfer in excess of the initial allocation. Whether this takes place depends on the profit per vessel in the previous year $y-1$. A distinction is made between the following cases:

1. $P_{y, f} / N V_{y, f}>P_{y-1, f} / N V_{y-1, f}$ and $N V_{y, f} \leq N V_{y-1, f}$, i.e. the profit per vessel in segment $f$ increases while the number of vessels in segment $f$ decreases from year $y-1$ to year $y$.

2. $P_{y, f} / N V_{y, f}>P_{y-1, f} / N V_{y-1, f}$ and $N V_{y, f}>N V_{y-1, f}$, i.e. the profit per vessel in segment $f$ increases while the number of vessels in segment $f$ also increases from year $y$-1 to year $y$.

3. $P_{y, f} / N V_{y, f}<P_{y-1, f} / N V_{y-1, f}$ and $N V_{y, f}>N V_{y-1, f}$ while $P_{y, f}>P_{y-1, f}$, i.e. the number of vessels and total profit in segment $f$ increases from $y-1$ to $y$, while the profit per vessel decreases.

4. $\quad P_{y, f} / N V_{y, f}<P_{y-1, f} / N V_{y-1, f}$ and $P_{y, f}<P_{y-1, f}$, i.e. the profit per vessel and the total profit in segment $f$ decreases from year $y-1$ to year $y$. 
In cases 1-3 it is assumed that quota transfer takes place. In case 4 it is assumed that the average vessel in vessel group $f$ will not have had any quota transfer, given that both the total profit for the vessel group, and the profit per vessel decreases.

In cases 1-3 the price of quotas purchased per vessel is assumed to be given by the average of the sellers' willingness to accept and the buyers' willingness to pay. It is noted, that when the transfer (costs of the extra quota) is estimated, the profits before transfers are used for comparison. In this way it is assumed that the fishers know what the optimal quota allocation for the coming year is before any money transfer takes place. This assumption is necessary to compute future profit and compare it to historical profit in a consistent way.

Case 1: $P_{y, f} / N V_{y, f}>P_{y-1, f} / N V_{y-1, f}$ and $N V_{y, f} \leq N V_{y-1, f}$

In this case, where the profit per vessel increases while the number of vessels decreases from year $y$ - 1 to year $y$, the segment's willingness to pay is assumed to be equal to the profit increase from year $y-1$ to year $y$ of the vessels remaining in the segment, i.e.:

Willingness to pay| $\left.\right|_{N V_{y, f} \leq N V_{y-1, f}}=N V_{y, f} \cdot\left(P_{y, f} / N V_{y, f}-P_{y-1, f} / N V_{y-1, f}\right)(\mathrm{a} 25)$

The willingness to accept is equal to the profit leaving the segment, i.e. the value of the transferred catches:

Willingness to accept $\left.\right|_{N V_{y, f} \leq N V_{y-1, f}}=\left(N V_{y-1, f}-N V_{y, f}\right) \cdot\left(P_{y-1, f} / N V_{y-1, f}\right)$ a26)

Thus, the total costs of quota transfer to the segment, given that $P_{y, f} / N V_{y, f}>$ $P_{y-1, f} / N V_{y-1, f}$ and $N V_{y, f} \leq N V_{y-1, f}$ is given by:

$$
\begin{array}{r}
\text { Quota transfer }\left.\operatorname{costs}\right|_{N V_{y, f} \leq N V_{y-1, f}} \\
=\left[\left(N V_{y-1, f}-N V_{y, f}\right) \cdot\left(\frac{P_{y-1, f}}{N V_{y-1, f}}\right)+N V_{y, f} \cdot\left(\frac{P_{y, f}}{N V_{y, f}}-\frac{P_{y-1, f}}{N V_{y-1, f}}\right)\right] / 2
\end{array}
$$

Case 2: $P_{y, f} / N V_{y, f}>P_{y-1, f} / N V_{y-1, f}$ and $N V_{y, f}>N V_{y-1, f}$

In this case, where vessels have entered the vessel group and the profit per vessel increased from $y-1$ to $y$, the willingness to pay is the total profit entering the segment from year $y$ - 1 to year $y$ :

Willingness to pay $\left.\right|_{N V_{y, f}>N V_{y-1, f}}=P_{y, f}-P_{y-1, f}$ (a28)

The willingness to accept is estimated as the number of vessels entering the fishery times the average profit per vessel in the vessel group in year $y$-1, i.e. the lowest possible profit new vessels entering the fishery in year $y$ can expect to obtain: 
Willingness to accept $\left.\right|_{N V_{y, f}>N V_{y-1, f}}=\left(N V_{y, f}-N V_{y-1, f}\right) \cdot\left(P_{y-1, f} / N V_{y-1, f}\right)$ (a2g)

Thus, the total cost of quota transfer to the segment is given by:

Quota transfer costs $\left.\right|_{N V_{y, f}>N V_{y-1, f}} \cdots$

$=\left[\left(N V_{y, f}-N V_{y-1, f}\right) \cdot\left(P_{y-1, f} / N V_{y-1, f}\right)+\left(P_{y, f}-P_{y-1, f}\right)\right] / 2$

Case 3: $P_{y, f} / N V_{y, f}<P_{y-1, f} / N V_{y-1, f}$ and $N V_{y, f}>N V_{y-1, f}$ while $P_{y, f}>P_{y-1, f}$

In this case, where vessels, and profit, has entered the segment, even though the profit per vessel has decreased, the same procedure is used as in Case 2. I.e. the willingness to pay is assumed to be the total profit entering the segment (equation 6), the willingness to accept is assumed to be equal to the lowest profit new vessels entering the fishery could obtain (equation a29) and the quota transfer cost thus equal to equation (azo). 


\section{List of abbreviations}

- $\quad$ ITQ = Individual Transferable Quotas.

- $\mathrm{MBFM}=$ Market Based Fisheries Management.

- $\mathrm{MSY}=$ Maximum Sustainable Yield. 
Nordic Council of Ministers

Nordens Hus

Ved Stranden 18

DK-1061 Copenhagen K

www.norden.org

\section{Structural Adjustment and Regulation of Nordic Fisheries until 2025}

Fishery policies are broadly debated in the Nordic countries, focusing on balancing biological concern of fish stocks, economic return to society and coastal communities' interests. Market Based Fisheries Management is used in several Nordic countries today and is the core of these debates. While it by many is considered a powerful tool that works towards ensuring improved economy of fisheries, it is also considered a controversial tool.

This report "Structural Adjustment and Regulation of Nordic Fisheries until 2025" document the effects of Marked Based Management of selected Nordic fisheries, forecast the structural development of these until 2025 under the current and alternative fishery management. Nordic lessons on Market Based Fisheries Management are also provided as a basis for the political debate on the future of Nordic Fisheries. 